\title{
CARLA ULASOWICZ
}

\section{Uma avaliação da influência do Programa de Enriquecimento}

Instrumental no desempenho cognitivo de idosos

(Versão corrigida)

Tese apresentada ao Instituto de Psicologia da Universidade de São Paulo para a obtenção do título de Doutor em Psicologia.

Área de concentração: Psicologia Escolar e do Desenvolvimento Humano. Linha de Pesquisa: Desenvolvimento e Aprendizagem.

Orientador: Prof. Associado Dr. José Fernando Bitencourt Lomônaco.

\section{São Paulo}




\section{AUTORIZO A REPRODUÇÃO E DIVULGAÇÃO TOTAL OU PARCIAL DESTE TRABALHO, POR QUALQUER MEIO CONVENCIONAL OU ELETRÔNICO, PARA FINS DE ESTUDO E PESQUISA, DESDE QUE CITADA A FONTE.}

Catalogação na publicação

Biblioteca Dante Moreira Leite

Instituto de Psicologia da Universidade de São Paulo

Ulasowicz, Carla.

Uma avaliação da influência do programa de enriquecimento instrumental no desempenho cognitivo em idosos / Carla Ulasowicz; orientador José Fernando Bitencourt Lomônaco. -- São Paulo, 2016.

$237 \mathrm{f}$.

Tese (Doutorado - Programa de Pós-Graduação em Psicologia. Área de Concentração: Psicologia da Aprendizagem, do Desenvolvimento e da Personalidade) - Instituto de Psicologia da Universidade de São Paulo.

1. - Programa de Enriquecimento Instrumental - PEI 2. Funções cognitivas 3. Envelhecimento 4. Idosos I. Título. 
Carla Ulasowicz.

Uma avaliação da influência do Programa de Enriquecimento Instrumental no desempenho cognitivo de idosos.

Tese apresentada ao Instituto de Psicologia da Universidade de São Paulo para obtenção do título de Doutor em Psicologia.

Área de concentração: Psicologia Escolar e do Desenvolvimento Humano.

Linha de Pesquisa: Desenvolvimento e Aprendizagem.

Aprovado em: de de

\section{Banca examinadora}

Prof(a). Dr(a). Instituição:

Julgamento: Assinatura:

Prof(a). Dr(a). Instituição:

Julgamento: Assinatura:

Prof(a). Dr(a). Instituição:

Julgamento: Assinatura:

Prof(a). Dr(a). Instituição:

Julgamento: Assinatura:

Prof(a). Dr(a). Instituição:

Julgamento: Assinatura: 
À linda Gabriella, sol da minha vida, alegria contagiante, que desabrocha um amor sem fim.

Ao Phillipe, meu amoreco de hoje e sempre, por me mostrar que os caminhos são alegres e cheios de vida.

Ao Rogerio, meu anjo da guarda, companheiro de todas as horas, meu porto seguro, parceria que tornou possível esta e muitas outras conquistas. 


\section{Agradecimentos especiais....}

Aos meus pais, que me ensinaram que o amor, o respeito, a ética, a verdade e $o$ conhecimento são fundamentais para todas as conquistas da vida. Por me ensinarem a ter persistência, coragem e lutar bravamente para alcançar meus objetivos.

Ao Rogerio, por ter sido pai e mãe da nossa Gabi na minha ausência, pelo seu amor, apoio e incentivo, por estar sempre presente e por cuidar tão bem de nós.

À Gabriella e ao Phillipe, por me fazerem descobrir que o amor é incondicional.

À minha querida irmã, Cássia, por me ensinar a ser mais flexível com a vida e menos racional. Por me fazer enxergar, por meio das suas fantasias, histórias, pinturas e "maluquices pela educação", a beleza de ensinar.

Ao Edilson Rufino, pela alegria e humildade. Por abraçar com competência a responsabilidade de cuidar tão bem de pessoas muito queridas: Cássia e Phillipe.

Aos meus amigos visíveis e "invisíveis", pelo incentivo nesta caminhada.

À Deus, nosso Pai Maior, que possibilitou o convívio e aprendizado com pessoas tão queridas e especiais. 


\section{Agradecimentos....}

Todas as palavras serão poucas para agradecer ao professor José Fernando Bitencourt Lomônaco. Excelente pessoa e exímio MESTRE. Muito obrigada por toda paciência, compreensão e aprendizado que me foram oferecidos desde o ingresso do mestrado ao final do doutorado, por entender minhas limitações e ajudar-me a superá-las de maneira tranquila e agradável, por respeitar o meu tempo e transmitir muita segurança. Minha eterna gratidão.

Ao professor Reuven Feuerstein (in memorian) que se mostrou receptivo e feliz com o tema da pesquisa, sempre disposto a ajudar-nos, mas que infelizmente não pôde conhecer os resultados finais.

À neuropsicóloga Rosimeire de Oliveira, pelo auxílio em todas as etapas da pesquisa, pela amizade e por sempre ter uma palavra de conforto mediante meus conflitos pessoais, profissionais e acadêmicos.

À Ligia Furusawa, pelas dúvidas sanadas em relação aos testes.

Aos professores Wilson Jacob Filho e Mônica Sanches Yassuda, pelas valiosas considerações na ocasião do exame de qualificação.

Aos professores Maria Helena Souza Patto, Audrey Setton Lopes de Souza, Wilson Jacob Filho, Yeda Aparecida de Oliveira Duarte, Maria Lúcia Lebrão, Cassio Machado de Campos Bottino e aos alunos da pós-graduação, pelos conhecimentos compartilhados.

Às professoras Maria Luíza de Jesus Miranda, Ana Martha Almeida Limongeli, Ana Paula Palmezan Milinavicius e ao Padre Antônio Nazarko, pelas portas que me foram abertas para a composição dos grupos da pesquisa.

Aos idosos que participaram da pesquisa, por acreditarem no trabalho desenvolvido e, principalmente, por permitirem mudar conceitos e crenças.

Ao Diego Monteforte Pintor, Bruna Teixeira de Almeida e Henrique Alves da Silva, pela análise estatística. 
Aos professores Luiz Sanches Neto e Dianna Vargas Carbajal, pelas versões dos resumos em inglês e espanhol.

Aos professores Luiz Sanches Neto, Jéssica Rodrigues, Tiemi Okimura Kerr, Luciana Venâncio, André França, Luciano Corsino, Rosangela Matias, William Lazaretti e Leandro Oliveira, pelo companheirismo, pela amizade, pelas risadas, pelas conquistas, pelos conflitos e angústias de sermos pós-graduandos. Vocês foram um dos incentivos para continuar.

Às professoras Silene Sumire Okuma, Maria Luiza de Jesus Miranda, Rosana Andreotti e Marília Velardi, por me proporcionarem os passos iniciais na vida acadêmica.

À professora Priscilla Santos, pelas substituições das aulas na escola para que eu pudesse cumprir os compromissos da pós-graduação e pela amizade constante.

À professora Patrícia Alonso de Oliveira Fruchi, por me apresentar o PEI, por realizar um trabalho tão valioso com as crianças autistas.

À Olívia Miranda e Domitila Miranda, pela competência com que dirigem os ensinamentos sobre o PEl.

À Adriana Inácio Iha, ao Arthur Inácio Iha, à todos os meus alunos e ex-alunos de PEI, bem como seus pais e familiares, por acreditarem na eficácia do trabalho.

Ao Instituto Coaching \& Vida e equipe, representado pelos amigos Cesar Fialho, Francisco Renaldo Costa e Leonardo Barros, por me ensinarem a ser proativa.

A todas as pessoas que direta ou indiretamente contribuíram para que esta pesquisa fosse possível.

A todos vocês, o meu muito obrigado. 
Não quero mudar as diferenças entre os indivíduos. Sinceramente, desejo que os indivíduos sejam diferentes. O que me incomoda é que sendo a diversidade da humanidade seu maior sinal de riqueza, e que nos enriquecemos precisamente a partir dessas diferenças, tenham sido consideradas essas mesmas diferenças como uma desvantagem para o indivíduo e como a fonte principal de desigualdade entre as pessoas.

Reuven Feuerstein. 


\section{RESUMO}

ULASOWICZ, C. Uma avaliação da influência do Programa de Enriquecimento Instrumental no desempenho cognitivo de idosos. 2016. 237 f. Tese (Doutorado) Instituto de Psicologia, Universidade de São Paulo, São Paulo, 2016.

O Programa de Enriquecimento Instrumental (PEI) é um programa psicoeducativo que busca, por meio de instrumentos apropriados, estimular funções cognitivas de forma que o aluno otimize seu pensamento e torne-o mais reflexivo. O objetivo desta pesquisa foi realizar uma avaliação da influência do Programa de Enriquecimento Instrumental sobre algumas funções cognitivas dos idosos, quais sejam: resolução de problemas, memória, atenção e concentração. Participaram 66 indivíduos voluntários de ambos os sexos, com idade igual ou superior a 60 anos, fisicamente independentes e saudáveis, com escolaridade mínima $4^{\text {a }}$ série do ensino fundamental I (atual $5^{\circ}$ ano) e máxima $8^{\text {a }}$ série do ensino fundamental II (atual 9oㅜ ano), sem restrições quanto ao nível socioeconômico, subdivididos em dois grupos: experimental e controle. Os sujeitos de ambos os grupos foram avaliados antes do início do programa de intervenção (fase pré-teste) e ao seu final (fase pós-teste) por meio dos seguintes testes: Teste Wisconsin de classificação de cartas - versão para idosos, subescala memória do Exame Cognitivo de Addenbrooke, Teste de Memória de Lista de Palavras, Teste de Repetição de Pseudoplavaras, subescala atenção e orientação do Exame Cognitivo de Addenbrooke e teste de Trilhas parte $\mathrm{A}$ e parte B. Com o objetivo de rejeitar a hipótese de que a melhora do desempenho do grupo experimental, que recebeu a intervenção cognitiva, pudesse ser devida a aprendizagem dos testes na primeira fase em que foram aplicados, outros testes 
para avaliação das mesmas funções investigadas foram realizados nas fases pós e reteste, esta última realizada após três meses do término do programa de intervenção. Os testes com este objetivo foram: subteste cubos da Escala Wechsler Abreviada de Inteligência, testes de extensão de dígitos em ordem direta e em ordem inversa da Escala de Memória Wechsler de Inteligência para Adultos, Bateria Psicológica para Avaliação da Atenção. A escala de autoestima foi aplicada nas fases pré, pós e reteste apenas para o grupo experimental. As aulas do Programa de Enriquecimento Instrumental foram ministradas ao grupo experimental pela pesquisadora durante cinco meses e meio, uma vez por semana com a duração de 90 minutos cada, totalizando 21 aulas. A avaliação dos resultados mostrou que o Programa de Enriquecimento Instrumental levou a um maior desempenho do grupo experimental quando comparado ao grupo controle em todas as funções cognitivas analisadas, as quais ou se mantiveram ou apresentaram melhoras no desempenho mesmo após três meses do término do programa. Na discussão dos resultados procurou-se identificar e relacionar os instrumentos do PEI com as funções cognitivas avaliadas.

Palavras-chave: PEI, funções cognitivas, envelhecimento, idoso. 


\section{ABSTRACT}

Ulasowicz, C. (2016). An assessment of the Instrumental Enrichment Program influence in the elderly cognitive performance. 237 pages. Thesis (Ph.D.) - Institute of Psychology, University of São Paulo, São Paulo.

The Instrumental Enrichment Program (IEP) is a psycho-educative program that seeks, through appropriate instruments, to stimulate cognitive functions so the student optimizes her/his thinking and makes it more reflective. The objective of this research was to conduct an assessment of the Instrumental Enrichment Program influence on some cognitive functions of the elderly, such as: problem solving, memory, attention and concentration. Sixty-six volunteers from both sexes participated, aged 60 years or older, physically independent and healthy, schooled until the $4^{\text {th }}$ grade of elementary school (currently $5^{\text {th }}$ year) at minimum and until the 8th grade of secondary school (currently $9^{\text {th }}$ year) at maximum, without restrictions on the socioeconomic level, subdivided into two groups: experimental and control. The subjects from both groups were assessed before the intervention program (pre-test phase) and its ending (post-test phase) through the following tests: Wisconsin Card Sorting Test - version for the elderly, memory subscale of Addenbrooke's Cognitive Examination, Word List Memory Test, Pseudowords Repetition Test, attention and guidance subscale of Addenbrooke's Cognitive Examination, and Trails Test parts A and B. In order to reject the hypothesis that improvement in the experimental group performance, that received cognitive intervention, could be due to the learning of tests during the first phase in which they have been applied, other tests for evaluation of the same investigated functions were performed in post-test and retest phases, the latter performed after three months of the intervention program completion. The tests 
used for this purpose were: Wechsler's Abbreviated Scale of Intelligence cubes subtest, digit extension tests in direct and in reverse order from Wechsler's Adult Intelligence Memory Scale, and Psychological Battery for Attention Assessment. The self-esteem scale was applied in the pre, post and retest phases only for the experimental group. The Instrumental Enrichment Program classes were given to the experimental group by the researcher for five and a half months, once a week, lasting 90 minutes each, totaling 21 classes. Evaluation of the results showed that the Instrumental Enrichment Program has led to a higher performance by the experimental group compared to the control group in all cognitive functions analyzed, which either remained or showed improvement in performance even after three months of program completion. The discussion of results sought to identify and relate the IEP instruments with the assessed cognitive functions.

Keywords: IEP, cognitive functions, aging, elderly. 


\section{RESUMEN}

ULASOWICZ, C. Una evaluación de influencia del Programa de Enriquecimiento Instrumental en el desempeño cognitivo de los ancianos. 2016. 237 f. Tesis (Doctorado) - Instituto de Psicología, Universidad de São Paulo, São Paulo, 2016.

El programa de Enriquecimiento Instrumental a través de instrumentos es un programa psicoeducativo que busca a través de instrumentos apropiados, estimular las funciones cognitivas a manera de que el alumno optimice su pensamiento y lo vuelva más reflexivo. El objetivo de esta investigación fue de realizar una evaluación de influencia del Programa de Enriquecimiento Instrumental sobre algunas funciones cognitivas de los ancianos, sean éstas como: la resolución de los problemas, memoria, atención y concentración. Participaron 66 individuos voluntarios de ambos sexos, entre edades igual o superior a 60 años, físicamente independientes y saludables, con grado de escolaridad mínima $4^{\circ}$ grado de la primaria I (actual $5^{\circ}$ año) y máximo $8^{\circ}$ grado de la primaria II (actual $9^{\circ}$ año), sin restricciones en relación al nivel socioeconómico, subdivididos en dos grupos: experimental y control. Los sujetos de los dos grupos fueron evaluados antes del inicio del programa de intervención (fase pre-test) y a su final (fase pos-test) a través de los siguientes : Test Wisconsin de clasificación de cartas - versión para ancianos, subescala memoria del Examen Cognitivo de Addenbrooke, Test de Memoria de Lista de Palabras, Test de Repetición de Pseudopalabras, subescala atención y orientación del examen Cognitivo de Addenbrooke y teste de Caminos parte A y parte B. Con el objetivo de rechazar la hipótesis de que la mejoría del desempeño del grupo experimental, que recibió la intervención cognitiva, pudiera ser debido al aprendizaje 
de los tests en la primera fase en que fueron aplicados, otros tests para evaluación de las mismas funciones investigadas fueron realizados en las fases pos y retest, esta último realizada después de tres meses del término del programa de intervención. Los tests con este objetivo fueron: subtest cubos de Escala Wechsler Abreviada de Inteligencia, tests de extensión de dígitos en reden derecho y en orden inverso de la Escala de Memoria Wechsler de Inteligencia para Adultos, Batería Psicológica para Evaluación de Atención. La escala de autoestima fue aplicada en las fases pre, pos y retest únicamente para el grupo experimental. Las clases del programa de Enriquecimiento Instrumental fueron ministrados al grupo experimental por la investigadora durante cinco meses y medio, una vez a la semana durando 90 minutos cada uno, al total 21 clases. La evaluación de los resultados mostró que el Programa de Enriquecimiento Instrumental llevó a un mayor desempeño del grupo experimental cuando fue comparado al grupo controle en todas las funciones cognitivas analizadas, las cuales o se mantuvieron o presentaron mejorías en el desempeño, aún después de tres meses del término del programa. En la discusión de los resultados se buscó identificar y relacionar los instrumentos del PEI con las funciones cognitivas evaluadas.

Palabras-clave: PEI, funciones cognitivas, envejecimiento, ancianos. 


\section{LISTA DE QUADROS}

QUADRO 1 - Relação dos testes aplicados para avaliação da amostra nas fases de pré, pós e reteste........................................................................94

QUADRO 2 - Relação dos instrumentos e folhas desenvolvidas em cada uma das

21 sessões. 


\section{LISTA DE TABELAS}

TABELA 1 - Perfil sócio-demográfico da amostra, grupo controle $(n=32)$ e grupo experimental $(n=34)$

TABELA 2 - Porcentagem dos sujeitos da amostra por agrupamento das variáveis sociodemográficas, grupo controle $(n=32)$ e grupo experimental $(n=34)$.

TABELA 3 - Indicadores interpretativos do teste WCST nas diferentes fases do programa, grupo controle $(n=32)$ e grupo experimental $(n=34)$.

TABELA 4 - Indicador interpretativo do teste WCST: número de ensaios administrados, grupo controle $(n=32)$ e grupo experimental $(n=34) \ldots 122$

TABELA 5 - Indicador interpretativo do teste WCST: número total de respostas corretas, grupo controle $(n=32)$ e grupo experimental $(n=34)$.

TABELA 6 - Indicador interpretativo do teste WCST: número total de erros, grupo controle $(n=32)$ e grupo experimental $(n=34)$

TABELA 7 - Indicador interpretativo do teste WCST: respostas perseverativas, grupo controle $(n=32)$ e grupo experimental $(n=34)$

TABELA 8 - Indicador interpretativo do teste WCST: erros perseverativos, grupo controle $(n=32)$ e grupo experimental $(n=34)$

TABELA 9 - Indicador interpretativo do teste WCST: erros não perseverativos, grupo controle $(n=32)$ e grupo experimental $(n=34)$

TABELA 10 - Indicador interpretativo do teste WCST: respostas de nível conceitual, grupo controle $(n=32)$ e grupo experimental $(n=34)$ 
TABELA 11 - Indicador interpretativo do teste WCST: número de categorias completadas, grupo controle $(n=32)$ e grupo experimental $(n=34) \ldots . .129$

TABELA 12 - Indicador interpretativo do teste WCST: ensaios para completar a primeira categoria, grupo controle $(n=32)$ e grupo experimental $(n=34)$.

TABELA 13 - Indicador interpretativo do teste WCST: fracasso em manter o contexto, grupo controle $(n=32)$ e grupo experimental $(n=34)$

TABELA 14 - Médias das pontuações do subteste Cubos da Escala Wechsler Abreviada de Inteligência, grupo experimental $(n=34)$.

TABELA 15 - Médias das pontuações na escala ACE-R, subescala Memória, grupo controle $(n=32)$ e grupo experimental $(n=34)$

TABELA 16 - Médias das pontuações no teste TMLP, grupo controle $(n=32)$ e grupo experimental $(n=34)$

TABELA 17 - Médias das pontuações no Teste de Repetição de Pseudopalavras, grupo controle $(n=32)$ e grupo experimental $(n=34)$. 134

TABELA 18 - Médias no teste extensão de dígitos em ordem direta e em ordem inversa da escala WAIS-III, grupo experimental $(n=34)$. 135

TABELA 19 - Médias das pontuações na escala ACE-R, subescala Atenção e Orientação, grupo controle ( $n=32)$ e grupo experimental $(n=34)$. 136

TABELA 20 - Médias das pontuações para erros e tempo no teste Trilhas parte A, grupo controle $(n=32)$ e grupo experimental $(n=34)$ 137

TABELA 21 - Médias das pontuações para erros e tempo de execução no teste Trilhas parte $B$, grupo controle $(n=32)$ e grupo experimental $(n=34)$ 
TABELA 22 - Médias das pontuações na Bateria Psicológica para Avaliação da Atenção (BPA): atenção geral, atenção concentrada, atenção dividida e atenção alternada, grupo experimental $(n=34)$. 139

TABELA 23 - Médias das pontuações na escala de autoestima, grupo experimental $(n=34)$

TABELA 24 - Médias das pontuações na escala ACE-R, grupo controle $(n=32)$ e grupo experimental $(n=34)$.

TABELA 25 - Médias das pontuações da MEEM na escala ACE-R, grupo controle $(n=32)$ e grupo experimental $(n=34)$. .142

TABELA 26 - Médias das pontuações no subteste Raciocínio Matricial da Escala Wechsler Abreviada de Inteligência (WASI), grupo experimental $(n=34)$.

TABELA 27 - Médias das pontuações no subteste Semelhanças, da Escala Wechsler Abreviada de Inteligência (WASI), grupo experimental $(n=34)$ 144

TABELA 28 - Porcentagem de respostas na escala de percepção sobre modificações após o programa, grupo experimental $(n=34)$. 145

TABELA 29 - Porcentagem de respostas sobre as perspectivas do programa antes da intervenção, grupo experimental $(n=34)$.

TABELA 30 - Porcentagem de respostas sobre as perspectivas do programa após a intervenção, grupo experimental $(n=34)$.

TABELA 31 - Pontuações dos idosos do Grupo 1 e do Grupo 2 na fase reteste do programa, $(n=08)$ 
TABELA 32 - Avaliação da homogenidade da amostra por meio do teste estatístico qui-quadrado de Pearson, grupo controle $(\mathrm{n}=32)$ e grupo experimental $(n=34)$

TABELA 33 - Comparações entre os resultados referentes aos indicadores interpretativos do Teste Wisconsin e do subteste WASI -Cubos, nas diferentes fases do estudo, por meio do teste estatístico Wilcoxon, grupo controle $(n=32)$ e grupo experimental $(n=34)$ 162

TABELA 34 - Comparações entre as respostas nas diferentes fases do estudo referente à avaliação da variável memória por meio do teste estatístico Wilcoxon, grupo controle $(n=32)$ e grupo experimental $(n=34)$

TABELA 35 - Comparações entre as respostas nas diferentes fases do estudo referentes à variável atenção e concentração por meio do teste estatístico Wilcoxon, grupo controle $(n=32)$ e grupo experimental $(n=34)$

TABELA 36 - Comparação entre as respostas nas diferentes fases do estudo referente à autoestima por meio do teste estatístico Wilcoxon, grupo experimental $(n=34)$

TABELA 37 - Comparação entre as respostas nas diferentes fases do estudo na escala ACE-R, no MEEM e no subteste Raciocínio Matricial e Semelhanças da Escala Wechsler Abreviada de Inteligência (WASI), por meio do teste estatístico Wilcoxon, grupo controle $(n=32)$ e grupo experimental $(n=34)$ 168

TABELA 38 - Comparação entre os grupos controle e experimental no pré e pósteste nos indicadores interpretativos do Wisconsin por meio do teste estatístico Mann-Whitney, grupo controle $(n=32)$ e grupo experimental $(n=34)$ 169 
TABELA 39 - Comparação entre os grupos experimental e controle no pré e pósteste na avaliação da variável memória, por meio do teste estatístico Mann-Whitney, grupo controle $(n=32)$ e grupo experimental $(n=34)$.

TABELA 40 - Comparação das respostas entre os grupos controle e experimental no pré e pós-teste, no teste ACE-R, Trilhas A e B, por meio do teste estatístico Mann-Whitney, grupo controle $(n=32)$ e grupo experimental $(n=34)$

TABELA 41 - Comparação entre os grupos controle e experimental no pré e pósteste na escala ACE-R e no MEEM por meio do teste estatístico Mann-Whitney, grupo controle $(n=32)$ e grupo experimental $(n=34)$

TABELA 42 - Médias dos testes aplicados e o p-valor de cada variável de acordo com o teste estatístico $t$-student, grupo experimental $(n=34)$. 


\section{LISTA DE SIGLAS}

AA

ABEP

AC

ACE-R

AD

BPA

CBM

$\mathrm{CCL}$

CCEB

COWAT

DP

DPAC

EAM

EEFEUSP

EF

GDS

GREPEFI

IEP

IQCODE

MEEM

MOANS
Atenção Alternada

Associação Brasileira de Empresas de Pesquisa

Atenção Concentrada

Addenbrooke's Cognitive Examination - Revised / Exame

Cognitivo de Addenbroke versão revisada

Atenção Dividida

Bateria Psicológica para Avaliação da Atenção

Centro Brasileiro da Modificabilidade

Comprometimento Cognitivo Leve

Critério de Classificação Econômica Brasil

Controlled Oral Word Association Test

Desvio Padrão

Distúrbio do Processamento Auditivo Central

Experiência de Aprendizagem Mediada

Escola de Educação Física e Esportes da Universidade de São Paulo.

Educação Física

Geriatric Depression Scale - Escala de Depressão Geriátrica

Grupo de Estudos e Pesquisas em Educação Física para Idosos Instrumental Enrichment Program

Questionário de Declínio Cognitivo do Idoso

Mini-Exame do Estado Mental

Mayo Older American Normative Studies 
OP

PAAF

PEI

Q।

SP

TCLE

TMLP

TSM

WAIS

WASI

WCST
Organização de Pontos

Programa Autonomia para a Atividade Física

Programa de Enriquecimento Instrumental

Quoeficiente de Inteligência

São Paulo

Termo de Consentimento Livre e Esclarecido

Teste de Memória da Lista de Palavras

Teoria do Se-Movimentar

Escala de Memória de Wechsler de Inteligência para Adultos

Escala Wechsler Abreviada de Inteligência

Teste WISCONSIN de Classificação de Cartas - versão para idosos 


\section{SUMÁRIO}

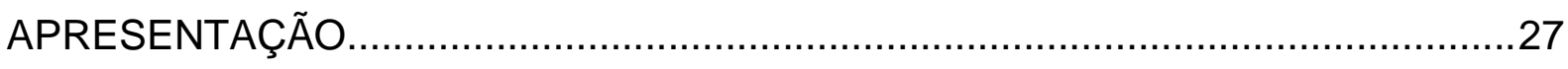

1 ENVELHECIMENTO E DESEMPENHO COGNITIVO: ESTUDOS E

DESAFIOS

2 O PROGRAMA DE ENRIQUECIMENTO INSTRUMENTAL: UM PROGRAMA DE

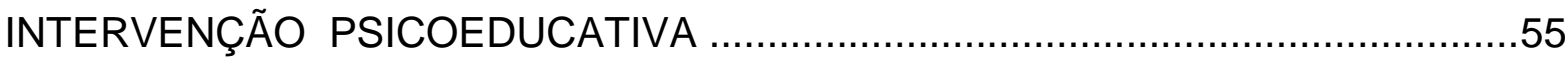

2.1 Teoria da Modificabilidade Cognitiva Estrutural .....................................55

2.2 Funções Cognitivas Deficientes ..........................................................64

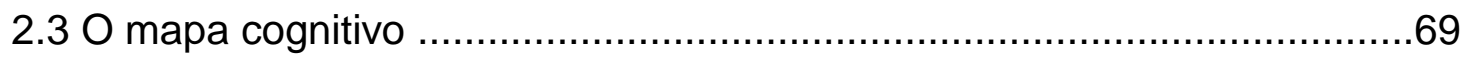

2.4 Os instrumentos do PEI Standard I ..................................................72

2.5 Pesquisas brasileiras com o PEl: uma breve revisão ................................75

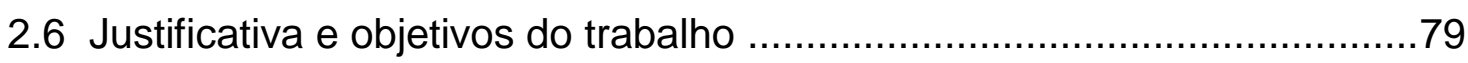

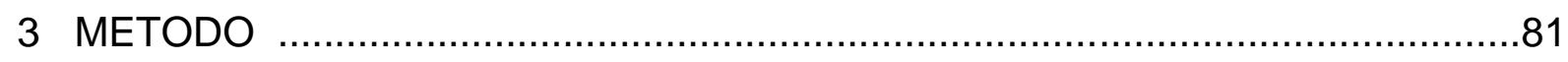

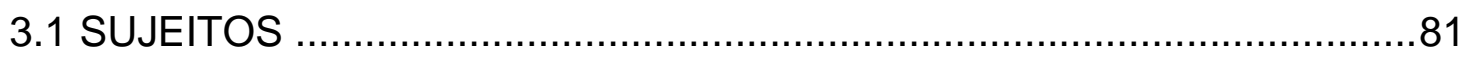

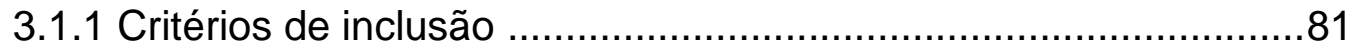

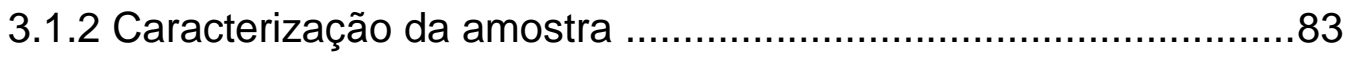

3.1.2.1 Grupo experimental ......................................................... 83

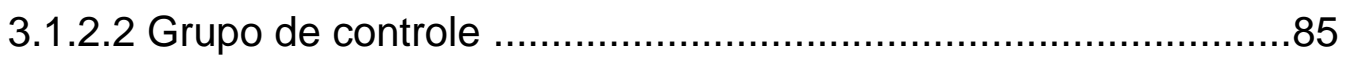

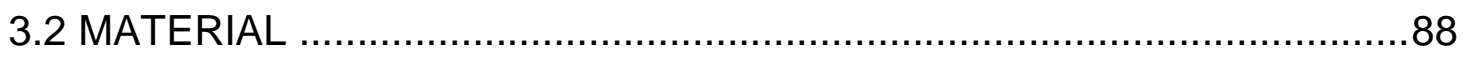

3.2.1 Instrumentos para seleção da amostra ........................................8

3.2.1.1 Ficha de Identificação …………..............................................8

3.2.1.2 Mini-Exame do Estado Mental (MEEM) ..................................89

3.2.1.3 Escala de Depressão Geriátrica (GDS) …………………......90

3.2.1.4 Questionário de Atividades Funcionais, 


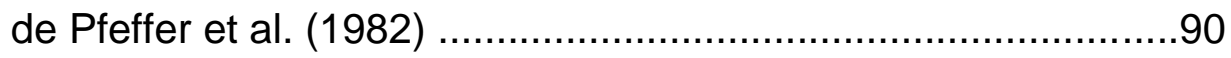

3.2.1.5 Questionário de Declínio Cognitivo do Idoso (IQCODE) ..........91

3.2.2 Testes psicológicos para avaliação da amostra .........................92

3.2.2.1 Testes da primeira bateria - testes alvos ……...............95

3.2.2.1.1 Teste de Trilhas,Parte A e Parte B (Trail Making Test A

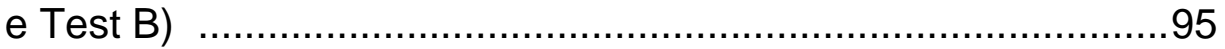

3.2.2.1.2 Teste de Memória da Lista de Palavras (TMLP) .........95

3.2.2.1.3 Teste de Repetição de Pseudopalavras ......................96

3.2.2.1.4 Teste WISCONSIN de Classificação de Cartas - versão

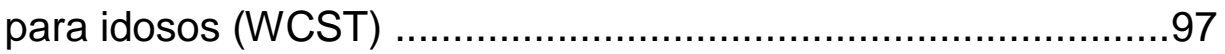

3.2.2.1.5 Exame Cognitivo de Addenbrooke (ACE-R) ................99

3.2.2.1.6 Escala de Avaliação da Autoestima ...........................100

3.2.2.2 Testes da segunda bateria - testes de transferência ..............101

3.2.2.2.1 Escala Wechsler Abreviada de Inteligência (WASI)...101

3.2.2.2.2 Testes de extensão de dígitos em ordem direta e em ordem inversa da Escala de Memória Wechsler de Inteligência para Adultos (WAIS-III) ........................................................104

3.2.2.2.3 Bateia Psicológica para Avaliação da Atenção

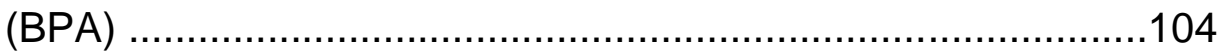

3.2.3 Instrumentos do PEI para a intervenção cognitiva ....................105

3.2.4 Escala de percepção subjetiva sobre modificações após o programa 106

3.2.5 Perspectiva Individual sobre o Programa ………....................107

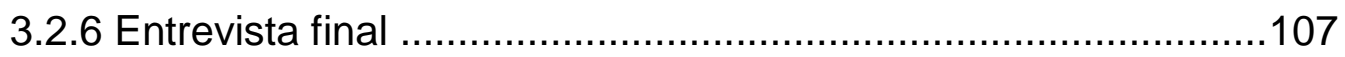

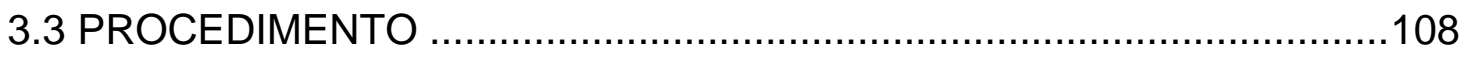


4.1 Análise descritiva dos dados

4.1.1 Homogenidade da amostra

4.1.2 Resolução de problemas .....................................................119

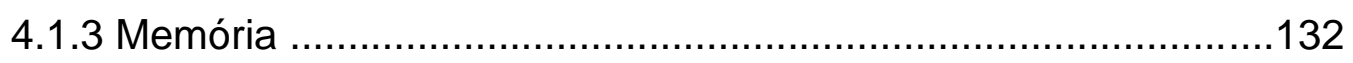

4.1.4 Atenção e Concentração ……………………………..........135

4.1.5 Escala de Autoestima …………………………...............139

4.1.6 Testes complementares: Exame Cognitivo de Addenbrooke (ACER), Mini-Exame do Estado Mental (MEEM), subtestes Raciocínio Matricial e Semelhanças da Escala Wechsler Abreviada de Inteligência (WASI) 140

4.1.7 Escala de percepção subjetiva sobre modificações após o programa 144

4.1.8 Perspectiva Individual sobre o Programa ................................147

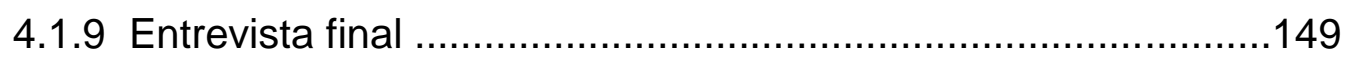

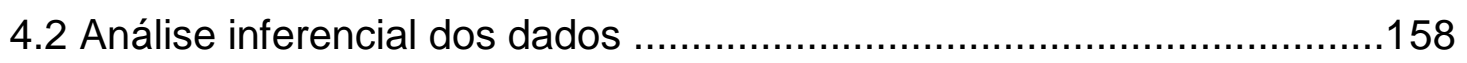

4.2.1 Homogenidade da amostra ..................................................160

4.2.2 Comparações Intragrupos ....................................................161

4.2.2.1 Resolução de problemas ............................................161

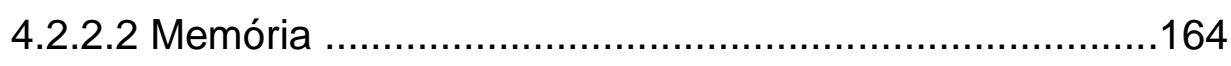

4.2.2.3 Atenção e Concentração .............................................165

4.2.2.4 Escala de Autoestima ……..........................................166

4.2.2.5 Testes complementares ............................................167

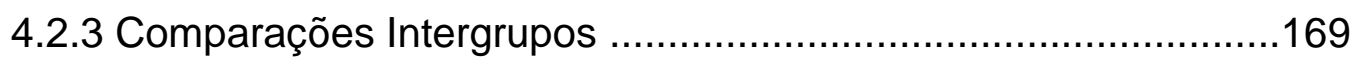

4.2.3.1 Resolução de problemas ............................................169 
4.2.3.3 Atenção e Concentração .............................................171

4.2.3.4 Testes complementares ….........................................173

4.2.3 Transferência da aprendizagem ...........................................173

4.2.4 Síntese dos resultados ..................................................176

5 DISCUSSÃO

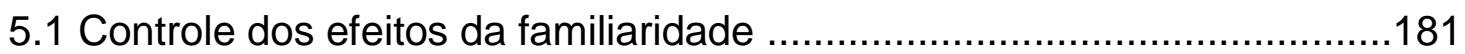

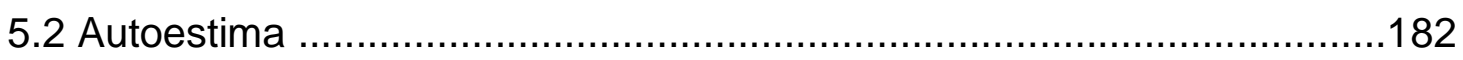

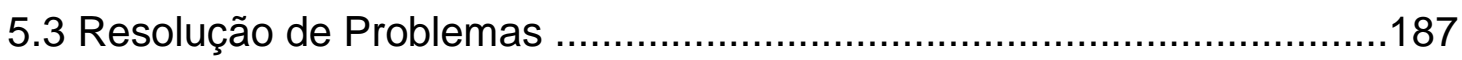

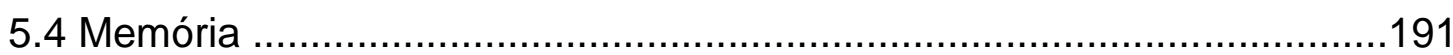

5.5 Atenção e Concentração .................................................................194

5.6 Raciocínio abstrato e Raciocínio verbal abstrato ...................................197

5.7 Considerações e limitações do trabalho ...............................................199

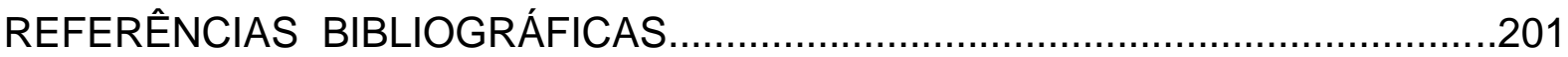

APÊNDICE A - Termo de Consentimento Livre e Esclarecido - Grupo

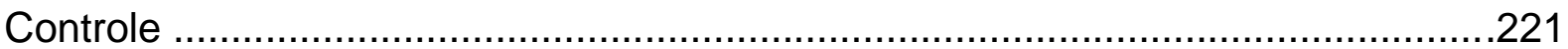

APÊNDICE B - Termo de Consentimento Livre e Esclarecido - Grupo

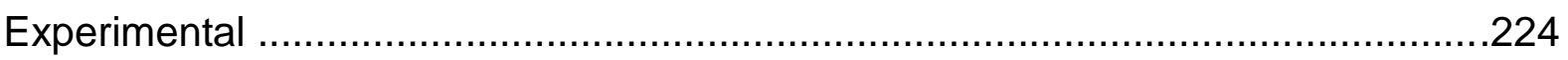

APÊNDICE C - Ficha de Identificação ……………....................................228

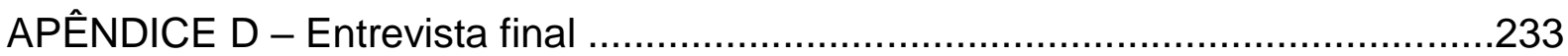

APÊNDICE E - Escala de percepção sobre modificações após o programa ........ 234

ANEXO A - Instrumentos do Programa de Enriquecimento Instrumental

Standard I 


\section{APRESENTAÇÃO}

"Um momento... Deixe-me pensar!"

Conheci o Programa de Enriquecimento Instrumental (PEI) desenvolvido pelo Profo Reuven Feuerstein por intermédio da Profa Patrícia Alonso de Oliveira Fruchi, professora e hoje coordenadora pedagógica do Projeto Amplitude, uma organização não governamental que possui como objetivo proporcionar às crianças carentes com Transtorno de Desenvolvimento, mais especificamente o Transtorno do Espectro Autista, assistência gratuita por meio da terapia comportamental, da fonoaudiologia e do apoio pedagógico. Dentre os trabalhos desenvolvidos na assessoria pedagógica, destaca-se o PEI, um modelo de intervenção cognitiva mediada pelo professor e facilitadora da maneira do aluno construir pensamentos mais lógicos e objetivos.

A professora Patrícia, que na época ministrava aulas para a educação básica na mesma instituição que eu, teve conhecimento deste programa por comentários de uma professora colega de trabalho de que um aluno integrante da $4^{\mathrm{a}}$ série (atual $5^{\mathrm{a}}$ ano) era mediado pelo PEI e obteve ótimo desempenho na disciplina de Matemática. Por ser professora e estar em constante atualização, Patrícia foi investigar quais os objetivos e finalidades do PEI. Posteriormente, uma aluna sua que apresentava dificuldades no processo de alfabetização (leitura e escrita) obteve um melhor rendimento escolar em todas as disciplinas do currículo, aluna essa que realizava as mediações do PEI.

Em uma de nossas reuniões pedagógicas na instituição, em que discutimos os casos dos alunos com dificuldades de aprendizagem e qual poderia ser considerada, em nossa percepção como professores, a melhor alternativa para ajudá-los, a professora Patrícia realizou uma apresentação do PEI discutindo a metodologia de 
trabalho do programa em questão, bem como os benefícios proporcionados por ele. A maneira como ela conduzia a apresentação, de forma empolgante e envolvente, explicando minuciosamente a maneira de utilização dos instrumentos e os objetivos de cada um deles, fez com que eu enxergasse uma luz ao final do túnel. Melhor dizendo, reafirmou minha crença de que cada aluno poderia alcançar os objetivos estipulados para a aprendizagem no ano letivo, porém por caminhos diferenciados. Como a própria professora afirmou: Nosso papel é despertar as crianças para a aventura que é aprender..., considerando o professor uma das fontes motivadoras para esta aventura.

Assim, caberia ao professor utilizar os conhecimentos adquiridos pelos alunos no decorrer de sua escolaridade e do seu curso de vida para tornar essa aventura mais acessível e prazerosa. A esse princípio eu chamaria, mais tarde, de mediação.

Quando tudo começou....

Minha formação inicial é a de licenciatura em Educação Física (EF). Decidi cursá-la por ter-me dedicado à atividade amadora de jogadora de voleibol. No decorrer do curso de graduação, deparei-me com diferentes formas de ensinar as práticas corporais aos alunos sem a violência de estereotipar padrões estéticos e desempenhos máximos. Ensiná-los-ia respeitando seus limites corporais e culturais. Aprendi que a Educação Física, como disciplina curricular, vai além dos músculos e das repetições de exercícios; que ela deve visar o desenvolvimento do ser humano na sua integridade, corpo e mente, por meio de estratégias de trabalho que integram vivências práticas e teóricas de modo que o aluno entenda o se-movimentar (a Teoria do Se-Movimentar (TSM) enfatiza o movimento humano como expressão própria do sujeito, e não como uma parte predeterminada de modelos que separam o movimento do sujeito-que-se-movimenta (BETTI et al, 2014)). 
Desta forma, o papel da Educação Física está relacionado ao ensino e aprendizagem de conhecimentos de fatos, conceitos, princípios, procedimentos, normas, valores e atitudes referentes ao movimento humano, possibilitando a integração, o controle e a transformação do ambiente físico e social do aluno. (MARIZ DE OLIVEIRA, 1999; 2005).

Embora seja considerada uma área de atuação vinculada à saúde, a EF na escola deve possibilitar intervenções pedagógicas (grifo nosso) ligadas à Cultura Corporal de Movimento para uma educação à saúde. Visto que o tema saúde é de responsabilidade de todos e não apenas da EF (OLIVEIRA et al, 2015).

Tendo em vista esta preocupação com a saúde, deparei-me com questões sobre 0 envelhecimento. $O$ interesse pelo tema deu-se em função das transformações que ocorriam com meus pais (na época adentrando esta fase) e o que poderia ser feito para ajudá-los a envelhecer com qualidade por meio dos métodos de prevenção e controle. Apaixonada pelo tema, fiz meu trabalho de conclusão de curso relacionando à reabilitação cardiovascular de idosos acometidos por eventos cardíacos. Neste mesmo ano em que conclui a graduação (1998), recebi o convite da Profa Dra Marília Velardi para participar do PAAF (Programa Autonomia para a Atividade Física), um programa de Educação Física para idosos desenvolvido pelo Grupo de Estudos e Pesquisas em Educação Física para Idosos (GREPEFI), na Escola de Educação Física e Esportes da Universidade de São Paulo, e que integrava um dos serviços de atendimento à comunidade, coordenado pela Prof ${ }^{\underline{a}}$ Dra Silene Sumire Okuma, pela qual tenho grande admiração e respeito.

Um dos objetivos deste grupo era fazer com que o idoso adquirisse conhecimentos para o autocuidado, aprendendo sobre o porquê fazer, o que fazer, 
como fazer e o quanto fazer de atividades motoras que ampliassem as capacidades dos diferentes sistemas do seu corpo (OKUMA, 2002).

O PAAF baseava-se num modelo pedagógico que ultrapassava a visão tradicional de educação (acúmulo de informações), adotava uma perspectiva de aprendizagem construtiva e significativa, tendo o indivíduo como "sujeito" do processo de ensino-aprendizagem.

Os autores que embasavam o referencial teórico do PAAF eram Coll e colaboradores (1998). Considero que, a partir da participação do PAAF, aprendi a ministrar aulas com maior qualidade, pensando no aluno como ser único e coparticipante deste processo.

De posse desses conhecimentos e tendo esta metodologia de trabalho como um guia orientador, iniciei meus trabalhos na escola adaptando-a às minhas aulas. Percebi o quão significativo era para os alunos o aprender e para mim o ensinar. Uma vez que meus estudos estavam vinculados ao processo ensino-aprendizagem, busquei na Psicologia respostas às inúmeras perguntas sobre minha atuação como professora e sobre as dificuldades demonstradas pelos alunos. Assim sendo, ingressei no Mestrado do Instituto de Psicologia da Universidade de São Paulo (IPUSP), sob orientação do Prof. Dr. José Fernando Bitencourt Lomônaco, excelente pessoa e exímio mestre, realizando uma pesquisa sobre a importância do conhecimento como fator motivador da prática de atividades físicas, da qual resultou minha dissertação de mestrado.

Porém, mesmo estudando e adaptando as situações de aprendizagem aos alunos, ainda havia aqueles que demonstravam muitas dificuldades no entendimento das situações de aulas. O que fazer? Como ajudá-los? Haveria perspectivas de integração e aprendizado do aluno com Transtorno do Espectro Autista, Transtorno 
do Déficit de Atenção e Hiperatividade, Distúrbio do Processamento Auditivo Central, Síndrome de Down, dentre outras deficiências? A fim de ampliar meus conhecimentos sobre como o aluno é capaz de aprender, realizei cursos de formação em Neurociências, participei de congressos, seminários, reuniões com professores especializados, workshops, até que conheci a teoria do Prof. Reuven Feuerstein e mais precisamente o PEl.

O PEI é um programa de ensino que tem como objetivo otimizar o funcionamento cognitivo do participante. Inicialmente criado tendo como foco crianças e jovens desfavorecidos e com atraso cognitivo, o PEI tem sido utilizado atualmente com pessoas de várias faixas etárias e perfis diversos, tanto em ambientes clínicos quanto educacionais.

Para maior aprofundamento da teoria feuersteniana e para tornar-me uma mediadora do programa, realizei o curso de formação de mediadores do PEI no Centro Brasileiro da Modificabilidade (CBM), um dos representantes do Instituto Feuerstein (The Feuerstein Institute) no Brasil, dirigido por Olivia Miranda e Domitila Miranda, grandes mestras e pessoas fundamentais na divulgação e trabalho do PEl, e iniciei os atendimentos extra-curriculares na escola em que atualmente leciono e em outras escolas da região, primeiramente com crianças que tinham dificuldades de aprendizagem e, posteriormente, com aquelas que se interessaram pela proposta do trabalho.

Verifiquei, por meio de observações e relatos dos professores regentes de sala, o quanto as crianças que participavam do programa alcançavam melhores resultados nas disciplinas curriculares e em seu comportamento em sala de aula. Durante a devolutiva do processo de trabalho para os pais/responsáveis por esses alunos, também ouvi relatos das modificações perceptíveis na vida cotidiana desses 
alunos. Todos relatos eram positivos, porém não havia comprovações científicas da melhora por meio de testes específicos.

O caso mais especial dentre os de minha mediação, e no qual tive a convicção de que o programa pode proporcionar modificações positivas, foi o do meu primeiro aluno de $\mathrm{PEI}, \mathrm{AR}^{1}$, que apresentava diagnóstico de Distúrbio do Processamento Auditivo Central (DPAC), distúrbio este caracterizado por afetar as áreas cerebrais relacionadas às habilidades auditivas e de interpretação das informações sonoras.

AR , que se encontrava em tratamento fonoaudiológico desde os seis anos de idade, iniciou as mediações de PEI após sua mãe e tia terem conhecimento dos pressupostos do programa por meio de uma palestra aberta aos pais e interessados para apresentação do programa em uma das escolas em que pretendíamos realizar os atendimentos.

Durante os meses de mediação, o aluno mostrou-se sempre disposto a realizar as atividades com zelo, dedicação, objetividade e persistência (considero esta uma das suas maiores qualidades), obteve grandes êxitos nas intervenções do programa, principalmente no instrumento intitulado Organização de Pontos, cujo objetivo, segundo Feuerstein e Hoffmam (2000) e Cruz (2007), é o de desenvolver a projeção de relações virtuais por meio de tarefas que requeiram do aluno a identificação e o delineamento das figuras indicadas pela folha do instrumento, em uma nuvem de pontos. Tal instrumento ajuda no controle da impulsividade e auxilia o aluno a tornar-se mais independente (FEUERSTEIN \& HOFFMAN, 2000).

Por relatos de seus familiares e do aluno, o PEI contribuiu para que ele realizasse as atividades escolares e cotidianas com mais atenção, concentração e

\footnotetext{
${ }^{1} \mathrm{O}$ nome do aluno foi substituído pela sigla AR.
} 
autonomia, colaborando no bom desempenho escolar. Contribuiu, também, para que conseguisse minimizar os sons distratores, além de adquirir mais fluência, postura e coragem na exposição de suas ideias e opiniões, uma de suas conquistas mais relevantes no ambiente familiar, segundo relatos de seus pares.

A partir desses avanços, como também dos proporcionados pela terapia fonoaudiológica, o tratamento fonoaudiológico que se encontrava em processo de finalização, resultou em alta definitiva e em conquistas que perduram em todo seu processo formativo e no desenvolvimento de outras habilidades.

Em face de minhas preocupações com o processo de envelhecimento, levantei a seguinte questão: Se estas modificações podiam ser observáveis em alunos na Educação Básica, tendo ou não dificuldades de aprendizagem, não poderia o PEI ser eficaz em pessoas que adentravam a fase de envelhecimento? Meus pais, que se queixavam da falta de concentração para a realização das tarefas e de lapsos de memória, poderiam se beneficiar do PEI?

Sempre tive a conviç̧ão, respaldada pelos estudos científicos, de que é necessário nos prepararmos para envelhecer com qualidade, amparando-nos nos conhecimentos advindos da Nutrição, das Ciências da Atividade Física, da Psicologia e, mais recentemente, das descobertas das Neurociências.

Como decorrência de tal reflexão, surgiu a ideia de realizar minha Tese de Doutorado investigando se o Programa de Enriquecimento Instrumental poderia também proporcionar benefícios aos idosos no tocante a seu desempenho cognitivo. $\mathrm{Na}$ impossibilidade de avaliar todas as funções mentais, por demais abrangentes, necessário se fez delimitar o estudo e focalizar apenas quatro funções, quais sejam: memória, resolução de problemas, atenção e concentração, autoestima, em face de 
sua importância/relevância para o funcionamento mental do ser humano, e também pelo fato de serem objeto da grande parte das queixas dos idosos.

Realizada a pesquisa, o relato da mesma foi assim delineado:

1) No Capítulo 1 são tecidas considerações sobre o envelhecimento e as variáveis consideradas responsáveis pelo menor desempenho cognitivo.

2) No Capítulo 2 é descrito o Programa de Enriquecimento Instrumental, apresentado estudos que se utilizaram do mesmo e expostos os objetivos e hipóteses da pesquisa.

3) O Capítulo 3 apresenta a seção do Método, explicitando as características da amostra, os instrumentos utilizados e os procedimentos adotados.

4) No Capítulo 4 são apresentadas as análises dos resultados da pesquisa.

5) Finalmente, no Capítulo 5 são analisados e discutidos os resultados encontrados, apontadas as limitações do trabalho e sugeridas novas pesquisas sobre o tema.

A autora da pesquisa e seu orientador esperam que este trabalho possa contribuir para consolidar o PEI como um programa de intervenção cognitiva eficaz em, pelo menos, minimizar o envelhecimento das funções cognitivas, possibilitando um envelhecimento com maior qualidade na vida dos idosos. 


\section{CAPÍTULO 1}

\section{ENVELHECIMENTO E DESEMPENHO COGNITIVO: ESTUDOS E DESAFIOS}

Identificar as virtudes da idade madura é um desafio intelectual com o qual se envolveram vários pensadores ao longo dos tempos. Vivê-la de maneira positiva é questão existencial que se propõe a um número crescente de pessoas em todo o mundo, uma vez que o envelhecimento populacional está se generalizando. Identificar as condições que permitem envelhecer bem, com boa qualidade de vida e senso pessoal de bem-estar, é tarefa de várias disciplinas no âmbito das ciências biológicas, da psicologia e das ciências sociais (NERI, 1993, p. 9).

A partir da década de 1970, iniciou-se um processo de mudança nas concepções tradicionais de envelhecimento e uma busca de novos caminhos para explicar este fenômeno. Proposições da teoria do curso de vida e o modelo da velhice bem sucedida foram essenciais para a mudança de paradigma a respeito da velhice e do envelhecimento (NERI, 1995; NERI, 2000; NERI et al. 2013). Segundo a teoria do curso de vida, o desenvolvimento envolve mudanças de comportamento que ocorrem ao longo do tempo. É um processo multidirecional, não caracterizado por eventos isolados de crescimento ou declínio. Implica em adaptação constante, que inclui o equilíbrio entre ganhos e perdas. O conceito de desenvolvimento, segundo a teoria do curso de vida, está intimamente ligado a dois constructos: 
mudança e adaptação. Mudanças ocorrem desde a concepção até a morte e, embora sejam mais evidentes em fases como a infância e a adolescência, ocorrem durante toda a vida. Em decorrência dessas mudanças, o ser humano é estimulado a adaptar-se para que possa dar conta das demandas internas e externas (PAPALIA \& OLDS, 2000; PAPALIA \& FELDMAN, 2013).

Já o modelo de velhice bem sucedida, proposto por Baltes e Baltes (1991), baseia-se na premissa de que o desenvolvimento satisfatório e individual é um processo adaptativo que envolve componentes de seleção, otimização e compensação. O uso destes depende das circunstâncias pessoais à medida que se envelhece. Dentre suas proposições, uma se refere ao potencial de reserva latente (ou capacidade de reserva) que todos possuem, em qualquer etapa da vida. Tal qual as pessoas jovens, a maioria dos idosos possui ampla reserva que pode ser ativada pela aprendizagem e pelo exercício ou treinamento. A plasticidade de comportamento no idoso sustenta a possibilidade de otimização comportamental e compensação seletiva na velhice.

Portanto, de acordo com tais teorias, o envelhecimento pode ser visto como uma fase do desenvolvimento humano (PAPALIA \& FELDMAN, 2013). Ele compreende processos de transformação do organismo que ocorrem após a maturação sexual e implicam na diminuição gradual da probabilidade de sobrevivência. Embora o equilíbrio entre perdas e danos seja menos positivo na velhice, o potencial de desenvolvimento é resguardado dentro dos limites da plasticidade individual.

Envelhecer não significa apenas passar por um processo progressivo e irreversível de alterações, que levam o indivíduo a declínios em vários aspectos, mas significa também entrar em contato com uma série de questões psicológicas, 
sociais e culturais (NERI, 1995, 2013; ZIMERMAN, 2007; PAPALIA \& FELDMAN, 2013). Nesse sentido, Neri (1995) caracteriza o processo de envelhecimento a partir de três fatores: a) a senescência, relativa ao aumento da probabilidade da morte, com o avanço da idade; b) a maturidade social, correspondente à aquisição de papéis sociais e de comportamentos apropriados aos diversos grupos de idade; c) o envelhecimento em si, correspondente ao processo de autorregulação da personalidade.

Em alguns domínios do comportamento, como o físico e o cognitivo, as perdas parecem ser preponderantes, mas as investigações científicas têm mostrado que é possível melhorar ou adaptar alguns comportamentos nessa fase de vida para que se possa fazer frente às demandas da vida, entre elas a demência (OLIVEIRA, 2010; OPDEBEECK et al., 2016).

A demência pode ser definida como uma síndrome caracterizada pela presença de declínio cognitivo persistente (déficit progressivo da função cognitiva com maior ênfase na perda da memória, mas que podem estar presentes em outros domínios como funções executivas, habilidades visuoespaciais, linguagem e comportamento) que interfere nas atividades sociais e/ou profissionais do indivíduo e que independe de alterações do nível de consciência (NITRINI \& CARAMELLI, 2003; NETO, 2005; MCKHANN et al., 2011; SOUZA \& TEIXEIRA, 2013).

Os transtornos demenciais aumentam com a idade, passando de $1,3 \%$ nos indivíduos entre 65 e 69 anos para cerca de $17 \%$ entre os com 80 e 84 anos, chegando a alcançar aproximadamente $37,8 \%$ entre os que possuem 85 anos ou mais (NITRINI et al., 2003; WHO, 2012). A prevalência da demência dobra a cada cinco anos de aumento da faixa etária (LOPES \& BOTTINO, 2002). Ferri et al. (2005), em revisão sistemática sobre estudos de estimativas de prevalência de 
demência no mundo encontraram a ocorrência dessa doença em 24,3 milhões de pessoas com 60 anos ou mais em 2005, o surgimento de 4,6 milhões de novos casos/ano e um total de 81,1 milhões de pessoas em 2040 , sendo que $71 \%$ dessas viverão nos países em desenvolvimento. O total de novos casos de demência no mundo a cada ano é de aproximadamente 7,7 milhões (WHO, 2012; GODINHO, 2012).

As alterações e os déficits causados pelo declínio cognitivo levam ao declínio funcional, com diminuição e/ou perdas das habilidades necessárias para o desempenho das atividades cotidianas, interferindo de forma significativa na execução das denominadas atividades da vida diária (AVD) e gerando a necessidade de um cuidador que faça e assuma essas tarefas pelo idoso.

No início do processo demencial, o indivíduo apresenta declínio de memória, podendo parecer confuso, desorientado e com déficit de atenção, começando a apresentar dificuldades em lidar com situações mais complexas como, por exemplo, fazer uma compra ou manejar dinheiro. Pode, também, apresentar desorientação de tempo e de espaço, chegando a perder-se em locais já conhecidos (NITRINI et al., 2003; IZQUIERDO et al., 2013). Com a progressão do quadro pode surgir apraxia (incapacidade de realizar ato motor complexo, apesar de capacidade motora intacta) comprometendo o autocuidado e transformando as tarefas cotidianas simples em situações desafiadoras (BEAR et al., 2002; NITRINI \& CARAMELLI, 2003). Posteriormente, surge o comprometimento da linguagem que evolui até a significativa diminuição da compreensão e da produção oral. A incapacidade de orientar-se e reconhecer fisionomias e objetos sem que haja déficit sensorial ou sensitivo também ocorre com frequência (KANDEL et al., 2000). Sua capacidade de 
juízo crítico é afetada, podendo gerar atitudes inadequadas, sendo essas situações as que normalmente mais chamam a atenção dos familiares.

O diagnóstico nas fases iniciais da demência é um desafio (DAMASCENO, 1999). Segundo Bottino et al. (1998), indivíduos que evidenciam declínio no desempenho cognitivo superior ao esperado para a idade, usualmente demonstrado nos testes neuropsicológicos, mas que não atingem o diagnóstico de demência e que conseguem preservar as atividades da vida diária, recebem o diagnóstico de portadores de Comprometimento Cognitivo Leve (CCL). Estudos sugerem que a população com CCL apresenta maior risco de conversão para doença de Alzheimer (de 10 a 15\%) comparada com idosos saudáveis (de 1 a $2 \%$ ). De acordo com Reisberg et al. (2006), de 7 a 8\% de indivíduos normais com queixa de memória convertem-se para CCL a cada ano.

No Brasil, um estudo descrito por Godinho (2012) e realizado na cidade de Porto Alegre, encontrou taxa de $6,1 \%$ de prevalência de CCL, destes $24 \%$ permaneceram estáveis e $38 \%$ melhoraram ao longo do acompanhamento, sendo que a taxa de conversão para a Doença de Alzheimer foi de $8,5 \%$.

O declínio cognitivo e a demência estão fortemente associados ao declínio da funcionalidade e incapacidade, como mostram vários estudos (AGUERO-TORRES et al., 2002; NYGARD, 2003; LAKS et al., 2005; DIRIK et. al., 2006; FERRO et al., 2013). Outros fatores são, também, associados ao declínio cognitivo, tais como nível de escolaridade baixo, pouco contato social, sexo feminino, idade avançada, comorbidades como doença cerebrovascular, doença cardíaca e fratura de quadril (AGUERO-TORRES et al., 1998; FERNANDES et al., 2015), baixos resultados no MEEM (Mini-Exame do Estado Mental), tabagismo, viver sozinho, sedentarismo, incontinência urinária, queda e pobre atividade intelectual (DIRIK et al., 2006; 
ISHIZAKI et al., 2006; DI CARLO et al. 2007; NITRINI et al. 2009; PRINCE et al. 2012; FERNANDES et al., 2015).

La Rue (2012, p.77) afirma que um número crescente de pessoas idosas saudáveis está procurando conselho clínico sobre seus problemas cognitivos. Destaca que algumas desejam assegurar-se de que seus esquecimentos ocasionais não são sinais de doença de Alzheimer; outras querem encontrar maneiras de melhorar suas habilidades cotidianas.

Em face do exposto, cabe a seguinte questão: Será que a população de idosos envelhece com qualidade? Quais as formas de proporcionar-Ihes um envelhecimento bem-sucedido?

Papaléo Neto (2002), Zaslavsky e Gus (2002), Algarabe et al. (2012) e Izquierdo et al. (2013) destacam que, dentre as condições associadas a uma velhice bem-sucedida, além da prática de atividades físicas e de uma dieta balanceada, está o funcionamento mental adequado que pode ser preservado por meio de programas educacionais que possibilitem atividades intelectuais aos idosos.

As atividades intelectuais aparecem como uma possibilidade de compensação dos déficits cognitivos (DUNLOSKY \& HERTZOG, 1998; FERNANDES et al., 2015). Estas atividades permitem modificações em habilidades, como o aumento da velocidade do processamento mental. Verhaeghen (2000) acredita que tais atividades permitem ativar habilidades em desuso levando o indivíduo a aproximarse do seu desempenho máximo.

Estas alterações são possíveis devido à plasticidade neural ou neuroplasticidade, entendida como a capacidade de os neurônios fazerem novas conexões, alterando a eficiência das sinapses e, consequentemente, aumentando a 
transmissão dos impulsos nervosos e modulando o comportamento (NERI et al., 2001; ANNUNCIATO, 2005; FEUERSTEIN et al., 2013).

Segundo Freire (1999), Feuerstein et al. (2013) e Li et al. (2015), a neuroplasticidade possibilita tornar a pessoa mais capacitada para adaptar-se às mais diversas situações da vida diária. Em se tratando do idoso, a capacidade de adaptar-se a estas situações é um dos meios de se atingir um envelhecimento bemsucedido.

Santos de Sá (1999), Santos et al. (2000), Goulart e Ferreira (2012) e Sousa e Rodríguez-Miranda (2015) destacam que a educação é uma das formas dos idosos vencerem os desafios impostos pela idade e pela sociedade, proporcionandoIhes novos conhecimentos, atualização e novas oportunidades para buscar seu bemestar físico, mental e funcional. Ou seja, a educação/aprendizagem é um instrumento essencial que possibilita ao idoso uma mudança de comportamento (mudança atitudinal) frente ao envelhecimento.

Vários são os fatores que podem interferir no envelhecimento cognitivo. Tais fatores podem ser agrupados em socioculturais (p.ex. escolaridade), psicológicos (p.ex. motivação), e biológicos (p.ex. sexo).

Umas das principais diferenças no funcionamento cognitivo dos idosos são derivadas dos aspectos socioculturais, expressos por meio da educação. No dizer de Neri: falta de oportunidades educacionais pode tornar o idoso obsoleto, mas não decrépito (2002, p. 94).

A escolarização desempenha papel importantíssimo na manutenção do funcionamento intelectual, uma vez que estimula o desenvolvimento de habilidades e estabelece as bases do conhecimento para futura aprendizagem de idosos. Atualmente considera-se que a assimilação de novos conhecimentos, atitudes e 
hábitos pode ocorrer em qualquer idade, embora a rapidez de assimilação das novas informações se altere com o decorrer dos anos (FARIA JUNIOR, 2000; MOSQUERA \& STOBAUS, 2012). Assim, derruba-se o mito da incapacidade do ser humano efetuar novas aprendizagens em idades avançadas, ainda que tais aprendizagens possam ser afetadas por fatores não cognitivos como a motivação, o interesse e a boa saúde, entre outros.

Elias et al. (1997) e Ishizaki et al. (1998) ressaltam que estudos epidemiológicos em idosos têm constatado que, quanto menor o nível de escolarização, pior o desempenho em testes de memória lógica. Estes achados também foram encontrados nos trabalhos de Chariglione e Janczura (2013). Moura (1999) aponta que indivíduos mais escolarizados apresentam uma maior possibilidade de pensamento descontextualizado, abstraído de experiências pessoais e da realidade concreta e imediata, diferente das pessoas pouco ou não escolarizadas, cujos modos de funcionamento intelectual apresentam-se mais presos à realidade vivenciada, concreta e imediata. Outra variável sociocultural que afeta o envelhecimento cognitivo, de acordo com Liu (1998) e Zhang et al. (2015), refere-se à renda, na medida em que reduz o acesso a recursos educacionais. Neri (2002) e Fernandes et al. (2015) destacam que a privação econômica, com a consequente redução dos recursos necessários para uma qualidade de vida aceitável, contribui para o risco de declínio cognitivo na velhice.

Dentre as funções psicológicas, a memória é, sem dúvida, um dos mais afetados pelo envelhecimento.

Yassuda (2011), Baddeley et al. (2011) e Yi e Friedman (2014) consideram a memória como uma das mais importantes funções cognitivas do homem, responsável pelo armazenamento de informações sobre o indivíduo e o meio que o 
cerca. Conforme os autores, mesmo na ausência de patologias graves, o envelhecimento leva a um declínio modesto, mas significativo da memória, conhecido como comprometimento cognitivo leve, o qual é influenciado pela composição genética, nível sócio-econômico, estilo de vida, acuidade visual e auditiva, relações sociais etc. Neri (2002) e Badham e Maylor (2013) também apontam que as perdas da memória não devem ser atribuídas apenas ao déficit no processamento de informações, mas também a déficits motivacionais, baixa autoestima, falta de confiança nas próprias capacidades, depressão, estresse, fadiga, efeitos colaterais dos remédios, entre outros.

As falhas da memória são muitas vezes vistas como uma consequência inevitável do envelhecimento. Porém, seu funcionamento em pessoas mais velhas pode variar (PAPALIA \& OLDS, 2000; PAPALIA \& FELDMAN, 2013). A memória de curto prazo possui dois componentes: a memória primária e a memória de trabalho. A memória primária é considerada como um local de armazenamento de pequenas quantidades de informações recém-adquiridas por períodos muito curtos de tempo. Essa memória é descrita como o centro da consciência humana, pois abriga os pensamentos e as informações a que damos atenção no momento (NERI, 2002; BADDELEY et al. 2011). De acordo com Papalia e Olds (2000) e Papalia e Feldman (2013), as diferenças etárias em tarefas que requerem a memória primária são muito pequenas. Já a memória de trabalho, não apenas armazena a informação como também a manipula. Acredita-se que a capacidade de manipulação (reorganização e manipulação) reduza-se com a idade (TAUSSIK \& WAGNER, 2006; BADDELEY et al. 2011).

A memória de longo prazo, considerada a capacidade que temos de manter informações gravadas por longos períodos de tempo, é afetada em menor grau pelo 
envelhecimento e subdivide-se em três tipos: memória semântica, episódica e procedimental. De acordo com Yassuda (2011) e BADDELEY et al. (2011), a memória semântica é a capacidade de registrar informações lingüísticas (nome de pessoas e lugares, descrições de acontecimentos, vocabulários, significados e normas semânticas e sintáticas de idiomas). Essa habilidade é pouco afetada durante o envelhecimento (MACHADO, 2015).

Jaeger (2006) e Yassuda (2011) relatam três possíveis explicações para a resistência deste tipo de memória ao envelhecimento: (1) as estruturas neuroanatômicas são menos afetadas pelo processo de envelhecimento; (2) talvez esta memória decline tanto quanto outros tipos, mas as experiências com a linguagem durante a vida podem ter a capacidade de compensar este declínio; (3) é possível que a organização do conhecimento semântico seja altamente redundante e resistente ao envelhecimento biológico.

A memória episódica que, segundo Brown (1975) e Taussik e Wagner (2006), refere-se ao armazenamento e recuperação de dados relacionados à localização espacial de eventos experimentados pessoalmente (episódicos), ou seja, informações sobre quando, onde e como um evento ocorreu, parece bastante sensível ao envelhecimento, sendo o componente da memória de longo prazo que mais tende a se deteriorar com a idade (PAPALIA \& OLDS, 2000; PAPALIA \& FELDMAN, 2013). Yassuda (2011) relata que, durante testes cognitivos de memorização de itens (por exemplo nome de pessoas), os jovens apresentam melhor desempenho de memorização do que os idosos. Isso pode ser explicado pela dificuldade no processo de resgate das informações por conta própria. Já, quando os idosos têm que reconhecer as informações dentre as estudadas e não estudadas em testes de reconhecimento, a diferença de desempenho entre jovens e 
idosos diminui. Assim, a autora sugere que a diferença entre jovens e idosos em tarefas de memória episódica aumenta quando as exigências cognitivas da tarefa também aumentam.

A memória procedimental, ou memória de procedimentos, inclui habilidades motoras, hábitos e maneiras de fazer coisas que muitas vezes podem ser lembradas sem esforço consciente (PAPALIA \& OLDS, 2000; BADDLEY et al. 2011; PAPALIA \& FELDMAN, 2013). Usamos a memória de procedimentos para realizar ações rotineiras, que, pela prática, se tornaram automáticas como, por exemplo, dirigir um automóvel ou operar um microondas. Esta memória tem se mostrado bastante resistente ao envelhecimento e poucas diferenças são encontradas entre jovens e idosos (YASSUDA, 2011).

Outras funções psicológicas afetadas pela idade são a resolução de problemas e a tomada de decisões.

A resolução de problemas, segundo Schneider (2006), pode ser definida como um processo no qual um conjunto de procedimentos é empregado com o objetivo de eliminar as barreiras existentes entre o estado atual e o estado que se busca atingir. Sternberg (2003) descreve-o como um ciclo pelo qual os solucionadores devem passar a fim de solucioná-los. Este ciclo apresenta sete etapas, cuja sequência não ocorre de forma rígida e o solucionador bem-sucedido é aquele que apresenta flexibilidade na mudança de estratégias conforme se modificam as situações apresentadas.

As sete etapas arroladas são: 1) reconhecer e identificar o problema; 2) definir e representar mentalmente o problema; 3) construir estratégias para a resolução; 4) organizar o conhecimento sobre o problema; 5) alocar recursos físicos e mentais; 6) 
monitorar o progresso em direção à meta; 7) avaliar a precisão da resolução do problema.

Uma vez que, com o envelhecimento, as pessoas apresentam declínios na velocidade de processamento cognitivo e na memória de trabalho, é de se esperar que a resolução de problemas por idosos sofrerá sua influência (SCHEIBEL, 1996; MURRAY \& BYRNE, 2013). Em contrapartida, o aumento da idade está relacionado ao ganho de conhecimentos e experiências que podem compensar as perdas cognitivas (PAPALIA \& FELDMAN, 2013). De acordo com Schneider (2006), as pesquisas têm demonstrado que a representação que o indivíduo faz dos seus problemas varia ao longo da vida e a seleção de estratégias sofre influências da idade e das representações em diferentes faixas etárias.

A tomada de decisões é definida por Stenberg (2000) e Schneider e Parente (2006) como uma função complexa, parte das funções executivas, que envolve a escolha entre duas ou mais opções. Para Damasio (1996), a tomada de decisão supõe uma situação que requer determinada decisão, as possibilidades de ação e suas consequências, sendo estas imediatas ou futuras.

No estudo realizado por Walker et al. (1997), foram examinadas a velocidade e a qualidade da tomada de decisão em uma tarefa que incluía a habilidade de dirigir. Os participantes deveriam selecionar rotas após terem informações sobre o tráfego e os limites de velocidade. Foi observado que não houve diferenças na qualidade de decisão dos participantes mais velhos quando comparados aos mais jovens, porém houve diferenças relativas à velocidade de decisão.

Em contrapartida, Finuncane et al. (2002), em um estudo destinado a avaliar e escolher opções sobre planos de saúde, verificaram maiores erros de compreensão em adultos mais velhos (idade de 65 a 94 anos) quando comparados aos mais 
jovens (idade de 18 a 64 anos), mesmo sendo consideradas as variáveis relacionadas à educação, à renda, à habilidade e à saúde autopercebidas.

Para Sanfey e Hastie (2001) estes achados sugerem que a capacidade da memória de trabalho dos idosos declina com a idade, o que leva a um menor acúmulo de informações. Porém, os autores consideram que, se houver menos informações a serem manipuladas para a tomada de decisões, é possível que a experiência dos adultos mais velhos seja realizada de forma competente.

Nos últimos anos, os pesquisadores têm atribuído uma maior importância ao estudo das funções executivas (FE) e sua relação com o envelhecimento, principalmente devido ao crescente número de trabalhos que indicam que o declínio das FE precedem os declínios de memória e ajudam a diferenciar idosos normais de idosos com déficit cognitivo (HOBSON \& LEEDS, 2001; PAULA et al., 2013; DELPERO et al., 2015).

As FE são definidas, segundo Kristensen (2006) e Delazer et al. (2007), como processos cognitivos de controle e integração destinados à execução de um comportamento dirigido a objetivos, necessitando do desempenho de componentes como atenção, programação e planejamento de sequencias, inibição de processos e informações concorrentes e monitoramento. O funcionamento executivo é frequentemente associado aos lobos frontais e os termos funções frontais e FE são usados como sinônimos na literatura. Assim, os atuais modelos neuropsicológicos propõem que algumas mudanças relacionadas com o aumento da idade são devidas a uma deterioração do lobo frontal (SALTHOUSE et al., 2003; WEST, 1996, cit in ANDERSON et al., 2008). Estudos demonstram que, comparativamente a adultos mais jovens, adultos mais velhos tendem a apresentar níveis mais baixos de ativação do lobo frontal (MILLER \& CUMMINGS, 2007). Ou seja, o envelhecimento 
ocasiona maiores mudanças neuroanatômicas e neuroquímicas no lobo frontal do que em qualquer outra área do cérebro (FUSTER, 1989; WOODRUFF-PAK, 1997, cit. in PHILLIPS \& HENRY, 2008) e está relacionado com funções neurológicas elementares, linguagem e capacidades linguísticas, movimentos oculares voluntários, comportamentos motivacionais, competência social, capacidade executiva, regulação e monitoração do comportamento, abstração, capacidade de resolução de problemas e capacidade de inibição (MILLER \& CUMMINGS, 2007; PAULA et al. 2013).

Estudos indicam que as diferenças devidas à idade em funções atribuídas ao lobo frontal podem apresentar diferentes trajetórias, dependendo da área que uma determinada tarefa requer que seja ativada, sendo a área dorsolateral mais sensível ao declínio da idade (MACPHERSON et al, 2002).

Uma outra variável de caráter psicológico que interfere nas capacidades cognitivas dos idosos é a motivação para a tarefa, que, segundo Hall (1992), pode ser influenciada por crenças do indivíduo na sua capacidade de memória, em suas forças e fragilidades. Spinger-Littles e Anderson (1999) destacam que, no ensino de idosos, a motivação torna-se maior quando é disponibilizado a ele algum controle sobre a situação de aprendizagem e quando há referência aos conhecimentos prévios e experiências passadas.

No que se refere aos aspectos biológicos, um dos mais importantes, sem dúvida, é a plasticidade cerebral ou neuroplasticidade. De acordo com Cosenza e Guerra (2011), a plasticidade cerebral refere-se à capacidade do sistema nervoso fazer e desfazer as ligações entre os neurônios, derivada das interações do indivíduo com o ambiente externo e interno do corpo. Os mesmos autores descrevem que a plasticidade, embora diminuída na fase adulta e no 
envelhecimento, permanece pela vida inteira. Mesmo havendo diminuição da taxa de aprendizagem de novas informações, a capacidade de utilizar e elaborar o que foi aprendido é aumentada.

A plasticidade cerebral é um conceito presente na abordagem de desenvolvimento de Baltes (1994), considerando que o desempenho cognitivo em adultos mais velhos pode ser aperfeiçoado com treinamento e prática. Cosenza e Guerra (2011) e Izquierdo et al. (2013) também salientam que o treino e a aprendizagem podem levar à criação de novas sinapses e facilitar o fluxo de informação dentro de um circuito nervoso. Um acompanhamento de sete anos no ADEPT (Projeto de Desenvolvimento e Enriquecimento de Adultos) (BALTES \& WILLS, 1982) que fornece programas de aprimoramento cognitivo a voluntários idosos, mostrou que os participantes que receberam treinamento tiveram declínio cognitivo significativamente menor do que o grupo controle. Tais resultados sugerem fortemente que nossas potencialidades cognitivas podem ter diferentes desenvolvimentos em função do contexto sociocultural em que se vive.

Uma vez consideradas as variáveis que afetam a cognição no envelhecimento, cabe considerar alguns estudos que buscaram avaliar o efeito de programas de intervenção sobre o desempenho cognitivo de idosos.

Com o objetivo de replicar resultados internacionais referentes a treino de memória com uma amostra brasileira de idosos saudáveis e investigar mecanismos, como o uso de estratégias, que possam explicar seus benefícios, Yassuda et al. (2006) estudaram 69 idosos saudáveis, subdivididos em grupo controle e grupo experimental. Ambos os grupos realizaram uma pré-avaliação individual para obtenção de dados sócio-demográficos e verificação dos critérios de exclusão e participaram da sessão do pré-teste, a qual incluiu avaliações de memória episódica, 
uso de estratégias de memória, velocidade de processamento das informações, metamemória (queixas de memória e autoeficácia para memória) e humor. O grupo experimental realizou quatro sessões de treino; logo após ambos os grupos realizaram o pós-teste. Os resultados indicaram que, após o treino, os idosos fazem uso mais intenso de estratégias de memória, mas este fato não garante um melhor desempenho; houve um aumento significativo no uso de grifos durante a memorização do texto e um aumento modesto na categorização da lista para o grupo experimental. Não houve melhora da autoeficácia e do humor. Para o grupo controle, apenas a participação nas sessões de avaliação, foi suficiente para reduzir as queixas de memória e aumentar a velocidade de processamento.

Carvalho et al. (2010a) tiveram como objetivo verificar os efeitos do treino de memória episódica em idosos saudáveis brasileiros, analisando 57 idosos subdivididos aleatoriamente em grupo controle e grupo experimental. Neste estudo, o grupo experimental participou de cinco sessões de treino de memória episódica, nas quais foram instruídos a categorizar listas de supermercado e figuras. Os resultados indicaram que o treino de memória episódica envolvendo a aprendizagem e a prática com a estratégia de categorização promoveu melhora significativa no desempenho em tarefa de memória episódica e um maior uso da estratégia treinada.

Um estudo realizado por Silva et al. (2011) objetivou testar a eficácia de um programa de treino cognitivo baseado em tarefas como a memorização de listas de supermercado e manuseio de dinheiro em tarefas de troco. Os idosos foram subdivididos em dois grupos: intervenção e controle. O grupo de intervenção apresentou melhora significativa no teste de fluência verbal e no resgate imediato da lista de palavras. O grupo controle não apresentou alterações significativas entre o pré e o pós-teste, para as variáveis avaliadas. Os resultados sugerem que o treino 
cognitivo pode gerar melhora no desempenho em tarefas de memorização e cálculos entre idosos.

Ainda relacionando os estudos à memória, Brum (2012) avaliou o impacto do treino de memória de oito sessões oferecido a idosos normais e com comprometimento cognitivo leve (CCL) com alta escolaridade. Ambos os grupos, experimental e controle, continham idosos normais e idosos com CCL. Os resultados demonstram melhoras do grupo experimental em relação ao grupo controle nos testes de atenção, velocidade de processamento, estratégias mnemônicas e em testes de memória. De acordo com o estudo, os efeitos parecem manter-se a curto e a longo prazo, mostrando os benefícios do treino e a existência de plasticidade cognitiva em ambas as populações estudadas.

Kissaki et al. (2012) objetivaram investigar se a participação de idosos em uma Universidade Aberta à Terceira Idade (UnATI) poderia contribuir para a manutenção do desempenho cognitivo. Foram entrevistados 180 idosos no início do primeiro ou do segundo semestres do ano de 2010 e após seis meses de participação. Os dados obtidos indicam que os idosos apresentam melhor desempenho em tarefas de memória episódica no pós-teste, sugerindo que a participação na UnATI pode favorecer a manutenção das habilidades cognitivas.

Lopes (2014) teve como objetivo verificar os efeitos do treino nas funções executivas e memória em idosos. Participaram 83 idosos divididos em grupo controle (38) e grupo experimental (45). Foram realizadas três sessões de treinamento com o grupo experimental e os idosos foram avaliados por meio dos seguintes testes nas etapas pré e pós-teste: Subtestes Dígitos, Vocabulário, Cubos, Código, Sequência de Números e Letras - SNL e Procurar Símbolos do WAIS-III; TMT; WCST; Figuras Complexas de Rey; Paradigma de Sternberg; Fluência Verbal semântica (animal) e 
fonêmica (letras F, A, S), RVLT; Teste Stroop de Cores e Palavras; Tarefas go-no-go. Os resultados indicam que o grupo experimental, após o treino, apresentou melhoras em relação ao grupo controle tanto nas funções executivas avaliadas como também no bem-estar psicológico.

Irigaray et al. (2012) objetivou verificar os efeitos de um treino de atenção, memória e funções executivas na cognição de idosos saudáveis. Participaram do estudo 76 idosos saudáveis, divididos em grupo experimental e grupo controle, cada um com 38 indivíduos. O grupo experimental recebeu 12 sessões de treino de atenção, memória e funções executivas, apresentando melhora no desempenho na comparação com o grupo controle em tarefas de atenção, memória de trabalho, linguagem (inferências e escrita espontânea), praxia construcional, resolução de problemas e funções executivas. Desta forma, o treino revelou resultados significativos para uma intervenção de 12 sessões, indicando que idosos saudáveis podem melhorar seu desempenho cognitivo.

Outros estudos apontam a importância da intervenção cognitiva em relação à melhora da qualidade de vida e bem-estar psicológico.

Com o objetivo de analisar a eficácia da estimulação cognitiva na sintomatologia depressiva e nas atividades instrumentais da vida diária de idosos em um contexto comunitário, Apóstolo et al. (2011) realizou um estudo com 23 idosos subdivididos em grupo controle e grupo experimental. Ambos os grupos realizaram o pré e pós-testes por meio dos seguintes instrumentos: Montreal Cognitive Assessment, Geriatric Depression Scale-15 e Lawton Brody Instrumental Activities of Daily Living. O grupo experimental foi submetido a 14 sessões de estimulação cognitiva "Fazer a diferença" (PEC-FD), versão portuguesa de Making a Difference: An Evidence-based Group Programme to Offer Cognitive Stimulation Therapy (CST) 
to People with Dementia. Os resultados indicam que O PEC-FD contribuiu para a manutenção da saúde cognitiva dos idosos, podendo atrasar a instalação do quadro demencial e, consequentemente, melhorar a autonomia e independência destas pessoas.

Irigaray et al. (2011) tiveram como objetivo verificar os efeitos de um treino cognitivo na qualidade de vida e no bem-estar psicológico de 76 idosos saudáveis, divididos em grupo experimental e grupo controle. $\mathrm{O}$ grupo experimental recebeu doze sessões de treino cognitivo, as quais foram divididas em três partes de aproximadamente 30 minutos cada. Na primeira parte, houve exposição teórica com abertura para discussão sobre os conceitos e tipos de atenção, memória e funções executivas e sua relação com o processo de envelhecimento. A segunda parte das sessões envolveu a execução de exercícios práticos de atenção, de memória episódica e de funções executivas. A terceira parte compreendeu a apresentação e a discussão de tarefas realizadas em casa. Os participantes realizavam leituras e exercícios em casa, após cada sessão, a fim de se prepararem para o próximo encontro. Os resultados indicaram que, após o treino, os idosos deste grupo apresentaram melhor desempenho cognitivo, melhor percepção de qualidade de vida e maiores índices de bem-estar psicológico.

De acordo com o exposto, parece estar razoavelmente bem comprovado a existência de variáveis que afetam significativamente a cognição do indivíduo durante o envelhecimento. Em face de tal constatação e a fim de manter a qualidade de vida dos idosos, buscam-se recursos que minimizem os efeitos do declínio cognitivo. Dentre tais recursos destacam-se as intervenções cognitivas que auxiliam no tratamento, na prevenção das demências e na qualidade de vida dos idosos 
(OLCHIK, 2008; ZOLLIG et al., 2012). Um dos programas na área, o Programa de Enriquecimento Instrumental, será apresentado no próximo capítulo. 


\section{CAPÍTULO 2}

\section{O PROGRAMA DE ENRIQUECIMENTO INSTRUMENTAL: UM PROGRAMA DE INTERVENÇÃO PSICOEDUCATIVA}

A proposta de mediação, para Feuerstein, vai além de uma simples e orientada tarefa de um produto, de uma orientação de aprendizagem. Tem como principal objetivo, tornar o indivíduo capaz de agir independentemente de situações específicas, e isso torna o aprendiz capaz de se adaptar às novas dimensões com as quais ele irá se defrontar (WEINERT,2008, p.10).

\subsection{Teoria da Modificabilidade Cognitiva Estrutural}

A Teoria da Modificabilidade Cognitiva Estrutural foi desenvolvida por Reuven Feuerstein e colaboradores a partir de trabalhos realizados em Israel com crianças e jovens que apresentavam baixo desempenho em diferentes áreas e dificuldades de integração aos grupos sociais a que pertenciam (CRUZ, 2007; CARVALHO, 2008; MEIER \& GARCIA, 2009).

Para o autor, a modificabilidade é uma característica de todo ser humano que Ihe permite mudar / alterar o curso de seu desenvolvimento, a partir de sua própria decisão, de forma consciente e efetiva, estando diretamente relacionada à qualidade de mediação ${ }^{2}$ e aos processos cognitivos e afetivos da pessoa (SOUZA et al. 2004).

\footnotetext{
${ }^{2}$ Mediação é um termo que adquire significados diferenciados, conforme a postura teórica de quem o utiliza. Para Feuerstein, mediação significa um processo de interação entre o organismo humano em desenvolvimento e o indivíduo com experiências e intenção que
} 
Para que a modificabilidade ocorra, há necessidade de desenvolver as estruturas mentais do sujeito que recebe a mediação. Feuerstein (1980) afirma que, muitas vezes, algumas estruturas mentais podem manifestar-se de forma rígida (cristalizada), evidenciando a necessidade de uma intervenção que auxilie o indivíduo na busca de maior flexibilidade. Afirma ainda que, embora essas estruturas levem a um comportamento muitas vezes rígido e inflexível por parte dos indivíduos, este aspecto não deve ser entendido como uma característica geral no conjunto de sua personalidade, mas como uma função cognitiva que pode e deve ser melhorada.

Em suas investigações, Feuerstein adaptou e organizou instrumentos que possibilitam uma Avaliação Dinâmica do Potencial de Aprendizagem (chamado de LPAD) e que oferece suporte psicopedagógico para o desenvolvimento do potencial de cada sujeito: Programa de Enriquecimento Instrumental (PEI). O elemento fundamental que permeia a aplicação desses instrumentos é o que Feuerstein denominou mediação e que se concretiza nas Experiências de Aprendizagem Mediada (EAM), fundamentadas nas ideias de Piaget e Vygotsky (GOULART, 2000; GOMES, 2002; CARVALHO, 2008).

Por Experiências de Aprendizagem Mediada (EAM), Feuerstein refere-se ao caminho pelo qual os estímulos do ambiente são transformados por um agente mediador $^{3}$, normalmente os pais, irmãos ou outros. Esse agente mediador, guiado por suas intenções, cultura e investimento emocional, seleciona e organiza o mundo de estímulos para o indivíduo (FEUERSTEIN, 1980). O mediador seleciona os

seleciona, enfoca, retroalimenta as experiências ambientais e os hábitos de aprendizagem. É o resultado articulado da exposição direta ao mundo e a experiência mediada pela qual se transmitem as culturas (FEUERSTEIN, 1980).

\footnotetext{
${ }^{3} \mathrm{Na}$ perspectiva de Feuerstein, o mediador é aquele capaz de enriquecer a interação do mediado com seu ambiente, utilizando ingredientes que não pertencem aos estímulos imediatos, mas que preparam a estrutura cognitiva desse mediando (SOUZA et al. 2003).
} 
estímulos que lhe parecem mais apropriados e, então, molda-os, filtra-os, programaos; ele determina a presença ou ausência de certos estímulos e ignora outros.

Nesse sentido, Feuerstein et al. (1994, p. 7) afirma que:

[...] uma interação qualitativa entre o organismo e seu meio ambiente. Esta qualidade é assegurada pela interposição intencional de um ser humano que medeia os estímulos capazes de afetar o organismo. Este modo de interação é paralelo e qualitativamente diferente das modalidades de interação generalizadas e difusas entre $o$ mundo e o organismo, conhecido como contato direto com o estímulo.

Reuven Feuerstein acredita que existem duas formas de aprendizagem: uma direta e outra mediada. A abordagem direta segue a fórmula proposta por Piaget: interação direta do organismo (O) ou aprendiz com o estímulo (S) do mundo, produzindo uma resposta $(\mathrm{R})$, que gera uma aprendizagem incidental.

Para Beltrán (1994) na abordagem mediada, Feuerstein inclui o "agente mediador", enfatizado por Vygotsky, denominando-o de mediador humano $(\mathrm{H})$ entre o mundo de estímulos $(\mathrm{S})$, o organismo $(\mathrm{O})$ e a resposta $(\mathrm{R})$, ocorrendo assim uma aprendizagem intencional.

Ambas as formas de aprendizagem - direta (S-O-R) e mediada (S-H-O-H-R), são relevantes para o desenvolvimento cognitivo. No entanto, por intermédio da EAM, o aluno constrói as atitudes e competências básicas para a aprendizagem auto dirigida. Quanto mais mediação lhe for oferecida, maior será a sua capacidade de se modificar, de organizar, classificar, analisar, argumentar sobre o que aprende e de se adaptar às novas situações. 
Segundo Feuerstein et al. (1994), a EAM demanda a presença de parâmetros de mediação. Desde que elaborou a EAM, ele identificou dez critérios para uma mediação efetiva que se encaixam em diferentes circunstâncias: na sala de aula, em casa, em atividades comunitárias ou de aconselhamento.

É importante salientar que os critérios não devem ser vistos de forma estanque, eles se inter-relacionam durante o desenvolvimento da mediação.

Os dez critérios serão arrolados a seguir, segundo Carvalho (2008) e Da Ros (2002):

1) Intencionalidade - Reciprocidade: É a condição fundamental numa EAM. O mediador modifica o estímulo para que este afete, de fato, os mediados, instigando-os à reciprocidade. Três elementos estão envolvidos neste critério: o mediador, o mediado e o estímulo. O professor, como mediador, apresenta o estímulo aos alunos, com intencionalidade definida. Na sala de aula, o professor chama a atenção selecionando um estímulo que desperte o interesse e a motivação dos alunos para a aula. Os alunos participam ouvindo e respondendo, enquanto o professor se interessa pelos trabalhos de todos, elogiando-os ou corrigindo-os, em vista dos objetivos previstos. Trata-se de oferecer aos alunos situações desequilibradoras, incentivando a criatividade.

2) Significado: Representa a energia, o afeto, o poder emocional que vence as resistências ao saber. Pode ser mediado por gestos, palavras, atitudes que despertem para o sentido do que vai ser ensinado. O significado é mediado tanto no aspecto cognitivo (intelectual) quanto no afetivo (emocional). Valores e crenças referem-se ao aspecto cognitivo; energia e entusiasmo ao aspecto afetivo. Na sala de aula, o professor ressalta o sentido de cada conteúdo para os alunos; explicita as 
estratégias e habilidades envolvidas na tarefa, sua importância, alterando sua frequência ou intensidade, conforme a necessidade dos discentes.

3) Transcendência: A transcendência desenvolve no aluno uma profunda compreensão do mundo, uma percepção de como as coisas estão interligadas. Leva a descobrir relações entre fatos e coisas; desperta o desejo de saber mais e buscar explicação em tudo. Na sala de aula, o professor relaciona o tema da aula com o passado e o futuro; revela as relações entre o conteúdo específico e os objetivos gerais; dá preferência a perguntas do tipo "por quê?", "como?", em vez de "quem?" e "o que?". O professor generaliza e pede a cada aluno que o faça também, a partir de situações específicas; evoca a necessidade de buscar e encontrar relações complexas, apresentando exemplos de conexão entre os fatos da vida, os conteúdos e a realidade.

4) Competência: A competência não deve ser vista em termos absolutos nem como uma capacidade ou deficiência inata, mas como um processo. A competência para uma tarefa melhora o todo, principalmente a autoestima. $\mathrm{Na}$ sala de aula, o professor modifica o estímulo de acordo com as necessidades dos alunos. $O$ professor coloca as condições para o sucesso e certifica-se de que o aluno compreendeu os processos que levam a um desempenho bem-sucedido. Não basta que o aluno saiba que acertou. Ele precisa sentir-se competente. Nem sempre a competência é acompanhada do sentimento de competência. Neste sentido, acertar e ser elogiado são fatores relevantes. Para isso, o professor deve selecionar atividades adaptadas ao aluno e ao esforço que se requer para alcançar êxito. É essencial trabalhar os pré-requisitos para o bom desempenho das atividades escolares, além de oferecer feedback ao discente sobre o êxito obtido nas atividades. 
5) Auto-regulação e Controle do Comportamento: O objetivo é encorajar o mediado a assumir responsabilidades pela própria aprendizagem e comportamento. Implica ensinar-Ihe a refletir sobre sua própria forma de pensar (meta cognição), sobre seu comportamento, assim como escolher e analisar as respostas apropriadas a um estímulo ou situação particular. Quando dizemos ao aluno como ele deve resolver e estruturar suas ações, reduzimos sua chance de autonomia e automonitoramento. Na sala de aula, a autodisciplina deve ser estimulada e o comportamento regulado. O professor não se interpõe às respostas do aluno. Sugere-Ihe o controle da impulsividade. Ajuda-o na regulação do comportamento, solicitando-lhe que pense antes de agir. Exemplo: "leiam novamente certos parágrafos, pensem antes de responder, verifiquem seus trabalhos".

6) Compartilhamento: A mediação do compartilhamento ocorre quando o mediador e o mediado ou um grupo de aprendizes atuam juntos numa atividade, trabalham em equipe, auto-ajudam-se. O mediador compartilha ideias e sentimentos, encorajando o mediado a fazer o mesmo (CARVALHO, 2008). Na sala de aula, o professor encoraja os alunos a se ajudarem, a ouvirem uns aos outros. Desperta a sensibilidade em relação ao próximo; seleciona a matéria e as atividades para o aluno, destacando a relevância da cooperação na realização dos trabalhos.

7) Individuação: Leva em conta o mediado, suas necessidades, faz-se presente a ele. Os pais e professores que não acreditam na capacidade das crianças de assumir o controle e a responsabilidade por si mesmas, impedirão sua individuação e autoexpressão. Na sala de aula, o professor aceita respostas divergentes, encoraja o pensamento independente e original. Exige responsabilidade por parte dos alunos; confere-lhes tarefas específicas. Deixa que eles exerçam sua capacidade de escolha e encoraja a diversidade no uso do tempo livre. 
8) Planejamento de Objetivos: O mediador é claro ao propor as metas educativas. Orienta o mediado a fim de que ele estabeleça também seus objetivos e escolha os meios para alcançá-los. Na sala de aula, o professor mostra ao aluno a necessidade de estabelecer metas realistas; encoraja a perseverança, a paciência e a diligência na busca do objetivo; promove uma atitude autônoma voltada para o futuro.

9) Desafio: Num mundo em que as mudanças acontecem de forma constante e rápida, a novidade e a complexidade são a norma. A mediação do desafio prepara o mediado para conduzir tais mudanças. Essa mediação implica a superação do medo do desconhecido e a resistência a algo difícil ou incomum. Na sala de aula, o professor propõe aos alunos situações novas, complexas e desafiadoras de acordo com a competência deles; estimula a curiosidade intelectual, a originalidade e a criatividade, apresentando tarefas não convencionais, num clima livre de julgamentos.

10) Automodificação: Feuerstein acredita que o ser humano é dotado de uma tendência para se modificar. Esse é um processo inevitável, apesar de muitas vezes o aluno não tomar consciência do que está acontecendo, nem assumir responsabilidade pela mudança. Na sala de aula, o professor encoraja a autoavaliação do progresso individual. O professor não rotula, mas ajuda o aluno a monitorar sua automodificação.

Souza et al. (2003) enfatizam que alguns critérios não podem faltar na mediação, pois são universais (intencionalidade e reciprocidade; transcendência; significado), enquanto que outros vão se agregando aos universais durante a mediação (competência; autorregulação e controle do comportamento; compartilhamento; individuação e diferenciação psicológica; planejamento para 
alcance dos objetivos; desafio, automodificação; otimismo; e sentimento de pertencer).

Convém notar que nem toda experiência de sala de aula é uma experiência de aprendizagem mediada. Esta é sempre intencional e focalizada. Processo aberto e dinâmico, a mediação requer da pessoa envolvida com a educação, um olhar de alteridade acima da média. Quando isso acontece, é possível auxiliar o outro a se situar no mundo com autonomia. Ao apostar no desenvolvimento da inteligência e no papel do mediador - peça primordial de sua filosofia - o Professor Reuven Feuerstein tem gerado expectativas altamente positivas no meio educacional, propiciando a experiência de êxito em lugar do fracasso escolar (FONSECA, 2002a, 2002b, 2002c).

O trabalho proposto pela EAM baseia-se em elementos cognitivos e afetivos (FEUERSTEIN, 1980). A modificabilidade é uma característica de todo ser humano e se manifesta, em maior ou menor grau, em função das experiências vivenciadas, do meio em que se é criado, assim como de condições físicas e biológicas. Como define o autor:

[...] Não é um evento isolado, mas uma maneira de o sujeito interagir com. Isto é, respondendo e atuando sobre as fontes de informação. Assim, uma transformação da estrutura, uma vez colocada em movimento, determinará a caminhada futura do desenvolvimento estrutural (p. 9).

Feuerstein e colaboradores (1998) organizaram uma lista de funções cognitivas que podem manifestar-se de forma deficiente durante as fases de início, elaboração e término do ato mental realizado pelo sujeito. Tais funções são um ponto de referência para a observação e o planejamento de uma intervenção 
mediadora. A identificação das funções cognitivas deficientes, o grau de sua modificabilidade e a mediação necessária para modificá-las são consideradas de suma importância para a prescrição da aprendizagem futura.

As funções cognitivas são uma parte fundamental do modelo conceptual que compõe o alicerce tanto da Avaliação Dinâmica do Potencial de Aprendizagem (LPAD) como do Programa de Enriquecimento Instrumental (PEI).

Segundo Feuerstein (1980), os processos de pensamento lógico, de aprendizagem e de resolução de problemas têm como suporte uma série de funções cognitivas.

As funções cognitivas são consideradas por Feuerstein como elementos básicos da inteligência e constituem o suporte do ato mental. A aquisição de funções e processos cognitivos auxilia na interiorização da informação, além de permitir a auto-regulação do organismo, contribuindo também no desenvolvimento da capacidade de utilização de experiências anteriores para a adaptação a novas situações (SÁNCHEZ,1989). As funções cognitivas servem de base ao pensamento interiorizado, representativo e operativo. Em outras palavras, funções cognitivas são estruturas psicológicas e mentais interiorizadas que possuem elementos estáticos (biológicos) e dinâmicos (necessidades, capacidades) que nos permitem melhorar uma conduta.

Ato mental (ou operação mental), para Feuerstein (1980), é o resultado da operação de uma ou mais funções cognitivas visando um dado objetivo. As funções cognitivas podem se manifestar, de forma adequada ou não, no momento em que o sujeito entra em contato com a situação problema, na coleta de dados (entradainput); no momento de analisar o que está ocorrendo, isto é, de refletir sobre uma determinada situação e estabelecer estratégias ou operações cognitivas para 
resolução do problema (elaboração) ou, ainda, no momento em que o sujeito reage ao problema, responde aos fatos, enfim, manifesta a solução que considera apropriada (resposta-output).

De acordo com a dificuldade encontrada pela pessoa nas diferentes fases do ato mental, as funções cognitivas podem se manifestar de forma deficiente (ou não) e, caso isto ocorra, é preciso identificá-las. Assim, tais funções dizem respeito e auxiliam a identificação de atos mentais, uma vez que constituem sua base internalizada, representacional e operacional.

\subsection{Funções Cognitivas Deficientes}

As funções cognitivas deficientes são concebidas como produto de uma carência ou insuficiência de experiências de aprendizagem mediada e, desta forma, as responsáveis pela manifestação inadequada ou "deficiente" do sujeito. As funções cognitivas deficientes podem estar presentes em uma das seguintes fases do ato mental (FEUERSTEIN, 1980):

A- Fase de entrada ou apropriação: a) Percepção superficial e confusa: o indivíduo não se detém pelo tempo necessário no estímulo para identificar com clareza os aspectos relevantes; não distingue dados relevantes dos irrelevantes. Não consegue perceber os atributos de um objeto e descrevê-los; b) Comportamento impulsivo, assistemático: realiza a tarefa de forma impulsiva, precipitada e desorganizada, sem planejar o que pretende fazer. Desta forma pode adotar estratégias pobres ou inadequadas, sem utilizar todas as fontes de informação a que tem acesso; c) Vocabulário deficiente de conceitos: utiliza a linguagem sem precisão, possui vocabulário muito pobre, domina poucos conceitos, interpreta instruções e perguntas 
inadequadamente, tem dificuldade de compreensão; d) Deficiência na orientação espaço-temporal: não possui um sistema pessoal de referências espaciais, nem vocabulário para descrever posição no espaço e relações entre objetos. Ainda não consegue utilizar o espaço adequadamente, seja com o próprio corpo, seja no planejamento do uso desse espaço. Aponta a posição dos objetos ou pessoas ao invés de descrevê-las; tem dificuldade de localizar-se mentalmente no espaço. Em relação ao conceito temporal, ainda não manifesta necessidade de ordenação, soma, comparação e sequenciamento; e) Percepção deficiente da constância e permanência dos objetos; falta de sistema de referências: não compreende a possibilidade de conservar a constância de um objeto frente à variação de alguns de seus atributos e dimensões (que a identidade do objeto permanece a mesma). Focaliza apenas a aparência imediata de um objeto ou fato, sem estabelecer relações (visão episódica da realidade); f) Prejuízo na capacidade de precisão e exatidão ao recolher dados: não demonstra precisão quando coleta dados, ao expressar ou utilizar-se de uma informação ou instrução. Não estabelece relações entre várias fontes de informações; g) Dificuldade de lidar com duas ou mais fontes de informação: tende a valorizar somente uma fonte de informação entre as várias existentes, não se lembra de todos os dados necessários para realizar uma determinada tarefa; tem dificuldade em utilizar informações fragmentadas e organizar um todo significativo.

B- Fase de elaboração: a) Dificuldade de perceber e definir o problema: para perceber um problema, a pessoa precisa relacionar as várias informações e verificar se não há divergência entre elas; b) Dificuldade em distinguir 
dados relevantes dos irrelevantes: um dado é considerado relevante em função da importância que possui dentre outras informações para atender a uma determinada meta estabelecida pelo indivíduo. Desta forma, antes de tudo, a pessoa precisa estabelecer o que pretende para, então, selecionar aqueles dados que atendam de maneira satisfatória seus objetivos. Muitas vezes o indivíduo não consegue selecionar quais aspectos serão úteis numa situação em particular; c) Ausência de conduta comparativa espontânea: o comportamento comparativo espontâneo é fundamental para alcançar processos cognitivos mais elevados. Permite ao indivíduo ir além da percepção imediata e estabelecer relações. A deficiência nesta função prejudica a capacidade de tomar decisões; d) Estreitamento do campo mental: essa dificuldade manifesta-se como uma capacidade limitada de memória. O sujeito não consegue integrar e associar os diferentes dados apreendidos anteriormente, não se lembrando de experiências passadas relevantes; e) Percepção episódica da realidade: o indivíduo não estabelece ligações entre os diferentes dados e fatos, formando um todo significativo. Apresenta uma visão fragmentada, sem ligações com o que já ocorreu ou com futuras consequências; f) Falta de raciocínio lógico: a inconsistência observada no comportamento dos indivíduos pode revelar uma deficiência no sistema de necessidades dos sujeitos no qual a evidência lógica não é relevante. O aluno não é capaz de defender uma determinada posição, opinar utilizando argumentos lógicos; aceita sem questionamentos todas as informações ou explicações; g) Dificuldade em interiorizar o próprio comportamento: a dificuldade de internalização de dados, experiências, é evidente. O aluno não consegue manipular as informações 
mentalmente, permanecendo dependente de situações concretas, de apoio sensorial; h) Deficiência de pensamento hipotético e inferencial: dificuldade para fazer inferências e generalizações, de buscar alternativas a partir de experiências já vivenciadas (a utilização da proposição "se...então" não faz parte de seu repertório; i) Não estabelecimento de estratégias para verificar hipóteses: o sujeito não consegue definir ou selecionar um método adequado para avaliar uma determinada hipótese. Não é capaz de selecionar e manter várias hipóteses alternativas e, dentre elas, selecionar a que considera mais relevante; j) Dificuldade em planejar sua conduta: o aluno não estabelece previsões a longo prazo, preocupando-se apenas com o presente. Sua ação está voltada apenas para o imediato, não manifestando nenhuma necessidade de planejamento; k) Dificuldade em elaborar categorias cognitivas: a falta de habilidades verbais pode prejudicar seriamente a capacidade do educando de realizar certas operações cognitivas. O indivíduo permanece preso a tarefas que consegue efetivar concretamente, apresentando dificuldades em generalizar, transferir a operação realizada para outras situações ou atividades; I) Dificuldade para estabelecer relações virtuais: a pessoa não consegue estabelecer relações entre várias situações que podem ocorrer "virtual ou potencialmente". Assim, prende-se a uma relação fixa, mesmo quando houve alteração nos dados ou estímulos.

C- Fase de saída ou representação: a) Percepção e/ou comunicação egocêntrica: o aluno não consegue ainda superar a forma egocêntrica de percepção do mundo. Relaciona-se com os demais apenas a partir do próprio ponto de vista e não leva em consideração a opinião de seus pares; b) 
Dificuldade na projeção de relações virtuais: não percebe que as relações entre objetos ou dados não dependem deles próprios, mas da capacidade de relacioná-los; c) Bloqueio na comunicação das respostas: manifesta-se, muitas vezes, por meio da falta de iniciativa ou mesmo da indiferença ou recusa em responder a um determinado estímulo. Reações emocionais, falta de vocabulário e falhas de conceituação, são exemplos dessa dificuldade; d) Respostas por ensaio e erro: o comportamento aleatório pode ser reforçado pela aprendizagem por tentativa e erro, impedindo o indivíduo de descobrir as relações existentes entre os dados. O indivíduo repete os erros cometidos, sem refletir sobre as possíveis causas desses erros; e) Carência de instrumentos verbais adequados: a falta de vocabulário e de habilidade de comunicação, dificultam a utilização de relações mais complexas assim como a compreensão, comunicação e operações mais abstratas; f) Falta de precisão e exatidão ao comunicar respostas: é fundamental que o indivíduo procure agir com precisão e exatidão ao interagir com seu meio. Nem sempre manifesta a necessidade de comunicação detalhada e correta, da escolha de termos mais precisos ao comunicar algo; g) Transporte visual inadequado: a deficiência de transporte visual é definida como uma falha na retenção de características de um dado objeto na memória, em sua representação mental e possível transformação; h) Conduta impulsiva: a impulsividade, como as demais funções cognitivas deficientes, pode afetar negativamente as três fases do ato mental (entrada, elaboração e saída). Impede a obtenção, pelo aluno, de informações precisas e completas ao enfrentar a situação -problema (entrada). Não permite um processamento adequado dos dados (elaboração), uma vez que pode interferir nos processos 
de representação interna, levando a condutas de ensaio e erro. A emissão da resposta (saída), também pode sofrer influências dessa função deficiente, que se manifesta através de escolhas imprecisas entre alternativas dadas e em repostas inadequadas ou erradas, embora tenha ficado claro que o sujeito possui repertório para oferecer uma resposta correta.

\subsection{O mapa cognitivo}

Segundo Feuerstein (1980), o mapa cognitivo do PEl é um modelo de análise do ato mental que permite conceituar a relação entre as características de uma tarefa e o rendimento do sujeito/aluno.

Para Feuerstein, o mapa cognitivo define o ato mental por meio de sete parâmetros, os quais são de grande importância para a interação professor-aluno na medida em que é utilizado para validar as hipóteses relativas às deficiências cognitivas e às dificuldades do sujeito/aluno. São eles, descritos por Gomes (2002), Da Ros (2002), Souza et al. (2003), Varela (2007) Meier e Garcia (2009):

1) Conteúdo: cada ato mental pode ser descrito de acordo com o assunto que se trata e pode ser analisado em termos do universo do conteúdo que opera. Na sua perspectiva, um determinado assunto no PEI pode ser derivado da matemática para auxiliar na compreensão de um evento histórico ou geográfico, por exemplo. É neste sentido que se opera a natureza livre do conteúdo. Entretanto, a competência do indivíduo no conhecimento de uma matéria específica está diretamente ligada à sua experiência histórica, educativa, pessoal e cultural.

2) Operações mentais: como descritas anteriormente, podem ser definidas como um conjunto de ações interiorizadas e organizadas que nos 
possibilitam elaborar as informações derivadas de fontes externas ou internas. Elas podem abranger desde a identificação das características dos objetos e eventos a atividades de ordem mais elevada, tais como o estabelecimento de analogias e realização de inferências. Segundo Feuerstein (1980), essas operações são classificadas em relativamente simples ou complexas, dependendo das exigências da tarefa e do comportamento do aluno em relação ao seu grau de facilidade ou dificuldade. Apresentamos os tipos de raciocínios ou operações mentais que, segundo Feuerstein são desenvolvidos nos alunos a partir da aplicação da sua proposta: 1) Raciocínio lógico ou formal: aplicação, na resolução de problemas, analogia, generalização, relação de causa e efeito; 2) Raciocínio divergente: estabelecimento de novas relações que conduzem a ideias novas, criativas; 3) Raciocínio transitivo: consiste em ordenar, comparar e descrever uma relação de modo que se chegue a uma conclusão. È dedutivo, pois permite a inferência de novas relações a partir das já existentes; 4) Raciocínio hipotético: capacidade de realizar inferências e predição de fatos, a partir dos já conhecidos e das leis que os relacionam; 5) Raciocínio inferencial: capacidade de realizar deduções e criar novas informações a partir dos dados percebidos; 6) Raciocínio analógico: é a operação pela qual dá-se três termos de uma proposição e se determina o quarto por dedução ou semelhança; 7) Raciocínio silogístico: trata-se da lógica formal proposicional e apoia-se sobre estruturas que permitem chegar à verdade lógica, por exemplo: Todo gato é malhado. Felix é um gato. Logo, Felix é malhado; 8) Identificação: reconhecimento de um determinado objeto por suas características globais 
mais unitárias; 9) Diferenciação: reconhecimento de algo por suas características, distinguindo as que são essenciais das irrelevantes em cada situação; 10) Análise-síntese: formas de perceber a realidade, decompondo o todo em seus elementos constitutivos, relacionando parte todo, para extrair inferências; 11) Comparação: estudam-se as semelhanças e as diferenças entre os objetos ou fatos, atentando-se às suas características; 12) Classificação: a partir de categorias, reúnem-se os grupos de elementos de acordo com atributos determinantes; 13) Codificação - decodificação: a codificação é a responsável pela produção de esquemas simbólicos e a decodificação pela compreensão destes esquemas simbólicos.; 14) Projeção de relações virtuais: capacidade de perceber estímulos externos em forma de unidades organizadas, fazendo-as ocupar lugar no espaço; 15) Representação mental: interiorização de características de um objeto, seja concreto ou abstrato. Não se refere à fotografia do objeto, mas a representação de traços que permitem defini-lo como tal (VARELA, 2007).

3) Modalidade linguística: as atividades do PEI se apresentam de maneira verbal, figurativa, numérica, gráfica, simbólica, pictórica, ou pela combinação de algumas destas formas. Segundo Feuerstein (1980), mesmo se um sujeito tiver a capacidade de elaboração de uma destas formas linguísticas, isto não significa necessariamente que a tenha diante das outras modalidades.

4) Fases do ato mental: como destacadas anteriormente, são em número de três: input, elaboração e output. Essas três fases estão interconectadas e cada uma delas tem sentido à medida que se relaciona com a outra. Para 
Feuerstein (1980) em cada uma dessas fases, o sujeito, que está privado de sua cultura apresenta as funções cognitivas deficientes.

5) Nível de complexidade: diz respeito à qualidade e à quantidade de informações necessárias para produzir uma dada operação mental. O mediador, ao analisar uma tarefa a partir deste parâmetro, procura estabelecer a quantidade de informações envolvidas pela tarefa e seu grau de familiaridade (CRUZ, 2007).

6) Nível de abstração: segundo o mesmo auto, é definido como a distância entre o ato mental e o objeto ou evento por meio do qual se opera, tendo como base a resolução da situação-problema. Como exemplo, o ato mental implicado no estabelecimento e produção de relações entre objetos apresenta um menor de grau de abstração que o ato mental implícito na análise de relações entre relações.

7) Nível de eficiência: pode ser mensurado pela rapidez, precisão e esforço necessários para a realização de uma tarefa. O mediador, ao analisar a tarefa a partir deste parâmetro, pretende estabelecer se há desafio cognitivo para o mediando ou se ele é pouco eficaz. A falta de eficiência, de acordo com Feuerstein (1980), pode ser resultado de fatores físicos, afetivos, ambientais e motivacionais.

\subsection{Os instrumentos do PEI Standard I}

Em síntese, o programa tem como objetivo geral estimular a modificabilidade cognitiva do indivíduo e aumentar sua capacidade de aprendizagem e como objetivos específicos: corrigir funções cognitivas deficientes; adquirir vocabulários, códigos, conceitos, operações e relações relevantes para as tarefas do PEI, bem 
como para a resolução geral de problemas; desenvolver a motivação intrínseca por meio da formação de hábitos em relação à tarefa; desenvolver o pensamento reflexivo e o insight; proporcionar ao indivíduo a mudança de papéis de receptor passivo para gerador ativo de novas informações. (SASSON, 2001; CRUZ, 2007; MIRANDA, 2010).

O Programa de Enriquecimento Instrumental Standard I, utilizado nessa pesquisa, é composto por sete instrumentos que objetivam fazer o aluno refletir sobre seu pensamento, bem como sobre a formulação e argumentação de suas respostas. Cada instrumento e seus objetivos específicos são arrolados a seguir (FEUERSTEIN \& HOFFMAM, 2000; SOUZA et al., 2003; CRUZ, 2007):

a) Organização de pontos: desenvolver a projeção de relações virtuais por meio de tarefas que requeiram do aluno a identificação e o delineamento das figuras indicadas pela folha do instrumento, em uma nuvem de pontos;

b) Orientação espacial I: desenvolver a prática no uso de referências internas - direita, esquerda, frente, atrás - para a orientação do aluno no espaço e em relação a outros objetos e pessoas;

c) Orientação espacial II: desenvolver a prática no uso de referências externas - pontos cardeais, coordenadas e gráficos - para a orientação do aluno no espaço;

d) Classificações: organização dos elementos em categorias, utilizando-se da comparação, diferenciação e discriminação;

e) Comparações: desenvolver o comportamento de comparar;

f) Percepção analítica: desenvolver a habilidade de dividir o todo em partes (diferenciação) e reunir as partes em um todo dado (integração); 
g) Ilustrações: situações nas quais os problemas que levam a um desequilíbrio devem ser reconhecidos e reestruturados pelo aluno, de modo que ele encontre uma solução apropriada para o problema identificado.

O PEI se diferencia de outros programas que lidam com habilidades de pensamento tanto por sua natureza como por seus objetivos. Segundo Miranda (2010) é um programa sem conteúdo, construído segundo critérios de mediação, o que contribui para motivar os indivíduos a aprender e beneficiar-se de suas próprias aprendizagens, transferindo-as para outras áreas temáticas.

Uma sessão do programa inclui as seguintes etapas: a) introdução; b) trabalho individual; c) discussão em grupo; d) resumo dos princípios concluídos na discussão (FEUERSTEIN \& HOFFMAN, 2000).

$\mathrm{Na}$ introdução, o mediador destaca a novidade e a complexidade das tarefas que serão trabalhadas, orientando os alunos para a solução do problema. Segundo Feuerstein (1980), os mediados devem obter uma percepção clara e precisa do problema, inteirar-se das intenções do mediador e compreender os conceitos, vocabulários, instruções e aplicações.

Após a introdução, o aluno inicia o trabalho individualmente. O professor observa o seu desenvolvimento e sua reação em relação às atividades propostas, procurando identificar os processos mentais utilizados para a resolução da tarefa, interpondo-se entre o sujeito e a folha do instrumento, utilizando os diferentes critérios de mediação com o objetivo de corrigir as funções cognitivas deficientes, expostas anteriormente. $\mathrm{Na}$ interação individual, o mediador visa mediar o sentimento de competência, o controle e a regulação da conduta por parte do aluno, bem como o comportamento de compartilhar as experiências. 
$\mathrm{Na}$ discussão em grupo, o professor discute com o aluno as soluções dadas aos problemas e se foram ou não eficazes as estratégias utilizadas e as justificativas apresentadas. É nesse momento que se exercita a transcedência, ou seja, são transferidos os conceitos do PEI para as tarefas do cotidiano. Ao final, discute-se o resumo dos princípios ou conclusões utilizados na atividade. Esta etapa de síntese refere-se ao feedback do que foi feito durante a sessão, incluindo os processos empregados para a intervenção.

Enquanto os mediados trabalham independentemente nas folhas dos instrumentos apresentados, o mediador movimenta-se entre eles, investigando seus processos cognitivos, promovendo o feedback interativo, prevenindo frustrações e modelando a conduta cognitiva.

$\mathrm{Na}$ discussão em grupo, as várias estratégias apresentadas para o problema são comparadas em relação à eficácia.

\subsection{Pesquisas brasileiras com o PEl: uma breve revisão}

Na revisão de literatura feita para fins deste projeto de pesquisa, não foram encontrados estudos relacionando a aplicação do PEI ao envelhecimento cognitivo, mas uma descrição da importância da EAM para a aprendizagem de crianças de diferentes faixas etárias, principalmente com necessidades especiais, entre outros.

Nos trabalhos encontrados sobre a aplicação do PEI, participaram sujeitos de diferentes faixas etárias visando avaliar a eficácia do $\mathrm{PEI}$ em relação ao desempenho cognitivo dos mediados.

Goulart (2000) objetivou analisar a Teoria da Modificabilidade Cognitiva Estrutural num período de três anos, em alunos de classes especiais para deficientes mentais e do ensino regular, de diferentes séries. Os resultados 
demonstraram que os alunos deficientes intelectuais inseridos em atividades socioculturais, no interior de grupos orientados e estruturados, manifestaram maior desenvolvimento do sentimento de autoestima, das capacidades de autorregulação e organização do pensamento do que as crianças consideradas normais, sem oportunidades de participação de qualquer tipo de atividade mediada.

O trabalho desenvolvido por Batista (2000) teve como objetivo investigar os efeitos do PEl na compreensão, raciocínio e resolução de problemas, na criatividade, na autoestima e no desempenho do trabalho de funcionários de limpeza e jardinagem de uma empresa de prestação de serviços. Participaram do estudo 19 sujeitos divididos em dois grupos, submetidos à aplicação dos instrumentos Organização de Pontos, Orientação espacial I e II, Comparações e Percepção Analítica, por um período de seis meses, uma vez por semana com a duração de duas horas cada sessão. Os resultados mais significativos desta pesquisa dizem respeito a autoestima e ao desempenho, mas também sobressaem: melhor planejamento e organização do trabalho; melhora nos testes de inteligência após a intervenção; realização do trabalho de maneira mais independente, reflexiva, com concentração e com menor grau de ansiedade; maior capacidade criativa (fluência, flexibilidade e originalidade de ideias).

Tendo por objetivo geral promover um pensar mais crítico e reflexivo de enfermeiros sobre o processo de cuidar e a prática da enfermagem, Negri (2004) aplicou quatro instrumentos do PEI a um grupo de sete enfermeiros, em duas sessões semanais, durante trinta e seis horas. Os resultados qualitativos indicam a ocorrência de transcendência, metacognição, aplicabilidade e o uso de mediação na perspectiva do outro entre os enfermeiros participantes, que relataram a modificabilidade ocorrida no grupo. 
Cruz (2007) avaliou o efeito do PEI Standard I em alunos do 3ํano do Ensino Médio de uma escola pública do estado de São Paulo. A amostra foi composta por 96 estudantes com idade média de dezesseis anos, divididos em grupo controle, que não recebeu a intervenção do PEI, e grupo experimental que recebeu a intervenção do PEI. Os resultados indicaram que a modificabilidade cognitiva dos estudantes do grupo experimental foi ampliada em comparação ao grupo controle.

Varela (2007) implantou o desenvolvimento das atividades do PEI no currículo de 64 escolas de ensino médio de dez municípios da Bahia, sendo este considerado o maior projeto do PEl em território nacional. A investigação foi elaborada a fim de verificar a eficiência do PEI a estes grupos de alunos que possuíam o PEI no seu currículo (grupo experimental) a grupos de alunos que não participaram da intervenção (grupo controle). Em relação aos professores, os resultados indicam que $82 \%$ destes percebem a colaboração do PEI no relacionamento professor/aluno, 90\% na compreensão da prática pedagógica por parte do professor após a formação/aplicação do programa, $79 \%$ na maior eficácia no desenvolvimento cognitivo da aluno, $60 \%$ não conseguirem ampliar a capacidade de aprender do aluno. Na comparação dos resultados do grupo experimental e do grupo controle, foi observado que o grupo experimental obteve melhoras nas competências de classificar, seriar, compor, decompor, justificar, calcular por estimativa, fazer generalizações.

Com o objetivo de observar se os Instrumentos de Enriquecimento Intelectual /Instrumental (PEI) promoveriam avanços conceituais no processo de alfabetização em um grupo de estudantes que apresentavam dificuldades de aprendizagem decorrentes de domínios cognitivos básicos, mais especificamente 0 da classificação e da conservação, Silva e Pereira (2011) estudaram 11 crianças com 
idades entre seis e dez anos de uma escola pública de classe média da cidade de Salvador. Os instrumentos do PEI Standard I aplicados foram o de Organização de pontos; Orientação Espacial I; Comparações; Ilustrações; Orientação Espacial II; Percepção Analítica e Classificações. Os resultados indicaram que houve avanços no final do estudo em relação à leitura e à escrita nos seguintes pontos: leitura com compreensão e interpretação do texto, elaborando transcendências do conteúdo para situações da vida real e relacionando com outras aprendizagens anteriores; avanços na capacidade de antecipar situações, na formulação de hipóteses, na identificação da ideia central dos textos, na recuperação de fatos e na criação e continuidade desses.

De acordo com os estudos descritos, observa-se que a aplicação do PEI tornou o aluno/mediado mais adaptável às exigências do ambiente, capacitando-o a tornar-se mais perceptivo, mais preciso e mais motivado (FONSECA, 1998), otimizando seu funcionamento cognitivo e viabilizando o desenvolvimento da autonomia, uma vez que o participante era desafiado a criar suas próprias estratégias de pensamento a partir das ferramentas cognitivas disponíveis.

Em face de tais achados de pesquisa é razoável perguntar/hipotetizar se, em se tratando do envelhecimento, o PEI seria também uma ferramenta eficaz para promover a funcionalidade cognitiva e a preservação/manutenção das funções cognitivas no idoso, importantes a sua saúde, qualidade de vida e ao seu bem-estar psicológico. É o que se pretende investigar neste estudo. 


\subsection{Justificativa e objetivos do trabalho}

Diversos autores enfatizam que o envelhecimento bem sucedido depende, em grande parte, da prevenção de doenças (MATSUDO et al, 2001; VERAS, 2009; BUENO et al, 2008; OLIVEIRA, 2010; ARAUJO, 2014), do adequado condicionamento físico (SHEPHARD, 2003; SPIRDUSO, 2005; LAGE, 2013; FERRETTI, 2015; STREIT et al., 2015; VALENTE, 2015) e da preservação/manutenção das funções cognitivas (YASSUDA, 2004; CORREA, 2009; GORDON et al., 2011; FERNANDES et al., 2015; KAMP e ZIMMER, 2015; ALVARENGA et al. 2005).

A necessidade de prevenção/manutenção das funções cognitivas é destacada por inúmeros estudos epidemiológicos que mostram que idosos com leves alterações cognitivas apresentam um maior risco de desenvolver demências, condição esta que afeta o cérebro, acarretando perda da memória e o comprometimento em várias áreas cognitivas (linguagem, função executiva, praxia etc.) (CORREA, 2009).

Face à relevância do propósito de garantir à população idosa uma velhice com qualidade, parece-nos justificado realizar uma avaliação do Programa de Enriquecimento Instrumental Standard I no tocante ao desempenho cognitivo de idosos, uma vez que, até o ponto em que a autora desta pesquisa tem conhecimento, inexistem os estudos que se preocuparam em avaliar a influência desta intervenção junto à população idosa.

A hipótese geral deste trabalho é a de que idosos submetidos à intervenção apresentarão um melhor desempenho nas variáveis consideradas quando comparados a idosos que não foram a ela submetidos. Hipóteses mais específicas, 
referentes à permanência das mudanças proporcionadas pelo PEI também serão consideradas. 


\section{CAPÍTULO 3 \\ MÉTODO}

\subsection{SUJEITOS}

\subsubsection{Critérios de inclusão}

A amostra foi constituída por 66 indivíduos voluntários de ambos os sexos, com idade igual ou superior a 60 anos, fisicamente independentes, que foram considerados saudáveis do ponto de vista clínico, alfabetizados, com escolaridade mínima correspondente à $4^{a}$ série do ensino fundamental I (atual $5^{\circ}$ ano) e máxima correspondente à $8^{\text {a }}$ série do ensino fundamental II (atual 9aa), sem restrições quanto ao nível socioeconômico, subdivididos em dois grupos: experimental e controle.

Para a formação de ambos os grupos, os idosos atenderam os critérios de inclusão definidos pela Mayo Older American Normative Studies (MOANS) para indivíduos normais em estudos neuropsicológicos (SMIITH; IVNIK, 2003), quais sejam:

- Ausência de doença psiquiátrica ou neurológica em curso;

- Ausência de queixa de dificuldade cognitiva e de transtornos com o potencial de afetar a cognição durante a anamnese;

- Ausência de uso de medicação psicotrópica em quantidades que possam comprometer a cognição ou sugerir transtorno neuropsiquiátrico;

- Status de vida independente na comunidade.

Precedentes de transtornos (por exemplo: alcoolismo, drogas) com potencial para afetar a cognição não foram critérios de exclusão automática, desde que os transtornos não estivessem em curso e que tenha havido recuperação sem sequela 
cognitiva aparente. Doenças médicas crônicas também não foram critérios de exclusão, desde que a condição não seja responsável por comprometimento da cognição, tal como atestada por médico.

Além disso, foram excluídos indivíduos que apresentaram:

- Escore inferior às notas de corte para demência no Mini-Exame do Estado Mental (MEEM), de Folstein et al. (1975). Foi requerido o mínimo de 25 pontos para indivíduos com quatro a sete anos de escolaridade e 26 pontos para oito anos de escolaridade, conforme as normas brasileiras de Brucki et al. (2003);

- Escore igual ou superior a 10 (indicativo de presença de sintomas depressivos) na Escala de Depressão Geriátrica - Geriatric Depression Scale de Yesavage et al. (1983);

- Escore superior a três no Questionário de Atividades Funcionais de Pfeffer et al. (1982), indicando dependência para a realização de atividades instrumentais da vida diária;

- Escore acima de 3,5 no Questionário sobre Declínio Cognitivo do Idoso Informant Questionnaire on Cognitive Decline in the Elderly (IQCODE), proposto por Jorm e colaboradores em 1994, traduzido e adaptado por Sanchez (2007), indicativo de queixas significativas de declínio cognitivo.

Também não fizeram parte da amostra indivíduos que: a) declararam, pessoalmente ou por meio de informante, serem portadores de deficiência visual e/ou auditiva grave, não corrigida, que impedissem o entendimento e a execução dos procedimentos dos testes e dos instrumentos dessa pesquisa; b) cujo idioma materno não fosse o português, exceto se o indivíduo estrangeiro atestar pelo 
menos dez anos de moradia no Brasil; c) apresentarem dificuldades de movimentar as mãos devido a doenças reumáticas ou neurológicas.

Dos indivíduos entrevistados para composição do grupo experimental, 38 foram excluídos, 36 mulheres e dois homens, pelos seguintes motivos: 23 por estarem em acompanhamento médico e tomando medicamentos para depressão, cinco por obterem escores superiores a 10 na Escala de Depressão Geriátrica, quatro por desistirem de realizar a segunda etapa das entrevistas, três por obterem menos de 25 pontos no MEEM, dois por terem artroses crônicas e possuírem deformidades nas mãos, um por apresentar dificuldades auditivas e não fazer uso de aparelho para correção.

Para a composição do grupo controle, 21 indivíduos foram excluídos, 19 mulheres e dois homens: 16 por terem escolaridade superior a $8^{a}$ série do ensino fundamental II, quatro por obterem menos de 25 pontos no MEEM e um por desistir de realizar a segunda etapa da entrevista.

Foi esclarecido a estes indivíduos o motivo pelo qual não puderam fazer parte do grupo para a pesquisa e sugerido que procurassem quatro instituições de serviços e atendimento ao público idoso para verificarem a possibilidade de integração.

\subsubsection{Caracterização da amostra}

\subsubsection{Grupo experimental}

O grupo experimental foi composto por 34 indivíduos, 30 mulheres e quatro homens $(X=69,23$ anos; mínimo = 60,00; máximo = 82,00; mediana $=68,00 ; d p=$ 5,53), sendo 19 indivíduos com escolaridade correspondente à $4^{\text {a }}$ série do ensino fundamental I e 15 indivíduos com escolaridade correspondente à $8^{\underline{a}}$ série do ensino 
fundamental II. Não houve distribuição paritária entre os sexos. Desses indivíduos, 20 pertencem à comunidade paroquial do bairro de Vila Bela, zona Leste de São Paulo - SP, e 14 pertencem a comunidade do bairro da Mooca, também zona Leste de São Paulo - SP.

Em relação à renda familiar, este grupo foi assim caracterizado: cinco indivíduos com renda familiar de até um salário mínimo, 14 indivíduos com renda de um a três salários mínimos, 12 indivíduos com renda de três a seis salários mínimos, dois indivíduos com renda de seis a nove salários mínimos e um indivíduo com renda de nove a 12 salários mínimos.

O estado civil deste grupo foi composto por 14 indivíduos casados, 15 viúvos, três separados e dois solteiros.

A classe socioeconômica foi avaliada por meio do Critério de Classificação Econômica Brasil (CCEB), desenvolvido pela Associação Brasileira de Empresas de Pesquisa (ABEP, 2012), que permite estratificar a população em oito classes econômicas (de $\mathrm{A}$ até $\mathrm{E}$ ), baseada nas respostas do entrevistado quanto à posse de bens, presença de empregada mensalista e grau de instrução do chefe da família. Cada bem que o indivíduo possui gera uma pontuação e a classe econômica é definida pela soma da pontuação. As classes definidas pelo CCEB são A1 (42-46 pontos), A2 (35-41 pontos), B1 (29-34 pontos), B2 (23-28 pontos), C1 (18-22 pontos), C2 (14-17 pontos), D (8 -13) e E (0-7 pontos).

Esse grupo, em relação à classificação econômica, foi assim distribuído: A2 quatro indivíduos; B1 - seis indivíduos; B2 - onze indivíduos; C1 - 10 indivíduos; C2 - dois indivíduos; e E - um indivíduo. 
Em relação à atividade profissional, todos os indivíduos são aposentados, porém 20 indivíduos realizam atividades profissionais esporádicas como costureira, serviços de manutenção, cabeleireiro, serviços de marcenaria, auxílio em tarefas de contabilidade, artesanato, limpeza; e 14 indivíduos são do lar.

\subsubsection{Grupo controle}

O grupo controle foi composto por 32 indivíduos, 29 mulheres e três homens $(X=72,00$ anos; mínimo $=62,00 ;$ máximo $=87,00 ;$ mediana $=72,00 ; d p=7,28)$, sendo 22 indivíduos com escolaridade correspondente à $4^{\underline{a}}$ série do ensino fundamental I e 10 indivíduos com escolaridade correspondente à 8a série do ensino fundamental II. Não houve distribuição paritária entre os sexos.

Desses indivíduos, 27 pertencem a uma comunidade paroquial do bairro de Vila Bela, zona Leste de São Paulo - SP, um pertence a comunidade do bairro da Mooca, também zona Leste de São Paulo - SP, e quatro pertencem à comunidade do bairro do Butantã, zona Sul de São Paulo - SP.

Em relação à renda familiar, este grupo foi assim delineado: três indivíduos com renda familiar de até um salário mínimo, 18 indivíduos com renda de um a três salários mínimos, oitos indivíduos com renda de três a seis salários mínimos, três indivíduos com renda de seis a nove salários mínimos.

O estado civil deste grupo foi composto por 19 indivíduos casados, 12 viúvos e um solteiro.

Em relação à classificação econômica foi assim distribuído: A2 - um indivíduo; B1 - três indivíduos; B2 - dez indivíduos; C1 - 17 indivíduos e E - um indivíduo. 
Em relação à atividade profissional, todos os indivíduos são aposentados e apenas quatro indivíduos realizam atividades profissionais esporádicas como costureira e manicure.

As informações referentes ao perfil sócio-demográfico do grupo controle e do experimental são apresentadas na Tabela 1. 
Tabela 1 - Perfil sócio-demográfico da amostra, grupo controle $(n=32)$ e grupo experimental $(n=34)$

\begin{tabular}{|c|c|c|c|c|c|c|}
\hline \multirow{2}{*}{ VARIÁVEL } & \multicolumn{2}{|c|}{ CONTROLE } & \multicolumn{2}{|c|}{ EXPERIMENTAL } & \multicolumn{2}{|c|}{ TOTAL } \\
\hline & $\mathbf{F}$ & $\%$ & $\mathbf{F}$ & $\%$ & $\mathbf{F}$ & $\%$ \\
\hline \multicolumn{7}{|l|}{ GÊNERO } \\
\hline Masculino & 3 & $9,4 \%$ & 4 & $11,8 \%$ & 7 & $10,6 \%$ \\
\hline Feminino & 29 & $90,6 \%$ & 30 & $88,2 \%$ & 59 & $89,4 \%$ \\
\hline \multicolumn{7}{|l|}{ IDADE (EM ANOS) } \\
\hline Média & \multicolumn{2}{|c|}{72,0} & \multicolumn{2}{|c|}{69,2} & \multicolumn{2}{|c|}{69,9} \\
\hline DP & \multicolumn{2}{|c|}{7,3} & \multicolumn{2}{|c|}{5,5} & \multicolumn{2}{|c|}{6,2} \\
\hline Mediana & \multicolumn{2}{|c|}{72,0} & \multicolumn{2}{|c|}{68,0} & \multicolumn{2}{|c|}{68,5} \\
\hline Mínimo & \multicolumn{2}{|c|}{62,0} & \multicolumn{2}{|c|}{60,0} & \multicolumn{2}{|c|}{60,0} \\
\hline Máximo & \multicolumn{2}{|c|}{87,0} & \multicolumn{2}{|c|}{82,0} & \multicolumn{2}{|c|}{86,0} \\
\hline \multicolumn{7}{|l|}{ ESTADO CÍVIL } \\
\hline Solteiro (a) & 1 & $3,1 \%$ & 2 & $5,9 \%$ & 3 & $4,5 \%$ \\
\hline Casado (a) & 19 & $59,4 \%$ & 14 & $41,2 \%$ & 33 & $50,0 \%$ \\
\hline Separado (a) & - & $0,0 \%$ & 3 & $8,8 \%$ & 3 & $4,5 \%$ \\
\hline Divorciado (a) & - & $0,0 \%$ & - & $0,0 \%$ & - & $0,0 \%$ \\
\hline Viúvo (a) & 12 & $37,5 \%$ & 15 & $44,1 \%$ & 27 & $40,9 \%$ \\
\hline \multicolumn{7}{|l|}{ ESCOLARIDADE } \\
\hline 19 a 4a Serie Fundamental I & 22 & $68,8 \%$ & 19 & $55,9 \%$ & 41 & $62,1 \%$ \\
\hline 5a a 8a Serie Fundamental II & 10 & $31,3 \%$ & 15 & $44,1 \%$ & 25 & $37,9 \%$ \\
\hline \multicolumn{7}{|l|}{ RENDA FAMILIAR } \\
\hline Até 1 salário mínimo & 3 & $9,4 \%$ & 5 & $14,7 \%$ & 7 & $10,6 \%$ \\
\hline De 1 a 3 sálarios mínimos & 18 & $56,3 \%$ & 14 & $41,2 \%$ & 31 & $47,0 \%$ \\
\hline De 3 a 6 sálários mínimos & 8 & $25,0 \%$ & 12 & $35,3 \%$ & 19 & $28,8 \%$ \\
\hline De 6 a 9 sálários mínimos & 3 & $9,4 \%$ & 2 & $5,9 \%$ & 5 & $7,6 \%$ \\
\hline De 9 a 12 sálários mínimos & - & $0,0 \%$ & 1 & $2,9 \%$ & 1 & $1,5 \%$ \\
\hline \multicolumn{7}{|l|}{ CLASSE ECONÔMICA } \\
\hline A1 & - & $0,0 \%$ & - & $11,8 \%$ & 5 & $7,6 \%$ \\
\hline $\mathrm{A} 2$ & 1 & $3,1 \%$ & 4 & $17,6 \%$ & 9 & $13,6 \%$ \\
\hline B1 & 3 & $9,4 \%$ & 6 & $32,4 \%$ & 21 & $31,8 \%$ \\
\hline B2 & 10 & $31,3 \%$ & 11 & $29,4 \%$ & 25 & $37,9 \%$ \\
\hline $\mathrm{C} 1$ & 17 & $53,1 \%$ & 10 & $5,9 \%$ & 2 & $3,0 \%$ \\
\hline $\mathrm{C} 2$ & - & $0,0 \%$ & 2 & - & 2 & $3,0 \%$ \\
\hline $\mathrm{D}$ & - & $0,0 \%$ & - & $2,9 \%$ & 2 & $3,0 \%$ \\
\hline$E$ & 1 & $3,1 \%$ & 1 & - & - & $3,1 \%$ \\
\hline TOTAL GERAL & 32 & $100,0 \%$ & 34 & $100,0 \%$ & 66 & $100,0 \%$ \\
\hline
\end{tabular}

$F=$ frequência de sujeitos 


\subsection{MATERIAL}

Os testes selecionados para esta pesquisa não foram utilizados para efeito de diagnóstico clínico e/ou terapêutico, mas para verificar a evolução dos sujeitos participantes em cada uma das variáveis analisadas, nas diferentes fases do programa, por meio dos seus escores brutos. Os testes foram aplicados por uma neuropsicóloga e pela pesquisadora responsável sob supervisão desta, as quais foram treinadas tanto para a aplicação quanto para a correção destes testes ${ }^{4}$.

\subsubsection{Instrumentos para seleção da amostra}

Os instrumentos descritos a seguir foram utilizados como critério para a seleção da amostra, tanto para o grupo controle quanto para o grupo experimental.

\subsubsection{Ficha de Identificação}

$\mathrm{Na}$ entrevista inicial foram levantadas informações sobre os seguintes aspectos: 1) dados pessoais e histórico profissional; 2) escolaridade; 3) condições visuais e auditivas; 4) condições gerais sobre o estado de saúde; 5) doenças neurológicas e psiquiátricas; 6) história prévia de problemas neurológicos, psiquiátricos e cardiovasculares; 7) uso de medicamentos regulares e posologia; 8) relato de hábitos de leitura e escrita ao longo da vida; 9) classe socioeconômica e 10) renda familiar.

Como descrito anteriormente, a exclusão dos sujeitos da amostra deu-se pelas informações referentes à escolaridade, condições visuais e auditivas, condições de saúde, casos de doenças prévias ou instaladas relacionadas a

\footnotetext{
${ }^{4}$ Os testes utilizados nesta pesquisa não estão disponíveis na seção ANEXOS por serem, alguns deles, de uso restrito à psicólogos.
} 
problemas neurológicos, psiquiátricos e cardiovasculares, bem como uso de determinados medicamentos que poderiam afetar a cognição.

A classe socioeconômica foi avaliada por meio do Critério de Classificação Econômica Brasil (CCEB), desenvolvido pela Associação Brasileira de Empresas de Pesquisa (ABEP, 2012), como apontado anteriormente.

A Ficha de Identificação encontra-se no APÊNDICE C.

\subsubsection{Mini-Exame do Estado Mental (MEEM)}

O MEEM é um teste de rastreio para o diagnóstico de demência e déficit cognitivo. A versão brasileira foi inicialmente desenvolvida por Bertolucci et al. (1994) e, posteriormente, revisada por Brucki et al. (2003). De acordo com Almeida (1998), o teste é uma medida de funcionamento cognitivo global, composto por diversas questões agrupadas em sete categorias, cada uma delas objetivando avaliar funções cognitivas específicas, tais como: orientação temporal (cinco pontos), orientação espacial (cinco pontos), memória imediata (três pontos) e de evocação (três pontos), atenção e cálculo (cinco pontos), linguagem (oito pontos) e praxia construtiva (um ponto).

Seu escore pode variar de um mínimo de zero até um total máximo de 30 pontos, com as seguintes indicações: de 30 a 26 pontos funções cognitivas preservadas; de 25 a 24 pontos alterações não sugestivas de déficit; de 23 pontos ou menos indicativo de déficit cognitivo (VIEIRA \& KOENIG, 2002; YASSUDA,. 2010).

Neste estudo, foi utilizado o MEEM integrante do Exame Cognitivo de Addenbroke, versão adaptada para uso com a população brasileira (CARVALHO et 
al., 2010b) e considerados escores maiores ou iguais a 25 pontos para inclusão dos indivíduos com pelo menos quatro anos de escolaridade.

\subsubsection{Escala de Depressão Geriátrica (GDS)}

Esta escala é amplamente utilizada como instrumento diagnóstico para depressão em pessoas idosas. Consiste em 30 perguntas com respostas do tipo sim/não que investigam perda de interesse por atividades cotidianas, tristeza, pessimismo, sensação de fracasso, falta de satisfação, sensação de culpa, sensação de punição, autodepreciação, ideias suicidas, crises de choro, irritabilidade, retração social, indecisão, perda de concentração, perda de energia, fadiga e sensação de inutilidade (OLIVEIRA et al., 2014).

Para cada pergunta pontua-se 0 se a resposta for negativa e 1 se resposta for positiva. O somatório dos pontos é avaliado por uma grade de pontuação, conforme segue: de zero a nove pontos o estado do indivíduo é considerado normal; de 10 a

19 pontos o indivíduo é considerado levemente deprimido; e de 20 a 30 pontos o indivíduo é considerado severamente deprimido. (YESAVAGE et al., 1983; STRAUSS et al., 2006).

Nesse estudo foram excluídos indivíduos com escores iguais ou superiores a 10 pontos.

\subsubsection{Questionário de Atividades Funcionais, de Pfeffer et al. (1982)}

O questionário de Pfeffer et al. (1982) consiste em dez perguntas que avaliam o funcionamento do indivíduo nas seguintes atividades instrumentais da vida diária: manusear seu dinheiro, fazer compras, cozinhar, manter-se em dia com as atualidades, acompanhar/entender programas de televisão ou rádio, lembrar-se de 
compromissos, manusear remédios, orientar-se em locais familiares e ficar em casa sozinho.

Realiza-se o somatório das respostas às questões. Quanto menor a pontuação obtida pelo indivíduo, maior a sua independência. O escore mínimo é de zero e o máximo é de 30 , sendo que escores superiores a cinco indicam dependência para a realização de atividades instrumentais da vida diária e são utilizados para o pré-diagnóstico de demência. No presente estudo, adotamos um ponto de corte mais conservador (três pontos) a fim de evitar a inclusão de indivíduos que pudessem apresentar declínio cognitivo leve.

\subsubsection{Questionário de Declínio Cognitivo do Idoso (IQCODE)}

O IQCODE versão reduzida é uma escala de 16 itens sobre memória e alterações na capacidade de realização das atividades diárias. Cada item é pontuado de um a cinco pontos indicativos de "muito melhor" a "muito pior", sempre

comparando o desempenho atual do indivíduo com o que apresentava há 10 anos. É considerado um bom instrumento para rastreamento de demência (JORM et al., 1991) e também para avaliar alterações cognitivas longitudinalmente (JORM et al., 2000; SANCHEZ, 2007).

As perguntas são apresentadas em uma escala do tipo Likert, com cinco opções de respostas que comparam o desempenho atual do indivíduo com o desempenho de dez anos atrás: 1 - muito melhor; 2 - um pouco melhor; 3 - não houve mudança; 4 - um pouco pior; 5 - muito pior. O resultado final é obtido por meio do somatório dos itens, dividindo-os pelo total de itens da escala. O escore varia de um a cinco; os escores menores ou iguais a três indicam que não está havendo alteração, igual a quatro indica uma considerável alteração, e igual a cinco 
indica muita alteração. O ponto de corte obtido no estudo original foi de $3,27 / 3,30$ (JORM \& KORTEN, 1988).

Os autores propõem que o instrumento seja aplicado em parente ou amigo próximo que conviva com o idoso há pelo menos dez anos, com o objetivo de comparar as alterações no desempenho do indivíduo durante este período de convivência. Porém, nessa pesquisa o instrumento foi respondido pelo próprio sujeito.

Sua pontuação reflete declínio cognitivo prévio, prevê quadros demenciais, correlaciona-se com vários testes cognitivos e, segundo Sanchez (2007), não sofre influência da escolaridade.

\subsubsection{Testes psicológicos para avaliação da amostra}

Os testes para a avaliação da amostra foram divididos em duas baterias. A primeira bateria, contendo os testes alvos, foi aplicada para o grupo experimental em três fases do programa: antes da intervenção cognitiva ou fase de pré-teste, após a intervenção cognitiva ou fase de pós-teste e após três meses do término da intervenção cognitiva ou fase de reteste. Para o grupo controle, esta bateria foi aplicada apenas nas fases de pré e pós-teste.

As variáveis avaliadas e os respectivos testes que a compuseram foram: a) resolução de problemas: teste Wisconsin de classificação de cartas - versão para idosos (TRENTINI, et al. 2010); b) memória: subescala memória do Exame Cognitivo de Addenbrooke (ACE-R) (CARVALHO et al., 2010b), teste memória de lista de palavras (TMLP) (BERTOLUCCI et al., 2001) e teste de repetição de pseudoplavaras (GATHERCOLE \& BADDELEY, 1994; SANTOS \& BUENO, 2003); c) atenção e concentração: subescala atenção e orientação do Exame Cognitivo de Addenbrooke 
(ACE-R) (CARVALHO et al., 2010b) e teste de Trilhas partes A e B (REITAN, 1958; STRAUSS et al., 2006).

A segunda bateria, contendo os testes de transferência, foi aplicada apenas para o grupo experimental nas fases de pós-teste e reteste. Ela objetivou avaliar as mesmas variáveis da primeira bateria, porém por meio de outros testes com a finalidade de minimizar os efeitos da retestagem, ou seja, na hipótese dos sujeitos possuírem escores superiores nos testes da primeira bateria da fase de pré-teste para a de pós-teste, os testes de transferência diminuiriam esta possibilidade na hipótese de aprendizagem desses testes.

As variáveis avaliadas e os respectivos testes que a compuseram foram: a) resolução de problemas: subteste cubos da Escala Wechsler Abreviada de Inteligência - WASI (TRENTINI el al. 2014); b) memória: testes de extensão de dígitos em ordem direta e em ordem inversa da Escala de Memória de Wechsler (WECHSLER, 1987); c) atenção e concentração: Bateria Psicológica para Avaliação da Atenção (BPA) (RUEDA, 2013).

A escala de autoestima (ROSENBERG, 1965) foi aplicada nas fases pré, pós e reteste apenas para o grupo experimental.

O Quadro 1 apresenta os testes aplicados para avaliação da amostra nas diferentes fases do programa (pré, pós e reteste). 


\begin{tabular}{|c|c|c|c|c|c|c|}
\hline \multirow[b]{3}{*}{ VARIÁVEL } & \multirow[b]{3}{*}{ TESTES } & \multicolumn{5}{|c|}{ GRUPOS } \\
\hline & & \multicolumn{2}{|c|}{ CONTROLE } & \multicolumn{3}{|c|}{ EXPERIMENTAL } \\
\hline & & Pré-teste & Pós-teste & Pré-teste & Pós-teste & Reteste \\
\hline \multirow{2}{*}{$\begin{array}{l}\text { Resolução de } \\
\text { problemas }\end{array}$} & $\begin{array}{l}\text { Wisconsin - versão } \\
\text { para idosos }{ }^{*_{1}}\end{array}$ & $\checkmark$ & $\checkmark$ & $\checkmark$ & $\checkmark$ & $\checkmark$ \\
\hline & WASI - Subteste Cubos ${ }^{* 2}$ & - & - & - & $\checkmark$ & $\checkmark$ \\
\hline \multirow{4}{*}{ Memória } & ACE-R - subescala memória ${ }^{* 1}$ & $\checkmark$ & $\checkmark$ & $\checkmark$ & $\checkmark$ & $\checkmark$ \\
\hline & TMLP ${ }^{* 1}$ & $\checkmark$ & $\checkmark$ & $\checkmark$ & $\checkmark$ & $\checkmark$ \\
\hline & Pseudopalavras ${ }^{* 1}$ & $\checkmark$ & $\checkmark$ & $\checkmark$ & $\checkmark$ & $\checkmark$ \\
\hline & $\begin{array}{l}\text { Dígitos em ordem direta e em } \\
\text { ordem inversa }^{*_{2}}\end{array}$ & - & - & - & $\checkmark$ & $\checkmark$ \\
\hline \multirow{3}{*}{$\begin{array}{c}\text { Atenção e } \\
\text { Concentração }\end{array}$} & $\begin{array}{l}\text { ACE-R - subescala atenção e } \\
\text { orientação }^{* 1}\end{array}$ & $\checkmark$ & $\checkmark$ & $\checkmark$ & $\checkmark$ & $\checkmark$ \\
\hline & Trilhas partes A e B ${ }^{{ }^{*} 1}$ & $\checkmark$ & $\checkmark$ & $\checkmark$ & $\checkmark$ & $\checkmark$ \\
\hline & $\mathrm{BPA}^{* 2}$ & - & - & - & $\checkmark$ & $\checkmark$ \\
\hline Autoestima & Escala de autoestima ${ }^{* 1}$ & - & - & $\checkmark$ & $\checkmark$ & $\checkmark$ \\
\hline ACE-R & ACE-R - total $* 3$ & $\checkmark$ & $\checkmark$ & $\checkmark$ & $\checkmark$ & $\checkmark$ \\
\hline $\begin{array}{l}\text { Mini Exame do } \\
\text { Estado Mental }\end{array}$ & MEEM *3 & $\checkmark$ & $\checkmark$ & $\checkmark$ & $\checkmark$ & $\checkmark$ \\
\hline $\begin{array}{l}\text { Raciocínio } \\
\text { abstrato }\end{array}$ & $\begin{array}{l}\text { WASI - Subteste Raciocínio } \\
\text { Matricial } *^{3}\end{array}$ & - & - & - & $\checkmark$ & $\checkmark$ \\
\hline $\begin{array}{c}\text { Raciocínio } \\
\text { verbal abstrato }\end{array}$ & WASI - Subteste Semelhanças $*^{3}$ & - & - & - & $\checkmark$ & $\checkmark$ \\
\hline
\end{tabular}

* 1 - Testes que compõem a primeira bateria (testes alvos); * 2 - Testes que compõem a segunda bateria (testes de transferência); ${ }^{*} 3$ - Testes que não fazem parte das baterias de avaliação da pesquisa, mas que foram aplicados como testes complementares.

Quadro 1 - Relação dos testes aplicados para avaliação da amostra nas fases de pré, pós e reteste. 


\subsubsection{Testes da primeira bateria - testes alvos}

\subsubsection{Teste de Trilhas, Parte A e Parte B (Trail Making Test A e Test B)}

Este teste é composto de duas partes (Trilhas A e Trilhas B). A tarefa é executada após um treinamento curto do percurso a ser realizado. A Parte A contém 25 círculos numerados e distribuídos de forma aleatória em uma folha. O sujeito é orientado a ligar os círculos em ordem crescente e por meio de uma linha contínua. A parte $B$ contém 25 números e 25 letras circulados e distribuídos aleatoriamente. A tarefa implica em ligar alternadamente os números e as letras correspondentes (1-A,2-B, 3-C, e assim por diante) (STRAUSS et al., 2006).

O escore do teste é obtido por meio dos erros de ligação cometidos e pelo tempo gasto, em segundos, na execução de cada umas das provas (VIEIRA e KOENIG, 2002). Não houve limite de tempo ou de erros para a execução de ambos os testes pelos sujeitos da pesquisa e estes eram finalizados quando completados ou quando os sujeitos optavam por não prossegui-los.

A parte A é uma prova que avalia a atenção, a orientação visuoespacial e a velocidade psicomotora. A parte B avalia a capacidade de atenção dividida, a flexibilidade cognitiva e também a velocidade de processamento de informações, capacidade inibitória (STRAUSS et al., 2006; KRISTENSEN, 2007).

\subsubsection{Teste de Memória da Lista de Palavras (TMLP)}

O TMLP é utilizado para aferir a memória imediata (memória de curto prazo), importante para o armazenamento de dados na memória (BRUCKI et al., 2003).

Neste teste são apresentadas, uma a uma, dez palavras escritas que devem ser lidas em voz alta pelo examinador / examinando ao ritmo de uma palavra a cada dois segundos. Quando a leitura termina, é feita a evocação (as palavras devem ser 
relembradas), por um período máximo de 90 segundos. O procedimento é repetido mais duas vezes com as palavras em outra ordem. O escore total do teste é o somatório das palavras lembradas nas três tentativas, sendo no máximo de 30 pontos (RIBEIRO, 2010). As palavras utilizadas neste teste foram manteiga, carta, poste, motor, braço, rainha, bilhete, praia, cabana e erva (BERTOLUCI et al., 2001).

\subsection{Teste de Repetição de Pseudopalavras}

Desenvolvido por Gathercole e colaboradores (1994) e adaptado para uso com a população brasileira por Santos e Bueno (2003), o teste consiste na repetição de pseudopalavras que variam conforme o número de sílabas e complexidade silábica, avaliando habilidades fonológicas, especialmente os processamentos envolvidos no armazenamento temporário de informações verbais (alça fonológica no modelo de Baddeley e Hitch, 1974, que possui como uma das principais funções fornecer armazenamento temporário das estruturas sonoras desconhecidas de novas palavras a partir do qual as representações lexicais mais estáveis são gradualmente construídas).

As pseudopalavras consistem em um estímulo dentro das regras estruturais de uma linguagem natural que pode ser lida, escrita e repetida, mas não tem nenhum significado conceitual ou valor semântico no léxico corrente da linguagem. Os indivíduos dependem da capacidade de seu sistema de memória fonológica para codificar e manter a sequência fonológica (BADDELEY \& WILSON, 2002).

Trata-se de um teste com 40 pseudopalavras que devem ser repetidas pelos participantes, a fim de investigar a produção da fala e a memória de trabalho (SANTOS \& BUENO, 2003). Para cada repetição correta é atribuído um ponto. 


\subsection{Teste WISCONSIN de Classificação de Cartas - versão para idosos (WCST)}

O Teste WISCONSIN é largamente utilizado para avaliar a resolução de problemas, ou seja, para avaliar a capacidade de abstração do indivíduo e a capacidade de mudar estratégias cognitivas em resposta a mudanças ambientais (BRITO et al., 2012) . Ele é considerado um medidor das funções executivas, sendo um teste clássico na literatura referente ao estudo de indivíduos com prejuízos nestas funções (HEATON et al., 2005; SCHNEIDER, 2006; STRAUSS et al., 2006;).

De acordo com Berman et al. (1995), o WCST foi elaborado visando avaliar a capacidade de abstração e a flexibilidade mental e, no momento, tem sido relevante para o exame da memória operacional.

Strauss et al. (2006), consideram no um avaliador da função executiva na medida em que requer do indivíduo examinado o planejamento estratégico, a pesquisa organizada, a capacidade de usar o feedback do ambiente para mudar as estratégias de ação, o comportamento orientado para metas, bem como a capacidade de modular a resposta impulsiva.

O examinando recebe um conjunto de 128 cartas com figuras coloridas, cada uma com diferentes formas como tipo de desenho (triângulo, estrela, cruz ou círculo), número de elementos em cada carta (variando de um a quatro), cor dos elementos (verde, vermelho, amarelo ou azul). A tarefa é a de combinar cada carta com uma de quatro cartas-estímulo, segundo um princípio que o examinando deve deduzir por meio do feedback do examinador. O examinador indica se a resposta do examinando é certa ou errada de acordo com o critério vigente (cor, forma, número). A cada dez acertos sucessivos o critério é modificado sem que o examinando seja alertado, sendo necessário empregar uma nova estratégia de categorização, 
exigindo a flexibilidade mental para passar de uma regra à outra. O teste termina quando forem completadas seis categorias (cor, forma, quantidade, cor forma, quantidade) ou quando terminarem as 128 cartas do baralho (TRENTINI et al. 2010).

A pontuação do teste é dada pelo número total de categorias completadas e pelo número total de erros cometidos (SPREEN \& STRAUSS, 1991; MAGILA \& CARAMELLI, 2001). Outros autores como Souza et al. (2001), Wagner (2006), e Silva Filho (2007) consideram importante ressaltar, além das categorias completadas, o números de erros perseverativos para a pontuação do teste.

Silva Filho (2007) e Trentini et al. (2010) descrevem a análise no desempenho no WCST por meio dos seguintes indicadores interpretativos: 1) número de ensaios administrados: número de cartas utilizadas para completar as seis categorias do teste; 2) número total de respostas corretas: número de acertos no teste, dentre os ensaios realizados; 3) número total de erros: número de erros no teste, dentre os ensaios realizados; 4) respostas perseverativas: são as respostas realizadas pela fixação de cartas num mesmo critério, indicando a não experimentação de outras alternativas para a solução do problema; 5) erros perseverativos: referem-se aos erros com característica de resposta perseverativa, ou seja, são aqueles ensaios em que o participante classificou o seu cartão com base no princípio da perseverança e não em relação ao princípio de classificação; 6) erros não perseverativos: correspondem às respostas erradas que não preenchem os critérios de resposta perseverativa; 7) respostas de nível conceitual: são respostas que indicam acertos intencionais, ocorridas a partir de uma sequência initerrupta de três ou mais acertos; 8) número de categorias completadas: corresponde ao total de categorias concluídas pelo examinando, cada categoria é completada quando dez cartas seguidas são ordenadas corretamente de acordo 
com o critério estabelecido (Cor-Forma-Número/Cor-Forma-Número); 9) ensaios para completar a primeira categoria: corresponde ao número de cartas utilizadas para completar a primeira categoria; 10) fracasso em manter o contexto: corresponde a erros inesperados que são cometidos no meio de uma sequência de acertos; 11) aprendendo a aprender: refere-se a aprendizagem da própria tarefa durante sua execução.

Nessa pesquisa não será considerado o indicador interpretativo de no 11 aprendendo a aprender. Isto se deve ao fato de que este indicador somente pode ser calculado se o examinando completar três ou mais categorias ou se completar duas categorias e tentar uma terceira. Nessa pesquisa, houve sujeitos que não conseguiram completar as duas ou três categorias exigidas para este cálculo.

\subsection{Exame Cognitivo de Addenbrooke (ACE-R)}

O Exame Cognitivo de Addenbrooke (Addenbrooke's Cognitive Examination) foi desenvolvido por pesquisadores da Unidade de Neurologia Cognitiva da Universidade de Cambrige, no Reino Unido, em 2000, e tem sido cada vez mais utilizado para o diagnóstico de demência (CARVALHO, 2009). Este instrumento foi adaptado para a população brasileira por Amaral Carvalho e Caramelli (2007) e tem sido muito utilizado devido a sua sensibilidade e especificidade para detectar demência em estágio leve (CÉSAR, 2014). O seu tempo de aplicação varia de 10 a 15 minutos, considerando cinco domínios cognitivos separadamente: 1) atenção e orientação - 18 pontos: 2) memória - 26 pontos; 3) fluência verbal - 14 pontos; 4) linguagem - 26 pontos; 5) habilidade visuoespacial - 16 pontos. A pontuação máxima é de 100 pontos. Neste total, estão inseridos 30 pontos relativos ao MEEM que também podem ser calculados à parte. 
$\mathrm{Na}$ avaliação da orientação e da atenção são utilizados os mesmos itens do MEEM. A memória é avaliada em seu aspecto episódico (recordação das três palavras do MEEM; a aprendizagem e a recordação tardia de um nome e endereço) e semântico. A linguagem é avaliada pela nomeação de 12 figuras, além de tarefas de compreensão, repetição, leitura e escrita. A habilidade visuoespacial é avaliada pela cópia de retângulos sobrepostas, do cubo e do relógio. A capacidade de fluência verbal é dividida por categoria fonêmica (palavras iniciadas com a letra "p") e semântica (dizer o maior número possível de nomes de animais). Os escores brutos são utilizados para a pontuação final em todos os itens, com exceção do item de fluência verbal, o qual exige uma conversão do número de palavras geradas em uma pontuação referente pré-estabelecida.

Nessa pesquisa, utilizamos a versão brasileira na íntegra.

\subsection{Escala de Avaliação da Autoestima}

A Escala de Avaliação da Autoestima de Rosenberg (1965) utilizada neste estudo e traduzida por Dini (2000), é uma escala é do tipo Likert e objetiva avaliar a autoestima - considerada como o sentimento, o apreço e a consideração que uma pessoa sente por si própria. É constituída por dez afirmações relacionadas à satisfação consigo mesma, com suas qualidades e capacidades, com o próprio valor, orgulho e respeito por si mesmo, atitude positiva em relação a si, sentimento de inutilidade e sensação de fracasso. As opções de resposta são: concordo totalmente, concordo, discordo e discordo totalmente, onde cada item de resposta varia de 1 a 4 pontos. Quanto maior o escore, maior a autoestima do individuo.

Essa escala foi aplicada apenas no grupo experimental nas fases de pré, pós e reteste desse trabalho. 


\subsubsection{Testes da segunda bateria - testes de transferência}

\subsection{Escala Wechsler Abreviada de Inteligência (WASI)}

A Escala Wechsler Abreviada de Inteligência (WASI - Wechsler Abbreviated Scale of Intelligence) foi desenvolvida por Wechsler (1999), com o objetivo de estimar o nível intelectual de forma rápida, ou seja, uma medida breve de inteligência para contextos clínicos e de pesquisa, fornecendo três medidas de inteligência: QI Verbal, QI Execução e QI Total (YATES et al. 2006; TRENTINI et al., 2014).

Essa bateria é composta por quatro subtestes, dois verbais (Semelhanças e Vocabulário), dois de execução (Cubos e Raciocínio Matricial) e permitem avaliar, segundo Yates et al. (2006), diferentes aspectos cognitivos, tais como conhecimento verbal, processamento de informação visual, raciocínio espacial e não-verbal, bem como inteligência fluida e cristalizada em diversos contextos, podendo ser aplicada em indivíduos entre 6 e 89 anos.

O subteste Vocabulário é uma medida de expressão do vocabulário do indivíduo sobre seu conhecimento verbal e de informações armazenadas, além de contribuir para medidas referentes à inteligência cristalizada, habilidade de aprendizagem e desenvolvimento de conceitos e de linguagem. (SATTLER, 1988; TRENTINI et al., 2014). Composto por 42 itens, os primeiros quatro itens requerem que o examinando nomeie figuras que são apresentadas uma por vez; os outros 38 itens são palavras apresentadas oral e visualmente que o examinando deve conceituar oralmente. A resposta é anotada pelo examinador no Protocolo de Registro e a pontuação pode variar de zero a dois pontos dependendo da resposta dada pelo examinando. O teste é interrompido após cinco erros consecutivos e, ao 
final, é realizado o somatório da pontuação de cada resposta para obter o escore bruto do teste.

O subteste Cubos avalia as habilidades relacionadas com a visualização espacial, coordenação visomotora e conceituação abstrata, sendo também uma medida de organização perceptual e inteligência geral (BANHATO \& NASCIMENTO, 2007; WAGNER \& TRENTINI, 2010; TRENTINI et al., 2014). Composto por 13 desenhos geométricos, o examinando deve usar os cubos para reproduzir modelos corretos dos mais simples para os mais complexos, de uma ou duas cores em um tempo determinado que pode variar de 60 segundos para figuras compostas de quatro cubos a 120 segundos para figuras de nove cubos. $O$ tempo gasto em segundos para a montagem da figura é convertido em uma pontuação referente préestabelecida que pode variar de zero a sete pontos. $O$ teste é interrompido após três erros consecutivos e, ao final, é realizado o somatório da pontuação de cada resposta para obter o escore bruto do teste.

O subteste Semelhanças é uma medida de formação de conceito verbal, de habilidade de raciocínio verbal abstrato e de habilidade intelectual geral, tendo como objetivo, durante a realização do teste, identificar figuras semelhantes nos primeiros quatro itens, ou explicar como dois objetos ou conceitos assemelham-se do quinto ao vigésimo sexto item (WECHSLER, 2005; MALLOY-DINIZ et al., 2008; TRENTINI et al., 2014). Para cada um dos itens de um a quatro é apresentado ao examinando, por meio do caderno de estímulos, uma figura de três objetos comuns na linha superior e quatro opções de associação à resposta na linha inferior. O examinando deve apontar na linha inferior do caderno de estímulos a opção de resposta semelhante ao da linha superior deste mesmo caderno. Para os itens verbais, de quinto ao vigésimo sexto item, é apresentado oralmente ao examinando um par de 
palavras e esse deve dizer o que há em comum entre as palavras. A resposta é anotada pelo examinador no Protocolo de Registro e a pontuação pode variar de zero a dois pontos dependendo da resposta dada pelo examinando. O teste é interrompido após quatro erros consecutivos e, ao final, é realizado o somatório da pontuação de cada resposta para obter o escore bruto do teste.

Por último, o subteste Raciocínio Matricial é uma medida de raciocínio fluído não verbal e de habilidade intelectual geral, processamento de informação visual e raciocínio abstrato (BANHATO \& NASCIMENTO, 2007; TRENTINI et al., 2014). O subteste é composto por quatro tipos de tarefas de raciocínio não verbal: completar padrões, classificação, analogia e raciocínio serial. O caderno de estímulos contem 35 padrões incompletos dispostos cada um deles em uma matriz própria que é apresentada ao examinando e este deve escolher dentre cinco alternativas qual a correta para completar a matriz das figuras. A pontuação para cada matriz varia de zero para respostas incorretas a um ponto para respostas corretas. O teste é interrompido após seis erros consecutivos e, ao final, é realizado o somatório da pontuação de cada resposta para obter o escore bruto do teste.

Nessa pesquisa, utilizamos os subtestes Cubos, Semelhanças e Raciocínio Matricial. Os dois últimos não foram aplicados com um objetivo específico, mas o interesse por estes testes derivou de eles serem muito semelhantes aos instrumentos Comparações, Classificações e Percepção Analítica, que foram desenvolvidos durante o programa. 


\subsection{Testes de extensão de dígitos em ordem direta e em ordem inversa da} Escala de Memória Wechsler de Inteligência para Adultos (WAIS-III)

O teste de extensão de dígitos em ordem direta e inversa é parte integrante da Escala de Memória de Wechsler de Inteligência para Adultos (WAIS-III - Wechsler Adult Intelligence Scale, 1987) que permite avaliar a memória de trabalho e a atenção, responsáveis por estratégias de seleção, controle e coordenação dos vários processos envolvidos na armazenagem de curto prazo, exigindo, simultaneamente, a armazenagem e o processamento da informação (FIGUEIREDO, 2007; OLIVEIRA et al., 2014).

Durante a aplicação do teste, a atenção seletiva é requerida na extensão de dígitos de ordem direta, enquanto a dividida é requerida na extensão de dígitos na ordem inversa (SPREEN \& STRAUSS,1991; STERNBERG, 2000; LEZAK et al., 2004).

O participante deve repetir uma sequência de dígitos que aumenta conforme ele consegue repetir corretamente a sequência anterior. Na prova de ordem direta deve-se repetir os dígitos na mesma ordem dita pelo avaliador. Na prova de ordem inversa o participante deve repetir os dígitos na ordem contrária ao que foi dito pelo avaliador. A pontuação de cada prova é atribuída de acordo com o número de dígitos das últimas duas sequências repetidas corretamente pelo participante em cada uma das provas e o escore total do teste é o somatório da pontuação das provas. (NASCIMENTO, 2005; OLIVEIRA et al., 2014).

\subsection{Bateria Psicológica para Avaliação da Atenção (BPA)}

A Bateria Psicológica para Avaliação da Atenção (BPA) tem como objetivo realizar uma avaliação da capacidade geral de atenção, como também uma 
avaliação de tipos de atenção específicos: atenção concentrada (AC), atenção dividida $(A D)$ e atenção alternada $(A A)$. Ela é composta por três testes, cada um deles tendo como objetivo avaliar um dos tipos atencionais propostos, e a análise dos três testes em conjunto fornece a medida de atenção geral (RUEDA, 2013)

Os testes foram construídos a partir de vários estímulos abstratos que serviram para compor as três folhas de respostas ( $A C, A D$ e $A A)$, sendo que ora eles foram estímulos-alvo, ora estímulos distratores. A distribuição dos estímulos segue a mesma quantidade em cada instrumento, contendo 400 estímulos distribuídos em 20 linhas com 20 estímulos cada. Do total, 120 são estímulos-alvo (pontuação máxima possível) e 280 distratores (RUEDA, 2013).

O resultado final de cada teste é obtido considerando os estímulos-alvo que a pessoa marcou, subtraído dos erros e das omissões que cometeu. Dessa forma chega-se ao total de pontos. No caso da capacidade geral da atenção, o resultado é obtido por meio do somatório dos pontos totais de cada um dos testes $(A C+A D+A A)$, sendo o máximo possível 360 pontos.

No que se refere ao tempo de aplicação, para o $A C 2$ minutos; para o $A D, 4$ minutos; e para o AA, 2 minutos e 30 segundos. A ordem de aplicação deve ser seguida rigorosamente, começando pelo $A C$, seguido pelo $A D$ e, por fim, o $A A$. $A$ aplicação pode ser coletiva ou individual. Neste estudo a aplicação foi individual.

\subsubsection{Instrumentos do PEI para a intervenção cognitiva}

Os instrumentos do Programa de Enriquecimento Instrumental Standard I que foram aplicados no grupo experimental dessa pesquisa, não foram utilizados na sua totalidade devido ao tempo de aplicação da intervenção cognitiva. Para tanto, foram aplicados metade das folhas contidas em cada instrumento, quais sejam: 1) 
Organização de Pontos: capa, folhas de um a sete, folha de erro 1, folha de erro 2 e folha de erro 3; 2) Comparações: capa, folhas de um a oito; 3) Classificações: capa, folhas de um a dez; 4) Orientação Espacial I: capa, folhas de um a 11; 5) Orientação Espacial II: capa folhas de um a nove; 6) llustrações: capa folhas de um a dez; 7) Percepção Analítica: capa, folhas de um a 12.

Antes da aplicação do instrumento Organização de Pontos, foram elaboradas folhas "pré-pontos". Elas eram compostas por exercícios e tinham como objetivo introduzir e/ou recordar os conceitos de pontos, retas, retas inclinadas, paralelas, paralelas horizontais, paralelas verticais, ângulo, nuvem de pontos, cujos conceitos eram primordiais à utilização do instrumento.

A explanação dos objetivos de cada instrumento do PEI Standard I foi realizado no Capítulo 2 dessa pesquisa e, como ilustração, uma folha de cada instrumento encontra-se no ANEXO A.

\subsubsection{Escala de percepção subjetiva sobre modificações após o programa}

Com o objetivo de conhecer se o participante percebe ou não modificações nas variáveis desenvolvidas pelo programa, foi elaborada uma escala em que são citadas 12 modificações a serem alcançadas no término do programa e cinco opções de respostas para cada modificação apresentada: "Muito melhor", "Bem melhor", "Melhor", "Sem alteração" e "Pior". As 12 modificações apresentadas foram: 1) Atenção e Concentração; 2) Controle da impulsividade (ansiedade) nas ações do dia-a-dia; 3) Resolução de problemas; 4) Memória; 5) Autoestima; 6) Pensar antes de agir para solucionar os problemas; 7) Motivação para aprender coisas em geral; 8) Capacidade de comunicar-se com as pessoas de maneira mais clara e objetiva; 9) Capacidade de classificar, comparar, organizar e discriminar as informações para a 
resolução de problemas; 10) Capacidade de percepção e análise; 11) Orientar-se no espaço em relação aos objetos e pessoas 12) Maior autonomia.

O idoso deveria ler a modificação e assinalar dentre as cinco opções, qual melhor reflete sua opinião no momento do preenchimento.

A escala de percepção sobre modificações após o programa encontra-se no APÊNDICE E.

\subsubsection{Perspectiva Individual sobre o Programa}

Com o objetivo de conhecer as perspectivas dos idosos que comporam o grupo experimental em relação ao programa a ser desenvolvido, foram elaboradas duas perguntas abertas a serem respondidas individualmente no início e no final do programa. A pergunta a ser respondida no início do programa, mas especificamente no primeiro dia de aula foi: "Quais perspectivas você tem com o programa que iremos realizar?". A segunda pergunta respondida no último dia de aula do programa foi: "Você considera que suas perspectivas foram alcançadas ao final do programa? Se sim, você poderia citá-las?".

\subsubsection{Entrevista final}

A entrevista final foi realizada com oito idosos do grupo experimental, quatro que obtiveram as piores pontuações e quatro que obtiveram as maiores pontuações na fase reteste do programa, em pelo menos três dos seguintes testes: a) ACE-R escore total; b) teste Wisconsin de classificação de cartas - versão para idosos, indicador avaliativo respostas de nível conceitual; c) bateria BPA - atenção geral; d) WASI: escore bruto do subteste Cubos. 
Dentre todos os testes realizados pelos sujeitos do grupo experimental, estes foram os que demonstraram maiores oscilações nos escores durante a tabulação e análise dos dados.

Essa entrevista teve como objetivo coletar dados qualitativos sobre as modificações perceptíveis ou não pelos idosos a respeito do seu comportamento durante e após o término do programa. Ela foi composta por quatro questões objetivas. A primeira questão refere-se à percepção da mudança de comportamento em alguma situação da vida diária durante e/ou após o término da intervenção a qual o idoso foi submetido. A segunda questão destina-se a conhecer se houve ou não modificações em algumas das funções cognitivas do idoso tais como: pensamento reflexivo; controle da impulsividade (ansiedade); comunicação clara e precisa; concentração; consciência do seu potencial; elevação da autoestima; motivação para aprender; maior autonomia; melhora da memória. A questão de número três indagou se as informações trabalhadas nas atividades da intervenção foram importantes para a realização das tarefas do cotidiano, ou seja, se a intervenção conseguiu proporcionar ao idoso a transcendência (transferir o aprendizado para as tarefas do dia-a-dia). E a quarta e última questão refere-se a declarações que o idoso achar importante fazer sobre programa realizado.

As perguntas referentes à entrevista encontram-se no APÊNDICE D.

\subsection{PROCEDIMENTO}

No início desse trabalho foram apresentados à coordenação das instituições os objetivos e procedimentos do estudo, solicitando a realização deste em suas dependências; a declaração de aprovação da pesquisa pelo Comitê de Ética em Pesquisa com Seres Humanos do Instituto de Psicologia da Universidade de São 
Paulo; declaração de que a pesquisadora era aluna regularmente matriculada no curso de Doutorado desta instituição; carta de apresentação do orientador para a realização da referente pesquisa.

Após a aprovação da realização da pesquisa pelas instituições, os idosos foram contatados e convidados a participarem de uma reunião em que foram explicados os objetivos da pesquisa e como seria realizada.

Os idosos interessados na participação do programa, tanto para a formação do grupo controle quanto para a formação do grupo experimental, preencheram a ficha de inscrição e nela assinalavam a opção de participação. Os interessados na participação do grupo experimental podiam escolher, dentre sete opções, o horário em que pretendiam frequentar o programa. A liberdade de escolha ocorreu porque em conversas informais com os possíveis participantes havia idosos interessados apenas na avaliação cognitiva proporcionada pelos testes e não disporiam de tempo para realizarem o programa devido a sua extensão. Outros alegaram que, se não participassem do programa, não gostariam apenas de realizar os testes para uma avaliação cognitiva. Devido a este fato e ao temor da perda da amostra, não foi possível realizar o sorteio duplo-cego para composição de ambos os grupos, controle e experimental.

Após a reunião informativa, os idosos foram novamente contatados para realizarem, individualmente, em dia e horário agendados, os testes para a seleção da amostra. Os idosos que não atenderam os critérios de inclusão para participarem da pesquisa, foram orientados a procurarem quatro instituições de serviços e atendimento ao público idoso para verificarem a possibilidade de integração.

Após serem selecionados na primeira etapa da entrevista (testes para a seleção da amostra), os idosos foram solicitados a comparecerem individualmente, 
em dia e horário agendados, para a assinatura do Termo de Consentimento Livre e Esclarecido (TCLE) (vide APÊNDICE A e B) e para realizarem a primeira bateria de testes da fase pré-teste do programa. O TCLE foi assinado em duas vias iguais, sendo que uma cópia ficou de posse da pesquisadora responsável e uma cópia de posse do participante. Neste dia, foi confirmado o dia e horário em que o idoso do grupo experimental participaria do programa.

A sequência de testes aplicados na primeira bateria, tanto para o grupo controle quanto para o grupo experimental, foi: 1) Exame Cognitivo de Addenbrooke (ACE-R); 2) teste Wisconsin de classificação de cartas - versão para idoso; 3) teste de Trilhas partes A e B; 4) teste memória de lista de palavras (TMLP); 5) teste de repetição de pseudopalavras. Ambos os grupos realizaram os testes nos meses de março, abril e maio de 2014.

Para o desenvolvimento do programa, que teve a duração de cinco meses e meio e foi realizado nos meses de julho, agosto, setembro, outubro, novembro, as duas primeiras semanas de dezembro do ano de 2014 e ministrado pela pesquisadora responsável, o grupo experimental foi subdividido em sete turmas, com no máximo oito alunos em cada turma. As sessões de intervenção foram realizadas uma vez por semana com a duração de 90 minutos cada, totalizando 21 sessões para cada turma, nos seguintes dias e horários:

- Turma 1 - Quarta-feira: das 8h as 9h30 - oito participantes;

- Turma 2 - Quarta-feira: das 9h30min às $11 \mathrm{~h}$ - quatro participantes;

- Turma 3 - Sexta-feira: das 8h as 9h30 - cinco participantes;

- Turma 4 - Quarta-feira: das 13h30min as 15h - cinco participantes;

- Turma 5 - Quarta-feira: das 15h às 16h30min - quatro participantes;

- Turma 6 - Sexta-feira: das $13 \mathrm{~h} 30 \mathrm{~min}$ às $15 \mathrm{~h}$ - cinco participantes; 
- Turma 7 - Sexta-feira: das $15 \mathrm{~h}$ às $16 \mathrm{~h} 30 \mathrm{~min}$ - três participantes.

$\mathrm{Na}$ primeira sessão de intervenção para cada turma, foram novamente enfatizados os objetivos da pesquisa; explanadas as informações gerais do programa; definido a quantidade de faltas para cada participante (no máximo três não consecutivas) que deveriam ser comunicadas com antecedência e repostas no sábado posterior à aula ausente; os participantes responderam individualmente a escala de autoestima (ROSENBERG, 1965); escreveram um breve relato sobre a sua expectativa do curso.

Iniciamos as mediações com as folhas preparatórias de pontos. Os instrumentos Organização de Pontos (OP) e llustrações permeavam a maioria das sessões. Devido à complexidade e ao cansaço apresentado pelos idosos para a realização do instrumento $\mathrm{OP}$, ele foi executado em sua metade num primeiro momento da intervenção, sendo retomado a outra metade na intervenção posterior. Optamos por dar ênfase, num primeiro momento, aos os instrumentos Orientação Espacial I e Comparações para, após, iniciarmos os instrumentos Classificações e Percepção Analítica.

Procurou-se seguir exatamente a programação pré-estabelecida para a realização das folhas dos instrumentos. Porém, por observações da mediadora e pela motivação para a tarefa demonstrada pelos idosos durante as sessões, algumas modificações foram realizadas quais sejam: a) não foi possível aplicar a folha de número 7 do instrumento OP. Este fato ocorreu pela complexidade das folhas do instrumento e pelo tempo hábil para realizar o programa; b) não foi aplicado a folha de erro 3 do instrumento OP porque esta não foi inclusa no pacote na compra dos instrumentos; c) não foi possível aplicar o instrumento Orientação Espacial II. Optamos em dar maior ênfase aos instrumentos que estavam em 
processo de mediação; d) foi acrescido à programação as folhas de números 9, 10, 11 e 12 do instrumento Comparações.

Como a mediação foi realizada em grupo e muitos idosos apresentavam dificuldades na localização da informação na folha do instrumento, foi necessário realizar a digitalização das folhas e a projeção destas em formato de slides. Após o término da sessão de intervenção, os slides referentes às folhas digitalizadas foram apagados.

Não foi permitida, durante a mediação, que os participantes que haviam concluído a folha do instrumento ajudassem ou informassem as respostas ao seu companheiro, exceto quando as atividades eram propostas em grupos. Toda dúvida do mediando (participante) era remetida à mediadora (pesquisadora) que transitava atentamente entre os participantes a fim de realizar as indagações referentes às folhas dos instrumentos de maneira individual.

Os participantes seguiram fielmente o pedido realizado pela mediadora, preocupando-se com o seu desenvolvimento e com o desenvolvimento do seu companheiro. Após o término de cada folha, era realizada discussão em grupo, o que permitia que cada idoso elaborasse e colocasse em questão a sua resposta em relação ao que era pedido na folha do instrumento.

Procurou-se seguir a mesma estrutura das sessões de intervenção para todas as turmas, com a mesma quantidade de folhas a serem mediadas, em média quatro folhas por aula, a fim de que todas as turmas seguissem o mesmo cronograma de trabalho. Quando a turma completava todas as folhas previstas para mediação naquela sessão, ela era dispensada. Este episódio ocorreu apenas duas vezes com a turma 7. Após, todas seguiram o mesmo tempo para mediação e não houve mediação em que as folhas previstas para a sessão não fossem contempladas. 
O Quadro 2 apresenta a relação dos instrumentos e o número das folhas desenvolvidas em cada sessão.

\begin{tabular}{|c|c|c|c|c|c|c|c|c|}
\hline \multicolumn{9}{|c|}{ INSTRUMENTOS } \\
\hline \multirow[t]{2}{*}{ 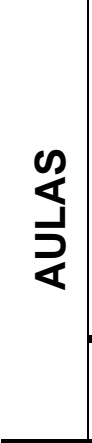 } & 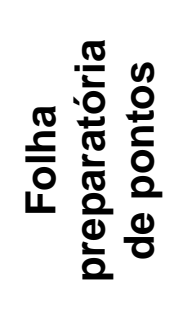 & 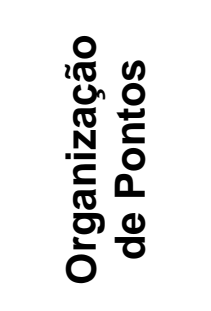 & 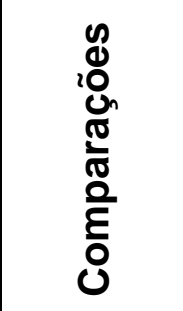 & 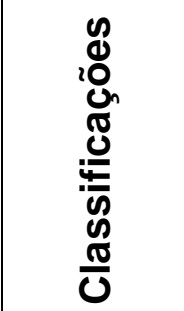 & 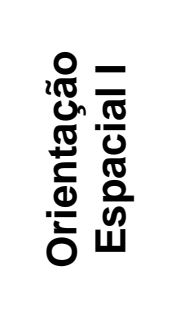 & 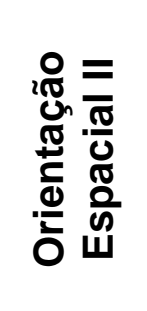 & 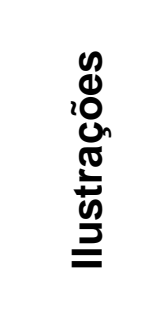 & 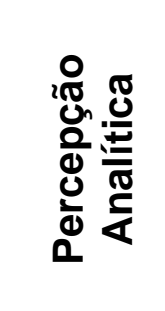 \\
\hline & $\begin{array}{c}\text { № } \\
\text { Folha }\end{array}$ & № Folha & $\begin{array}{c}\text { № } \\
\text { Folha }\end{array}$ & $\begin{array}{c}\text { № } \\
\text { Folha }\end{array}$ & $\begin{array}{c}\text { № } \\
\text { Folha }\end{array}$ & $\begin{array}{c}\text { № } \\
\text { Folha }\end{array}$ & $\begin{array}{c}\text { № } \\
\text { Folha }\end{array}$ & $\begin{array}{c}\text { № } \\
\text { Folha }\end{array}$ \\
\hline $1^{\underline{a}}$ & $1,2,3$ & - & - & - & - & - & Capa, 4 & - \\
\hline $2^{\underline{a}}$ & $4,5,6$ & - & - & - & Capa, 1 & - & - & - \\
\hline $3^{\underline{a}}$ & 7,8 & - & - & - & 2 & - & - & - \\
\hline $4^{\underline{a}}$ & - & - & $\begin{array}{c}\text { Capa, 1, } \\
2,3\end{array}$ & - & - & - & 2 & - \\
\hline $5^{\mathrm{a}}$ & - & Capa, 1 & 4 & - & - & - & - & - \\
\hline $6^{a}$ & - & $1 / 2^{*}$ erro 1 & - & - & 3,4 & - & - & - \\
\hline $7^{\mathrm{a}}$ & - & $1 / 2^{*}$ erro 1 & - & - & 5,6 & - & 3 & - \\
\hline $8^{\underline{a}}$ & - & folha 2 & 5,6 & - & - & - & 7 & - \\
\hline 9 a & - & $1 / 2^{*}$ erro 2 & 7,8 & - & - & - & 5 & - \\
\hline $10^{\mathrm{a}}$ & - & $1 / 2^{*}$ erro 2 & - & - & 7 & - & - & Capa, 1 \\
\hline $11^{\mathrm{a}}$ & - & - & - & - & 8,9 & - & - & - \\
\hline $12^{\mathrm{a}}$ & - & $1 / 2^{*} 3$ & - & - & - & - & - & 2,3 \\
\hline $13^{\underline{a}}$ & - & $1 / 2 * 3$ & - & - & 10,11 & - & 6 & - \\
\hline $14^{\mathrm{a}}$ & - & - & - & $\begin{array}{c}\text { Capa, } 1, \\
2\end{array}$ & , & - & - & 4,5 \\
\hline $15^{\underline{a}}$ & - & $1 / 2^{*} 4$ & - & 3,4 & - & - & - & - \\
\hline $16^{\underline{a}}$ & - & $1 / 2^{*} 4$ & - & & - & - & 1 & 6,7 \\
\hline $17^{\mathrm{a}}$ & - & - & - & $5,6,7$ & - & - & - & 8,9 \\
\hline $18^{\underline{a}}$ & - & 5 & - & - & - & - & 10 & - \\
\hline $19^{a}$ & - & $1 / 2^{*} 6$ & - & - & - & - & 8 & 10 \\
\hline $20^{\underline{a}}$ & - & $1 / 2^{*} 6$ & - & - & - & - & 9 & 11,12 \\
\hline $21^{\underline{a}}$ & - & - & $9,10,11$ & - & - & - & - & - \\
\hline
\end{tabular}

* $1 / 2$ refere-se ao desenvolvimento de metade da folha na respectiva aula.

Quadro 2 - Relação dos instrumentos e folhas desenvolvidas

em cada uma das 21 sessões. 
Todos os participantes foram assíduos às sessãos e as faltas referiram-se a consultas médicas, sendo repostas no sábado posterior ao da aula, como combinando anteriormente. Dentre os 34 participantes, apenas cinco necessitaram realizar as reposições.

Na última sessão $\left(21^{a}\right)$, os idosos responderam individualmente a escala de autoestima (ROSENBERG, 1965), escreveram um breve relato se conseguiram ou não atingir sua expectativa em relação ao programa proposto, preencheram a escala de percepção subjetiva sobre modificações após o programa e foram agendados os testes para a fase pós-teste do programa.

Como o programa teve seu término na segunda quinzena do mês de dezembro de 2014 e devido ao período de preparativos para as festas de final de ano, optou-se, em comum acordo com os participantes do grupo experimental, em iniciarmos os testes da fase pós-teste do programa a partir da segunda semana no mês de janeiro de 2015, juntamente com os participantes do grupo controle. Desta forma, os testes da fase pós-teste do programa foram realizados nos meses de janeiro, fevereiro e março de 2015. A prioridade de aplicação deu-se para o grupo experimental.

Entretanto, para minimizar a hipótese de aprendizagem dos testes da fase pré-teste para a fase pós-teste do programa no grupo experimental, este realizou os testes da segunda bateria. Procurou-se agendá-los até no máximo dez dias após a realização dos testes da primeira bateria.

A sequência de testes aplicados na segunda bateria para o grupo experimental foi: 1) Bateria Psicológica para Avaliação da Atenção (BPA); 2) subteste cubos da Escala Wechsler Abreviada de Inteligência - WASI; 3) subteste semelhanças da Escala Wechsler Abreviada de Inteligência - WASI; 4) subteste 
raciocínio matricial da Escala Wechsler Abreviada de Inteligência - WASI; 5) testes de extensão de dígitos em ordem direta e em ordem inversa da Escala de Memória de Wechsler.

Após três meses e meio do término do programa, nos meses de abril e maio de 2015, o grupo experimental realizou os testes da fase reteste do programa da primeira e da segunda bateria na mesma ordem em que foram agendados para os testes da fase pós-teste do programa. Seguiu-se o mesmo critério dos testes aplicados na fase pós-teste do programa, ou seja, os testes da segunda bateria foram realizados no máximo até 10 dias após os testes da primeira bateria. Em ambas as fases, os participantes do grupo controle e do grupo experimental foram interrogados sobre modificações no seu estado de saúde e as respostas foram negativas, ou seja, não houve alterações.

A entrevista final foi realizada com oito idosos do grupo experimental, quatro que obtiveram as menores pontuações e quatro que obtiveram as maiores pontuações nas fase reteste do programa, em pelo menos três dos seguintes testes: a) ACE-R escore total; b) teste Wisconsin de classificação de cartas - versão para idosos, subvariáveis números de ensaios corretos para completar a tarefa e número de erros não perseverativos; c) bateria BPA - atenção geral; d) WASI: escore bruto do subteste Cubos.

De posse dos resultados da análise estatística foi agendado, com cada participante do grupo controle e do grupo experimental, uma reunião para discutirmos o seu desempenho durante o programa. 


\section{CAPÍTULO 4}

RESULTADOS

Os resultados serão divididos em dois tipos de análise: descritiva e inferencial.

Por meio da análise descritiva, será possível esboçar um quadro geral do desempenho dos sujeitos em cada uma das variáveis analisadas. Cabe ressaltar, todavia, que as medidas apresentadas nas tabelas (média, desvio padrão, mínimo, mediana e máximo) servem apenas como referência da magnitude dos dados e não são levados diretamente em conta pelos testes de Wilcoxon e Mann-Witney, utilizados na análise inferencial, que são os equivalentes não-paramétricos do teste $t$ de Student. Inicialmente, serão apresentados os resultados referentes ao agrupamento das variáveis sociodemográficas de ambos os grupos (controle e experimental) em função da frequência e da porcentagem dos sujeitos em cada grupo. A seguir, os resultados de cada variável estudada, de acordo com os instrumentos utilizados para sua avaliação, em ambos os grupos (controle e experimental. Além dos resultados de cada variável analisada, nesta seção serão apresentados também os dados referentes à escala de percepção subjetiva sobre modificações após o programa, a perspectiva individual sobre o programa e a entrevista final, ambos realizados com os participantes do grupo experimental.

$\mathrm{Na}$ análise inferencial, serão apresentados os resultados referentes à homogenidade da amostra no tocante às variáveis sociodemográficas; a comparação do desempenho de cada variável de acordo com os instrumentos empregados para sua avaliação nas diferentes fases de aplicação (pré-teste, pósteste e reteste), considerando-se tanto as diferenças intragrupos quanto intergrupos. Por fim, serão apresentadas as análises entre as variáveis estudadas avaliadas por 
meio dos testes da primeira e da segunda baterias, a fim de verificar a transferência de aprendizagem.

\subsection{Análise descritiva dos dados}

\subsubsection{Homogenidade da amostra}

A fim de verificar a homogenidade da amostra, as variáveis sociodemográficas dos grupos controle e experimental foram agrupadas por categorias, quais sejam: idade (de 60 a 69 anos e de 70 anos ou mais), escolaridade (1a a $4^{a}$ série e $5^{\underline{a}}$ a $8^{\underline{a}}$ série), renda familiar (de 0 a 3 salários mínimos e de 4 a 6 salários mínimos) e classe econômica ( $A B$ e $C D E)$. O agrupamento foi necessário porque o teste estatístico utilizado para realizar a análise inferencial possuí a restrição de haver no mínimo cinco itens em cada categoria da variável para análise.

A Tabela 2 apresenta as variáveis sociodemográficas por agrupamento de categorias para ambos os grupos, controle e experimental. 
Tabela 2 - Porcentagem dos sujeitos da amostra por agrupamento das variáveis sociodemográficas, grupo controle $(n=32)$ e grupo experimental $(n=34)$.

\begin{tabular}{|c|c|c|c|}
\hline CATEGORIA & $\begin{array}{c}\text { CONTROLE } \\
\% \\
\end{array}$ & $\begin{array}{c}\text { EXPERIMENTAL } \\
\% \\
\end{array}$ & $\begin{array}{c}\text { TOTAL } \\
\% \\
\end{array}$ \\
\hline \multicolumn{4}{|l|}{ IDADE } \\
\hline 60 a 69 anos & 43,75 & 55,88 & 50,00 \\
\hline 70 anos ou + & 56,25 & 44,12 & 50,00 \\
\hline \multicolumn{4}{|l|}{ ESCOLARIDADE } \\
\hline 1a a 4a Serie Fundamental I & 68,75 & 55,88 & 62,12 \\
\hline 5a a 8 ${ }^{a}$ Serie Fundamental II & 31,25 & 44,12 & 37,88 \\
\hline \multicolumn{4}{|l|}{ RENDA FAMILIAR } \\
\hline 0 a 3 & 68,75 & 55,88 & 37,88 \\
\hline 4 a 6 & 31,25 & 44,12 & 62,12 \\
\hline \multicolumn{4}{|l|}{ CLASSE ECONÔMICA } \\
\hline $\mathrm{AB}$ & 43,75 & 61,76 & 53,03 \\
\hline $\mathrm{CDE}$ & 56,25 & 38,24 & 46,97 \\
\hline TOTAL GERAL & 100,00 & 100,00 & 100,00 \\
\hline
\end{tabular}

De acordo com a tabela acima, no tocante à variável idade, o grupo controle possui maior porcentagem na idade de 70 anos ou mais $(56,25 \%)$, enquanto que o grupo experimental a maior porcentagem encontra-se na idade de 60 a 69 anos (55,88\%). Em relação a variável escolaridade, em ambos os grupos (experimental e controle) observa-se uma maior porcentagem de sujeitos na $1^{\text {a }}$ a $4^{\text {a }}$ série do ensino fundamental I, $68,75 \%$ para o grupo controle e $55,88 \%$ o grupo experimental. Para a variável renda familiar, ambos os grupos têm a maior porcentagem na renda de zero a três salários mínimos, $68,75 \%$ para o grupo controle e $55,88 \%$ para o grupo experimental. Por fim, para a variável classe econômica a maior porcentagem está na classe $\operatorname{CDE}(56,25 \%)$ para o grupo controle e na classe $A B(61,76 \%)$ para 0 grupo experimental. 


\subsubsection{Resolução de problemas}

A variável resolução de problemas, como descrito anteriormente, foi avaliada pelo Teste Wisconsin de Classificação de Cartas - versão para idosos (WCST), tanto aplicado nas fases pré, pós e reteste para o grupo experimental e no pré e pósteste para o grupo controle, quanto pela Escala Wechsler Abreviada de Inteligência (WASI) - subteste Cubos no pós e reteste para o grupo experimental.

A Tabela 3 apresenta os dez indicadores interpretativos do teste WCST utilizados nesse estudo para ambos os grupos, nas diferentes fases do programa. 
Tabela 3 - Indicadores interpretativos do teste WCST nas diferentes fases do programa, grupo controle $(n=32)$ e grupo experimental $(n=34)$.

\begin{tabular}{|c|c|c|c|c|c|c|}
\hline Grupo & Fase & Média & DP & Mínimo & Mediana & Máximo \\
\hline \multicolumn{7}{|c|}{ INDICADOR INTERPRETATIVO: NÚMERO DE ENSAIOS ADMINISTRADOS } \\
\hline \multirow[t]{2}{*}{ Controle } & Pré-teste & 128,00 & 0,00 & 128,00 & 128,00 & 128,00 \\
\hline & Pós-teste & 126,53 & 5,85 & 101,00 & 128,00 & 128,00 \\
\hline \multirow[t]{3}{*}{ Experimental } & Pré-teste & 127,03 & 5,66 & 95,00 & 128,00 & 128,00 \\
\hline & Pós-teste & 117,15 & 16,12 & 73,00 & 128,00 & 128,00 \\
\hline & Reteste & 116,18 & 16,70 & 73,00 & 127,00 & 128,00 \\
\hline \multicolumn{7}{|c|}{ INDICADOR INTERPRETATIVO: NÚMERO TOTAL DE RESPOSTAS CORRETAS } \\
\hline \multirow[t]{2}{*}{ Controle } & Pré-teste & 57,59 & 17,80 & 23,00 & 60,00 & 84,00 \\
\hline & Pós-teste & 60,81 & 17,69 & 27,00 & 61,50 & 94,00 \\
\hline \multirow[t]{3}{*}{ Experimental } & Pré-teste & 66,06 & 15,39 & 35,00 & 65,50 & 97,00 \\
\hline & Pós-teste & 73,68 & 10,46 & 38,00 & 76,00 & 90,00 \\
\hline & Reteste & 79,12 & 7,85 & 60,00 & 80,00 & 90,00 \\
\hline \multicolumn{7}{|c|}{ INDICADOR INTERPRETATIVO: NÚMERO TOTAL DE ERROS } \\
\hline \multirow[t]{2}{*}{ Controle } & Pré-teste & 70,41 & 17,80 & 44,00 & 68,00 & 105,00 \\
\hline & Pós-teste & 65,72 & 20,19 & 21,00 & 66,50 & 101,00 \\
\hline \multirow[t]{3}{*}{ Experimental } & Pré-teste & 60,97 & 16,82 & 22,00 & 62,50 & 93,00 \\
\hline & Pós-teste & 43,47 & 18,00 & 9,00 & 44,00 & 90,00 \\
\hline & Reteste & 37,06 & 13,73 & 9,00 & 38,00 & 68,00 \\
\hline \multicolumn{7}{|c|}{ INDICADOR INTERPRETATIVO: RESPOSTAS PERSEVERATIVAS } \\
\hline \multirow[t]{2}{*}{ Controle } & Pré-teste & 57,47 & 40,08 & 11,00 & 42,00 & 127,00 \\
\hline & Pós-teste & 52,69 & 33,95 & 5,00 & 47,00 & 127,00 \\
\hline \multirow[t]{3}{*}{ Experimental } & Pré-teste & 32,35 & 16,97 & 10,00 & 30,00 & 69,00 \\
\hline & Pós-teste & 24,09 & 13,91 & 4,00 & 23,00 & 73,00 \\
\hline & Reteste & 21,00 & 9,38 & 4,00 & 21,00 & 40,00 \\
\hline \multicolumn{7}{|c|}{ INDICADOR INTERPRETATIVO: ERROS PERSEVERATIVOS } \\
\hline \multirow[t]{2}{*}{ Controle } & Pré-teste & 46,06 & 29,68 & 11,00 & 35,00 & 104,00 \\
\hline & Pós-teste & 42,09 & 24,82 & 5,00 & 36,50 & 99,00 \\
\hline \multirow[t]{3}{*}{ Experimental } & Pré-teste & 28,79 & 14,69 & 7,00 & 26,50 & 58,00 \\
\hline & Pós-teste & 21,59 & 11,15 & 4,00 & 21,00 & 56,00 \\
\hline & Reteste & 18,50 & 7,67 & 4,00 & 19,00 & 35,00 \\
\hline \multicolumn{7}{|c|}{ INDICADOR INTERPRETATIVO: ERROS NÃO PERSEVERATIVOS } \\
\hline \multirow[t]{2}{*}{ Controle } & Pré-teste & 24,41 & 16,16 & 1,00 & 27,00 & 54,00 \\
\hline & Pós-teste & 23,63 & 11,76 & 1,00 & 21,00 & 49,00 \\
\hline \multirow[t]{3}{*}{ Experimental } & Pré-teste & 32,18 & 13,46 & 9,00 & 30,50 & 68,00 \\
\hline & Pós-teste & 21,88 & 11,11 & 3,00 & 20,50 & 56,00 \\
\hline & Reteste & 18,56 & 8,95 & 4,00 & 19,00 & 41,00 \\
\hline
\end{tabular}

Continua. 
Continuação.

\begin{tabular}{lllllll}
\hline Grupo & Fase & Média & DP & Mínimo & Mediana & Máximo \\
\hline INDICADOR INTERPRETATIVO: RESPOSTAS DE NÍVEL CONCEITUAL & & & \\
\hline Controle & Pré-teste & 38,22 & 19,12 & 6,00 & 41,00 & 68,00 \\
& Pós-teste & 39,38 & 21,98 & 0,00 & 39,00 & 82,00 \\
\hline Experimental & Pré-teste & 44,76 & 20,55 & 11,00 & 43,00 & 83,00 \\
& Pós-teste & 59,76 & 13,02 & 13,00 & 63,50 & 75,00 \\
& Reteste & 66,59 & 9,74 & 35,00 & 68,50 & 82,00 \\
\hline INDICADOR INTERPRETATIVO: NÚMERO DE CATEGORIAS COMPLETADAS & & \\
\hline Controle & Pré-teste & 1,94 & 1,48 & 0,00 & 2,00 & 4,00 \\
& Pós-teste & 2,19 & 1,67 & 0,00 & 2,00 & 6,00 \\
\hline Experimental & Pré-teste & 2,21 & 1,81 & 0,00 & 2,00 & 6,00 \\
& Pós-teste & 4,50 & 1,80 & 0,00 & 5,00 & 6,00 \\
& Reteste & 4,82 & 1,47 & 1,00 & 5,50 & 6,00 \\
\hline \multirow{2}{*}{ INDICADOR INTERPRETATIVO: ENSAIOS PARA COMPLETAR A PRIMEIRA CATEGORIA } & \\
\hline Controle & Pré-teste & 54,50 & 49,42 & 1,00 & 30,00 & 129,00 \\
& Pós-teste & 41,91 & 46,05 & 10,00 & 18,50 & 129,00 \\
\hline Experimental & Pré-teste & 50,79 & 50,49 & 11,00 & 19,50 & 129,00 \\
& Pós-teste & 26,97 & 29,91 & 10,00 & 15,50 & 129,00 \\
& Reteste & 16,12 & 13,79 & 0,00 & 11,00 & 67,00 \\
\hline ExpiCADOR INTERPRETATIVO: FRACASSO EM MANTER O CONTEXTO & & \\
\hline Controle & Pré-teste & 0,97 & 1,03 & 0,00 & 1,00 & 3,00 \\
& Pós-teste & 1,19 & 1,15 & 0,00 & 1,00 & 3,00 \\
\hline \multirow{2}{*}{ Experimental } & Pré-teste & 1,56 & 1,08 & 0,00 & 1,00 & 4,00 \\
& Pós-teste & 1,06 & 1,28 & 0,00 & 1,00 & 6,00 \\
& Reteste & 1,29 & 1,24 & 0,00 & 1,00 & 4,00 \\
\hline
\end{tabular}

Devido ao grande número de informações constantes na tabela acima e visando facilitar a sua descrição, optou-se por subdividi-la em diferentes partes de acordo com o indicador interpretativo do teste em questão, os quais serão apresentados a seguir. Serão expostos os dados relacionados a cada indicador, tanto do grupo controle quanto do grupo experimental no pré, pós e reteste, seguidos de suas respectivas estatísticas descritivas: média, desvio padrão, mínimo, mediana e máximo. 
A Tabela 4 apresenta o primeiro indicador interpretativo: número de ensaios administrados.

Tabela 4 - Indicador interpretativo do teste WCST: número de ensaios administrados, grupo controle ( $n=32)$ e grupo experimental $(n=34)$.

\begin{tabular}{lllcccc}
\hline Grupo & Fase & Média & DP & Mínimo & Mediana & Máximo \\
\hline Controle & Pré-teste & 128,00 & 0,00 & 128,00 & 128,00 & 128,00 \\
& Pós-teste & 126,53 & 5,85 & 101,00 & 128,00 & 128,00 \\
\hline \multirow{2}{*}{ Experimental } & Pré-teste & 127,03 & 5,66 & 95,00 & 128,00 & 128,00 \\
& Pós-teste & 117,15 & 16,12 & 73,00 & 128,00 & 128,00 \\
& Reteste & 116,18 & 16,70 & 73,00 & 127,00 & 128,00 \\
\hline
\end{tabular}

O número de ensaios administrados refere-se à quantidade de cartas do baralho utilizadas pelo examinando durante a realização do teste. Observando a coluna Média dessa tabela, tem-se a menor média no grupo experimental, no reteste, de 116,18 , indicando o melhor desempenho neste indicador, uma vez que, quanto menor a média, menos cartas foram utilizadas para completar o teste e menos erros foram cometidos durante a sua realização. É preciso considerar, todavia, que o grau de dispersão dos valores em relação ao valor médio (desvio padrão) foi de 16,70, indicativo de alta dispersão.

Em relação ao pós-teste para ambos os grupos, a menor média foi a do grupo experimental, 117,15, que deve ser comparada à média de 126,53 do grupo controle. Nesta mesma fase, observa-se que o valor mínimo de cartas utilizadas no teste foi menor no grupo experimental, 73,00, em relação ao grupo controle cujo valor mínimo foi de 101,00 .

A Tabela 5 apresenta o segundo indicador interpretativo para o teste WCST: 0 número total de respostas corretas. 
Tabela 5 - Indicador interpretativo do teste WCST: número total de respostas corretas, grupo controle $(n=32)$ e grupo experimental $(n=34)$.

\begin{tabular}{llccccc}
\hline Grupo & Fase & Média & DP & Mínimo & Mediana & Máximo \\
\hline Controle & Pré-teste & 57,59 & 17,80 & 23,00 & 60,00 & 84,00 \\
& Pós-teste & 60,81 & 17,69 & 27,00 & 61,50 & 94,00 \\
\hline \multirow{2}{*}{ Experimental } & Pré-teste & 66,06 & 15,39 & 35,00 & 65,50 & 97,00 \\
& Pós-teste & 73,68 & 10,46 & 38,00 & 76,00 & 90,00 \\
& Reteste & 79,12 & 7,85 & 60,00 & 80,00 & 90,00 \\
\hline
\end{tabular}

Esse indicador refere-se ao número de acertos. Nessa tabela, observa-se que o maior número de acertos ocorreu no reteste do grupo experimental, média de 79,12 juntamente com o menor desvio padrão, 7,85. Em relação ao pós-teste, o grupo experimental também obteve a média mais alta, 73,68, comparativamente ao grupo controle, 60,81, embora a medida do grau de dispersão dos valores em relação ao valor médio (desvio padrão) tenha sido alta em ambos os grupos: 10,46 e 17,69, respectivamente. Na comparação entre as médias dos grupos no pré-teste, verifica-se que o grupo experimental obteve a maior média de acertos em relação ao grupo controle: 66,06 e 57,59, respectivamente. O valores mínimo e máximo de acertos desse tempo foram melhores no grupo experimental quando comparados ao grupo controle. Ou seja, o grupo experimental teve o mínimo de 35 e o máximo de 97 cartas corretas comparados ao mínimo de 23 e o máximo de 84 para o grupo controle.

De maneira geral, pode-se inferir que o grupo experimental teve melhor desempenho no teste em relação ao grupo controle, porém outros indicadores interpretativos devem ser avaliados.

A Tabela 6 apresenta o terceiro indicador interpretativo: número total de erros. 
Tabela 6 - Indicador interpretativo do teste WCST: número total de erros, grupo controle $(n=32)$ e grupo experimental $(n=34)$.

\begin{tabular}{llccccc}
\hline Grupo & Fase & Média & DP & Mínimo & Mediana & Máximo \\
\hline Controle & Pré-teste & 70,41 & 17,80 & 44,00 & 68,00 & 105,00 \\
& Pós-teste & 65,72 & 20,19 & 21,00 & 66,50 & 101,00 \\
\hline \multirow{2}{*}{ Experimental } & Pré-teste & 60,97 & 16,82 & 22,00 & 62,50 & 93,00 \\
& Pós-teste & 43,47 & 18,00 & 9,00 & 44,00 & 90,00 \\
& Reteste & 37,06 & 13,73 & 9,00 & 38,00 & 68,00 \\
\hline
\end{tabular}

É possível observar na tabela acima, para o indicador interpretativo número total de erros, que as menores médias foram as do grupo experimental em todas as fases em que o teste foi aplicado, indicando que quanto menor o número de erros cometidos durante a execução do teste, melhor o desempenho do grupo.

Em relação ao pré-teste, o grupo controle obteve a média de 70,41 enquanto que o grupo experimental, nesta mesma fase, obteve a média de 60,97. Os indicadores do limite mínimo e máximo de erros, para esta fase, também foram menores para o grupo experimental: mínimo de 44,00 e máximo de 105,00 para o grupo controle; mínimo de 22,00 e máximo de 93,00 para o grupo experimental.

No pós-teste, o grupo experimental alcançou a menor média, 43,47, quando comparado ao grupo controle que atingiu a média de 65,72 . O valor relativo ao mínimo de erros obtido pelo grupo experimental no pós-teste foi menor em relação ao grupo controle, 9,00 para o grupo experimental e 21,00 para o grupo controle.

Dentre todas as fases do grupo experimental, o reteste foi a que apresentou a menor média: 37,06 , comparada a 43,47 do pós-teste e a 60,97 do pré-teste. Embora o total mínimo de erros cometidos no teste tenha sido 9,00, tanto para o pós-teste quanto para o reteste, o máximo teve uma diminuição considerável, de 90,00 do pós-teste para 68,00 do reteste. 
A Tabela 7 apresenta o quarto indicador interpretativo para o teste WCST: respostas perseverativas.

Tabela 7 - Indicador interpretativo do teste WCST: respostas perseverativas, grupo controle $(n=32)$ e grupo experimental $(n=34)$.

\begin{tabular}{llccccc}
\hline Grupo & Fase & Média & DP & Mínimo & Mediana & Máximo \\
\hline Controle & Pré-teste & 57,47 & 40,08 & 11,00 & 42,00 & 127,00 \\
& Pós-teste & 52,69 & 33,95 & 5,00 & 47,00 & 127,00 \\
\hline \multirow{2}{*}{ Experimental } & Pré-teste & 32,35 & 16,97 & 10,00 & 30,00 & 69,00 \\
& Pós-teste & 24,09 & 13,91 & 4,00 & 23,00 & 73,00 \\
& Reteste & 21,00 & 9,38 & 4,00 & 21,00 & 40,00 \\
\hline
\end{tabular}

Como apresentado no capitulo anterior (Capítulo 3 - Método), as respostas perseverativas são respostas em que há a fixação de cartas num mesmo critério. Desta forma, quanto maior for a média para este indicador interpretativo, maior a falta de flexibilidade do sujeito em buscar diferentes alternativas para a solução do problema apresentado durante o teste.

Observando a coluna Média dessa tabela, tem-se a menor média para o grupo experimental no reteste, 21,00, menor desvio padrão, 9,38, e os menores valores para os limites mínimo e máximo, 4,00 e 40,00, respectivamente.

Em relação ao pós-teste para ambos os grupos, a menor média foi a do grupo experimental, 24,09, comparativamente à média de 52,69 do grupo controle. Nesta mesma fase, observa-se que os menores valores para o valor mínimo e o valor máximo de respostas perseverativas foram também os do grupo experimental: 4,00 e 73,00 respectivamente, comparando-os a 5,00 e 127,00 do grupo controle.

No pré-teste, a menor média foi a do grupo experimental, 32,35, em comparação à média de 57,47 do grupo controle. 
Pelos dados apresentados na Tabela 7 , verifica-se que, em relação ao indicador interpretativo respostas perseverativas, o grupo experimental obteve os menores resultados em todas as fases do estudo quando comparado ao grupo controle.

A Tabela 8 apresenta o quinto indicador interpretativo para o teste WCST: erros perseverativos.

Tabela 8 - Indicador interpretativo do teste WCST: erros perseverativos, grupo controle $(n=32)$ e grupo experimental $(n=34)$.

\begin{tabular}{llccccc}
\hline Grupo & Fase & Média & DP & Mínimo & Mediana & Máximo \\
\hline Controle & Pré-teste & 46,06 & 29,68 & 11,00 & 35,00 & 104,00 \\
& Pós-teste & 42,09 & 24,82 & 5,00 & 36,50 & 99,00 \\
\hline \multirow{2}{*}{ Experimental } & Pré-teste & 28,79 & 14,69 & 7,00 & 26,50 & 58,00 \\
& Pós-teste & 21,59 & 11,15 & 4,00 & 21,00 & 56,00 \\
& Reteste & 18,50 & 7,67 & 4,00 & 19,00 & 35,00 \\
\hline
\end{tabular}

O indicador interpretativo erros perseverativos está associado à resposta perseverativa, sendo definido como ensaios em que o participante classificou a carta do baralho com base no princípio da perseverança e não em relação ao princípio de classificação. Quanto maior o número de erros perseverativos, menos satisfatório o desempenho do grupo em relação ao aspecto avaliado.

De acordo com a tabela acima, os menores resultados foram os do grupo experimental em todas as fases em que o teste foi aplicado. A melhor média foi a do reteste,18,50, com a menor dispersão dos valores em relação à média (DP de 7,67) e os menores limites entre o mínimo e máximo 4,00 e 35,00, respectivamente.

Comparando-se os resultados do pós-teste entre os dois grupos, verifica-se que a menor média foi a do grupo experimental, 21,59, em relação a 42,09 do grupo 
controle. No pré-teste, o grupo experimental também apresentou o menor resultado o para este indicador, média de 28,79 , quando comparado à média de 46,06 do grupo controle.

A Tabela 9 apresenta o sexto indicador interpretativo para o teste WCST: erros não perseverativos.

Tabela 9 - Indicador interpretativo do teste WCST: erros não perseverativos, grupo controle $(n=32)$ e grupo experimental $(n=34)$.

\begin{tabular}{llccccc}
\hline Grupo & Fase & Média & DP & Mínimo & Mediana & Máximo \\
\hline Controle & Pré-teste & 24,41 & 16,16 & 1,00 & 27,00 & 54,00 \\
& Pós-teste & 23,63 & 11,76 & 1,00 & 21,00 & 49,00 \\
\hline \multirow{2}{*}{ Experimental } & Pré-teste & 32,18 & 13,46 & 9,00 & 30,50 & 68,00 \\
& Pós-teste & 21,88 & 11,11 & 3,00 & 20,50 & 56,00 \\
& Reteste & 18,56 & 8,95 & 4,00 & 19,00 & 41,00 \\
\hline
\end{tabular}

O indicador interpretativo erros não perseverativos corresponde às respostas erradas que não preenchem os critérios de resposta perseverativa. Da mesma forma que o indicador interpretativo erro perseverativo, quanto menor o valor apresentado pelo grupo, melhor é o desempenho no teste para este item avaliado.

Ao observar as médias dentre as apresentadas na tabela acima, verifica-se um regressão das médias do grupo experimental em todas as fases em que o teste foi aplicado: pré-teste 32,18 , pós-teste 21,88 e reteste 18,56 , indicando que o grupo obteve o melhor desempenho em todas as fases. Porém, no pré-teste, observa-se a menor média para o grupo controle 24,41 quando comparada ao pré-teste do grupo experimental, 32,18 .

A Tabela 10 apresenta o sétimo indicador interpretativo para o teste WCST: respostas de nível conceitual. 
Tabela 10 - Indicador interpretativo do teste WCST: respostas de nível conceitual, grupo controle $(n=32)$ e grupo experimental $(n=34)$.

\begin{tabular}{llccccc}
\hline Grupo & Fase & Média & DP & Mínimo & Mediana & Máximo \\
\hline Controle & Pré-teste & 38,22 & 19,12 & 6,00 & 41,00 & 68,00 \\
& Pós-teste & 39,38 & 21,98 & 0,00 & 39,00 & 82,00 \\
\hline \multirow{2}{*}{ Experimental } & Pré-teste & 44,76 & 20,55 & 11,00 & 43,00 & 83,00 \\
& Pós-teste & 59,76 & 13,02 & 13,00 & 63,50 & 75,00 \\
& Reteste & 66,59 & 9,74 & 35,00 & 68,50 & 82,00 \\
\hline
\end{tabular}

O indicador interpretativo respostas de nível conceitual representa a compreensão dos princípios corretos de classificação ocorridas a partir de uma sequência ininterrupta de três ou mais acertos. Neste sentido, quanto maior o número de respostas conceituais, melhor é o desempenho do grupo no teste para a avaliação deste item.

Ao analisar os dados da tabela acima, observa-se que há um aumento progressivo do pré-teste para o reteste no grupo experimental, com médias de 44,76, 59,76 e 66,59 , respectivamente.

Em relação ao grupo controle, observa-se uma progressão de apenas 1,16 pontos na média do pré-teste para o pós-teste. Nota-se que, para este grupo, no pós-teste houve examinandos que não pontuaram respostas de nível conceitual, pois o valor mínimo apresentado foi o de 0,00 . Por sua vez, o grupo experimental no reteste obteve o valor mínimo de 35,00 (o maior valor dentre os valores mínimos) o que indica que este grupo apresentou um mínimo de 35 respostas em nível conceitual, número bem superior aos das duas fases anteriores.

A Tabela 11 apresenta o oitavo indicador interpretativo para o teste WCST: número de categorias completadas. 
Tabela 11 - Indicador interpretativo do teste WCST: número de categorias completadas, grupo controle $(n=32)$ e grupo experimental $(n=34)$.

\begin{tabular}{llccccc}
\hline Grupo & Fase & Média & DP & Mínimo & Mediana & Máximo \\
\hline Controle & Pré-teste & 1,94 & 1,48 & 0,00 & 2,00 & 4,00 \\
& Pós-teste & 2,19 & 1,67 & 0,00 & 2,00 & 6,00 \\
\hline \multirow{2}{*}{ Experimental } & Pré-teste & 2,21 & 1,81 & 0,00 & 2,00 & 6,00 \\
& Pós-teste & 4,50 & 1,80 & 0,00 & 5,00 & 6,00 \\
& Reteste & 4,82 & 1,47 & 1,00 & 5,50 & 6,00 \\
\hline
\end{tabular}

Durante o teste, quando dez cartas do baralho são classificadas corretamente pelo examinando de acordo com o princípio estabelecido, é completada uma categoria. Quanto maior o número de categorias completadas no teste, melhor é o desempenho do grupo em relação a esse item. O teste encerra-se quando seis categorias foram completadas.

Analisando as informações demonstradas na tabela acima, observa-se que o grupo experimental alcançou as maiores médias nas três fases do estudo, quando comparado ao grupo controle, indicando haver um aumento progressivo das médias para este grupo. Todavia, em relação aos valores mínimo e máximo para a fase pósteste, os grupos controle e experimental, obtiveram os mesmos resultados: mínimo de 0,00 e máximo de 6,00. Como no reteste do grupo experimental o valor mínimo foi de 1,00 e o máximo de 6,00, verifica-se que todos os examinandos neste grupo completaram ao menos uma categoria.

A Tabela 12 apresenta o nono indicador interpretativo para o teste WCST: ensaios para completar a primeira categoria. 
Tabela 12 - Indicador interpretativo do teste WCST: ensaios para completar a primeira categoria, grupo controle $(n=32)$ e grupo experimental $(n=34)$.

\begin{tabular}{llccccc}
\hline Grupo & Fase & Média & DP & Mínimo & Mediana & Máximo \\
\hline Controle & Pré-teste & 54,50 & 49,42 & 10,00 & 30,00 & 129,00 \\
& Pós-teste & 41,91 & 46,05 & 10,00 & 18,50 & 129,00 \\
\hline \multirow{2}{*}{ xxperimental } & Pré-teste & 50,79 & 50,49 & 11,00 & 19,50 & 129,00 \\
& Pós-teste & 26,97 & 29,91 & 10,00 & 15,50 & 129,00 \\
& Reteste & 16,12 & 13,79 & 10,00 & 11,00 & 67,00 \\
\hline
\end{tabular}

A primeira categoria a ser completada no teste é a categoria Cor. Assim, esse indicador refere-se a quantidade de cartas utilizadas pelo examinando até a conclusão da primeira categoria de classificação. Quanto menor os números de ensaios para completar a primeira categoria, melhor o desempenho do grupo no teste para este item, sendo que o número mínimo é de 10 ensaios.

Conforme é possível analisar na Tabela 12, a menor média para esse indicador foi a do grupo experimental no reteste, 16,12; seguida de 26,97 para o grupo experimental no pós-teste; 41,91 para o grupo controle no pós-teste; 50,79 para o grupo experimental no pré-teste e, por final, 54,50 para o grupo controle no pré-teste. Os limites mínimo praticamente foram iguais para os dois grupos em todos as fases do teste, porém nota-se que o menor valor máximo foi obtido pelo grupo experimental no tempo reteste, 67,00 .

De maneira geral, observa-se que o grupo experimental teve melhor desempenho em relação a este indicador.

A Tabela 13 apresenta o décimo indicador interpretativo para o teste WCST: fracasso em manter o contexto. 
Tabela 13 - Indicador interpretativo do teste WCST: fracasso em manter o contexto, grupo controle $(n=32)$ e grupo experimental $(n=34)$

\begin{tabular}{llccccc}
\hline Grupo & Fase & Média & DP & Mínimo & Mediana & Máximo \\
\hline Controle & Pré-teste & 0,97 & 1,03 & 0,00 & 1,00 & 3,00 \\
& Pós-teste & 1,19 & 1,15 & 0,00 & 1,00 & 3,00 \\
\hline \multirow{2}{*}{ Experimental } & Pré-teste & 1,56 & 1,08 & 0,00 & 1,00 & 4,00 \\
& Pós-teste & 1,06 & 1,28 & 0,00 & 1,00 & 6,00 \\
& Reteste & 1,29 & 1,24 & 0,00 & 1,00 & 4,00 \\
\hline
\end{tabular}

O indicador interpretativo fracasso em manter o contexto refere-se a um erro inesperado cometido pelo examinando em meio a uma sequência de acertos. Esse erro é contabilizado quando o examinando acumula cinco ou mais acertos seguidos em um mesmo critério de classificação.

Ao analisar a tabela, verifica-se que o grupo controle apresenta a menor média dentre todas as médias da tabela: 0,97 no pré-teste. Esse fato indica que, nesse grupo, pode ter ocorrido menor quantidade de ensaios corretos, principalmente menores que cinco, o que inviabilizou a contagem desse indicador.

É importante salientar que os indicadores interpretativos para o teste WCST não podem ser analisados isoladamente para inferir o desempenho do grupo. Desta forma, mediante a análise dos indicadores apresentados nesta seção, inferimos que o grupo experimental obteve os melhores resultados neste indicador.

A Tabela 14 apresenta as médias obtidas no segundo teste utilizado para avaliar a variável resolução de problemas, o subteste Cubos da Escala Wechsler Abreviada de Inteligência (WASI) no pós e reteste do grupo experimental. 
Tabela 14 - Médias das pontuações do subteste Cubos da Escala Wechsler Abreviada de Inteligência, grupo experimental $(n=34)$.

\begin{tabular}{llccccc}
\hline Grupo & Fase & Média & DP & Mínimo & Mediana & Máximo \\
\hline \multirow{2}{*}{ Experimental } & Pós-teste & 30,21 & 10,23 & 6,00 & 32,00 & 49,00 \\
& Reteste & 33,76 & 8,70 & 15,00 & 36,00 & 48,00 \\
\hline
\end{tabular}

Como descrito no capítulo 3 (Método) desse trabalho, o escore do teste WASI - subteste Cubos refere-se ao tempo gasto pelo examinando para reproduzir modelos corretos em um tempo limite determinado. O tempo é calculado em segundos e convertido em uma pontuação pré-estabelecida. Desta forma, quanto menor o tempo usado para montagem do modelo, maior é a pontuação no teste.

Segundo a tabela acima, pode-se verificar que a maior média foi obtida pelo grupo na fase reteste, 33,76 comparada à média do pós-teste, 30,21. O limite mínimo da pontuação foi maior no reteste, 15,00 em relação a 6,00 do pós-teste. Porém, o valor máximo foi maior no tempo pós-teste, 49,00 com a diferença de 1,00 ponto para o tempo reteste, 48,00 . Os dados indicam que houve um progressão de acertos do pós-teste para o reteste.

\subsubsection{Memória}

A variável memória foi avaliada pela escala ACE-R, subescala memória, pelo TMLP e pelo Teste de Repetição de Pseudopalavras nas fases pré, pós e reteste para o grupo experimental e nas fases pré e pós-teste para o grupo controle. Foi também aplicado o teste de extensão de dígitos em ordem direta e em ordem inversa da Escala de Memória de Wechsler de Inteligência para Adultos WAIS-III nas fases pós e reteste para o grupo experimental. 
A Tabela 15 apresenta as médias das pontuações da subescala memória da escala ACE-R.

Tabela 15 - Médias das pontuações na escala ACE-R, subescala Memória, grupo controle $(n=32)$ e grupo experimental $(n=34)$.

\begin{tabular}{lllcccc}
\hline Grupo & Fase & Média & DP & Mínimo & Mediana & Máximo \\
\hline Controle & Pré-teste & 17,91 & 4,18 & 10,00 & 17,00 & 26,00 \\
& Pós-teste & 17,97 & 4,04 & 12,00 & 18,00 & 26,00 \\
\hline \multirow{2}{*}{ Experimental } & Pré-teste & 18,18 & 3,20 & 13,00 & 17,50 & 26,00 \\
& Pós-teste & 20,68 & 3,06 & 15,00 & 20,00 & 26,00 \\
& Reteste & 20,35 & 2,57 & 15,00 & 20,00 & 26,00 \\
\hline
\end{tabular}

O escore máximo que pode ser obtido na escala ACE-R, subescala memória, é de 26 pontos. De acordo com os dados da Tabela 15, observa-se que, para o grupo controle a média da variável memória não teve alterações do pré-teste para o pós-teste: de 17,91 no pré-teste para 17,97 no pós-teste. Já para o grupo experimental, a média variou de 18,18 no pré-teste para 20,68 no pós-teste, com um leve declínio no reteste. Em relação aos limites das médias, o máximo de 26,00 foi obtido por todos os grupos em todas as fases, sendo esta a pontuação máxima nesse subteste.

A Tabela 16 apresenta as médias das pontuações no teste TMLP.

Tabela 16 - Médias das pontuações no teste TMLP, grupo controle $(n=32)$ e grupo experimental $(n=34)$.

\begin{tabular}{llccccc}
\hline Grupo & Fase & Média & DP & Mínimo & Mediana & Máximo \\
\hline Controle & Pré-teste & 15,31 & 3,74 & 10,00 & 15,00 & 26,00 \\
& Pós-teste & 14,56 & 4,56 & 8,00 & 14,50 & 25,00 \\
\hline \multirow{2}{*}{ Experimental } & Pré & 16,29 & 3,83 & 7,00 & 17,00 & 22,00 \\
& Pós-teste & 16,71 & 3,33 & 9,00 & 17,00 & 24,00 \\
& Reteste & 18,12 & 3,28 & 12,00 & 17,50 & 24,00 \\
\hline
\end{tabular}


O teste memória de lista de palavras é um teste cuja pontuação máxima é de 30 pontos, somando-se as pontuações obtidas nas três tentativas do teste. Neste teste, as maiores médias foram as do grupo experimental nas três fases: 18,12 no reteste; 16,71 no pós-teste; e 16,29 no pré-teste. Para o grupo controle, a média do pré-teste foi de 15,31, com um leve decréscimo no pós-teste (média de 14,56). Comparando-se os valores mínimo e máximo verifica-se que a maior pontuação no teste foi a do grupo controle no pré-teste, com o limite máximo de 26,00, e a menor pontuação foi a do grupo experimental no pré-teste com o limite mínimo de 7,00. Observa-se que o grupo experimental teve um melhor desempenho em relação ao de controle, porém as pontuações para ambos os grupos, tais como avaliadas pela média, não apresentam grandes diferenças.

A Tabela 17 apresenta as médias das pontuações no Teste de Repetição de Pseudopalavras.

Tabela 17 - Médias das pontuações no Teste de Repetição de Pseudopalavras, grupo controle $(n=32)$ e grupo experimental $(n=34)$.

\begin{tabular}{llccccc}
\hline Grupo & Fase & Média & DP & Mínimo & Mediana & Máximo \\
\hline Controle & Pré-teste & 34,22 & 5,01 & 22,00 & 36,00 & 40,00 \\
& Pós-teste & 31,75 & 6,37 & 15,00 & 32,50 & 40,00 \\
\hline \multirow{2}{*}{ Experimental } & Pré-teste & 32,85 & 6,13 & 13,00 & 34,00 & 40,00 \\
& Pós-teste & 34,50 & 4,98 & 19,00 & 36,00 & 40,00 \\
& Reteste & 36,26 & 4,68 & 24,00 & 38,00 & 40,00 \\
\hline
\end{tabular}

O teste de repetição de pseudopalavras tem pontuação máxima de 40 pontos. Sendo assim, quanto maior o número de pontos, melhor o desempenho no teste. De acordo com os dados apresentados na tabela acima, observa-se que o grupo experimental teve um aumento progressivo do pré-teste para o reteste com as médias de: pré-teste 32,85; pós-teste 34,50 e reteste 36,26 . Vale ressaltar que, no 
reteste, o desempenho atingiu 90,65\%, da pontuação máxima. Para o grupo controle, o desempenho do teste foi decrescente, ou seja, a média no pré-teste foi de 34,22 e caiu no pós-teste para 31,75 .

A Tabela 18 registra as médias das pontuações no teste extensão de dígitos em ordem direta e em ordem inversa da Escala de Memória Wechsler de Inteligência para Adultos (WAIS-III), aplicado no grupo experimental.

Tabela 18 - Médias no teste extensão de dígitos em ordem direta e em ordem inversa da escala WAIS-III, grupo experimental $(n=34)$.

\begin{tabular}{llccccc}
\hline Grupo & Fase & Média & DP & Mínimo & Mediana & Máximo \\
\hline \multirow{2}{*}{ Experimental } & Pós-teste & 9,47 & 1,46 & 6,00 & 10,00 & 13,00 \\
& Reteste & 10,85 & 1,73 & 7,00 & 11,00 & 15,00 \\
\hline
\end{tabular}

A pontuação para o teste de extensão de dígitos é o somatório das pontuações das duas provas aplicadas durante a sua execução (ordem direta e ordem inversa). O escore máximo para este teste é o de 17 pontos. Na tabela acima, observa-se que a maior média foi obtida pelo grupo experimental no reteste $(10,85)$ representando $63,82 \%$ de desempenho neste teste, na comparação com o pósteste $(9,47)$ o que representou $55,71 \%$ de desempenho no teste.

\subsubsection{Atenção e Concentração}

A variável atenção e concentração, foi avaliada pela escala $A C E-R$, subescala atenção e orientação, e pelo teste de Trilhas partes A e B nas fases pré, pós e reteste para o grupo experimental e nas fases pré e pós-teste para o grupo controle; e pela Bateria Psicológica para Avaliação da Atenção (BPA) nas fases pós e reteste para o grupo experimental. 
A Tabela 19 apresenta as médias das pontuações da subescala atenção e orientação da escala ACE-R.

Tabela 19 - Médias das pontuações na escala ACE-R, subescala Atenção e Orientação, grupo controle ( $n=32)$ e grupo experimental $(n=34)$.

\begin{tabular}{llccccc} 
Grupo & Fase & Média & DP & Mínimo & Mediana & Máximo \\
\hline Controle & Pré-teste & 16,47 & 1,32 & 14,00 & 16,00 & 18,00 \\
& Pós-teste & 15,63 & 1,43 & 13,00 & 16,00 & 18,00 \\
\hline \multirow{2}{*}{ Experimental } & Pré-teste & 16,59 & 1,05 & 15,00 & 17,00 & 18,00 \\
& Pós-teste & 17,12 & 0,73 & 16,00 & 17,00 & 18,00 \\
& Reteste & 17,65 & 0,49 & 17,00 & 18,00 & 18,00 \\
\hline
\end{tabular}

A subescala atenção e orientação do ACE-R tem escore máximo de 18 pontos. Sendo assim, quanto maior o número de pontos, melhor o desempenho do grupo no teste. De acordo com os dados apresentados na tabela acima, observa-se que o grupo experimental teve um aumento progressivo do pré-teste para o reteste com as médias de: pré-teste 16,59; pós-teste 17,12 e reteste 17,65. É possível considerar que no reteste o desempenho foi de $98,06 \%$, atingindo quase que a pontuação máxima de 18 pontos. Para o grupo controle, o desempenho do teste foi decrescente, ou seja, a média no pré-teste foi de 16,47 e caiu no pós-teste para 15,63 .

A Tabela 20 apresenta as médias das pontuações na categoria tempo e erro para o teste Trilhas parte A. 
Tabela 20 - Médias das pontuações para erros e tempo no teste Trilhas parte A, grupo controle $(n=32)$ e grupo experimental $(n=34)$.

\begin{tabular}{|c|c|c|c|c|c|c|c|}
\hline Categoria & Grupo & Fase & Média & DP & Mínimo & Mediana & Máximo \\
\hline \multirow{5}{*}{ ERROS } & Controle & Pré-teste & 0,72 & 1,63 & 0,00 & 0,00 & 9,00 \\
\hline & & Pós-teste & 1,53 & 2,79 & 0,00 & 0,00 & 13,00 \\
\hline & Experimental & Pré-teste & 0,71 & 1,43 & 0,00 & 0,00 & 5,00 \\
\hline & & Pós-teste & 0,21 & 0,54 & 0,00 & 0,00 & 2,00 \\
\hline & & Reteste & 0,12 & 0,33 & 0,00 & 0,00 & 1,00 \\
\hline \multirow{5}{*}{$\begin{array}{l}\text { TEMPO DE } \\
\text { EXECUÇÃO }\end{array}$} & Controle & Pré-teste & 67,69 & 24,28 & 23,00 & 68,00 & 139,00 \\
\hline & & Pós-teste & 71,19 & 34,70 & 30,00 & 65,50 & 181,00 \\
\hline & Experimental & Pré-teste & 55,09 & 17,91 & 30,00 & 50,50 & 97,00 \\
\hline & & Pós-teste & 47,38 & 15,18 & 23,00 & 44,50 & 95,00 \\
\hline & & Reteste & 46,88 & 18,02 & 24,00 & 42,00 & 98,00 \\
\hline
\end{tabular}

A categoria Erros indica o número de erros cometidos pelos grupos nas diferentes fases do teste e a categoria Tempo de Execução indica o tempo, em segundos, no qual o teste foi realizado pelos grupos em suas diferentes fases. Assim, quanto menor o número de erros e o tempo de execução no teste, melhor é o desempenho do grupo.

De acordo com os dados apresentados na tabela acima, observa-se que o grupo experimental teve uma diminuição da pontuação do pré-teste para o reteste em relação a categoria Erros com as seguintes médias: pré-teste 0,71; pós-teste 0,21 e reteste 0,12 . Para o grupo controle, o desempenho do teste foi crescente, ou seja, a média no pré-teste foi de 0,72 e aumentou no pós-teste para 1,53. Assim, para a categoria Erros o grupo experimental apresentou melhor desempenho em relação ao grupo controle.

Para a categoria Tempo de Execução, o grupo experimental também apresentou melhor desempenho, uma vez que houve uma redução no tempo de execução nas três fases do teste: pré-teste 55,09; pós-teste 47,38 e reteste 46,88. Em relação ao grupo controle, houve um progressão do tempo de execução do préteste $(67,62)$ para o pós-teste $(71,19)$. 
A Tabela 21 apresenta as médias das pontuações na categoria tempo e erro para o teste Trilhas parte B.

Tabela 21 - Médias das pontuações para erros e tempo de execução no teste Trilhas parte $B$, grupo controle ( $n=32)$ e grupo experimental $(n=34)$.

\begin{tabular}{|c|c|c|c|c|c|c|c|}
\hline Categoria & Grupo & Fase & Média & DP & Mínimo & Mediana & Máximo \\
\hline \multirow{5}{*}{ ERROS } & Controle & Pré-teste & 11,19 & 7,62 & 0,00 & 11,50 & 24,00 \\
\hline & & Pós-teste & 10,13 & 6,93 & 0,00 & 10,50 & 22,00 \\
\hline & Experimental & Pré-teste & 9,62 & 7,01 & 0,00 & 10,00 & 22,00 \\
\hline & & Pós-teste & 4,82 & 4,96 & 0,00 & 3,50 & 17,00 \\
\hline & & Reteste & 3,53 & 4,23 & 0,00 & 2,00 & 13,00 \\
\hline \multirow{5}{*}{$\begin{array}{l}\text { TEMPO DE } \\
\text { EXECUÇÃO }\end{array}$} & Controle & Pré-teste & 212,00 & 110,38 & 76,00 & 186,50 & 552,00 \\
\hline & & Pós-teste & 207,88 & 104,44 & 65,00 & 189,50 & 439,00 \\
\hline & Experimental & Pré-teste & 201,65 & 92,21 & 68,00 & 181,00 & 450,00 \\
\hline & & Pós-teste & 143,21 & 58,50 & 51,00 & 148,50 & 297,00 \\
\hline & & Reteste & 141,41 & 52,11 & 51,00 & 141,00 & 251,00 \\
\hline
\end{tabular}

$\mathrm{Na}$ tabela acima, observa-se que ambos os grupos apresentaram reduções nas pontuações da categoria Erros e Tempo de Execução. Porém, o grupo experimental revela melhor desempenho em face da obtenção das menores médias em relação ao grupo controle nas três fases da aplicação do teste.

É importante salientar que, para análise do desempenho do grupo no teste Trilhas (A e B), devemos considerar o tempo de execução e o número de erros conjuntamente, mas, para efeito descritivo, as duas categorias foram separadas.

A Tabela 22 apresenta as médias das pontuações na Bateria Psicológica para Avaliação da Atenção (BPA): atenção geral, atenção concentrada, atenção dividida e atenção alternada; nas fases pós e reteste para o grupo experimental. 
Tabela 22 - Médias das pontuações na Bateria Psicológica para Avaliação da Atenção (BPA): atenção geral, atenção concentrada, atenção dividida e atenção alternada, grupo experimental $(n=34)$.

\begin{tabular}{lllcccc}
\hline Categoria & Fase & Média & DP & Mínimo & Mediana & Máximo \\
\hline Geral & Pós-teste & 171,21 & 53,59 & 66,00 & 179,00 & 321,00 \\
& Reteste & 198,91 & 41,00 & 132,00 & 201,00 & 271,00 \\
Concentrada & Pós-teste & 74,59 & 17,74 & 39,00 & 77,50 & 112,00 \\
& Reteste & 87,29 & 15,30 & 56,00 & 89,00 & 117,00 \\
Dividida & Pós-teste & 40,35 & 23,92 & $-16,00$ & 42,00 & 99,00 \\
& Reteste & 50,06 & 20,05 & 10,00 & 49,50 & 89,00 \\
Alternada & Pós-teste & 56,26 & 23,19 & 16,00 & 53,00 & 110,00 \\
& Reteste & 61,56 & 20,49 & 27,00 & 58,50 & 110,00 \\
\hline
\end{tabular}

A pontuação da atenção geral resulta do somatório dos testes da atenção concentrada, dividida e alternada na BPA. Assim, quanto maior a pontuação, melhor o desempenho do grupo no teste. Analisando a tabela acima, pode-se verificar que a maior média da atenção geral foi obtida pelo grupo no reteste, 198,91 comparada à média do pós-teste, 171,21. Pode-se verificar que as médias dos tempos estão próximas aos valores da mediana: 179,00 para o pós-teste e 201,00 para o reteste, indicando que a distribuição das pontuações no teste nas duas fases estão no centro da distribuição dos dados. No tocante aos tipos de atenção (concentrada, dividida e alternada), também houve aumento das médias da fase pós para o reteste.

\subsubsection{Escala de Autoestima}

A escala de autoestima foi aplicada apenas no grupo experimental nas três fases do programa: pré, pós e reteste. Quanto maior o valor obtido em sua pontuação, maior é a autoestima do idoso participante, sendo que a pontuação máxima a ser obtida é a de 40 pontos. 
A Tabela 23 apresenta as médias das pontuações na escala de autoestima, nas três fases do programa.

Tabela 23 - Médias das pontuações na escala de autoestima, grupo experimental $(n=34)$.

\begin{tabular}{llccccc}
\hline Grupo & Fase & Média & DP & Mínimo & Mediana & Máximo \\
\hline Experimental & Pré-teste & 32,56 & 3,72 & 26,00 & 32,50 & 40,00 \\
& Pós-teste & 33,47 & 3,84 & 28,00 & 33,50 & 40,00 \\
& Reteste & 34,88 & 3,28 & 28,00 & 36,00 & 39,00 \\
\hline
\end{tabular}

$\mathrm{Na}$ tabela acima, observa-se que a maior média foi a do reteste, 34,88 , comparativamente ao pós-teste, 33,47, e ao pré-teste, 32,56, indicando uma melhoria da autoestima do início para o final do programa.

\subsubsection{Testes complementares: Exame Cognitivo de Addenbrooke (ACE-R), Mini-Exame do Estado Mental (MEEM), subtestes Raciocínio Matricial e Semelhanças da Escala Wechsler Abreviada de Inteligência (WASI)}

Os testes considerados testes complementares não foram utilizados como instrumentos de avaliação neste estudo, mas foram aplicados na sua totalidade uma vez que parte desses testes foram utilizados como instrumentos de avaliação deste estudo. Ou seja, da escala ACE-R, a subescala atenção e orientação foi utilizada como um dos instrumentos para avaliar a variável atenção, a subescala memória como um dos instrumentos para avaliar a variável memória e o somatório de algumas de suas subescalas para compor o escore do MEEM, que foi um dos instrumentos utilizados para seleção da amostra, como mencionado no capítulo 3 deste estudo (Método). 
O escore total da escala ACE-R resulta do somatório das subescalas de atenção e orientação, memória, fluência, linguagem e visuoespacial, tendo como pontuação máxima 100 pontos, sendo esta escala considerada um bom instrumento para o rastreio de declínio cognitivo, principalmente em populações menos escolarizadas (BECKERT, 2015).

Uma vez que havia à disposição dos avaliadores o protocolo do teste na íntegra, optou-se em aplicá-lo na sua totalidade.

O mesmo procedimento foi adotado na Escala Wechsler Abreviada de Inteligência (WASI), com exceção do subteste Vocabulário. Mais especificamente, o subteste Raciocínio Matricial, de acordo com a sua aplicação, tem grande semelhança com o instrumento do PEI denominado Percepção Analítica, cujo objetivo é o de, segundo Feuerstein e Hoffman (2000), treinar a habilidade de dividir o todo em partes (diferenciação) e de reunir as partes em um todo (integração).

Por sua vez, o subteste Semelhanças da Escala Wechsler Abreviada de Inteligência (WASI), vai ao encontro da metodologia de trabalho dos instrumentos do PEI denominados Comparações e Classificações.

Assim sendo, procurou-se verificar a evolução dos sujeitos do grupo experimental nestes testes complementares.

A Tabela 24 apresenta as médias das pontuações na escala ACE-R nas três fases do programa para ambos os grupos, controle e experimental. 
Tabela 24 - Médias das pontuações na escala ACE-R, grupo controle $(n=32)$ e grupo experimental $(n=34)$.

\begin{tabular}{llccccc}
\hline Grupo & Fase & Média & DP & Mínimo & Mediana & Máximo \\
\hline Controle & Pré-teste & 78,78 & 8,73 & 63,00 & 79,50 & 96,00 \\
& Pós-teste & 77,13 & 9,16 & 56,00 & 78,00 & 93,00 \\
\hline \multirow{2}{*}{ Experimental } & Pré-teste & 82,12 & 6,70 & 70,00 & 82,00 & 95,00 \\
& Pós-teste & 86,26 & 7,09 & 72,00 & 88,00 & 99,00 \\
& Reteste & 87,74 & 5,70 & 74,00 & 88,50 & 98,00 \\
\hline
\end{tabular}

Conforme é possível observar, as maiores médias ocorreram no grupo experimental. No pré-teste, o grupo experimental alcançou a maior média, 82,12, quando comparada ao pré-teste do grupo controle, 78,78. No pós-teste, o grupo experimental atingiu a média de 86,26 , em comparação a 77,13 do grupo controle. Em relação às três fases do teste para o grupo experimental, a maior média foi a do reteste, 87,74 , quando comparada ao pré e ao pós-teste. Verifica-se, portanto, que as médias das fases estão próximas aos valores da mediana para ambos os grupos em todos as fases do teste. Ou seja, a distribuição das pontuações dos indivíduos no teste nas três fases estão no centro da distribuição dos dados. Porém, o grupo experimental demonstra melhor desempenho neste teste em relação ao grupo controle.

A Tabela 25 apresenta as médias das pontuações do MEEM, na escala ACE-R.

Tabela 25 - Médias das pontuações da MEEM na escala ACE-R, grupo controle $(n=32)$ e grupo experimental $(n=34)$.

\begin{tabular}{llccccc}
\hline Grupo & Fase & Média & DP & Mínimo & Mediana & Máximo \\
\hline Controle & Pré-teste & 27,09 & 1,77 & 25,00 & 27,00 & 30,00 \\
& Pós-teste & 26,34 & 1,62 & 23,00 & 27,00 & 30,00 \\
\hline \multirow{2}{*}{ Experimental } & Pré-teste & 27,35 & 1,52 & 25,00 & 27,00 & 30,00 \\
& Pós-teste & 27,94 & 1,13 & 26,00 & 28,00 & 30,00 \\
& Reteste & 28,35 & 1,07 & 26,00 & 28,50 & 30,00 \\
\hline
\end{tabular}


Como mencionado anteriormente, o MEEM é um teste de rastreio para o diagnóstico de demência e déficit cognitivo. Seu escore total máximo é de 30 pontos, com as seguintes indicações: de 30 a 26 pontos funções cognitivas preservadas; de 25 a 24 pontos alterações não sugestivas de déficit; de 23 pontos ou menos indicativo de déficit cognitivo

De acordo com os dados apresentados na tabela acima, verifica-se que houve um aumento das médias do grupo experimental nas três fases do teste: pré-teste 27,35; pós-teste 27,94 ; reteste 28,35 ; indicando funções cognitivas preservadas.

E, para o grupo controle uma diminuição nas duas fases do teste: pré-teste 27,09 e pós-teste: 26,34 , mantendo-se, porém, as funções cognitivas preservadas. Quando da comparação entre os grupos no pós-teste, verifica-se que o grupo experimental obteve a maior média, 27,94, em comparação a média de 26,34 do grupo controle.

A Tabela 26 apresenta as médias das pontuações no subteste Raciocínio Matricial da Escala Wechsler Abreviada de Inteligência (WASI), fases pós e reteste para o grupo experimental.

Tabela 26 - Médias das pontuações no subteste Raciocínio Matricial da Escala Wechsler Abreviada de Inteligência (WASI), grupo experimental ( $n=34)$.

\begin{tabular}{llccccc}
\hline Grupo & Fase & Média & DP & Mínimo & Mediana & Máximo \\
\hline Experimental & Pós-teste & 21,56 & 5,98 & 9,00 & 22,50 & 31,00 \\
& Reteste & 24,29 & 5,49 & 13,00 & 24,50 & 35,00 \\
\hline
\end{tabular}

Como descrito no capítulo 3 (Método) desse trabalho, o escore do teste WASI - subteste Raciocínio Matricial, refere-se ao número de acertos obtido na 
escolha das alternativas propostas para completar a matriz das figuras. $\mathrm{O}$ escore máximo deste teste, para a amostra avaliada, é de 32 pontos.

Analisando a tabela acima, pode-se verificar que a maior média foi alcançada no reteste, 24,29 comparada à média do pós-teste, 21,56. Os dados indicam que houve um aumento de acertos do pós-teste para o reteste.

A Tabela 27 apresenta as médias das pontuações no subteste Semelhanças da Escala Wechsler Abreviada de Inteligência (WASI), fases pós e reteste para o grupo experimental.

Tabela 27 - Médias das pontuações no subteste Semelhanças, da Escala Wechsler Abreviada de Inteligência (WASI), grupo experimental ( $n=34)$.

\begin{tabular}{llccccc}
\hline Grupo & Fase & Média & DP & Mínimo & Mediana & Máximo \\
\hline Experimental & Pós-teste & 34,06 & 5,56 & 13,00 & 34,00 & 43,00 \\
& Reteste & 35,76 & 5,16 & 16,00 & 36,00 & 44,00 \\
\hline
\end{tabular}

O escore do teste WASI - subteste Semelhanças para a idade da amostra é de 48 pontos. Este teste tem como objetivo identificar figuras semelhantes nos primeiros quatro itens do teste, ou explicar como dois objetos ou conceitos assemelham-se do quinto ao vigésimo sexto item do teste.

Analisando a tabela acima, pode-se verificar que a maior média foi obtida pelo grupo na fase reteste, 35,76 comparada à média do pós-teste, 34,06. Os dados indicam que houve um aumento de acertos do pós-teste para o reteste.

\subsubsection{Escala de percepção subjetiva sobre modificações após o programa}

A escala de percepção subjetiva sobre modificações após o programa foi aplicada apenas no grupo experimental. 
A Tabela 28 foi organizada de modo a apresentar a porcentagem das 12 modificações arroladas em cada uma das cinco alternativas de avaliação.

Tabela 28 - Porcentagem de respostas na escala de percepção sobre modificações após o programa, grupo experimental $(n=34)$.

\begin{tabular}{|c|c|c|c|c|c|c|}
\hline MODIFICAÇÃO & $\begin{array}{l}\text { Muito } \\
\text { melhor }\end{array}$ & $\begin{array}{c}\text { Bem } \\
\text { melhor }\end{array}$ & Melhor & $\begin{array}{c}\text { Sem } \\
\text { alteração }\end{array}$ & Pior & TOTAL \\
\hline & $\%$ & $\%$ & $\%$ & $\%$ & $\%$ & $\%$ \\
\hline Atenção e Concentração & 32,35 & 20,59 & 44,12 & 2,94 & 0,00 & 100,00 \\
\hline $\begin{array}{l}\text { Controle da impulsividade } \\
\text { (ansiedade) nas ações do dia-a- } \\
\text { dia }\end{array}$ & 23,53 & 32,35 & 41,18 & 2,94 & 0,00 & 100,00 \\
\hline Resolução de problemas & 23,53 & 35,29 & 41,18 & 0,00 & 0,00 & 100,00 \\
\hline Memória & 26,47 & 23,53 & 41,18 & 8,82 & 0,00 & 100,00 \\
\hline Autoestima & 50,00 & 17,65 & 26,47 & 5,88 & 0,00 & 100,00 \\
\hline $\begin{array}{l}\text { Pensar antes de agir para } \\
\text { solucionar os problemas }\end{array}$ & 35,29 & 26,47 & 38,24 & 0,00 & 0,00 & 100,00 \\
\hline Motivação para aprender & 32,35 & 32,35 & 29,41 & 5,88 & 0,00 & 100,00 \\
\hline $\begin{array}{l}\text { Capacidade de comunicar-se } \\
\text { com as pessoas de maneira } \\
\text { mais clara e objetiva }\end{array}$ & 38,24 & 23,53 & 26,47 & 11,76 & 0,00 & 100,00 \\
\hline $\begin{array}{l}\text { Capacidade de classificar, } \\
\text { comparar, organizar e } \\
\text { discriminar as informações } \\
\text { para a resolução de problemas }\end{array}$ & 29,41 & 35,29 & 35,29 & 0,00 & 0,00 & 100,00 \\
\hline $\begin{array}{l}\text { Capacidade de percepção e } \\
\text { análise }\end{array}$ & 32,35 & 32,35 & 35,29 & 0,00 & 0,00 & 100,00 \\
\hline $\begin{array}{l}\text { Orientar-se no espaço em } \\
\text { relação à objetos e pessoas }\end{array}$ & 35,29 & 26,47 & 38,24 & 0,00 & 0,00 & 100,00 \\
\hline Maior autonomia & 23,53 & 23,53 & 38,24 & 14,71 & 0,00 & 100,00 \\
\hline
\end{tabular}

$\%=$ porcentagem de respostas

A maior porcentagem de respostas dos participantes do programa refere-se à modificação na autoestima (50\%) representada pela resposta muito melhor. A segunda maior porcentagem de respostas diz respeito à atenção e concentração 
$(44,12 \%)$ na categoria de respostas melhor. Em terceiro lugar situam-se as modificações no controle da impulsividade nas ações do dia-a-dia, resolução de problemas e memória, ambas com $41,18 \%$ de respostas na categoria melhor. As modificações pensar antes de agir para solucionar os problemas, orientar-se no espaço em relação aos objetos e pessoas, maior autonomia atingiram 38,24\% das repostas na categoria melhor. Com a mesma porcentagem de respostas $(38,24 \%)$ destaca-se a capacidade de comunicar-se com as pessoas de maneira clara e objetiva, porém na categoria muito melhor. Em quinto lugar, com 35,29\% de respostas tanto na categoria bem melhor como na categoria melhor situa-se a capacidade de classificar, comparar, organizar e discriminar as informações para a resolução de problemas, e, também, a capacidade de percepção e análise, porém na categoria de resposta melhor. E em sexto lugar, tem-se a motivação para aprender com $32,35 \%$ das respostas nas categorias muito melhor e bem melhor. $\mathrm{Na}$ categoria sem alteração situam-se $2,94 \%$ para a modificação atenção e concentração e controle da impulsividade nas ações do dia-a-dia (com a frequência de uma resposta para cada modificação citada); 5,88\% de respostas para a autoestima e para motivação para aprender; 8,82\% de respostas para a memória, representando a frequência de três respostas; $11,76 \%$ de respostas para a capacidade de comunicar-se com as pessoas de maneira mais clara e objetiva; e por fim, $14,71 \%$ de respostas para maior autonomia.

É importante salientar que, em nenhuma modificação considerada, a categoria pior foi assinalada e, na categoria sem alteração a porcentagem de respostas foi geralmente baixa. 


\subsubsection{Perspectiva Individual sobre o Programa}

A primeira pergunta realizada no primeiro dia de aula do programa versou sobre quais as perspectivas que o aluno tinha em relação ao programa a ser desenvolvido. A pergunta foi aberta, e o participante poderia citar um ou mais objetivos que pretendia alcançar.

A Tabela 29 apresenta os objetivos mais citados pelos alunos e as porcentagens das respostas.

Tabela 29 - Porcentagem de respostas sobre as perspectivas do programa antes da intervenção, grupo experimental $(n=34)$.

\begin{tabular}{lc}
\hline \multicolumn{1}{c}{ PERSPECTIVAS ALMEJADAS } & $\%$ \\
\hline Melhorar a memória & 100,00 \\
Aprender coisas novas & 32,35 \\
Melhorar a concentração e a atenção & 32,35 \\
Melhorar a qualidade de vida & 20,59 \\
Conviver com outras pessoas & 14,71 \\
Evitar demência & 8,82 \\
Melhorar a autoestima & 8,82 \\
\hline \% porcentagem de respostas &
\end{tabular}

A tabela 29 apresenta, em ordem crescente de frequência, as perspectivas mais citadas pelos alunos. A maior frequência ocorreu na perspectiva melhorar a memória, essa citada por todos os alunos; a segunda maior perspectiva é a de aprender coisas novas e a de melhorar a concentração e a atenção, ambas com $32,25 \%$ de respostas; a terceira perspectiva foi a de melhorar a qualidade de vida, com 20,59\%; a quarta perspectiva citada a de conviver com outras pessoas, com 14,71\%; a quinta é a de evitar a demência e melhorar a autoestima, 8,82\% de respostas cada. 
Importante salientar a unanimidade de respostas no desejo de melhorar a memória. Na verdade, uma queixa muito comum em idosos.

A segunda pergunta realizada no último dia de aula do programa teve como objetivo verificar se as perspectivas citadas pelo aluno no início do curso foram alcançadas ao seu final. A pergunta também foi aberta, e o participante poderia citar um ou mais objetivos alcançados.

A Tabela 30 apresenta os objetivos mais citados pelos alunos e as porcentagens das respostas, após o programa.

Tabela 30 - Porcentagem de respostas sobre as perspectivas do programa após a intervenção, grupo experimental $(n=34)$.

\begin{tabular}{lc}
\hline \multicolumn{1}{c}{ PERSPECTIVAS ALCANÇADAS } & $\%$ \\
\hline SIM & 100,00 \\
NÃO & 0,00 \\
Melhora da memória & 91,18 \\
Pensar/Refletir antes de agir & 73,53 \\
Sentir-se mais feliz e capaz & 61,76 \\
Melhora da autoestima & 58,82 \\
Diminuição da ansiedade & 52,94 \\
Melhora na organização/planejamento & 50,00 \\
das atividades & 44,12 \\
Melhora da atenção & 38,24 \\
Pensamento rápido & 38,24 \\
Melhora na comunicação & 14,71 \\
Maior disposição & 8,82 \\
\hline Melhora em orientar-se no espaço &
\end{tabular}

Conforme é possível depreender da tabela acima, 34 sujeitos ou $100 \%$ da amostra do grupo experimental declararam que suas perspectivas foram alcançadas 
ao final do programa. Em ordem crescente de porcentagem, as perspectivas mais citadas pelos alunos foram: melhora da memória citada por 91,18\% dos alunos; pensar/refletir antes de agir citada por $73,53 \%$ dos alunos; sentir-se mais feliz e capaz citada por $61,76 \%$ dos alunos; melhora da autoestima citada por $58,82 \%$ dos alunos; diminuição da ansiedade citada por 52,94\% dos alunos; melhora na organização/planejamento das atividades citada por 50,00\% doa alunos; melhora da atenção citada por 44,12\% dos alunos; pensamento rápido e melhora na comunicação foram citados por $38,24 \%$ para cada perspectiva; maior disposição citado por $14,71 \%$ dos alunos; e por fim a perspectiva melhora em orientar-se no espaço foi citado por $8,82 \%$ dos alunos.

\subsubsection{Entrevista final}

Participaram da entrevista final oito idosos do grupo experimental divididos em dois grupos: o grupo 1 denominado de Melhor desempenho foi formado por quatro alunos identificados pelas siglas AM1, AM2, AM3 e AM4; o grupo 2 denominado Pior desempenho foi formado por quatro alunos identificados pelas siglas AP1, AP2, AP3 e AP4. Em ambos os grupos, o critério de escolha dos sujeitos foram as maiores (Grupo 1) e menores pontuações (Grupo 2) na fase reteste do programa em pelo menos três dos seguintes instrumentos: a) ACE-R escore total, optou-se por este teste por ele abranger os cinco domínios cognitivos em sua pontuação geral, quais sejam: atenção e orientação, memória, fluência verbal, linguagem, habilidade visuoespacial; b) Teste Wisconsin de Classificação de Cartas - versão para idosos, indicador avaliativo respostas de nível conceitual, optou-se por este indicador avaliativo por ele expressar acertos intencionais, discriminando-os dos aleatórios na variável resolução de problemas; c) bateria BPA - atenção geral, optou por esta 
consistir no somatório dos três tipos de atenção (alternada, concentrada e dividida); d) WASI: escore bruto do subteste Cubos, por ser este o teste utilizado para avaliar a resolução de problemas. A Tabela 31 apresenta as pontuações dos idosos nos respectivos testes, na fase reteste do programa.

Tabela 31 - Pontuações dos idosos do Grupo 1 e do Grupo 2 na fase reteste do programa, $(\mathrm{n}=08)$.

\begin{tabular}{|c|c|c|c|c|c|c|c|c|}
\hline \multirow{3}{*}{ TESTES } & \multicolumn{8}{|c|}{ ESCORE BRUTO } \\
\hline & \multicolumn{4}{|c|}{ GRUPO 1} & \multicolumn{4}{|c|}{ GRUPO 2} \\
\hline & AM1* & $\mathrm{AM} 2^{*}$ & $\mathrm{AM}^{*}$ & AM4* & AP1* & $\mathrm{AP} 2 *$ & $\mathrm{AP}^{*}$ & AP4* \\
\hline IDADE & 62 & 62 & 75 & 82 & 63 & 65 & 73 & 70 \\
\hline SEXO & $\mathrm{F}$ & $\mathrm{F}$ & $\mathrm{F}$ & $\mathrm{F}$ & $\mathrm{F}$ & $\mathrm{F}$ & $\mathrm{F}$ & $\mathrm{F}$ \\
\hline ACE-R & 98 & 96 & 94 & 92 & 80 & 78 & 76 & 74 \\
\hline \multicolumn{9}{|l|}{ Wisconsin - respostas de } \\
\hline nível conceitual & 82 & 81 & 75 & 73 & 58 & 57 & 55 & 35 \\
\hline WASI - subteste Cubos & 48 & 46 & 45 & 43 & 26 & 22 & 15 & 16 \\
\hline BPA - atenção Geral & 271 & 265 & 251 & 249 & 139 & 137 & 134 & 132 \\
\hline
\end{tabular}

$\mathrm{F}=$ Sexo feminino; * Os nomes dos alunos foram substituídos por siglas.

Em relação à questão da entrevista final referente à percepção de modificações no comportamento durante e após a aplicação do programa, todos os oito alunos afirmaram que perceberam modificações durante o programa.

No grupo 1, as modificações citadas foram: maior rapidez e objetividade para realizar as atividades do dia-a-dia, raciocínio mais rápido, organização nas tarefas, melhora da memória, não resolver os problemas por impulso, melhora na comunicação com as pessoas, menor impulsividade nas ações do dia-a-dia, aumento do curiosidade para aprender coisas de maneira geral, melhora na orientação do espaço, aumento da autoestima.

A seguir, serão selecionados, a título de ilustração alguns relatos significativos dos entrevistados de ambos os grupos: 
... se você quer saber, eu estou fazendo cálculos de cabeça...meu raciocínio ficou mais rápido. Eu faço as coisas de casa com mais organização, antes parava uma coisa, começava outra, não terminava as duas; agora não, começo e termino e já organizo o meu dia quando acordo (AM1).

Lembro dos números do telefone de primeira, antes não, eu tinha que ficar digitando, parava, olhava de novo, digitava. Agora não, eu olho o número uma vez, já digito. Lembro todos. Quando eu fiz isso eu falei: Meus Deus, eu tô lembrando (AM1).

Com certeza aqueles que você citou na aula: quando a gente está fazendo uma coisa fazer uma coisa de cada vez porque às vezes eu estava com a chave e tinha que guardar, aí eu achava outra coisa pra fazer, aí acabava perdendo a chave não sabia onde estava, aí eu aprendi a pensar pra fazer as coisas, para mim foi muito importante. Comecei a ler e fazer palavras cruzadas, com o tempo vai ficando com a memória melhor. Eu achei muito bom (AM2).

Melhorei muito quando ando na rua. Quando ia na 25 de março eu me perdia. Saía de uma loja, não sabia se virava à esquerda ou à direita. Nem me lembrava se o ponto de ônibus era para frente ou para trás. Agora eu ando, saio da loja e lembro que virei à direita ou à esquerda. Não me perco mais (AM2).

Quando cheguei aqui eu me achava um lixo. Eu disse no primeiro dia de aula pra minha filha: Ah! Filha, eu nem vou saber fazer tudo aquilo de pontos (risos), que nem ia acompanhar a turma. Aí depois você foi explicando que cada pessoa fazia no seu tempo, que cada pessoa teve uma vivência, ai eu fui melhorando. E agora eu gosto mais de mim, me sinto boa para coisas, não tenho medo. Vou fazer até curso de inglês (AM3). 
Eu era triste mas bem mais triste, assim eu me preocupava muito com o problema dos outros, esquecia de mim. Agora não, eu penso em mim primeiro, depois eu vou tentar ajudar alguém. Cuido muito bem da minha família, dos meus netos, tinha menos paciência com eles, agora eu tenho. Brinco de se jogar no chão, de pintar, de escrever, de dançar. Tá muito bom. Tá ótimo. Eu tô feliz. Me sinto gente viva. (AM1).

No grupo 2, as modificações citadas foram: melhora na memória, melhora da atenção e concentração, organização nas tarefas do dia-a-dia, refletir antes de tomar decisões, mais calma, menos impulsividade e ansiedade, raciocínio mais rápido e eficiente, melhora da comunição, aumento da autoestima, paciência.

...eu era atropelada (risos). Queria fazer tudo em cinco minutos, fazer tudo. Então, agora eu sei que não é isso, eu tenho que pensar mais. (AP1).

A atenção melhorou sim. Às vezes você está, igual agora eu sai na rua, eu atravessava em qualquer lugar. Agora não, eu já vou mais para a faixa de pedestres, eu tenho que atravessar aqui na faixa que é mais seguro, antes eu atravessava em qualquer lugar. Quando a minha filha fala, eu presto atenção e não preciso perguntar mais o que ela falou. Presto atenção em desligar o gás na hora de sair, guardar a chave no lugar certo pra não ficar procurando. (risos). Antes a minha filha falava pra comprar uma coisa. Passava o dia e quando eu ia comprar tinha que ligar pra ela pra lembrar. Agora eu já lembro. Minha filha falou que eu tô ligeira (risos). Pra pegar receita na TV; eu também presto atenção pra marcar no papel e não esqueço (AP4).

Eu queria fazer tudo de uma vez, muita coisa. Quando chegava seis horas da tarde eu falava: Não fiz nada. Agora eu programo e organizo tudo (AP2). 
Quando vou no mercado levo $R \$ 100,00$ e ia pegando as coisas. Às vezes ia no caixa e tinha que devolver coisas porque passava do dinheiro (risos). Era vergonha. Hoje eu levo o dinheiro, organizo a lista da compra em casa e no mercado vou fazendo as contas. Fiquei espertinha nas contas (risos) (AP3).

Quando conversava com as pessoas não sabia nem falar. Agora converso de tudo. Presto atenção no jornal, não esqueço, leio mais. Até meu genro falou que eu estou sabinha (risos). E você sabe que ele quando vai jantar em casa me fala pra contar sobre tal matéria. E eu conto. Isso me fez gostar mais de mim porque antes eu tinha medo de falar as coisas errado (AP1).

...antes assim, por exemplo, se eu tivesse que ir pra um lugar eu sempre pedia pra alguém pra me levar. Agora não, vou sozinha, me viro, acho o ônibus que passa, o metrô. Não fico esperando ninguém (AP1).

Para a questão referente às modificações que 0 programa poderia proporcionar ou não ao aluno e, se caso afirmativo, o aluno deveria citar uma situação em que a modificação tenha ocorrido, todos os integrantes do grupo 1 e do grupo 2 afirmaram que as modificações ocorreram. Para efeito de melhor organização, citar-se-á a modificação e as situações em que ocorreram para ambos os grupos.

A primeira modificação foi no pensamento reflexivo. Seis alunos deram como exemplo pensar sobre os argumentos antes de falar às pessoas envolvidas nos fatos, um aluno do grupo 2 não entendeu o conceito sobre o tema e não conseguiu citar a situação da modificação em questão e um aluno citou ser mais objetivo no que for falar às pessoas. 
A segunda modificação referiu-se ao controle da impulsividade (ansiedade). Seis alunos indicaram pensar antes de agir para ter cautela com as palavras e atos, um aluno citou conseguir controlar o nervosismo perante uma situação e um outro conseguir esperar a resolução de um problema pacientemente e não se exaltar com os envolvidos na situação.

A terceira modificação foi comunicação clara e precisa. No tocante a esta variável, todos as oitos alunos afirmaram que melhoraram a sua comunicação para contar fatos/histórias às pessoas e perceberam que estas pessoas entendem melhor o que eles estão dizendo sem a necessidade de repetirem.

A quarta modificação referiu-se à concentração. Quatro alunos afirmaram ler e trabalhar com ruídos externos, um aluno citou aprender a atividade com uma única explicação e conseguir executá-la, um aluno indicou conseguir escrever receitas culinárias em uma única tentativa e dois alunos lembraram que conseguem apreender melhor as informações dos noticiários.

A quinta modificação diz respeito à consciência do seu potencial. Todos os alunos afirmaram que, após o programa, sentiram-se capazes de realizar as atividades. Porém, completando a citação anterior, um aluno citou a perda do medo de tirar carta de motorista porque reconheceu que é capaz de dirigir, um outro matriculou-se em um curso de marcenaria e um terceiro citou que conseguiu desenhar um vestido de festa para ser confeccionado.

A sexta modificação foi a elevação da autoestima. Todos os alunos citaram que, após o programa, sentiram-se melhores, apesar da idade, porque são mais experientes, valorizam-se mais, sentem-se mais seguros na maneira de falar e comportar-se perante as pessoas ao seu redor. Os exemplos para este item foram 
atribuídos à modificação da consciência do potencial do aluno para realizar as atividades.

A sétima modificação referiu-se à motivação para aprender. Um aluno falou que irá tirar carta de motorista, um outro que fará curso de marcenaria, quatro alunos citaram que farão curso de inglês, um outro que fará curso de modista e um terceiro relatou motivação para cursos de culinária e afins.

A oitava modificação citada na entrevista referiu-se a maior autonomia. Cinco alunos citaram que não dependem mais dos filhos para resolver situações corriqueiras; dois alunos indicaram que tornaram-se mais independentes para organizar e realizar viagens, visto que antigamente necessitavam da autorização e opiniões dos filhos; um afirmou que organiza seus remédios sem depender de filhos e empregada.

Finalizando as modificações, a nona modificação referiu-se à melhora da memória. As citações foram: lembrar de tomar os remédios, lembrar dos dias e horários das consultas médicas, lembrar dos preços dos itens de um supermercado para o outro, lembrar de desligar o gás antes de sair de casa, lembrar o número dos telefones de pessoas mais próximas, lembrar dos recados a serem dados para os filhos/amigos, lembrar do itens que se deve comprar nas lojas/mercados, não esquecer de pagar as contas, lembrar dos fatos ocorridos (jornal, revista, etc.) para discutir com amigos e/ou parentes.

No tocante à questão referente sobre se 0 idoso considera que as informações fornecidas durante o programa foram importantes para a realização das tarefas do seu cotidiano, tanto os idosos do grupo 1 quanto do grupo 2 afirmaram que sim e que conseguem colocá-las na prática do seu dia-a-dia. Os exemplos de maior destaque foram: prestar maior atenção nas atividades que realizam - contas, 
mercado, leitura, horários médicos; serem mais calmos para as tarefas do dia-a-dia - fazer as atividades uma de cada vez; maior organização e planejamento planejar as atividades do dia; perceber e analisar os objetos/informações com clareza - ouvir notícias e saber interpretá-las; maior organização e melhora na comunicação - saber debater e discutir as informações de jornais, revistas etc.; raciocinar com mais clareza - pensar antes de tomar decisões; maior autonomia realizar atividade sozinhos. No tocante a esta questão um relato pode ser salientado:

É esse negócio de ser impulsiva mesmo. Por que na hora assim de ter que decidir alguma coisa eu ia no impulso e resolvia sem pensar. Aí, depois, eu parava, pensava, mais poxa eu podia ter ido por outro caminho, podia ter sido sei lá porque eu acho que quando você coloca para fora é mais complicado você estar acertando, mais nesse ponto eu acho que eu parei, até às vezes as meninas estão pedindo minha opinião, eu tô pensando, aí as meninas falam "você não fala nada"; calma, calma que eu ainda vou responder. E aquele tempinho pra mim no final eu mostro, tá vendo que eu falo para vocês esperar, que é isso que eu aprendi o tempo todo no programa: espera, pensa, reflete e fala. Elas falam "parece que tá com cara de paisagem, não responde"; Eu falo "espera, espera que eu respondo". Outra situação é, foi um caso: Minha filha e meu genro discutem muito. Aí eu me meto e vira uma confusão. Das últimas vezes eles discutiram e eu só observei. Aí minha filha falou: "Mãe, você não vai falar nada?" E eu disse: "Não, só to observando, depois eu falo". Quando eles acabaram, eu dei a minha opinião. Quer dizer eu vi o ponto de vista de um, vi o ponto de vista de outro e falei o meu. Depois eu falei "Vocês tem que fazer o curso da Carla pra saber ouvir, refletir e falar" (risos). Desejo que você possa ajudar outras pessoas e outras e outras (AP2). 
$\mathrm{Na}$ finalização da entrevista, o idoso poderia realizar comentários sobre o programa, tanto positivos quanto negativos. Os atributos positivos do Grupo 1 e do Grupo 2 foram: tornar uma pessoa melhor (três respostas); ensinar a ter foco (uma resposta); melhorar as dificuldades de atenção e concentração (quatro respostas); melhorar a memória (seis respostas); melhorar a comunicação e compreender melhor as informações (três respostas); melhorar o raciocínio (cinco respostas); melhorar a reflexão sobre as coisas (duas respostas); motivação para aprender coisas novas (duas respostas). Houve o comentário de um atributo negativo ao programa, mas referia-se a realização dos testes para avaliação (uma resposta). Como exemplo dos atributos podemos citar os seguintes relatos:

Eu não queria ir embora. Faz outro programa? Que você continue sendo essa pessoa maravilhosa que você é, que você é maravilhosa. Ajudando as pessoas, fazendo as pessoas melhorarem como eu (AP1).

Pra mim, Carla, você me fez uma pessoa muito melhor. Muito obrigada. Que olha eu tô me sentindo assim rejuvenescida, apesar das rugas, mais isso foram experiências que eu passei, não reclamo (AM1).

Eu acho que é foco, que a gente tem que ter foco. Focar em certas coisas que eu não tinha, que eu fazia as coisa tudo de qualquer jeito. Agora eu paro pra perceber, muita coisa eu fazia por impulso, acho que seria foco e impulso, pra mim resolveu tudo (AM3).

Nossa! Carla, estou muito contente, obrigada por você dar essa chance para nós. Adorei. Me ajudou muito na memória (AM4).

Eu resumiria assim que foi muito importante na minha vida, que me ensinou a pensar melhor nas coisas, me ensinou a comunicar melhor com as pessoas, ser 
mais compreensiva e conhecer outras pessoas, como você, você é maravilhosa (AM4).

Igual que você lembra que eu sempre quis tirar minha carta, sempre foi meu sonho tirar minha carta. Aí eu falei, assim não, não, mas agora eu vou tirar. Vou aprender porque sou capaz e consigo. Que que tem que eu tenho 65 anos?. (AP2).

Pra dizer que não foi, só aqueles testes. A gente ficava nervosa pra responder aquilo. Depois eu saia daqui e dizia: Eu sei, mas na hora fico nervosa e respondo errado e demoro (AM4).

\subsection{Análise inferencial dos dados}

A normalidade dos dados foi avaliada por meio do teste estatístico Kolmogorov-Smirnov (utilizado para determinar se as variáveis estudadas seguem uma distribuição de probabilidade específica, no caso a distribuição normal), nas três fases do estudo (pré-teste, pós-teste e reteste), separadamente para os grupos experimental e controle. Em todos os casos, a hipótese de normalidade foi rejeitada ao nível de significância de 5\%. Como os dados não seguem a distribuição normal, utilizou-se a alternativa não paramétrica para análise dos mesmos.

Para as comparações intragrupos nas três fases do estudo, tanto para o grupo experimental quanto para $\circ$ grupo controle, utilizou-se o teste estatístico Wilcoxon para amostras pareadas. Para as comparações intergrupos nestas mesmas fases, utilizou-se o teste estatístico Mann-Whitney. Por fim, para verificar a transferência de aprendizagem das variáveis estudadas entre os testes da primeira bateria e os da segunda bateria foi utilizado o teste estatístico $t$-Student.

As análises foram realizadas pelo programa estatístico $R$, versão 3.2.2. 
Não foram analisadas as diferenças intragrupos e intergrupos no tocante às variáveis idade, escolaridade, renda familiar e classe econômica devido ao número reduzido da amostra.

Em resumo, o plano geral de análise obedeceu às etapas abaixo relacionadas:

- Comparação entre os escores na fase pré e na fase pós, para o grupo controle, por meio do teste de Wilcoxon para amostras pareadas;

- Comparação entre os escores na fase pré e na fase pós, para o grupo experimental, por meio do teste de Wilcoxon para amostras pareadas;

- Comparação dos escores na fase pós e reteste, para o grupo experimental, por meio do teste de Wilcoxon para amostras pareadas;

- Comparação dos escores na fase pré e reteste, para o grupo experimental, por meio do teste de Wilcoxon para amostras pareadas;

- Comparação dos escores na fase pré para os grupos experimental e controle, por meio do teste de Mann-Whitney;

- Comparação dos escores na fase pós para os grupos experimental e controle, por meio do teste de Mann-Whitney;

- Comparação da diferença dos escores entre as fases pré e pós, para os grupos experimental e controle, por meio do teste de Mann-Whitney.

- Comparação das variáveis resolução de problemas, memória, atenção e concentração entre os testes da primeira e segunda baterias, por meio do teste $t$ de Student.

Todo o procedimento foi realizado separadamente para cada um dos testes psicológicos aplicados. O nível de significância adotado para todas as comparações foi o de $5 \%$. 


\subsubsection{Homogenidade da amostra}

Para verificar se a composição dos dois grupos era estatisticamente semelhante, foram consideradas as variáveis idade, escolaridade, renda familiar e classe econômica. Devido às três últimas variáveis serem categorias (escolaridade, renda familiar e classe econômica), ou seja, não numéricas, optou-se por classificar a variável idade também em categorias para maior uniformidade da análise dos dados, realizada por meio do teste qui-quadrado de Pearson. Porém, este teste tem a restrição de que cada categoria deve ter no mínimo cinco itens. Por este motivo, foi necessário agrupar as categorias das variáveis da seguinte forma: a) idade: de 60 a 69 anos e 70 anos ou mais; b) escolaridade: de $1^{\underline{a}}$ a $4^{\underline{a}}$ série e de $5^{\underline{a}}$ a $8^{a}$ série; c) renda familiar: de 0 a 3 salários mínimos e de 4 a 6 salários mínimos; d) classe econômica: $A B$ e CDE. Os dados obtidos por meio dessa análise estão apresentados abaixo, na Tabela 32. 
Tabela 32 - Avaliação da homogenidade da amostra por meio do teste estatístico qui-quadrado de Pearson, grupo controle $(n=32)$ e grupo experimental $(n=34)$.

\begin{tabular}{lc}
\hline CATEGORIA & p-valor $^{*}$ \\
\hline IDADE & \\
\hline 60 a 69 anos & 0,460 \\
70 anos ou mais & \\
\hline ESCOLARIDADE & \\
\hline 1a a 4a Serie Fundamental I & 0,410 \\
5a a 8a Serie Fundamental II & \\
\hline RENDA FAMILIAR & 0,410 \\
\hline 0 a 3 & \\
4 a 6 & 0,223 \\
\hline CLASSE ECONÔMICA & \\
\hline AB & \\
CDE &
\end{tabular}

Como se pode observar, o $p$-valor do teste foi maior do que 0,05 em todas as variáveis consideradas, o que não permite rejeitar a hipótese nula de que a distribuição é igual para os grupos experimental e controle, indicando que os grupos experimental e controle são homogêneos, ou estatisticamente iguais.

\subsubsection{Comparações Intragrupos}

\subsubsection{Resolução de problemas}

Os valores referentes à comparação entre as respostas nas diferentes fases do estudo no tocante à variável resolução de problemas, nos grupos controle e experimental, são apresentados na Tabela 33. 
Tabela 33 - Comparações entre os resultados referentes aos indicadores interpretativos do Teste Wisconsin e do subteste WASI-Cubos, nas diferentes fases do estudo, por meio do teste estatístico Wilcoxon, grupo controle $(n=32)$ e grupo experimental $(n=34)$.

\begin{tabular}{|c|c|c|c|c|c|}
\hline \multirow[t]{2}{*}{ TESTES } & & \multirow{2}{*}{$\begin{array}{l}\text { CONTROLE } \\
\text { Pré x Pós }\end{array}$} & \multicolumn{3}{|c|}{ EXPERIMENTAL } \\
\hline & & & Pré x Pós & Pós $x$ Reteste & Pré $\mathrm{x}$ Reteste \\
\hline \multicolumn{6}{|c|}{ WISCONSIN - INDICADORES INTERPRETATIVOS } \\
\hline \multirow{2}{*}{ Número de ensaios administrados } & p-valor & 0,180 & $0,005^{\star}$ & 0,434 & $0,001^{\star}$ \\
\hline & direção & - & Pré > Pós & - & Pré > Reteste \\
\hline \multirow{2}{*}{ Número total de respostas corretas } & p-valor & 0,273 & $0,023^{\star}$ & $0,005^{\star}$ & $0,000^{\star}$ \\
\hline & direção & - & Pós > Pré & Reteste > Pós & Reteste > Pré \\
\hline \multirow{2}{*}{ Número total de erros } & p-valor & 0,132 & $0,000^{\star}$ & $0,004^{\star}$ & $0,000^{\star}$ \\
\hline & direção & - & Pré > Pós & Pós > Reteste & Pré > Reteste \\
\hline \multirow{2}{*}{ Respostas perseverativas } & p-valor & 0,732 & $0,010^{\star}$ & 0,389 & $0,001^{\star}$ \\
\hline & direção & - & Pré > Pós & - & Pré > Reteste \\
\hline \multirow{2}{*}{ Erros Perseverativos } & p-valor & 0,616 & $0,006^{\star}$ & 0,114 & $0,001^{*}$ \\
\hline & direção & - & Pré > Pós & - & Pré > Reteste \\
\hline \multirow{2}{*}{ Erros não perseverativos } & p-valor & 0,374 & $0,002^{\star}$ & 0,098 & $0,000^{\star}$ \\
\hline & direção & - & Pré > Pós & - & Pré > Reteste \\
\hline \multirow{2}{*}{ Respostas de nível conceitual } & p-valor & 0,609 & $0,001^{\star}$ & $0,003^{\star}$ & $0,000^{*}$ \\
\hline & direção & - & Pós > Pré & Reteste > Pós & Reteste > Pré \\
\hline \multirow{2}{*}{ Número de categorias completadas } & p-valor & 0,389 & $0,000^{\star}$ & 0,193 & $0,000^{*}$ \\
\hline & direção & - & Pós > Pré & - & Reteste > Pré \\
\hline \multirow{2}{*}{ Ensaios para completar a primeira categoria } & p-valor & 0,198 & $0,045^{\star}$ & $0,012^{\star}$ & $0,000^{\star}$ \\
\hline & direção & - & Pré > Pós & Pós > Reteste & Pré > Reteste \\
\hline \multirow{2}{*}{ Fracasso em manter o contexto } & p-valor & 0,241 & 0,059 & 0,356 & 0,250 \\
\hline & direção & - & - & - & - \\
\hline \multicolumn{6}{|l|}{ WASI } \\
\hline \multirow{2}{*}{ Subteste Cubos } & p-valor & - & - & $0,000^{*}$ & - \\
\hline & direção & - & - & Reteste > Pós & - \\
\hline
\end{tabular}

$\mathrm{Na}$ comparação entre as fases pré e pós-teste no grupo controle não se verificou qualquer diferença significante em nenhum indicador interpretativo do teste WCST, indicando claramente que a mera passagem do tempo e/ou a aplicação inicial do instrumento não levou a qualquer melhoria no desempenho. Por outro lado, na comparação entre as fases pré e pós no grupo experimental foram identificadas diferenças significantes em nove dos dez indicadores interpretativos, quais sejam: número de ensaios administrados $(p=0,005)$; número total de respostas corretas ( $p$ $=0,023)$; número total de erros $(p=0,000)$; respostas perseverativas $(p=0,010)$; erros perseverativos $(p=0,006)$; erros não perseverativos $(p=0,002)$; respostas de nível conceitual $(p=0,001)$; número de categorias completadas $(p=0,000)$ e 
ensaios para completar a primeira categoria $(p=0,045)$. Apenas no indicador interpretativo fracasso em manter o contexto $\quad(p=0,059)$ não ocorreu diferença significante, embora o valor encontrado esteja muito próximo do nível de significância estabelecido.

No tocante à comparação entre as fases pós e reteste para o grupo experimental, ocorreram diferenças significantes em quatro indicadores interpretativos: número total de respostas corretas $(p=0,005)$, número total de erros $(p=0,004)$, respostas de nível conceitual $(p=0,003)$ e ensaios para completar a primeira categoria $(p=0,012)$, indicando que o desempenho não apenas se manteve, mas apresentou uma melhoria depois do pós-teste, ou seja, após aproximadamente três meses depois da intervenção.

$\mathrm{Na}$ comparação entre as fases pré e reteste para o grupo experimental, que teve como objetivo verificar a evolução da variável estudada, ocorreram diferenças significantes em nove dos dez indicadores interpretativos: número de ensaios administrados $(p=0,001)$; número total de respostas corretas $(p=0,000)$; número total de erros $(p=0,000)$; respostas perseverativas $(p=0,001)$; erros perseverativos ( $p=0,001)$; erros não perseverativos $(p=0,000)$; respostas de nível conceitual $(p=$ $0,000)$; número de categorias completadas $(p=0,000)$ e ensaios para completar a primeira categoria $(p=0,000)$. É importante observar que o valor de $p$-valor é menor ou igual a 0,001 , indicando que há menos de $0,1 \%$ de chances de que a diferença tenha ocorrido ao acaso. Como na comparação entre as fases pré e pós-teste, também nesta comparação apenas no indicador interpretativo fracasso em manter o contexto $(p=0,250)$ não ocorreu diferença significante.

A comparação entre as fases pós e reteste para o grupo experimental no teste WASI - subteste Cubos, realizado com o objetivo de verificar a transferência da 
aprendizagem, indicou diferença significante $(p=0,000)$ no sentido reteste-pós. Ou seja, o número de acertos na fase reteste foi maior do que na fase pós.

\subsubsection{Memória}

A Tabela 34 apresenta os valores referentes às comparações entre as respostas nas diferentes fases do estudo quando da avaliação da variável memória, nos grupos controle e experimental.

Tabela 34 - Comparações entre as respostas nas diferentes fases do estudo referente à avaliação da variável memória por meio do teste estatístico Wilcoxon, grupo controle $(n=32)$ e grupo experimental $(n=34)$.

\begin{tabular}{|c|c|c|c|c|c|}
\hline \multirow[t]{2}{*}{ TESTES } & & \multirow{2}{*}{$\begin{array}{l}\text { CONTROLE } \\
\text { Pré x Pós }\end{array}$} & \multicolumn{3}{|c|}{ EXPERIMENTAL } \\
\hline & & & Pré x Pós & Pós $x$ Reteste & Pré $\mathrm{x}$ Reteste \\
\hline \multirow{2}{*}{ ACE-R subescala Memória } & p-valor & 0,989 & $0,005^{*}$ & 0,482 & $0,006^{\star}$ \\
\hline & direção & - & Pós > Pré & - & Reteste > Pré \\
\hline \multirow{2}{*}{ TMLP } & $\mathrm{p}$-valor & 0,183 & 0,590 & $0,015^{\star}$ & $0,018^{\star}$ \\
\hline & direção & - & - & Reteste > Pós & Reteste > Pré \\
\hline \multirow{2}{*}{ Pseudopalavras } & p-valor & $0,000^{\star}$ & $0,011^{\star}$ & $0,003^{\star}$ & $0,000^{*}$ \\
\hline & direção & Pré > Pós & Pós > Pré & Reteste > Pós & Reteste > Pré \\
\hline \multirow{2}{*}{$\begin{array}{l}\text { WAIS-III extensão de dígitos em } \\
\text { ordem direta e em ordem inversa }\end{array}$} & p-valor & - & - & $0,000^{*}$ & - \\
\hline & direção & - & - & Reteste $>$ Pós & - \\
\hline
\end{tabular}

Não houve diferença significante na comparação entre o pré e o pós-teste do grupo controle para o teste ACE-R, subescala memória, e para o teste TMLP. Houve porém, diferença significante no teste Pseudopalavras $(p=0,000)$ com direção da diferença favorável ao pré-teste. Em relação ao grupo experimental, ocorreram diferenças significantes entre o pré e o pós no teste ACE-R, subescala memória ( $p=$ 0,005), e no teste Pseudopalavras $(p=0,011)$. Também ocorreram diferenças significantes entre o pós e reteste no teste $\operatorname{TMLP}(p=0,015)$, no teste 
Pseudopalavras $(p=0,003)$ e no teste WAIS-III extensão de dígitos $(p=0,000)$. Quando comparados o pré e reteste, ocorreram diferenças significantes no teste ACE-R, subescala memória $(p=0,006)$, teste $\operatorname{TMLP}(p=0,018)$ e no teste Pseudopalavras $(p=0,000)$. A direção das diferenças foram favoráveis à fase em que o teste foi realizado, indicando melhor desempenho do grupo na fase considerada.

\subsubsection{Atenção e Concentração}

A Tabela 35 apresenta os valores das comparações entre as respostas nas diferentes fases do estudo quando da avaliação da variável atenção e concentração, nos grupos controle e experimental.

Tabela 35 - Comparações entre as respostas nas diferentes fases do estudo referentes à variável atenção e concentração por meio do teste estatístico Wilcoxon, grupo controle $(n=32)$ e grupo experimental $(n=34)$.

\begin{tabular}{|c|c|c|c|c|c|}
\hline \multirow[t]{2}{*}{ TESTES } & & \multirow{2}{*}{$\begin{array}{l}\text { CONTROLE } \\
\text { Pré x Pós }\end{array}$} & \multicolumn{3}{|c|}{ EXPERIMENTAL } \\
\hline & & & Pré x Pós & Pós x Reteste & Pré $x$ Reteste \\
\hline \multicolumn{6}{|l|}{ ACE-R } \\
\hline Subescala Atenção e & p-valor & $0,001^{*}$ & $0,015^{\star}$ & $0,002^{*}$ & 0,000 * \\
\hline Orientação & direção & Pré > Pós & Pós > Pré & Reteste > Pós & Reteste > Pré \\
\hline \multicolumn{6}{|l|}{ Trilhas A } \\
\hline \multirow{2}{*}{ Erros } & p-valor & 0,056 & $0,015^{\star}$ & 0,257 & $0,007^{\star}$ \\
\hline & direção & - & Pré > Pós & - & Pré > Reteste \\
\hline \multirow{2}{*}{ Tempo } & p-valor & 0,822 & 0,001 * & 0,496 & $0,001^{*}$ \\
\hline & direção & - & Pré > Pós & - & Pré > Reteste \\
\hline \multicolumn{6}{|l|}{ Trilhas B } \\
\hline \multirow{2}{*}{ Erros } & p-valor & 0,536 & $0,000^{\star}$ & 0,076 & 0,000 * \\
\hline & direção & - & Pré > Pós & - & Pré > Reteste \\
\hline \multirow{2}{*}{ Tempo } & p-valor & 0,903 & $0,000^{*}$ & 0,488 & 0,000 * \\
\hline & direção & - & Pré > Pós & - & Pré > Reteste \\
\hline \multicolumn{6}{|l|}{ BPA } \\
\hline \multirow{2}{*}{ Atenção Geral } & p-valor & - & - & $0,000^{\star}$ & - \\
\hline & direção & - & - & Reteste > Pós & - \\
\hline \multirow{2}{*}{ Atenção Concentrada } & p-valor & - & - & $0,000^{\star}$ & - \\
\hline & direção & - & - & Reteste > Pós & - \\
\hline \multirow{2}{*}{ Atenção Dividida } & p-valor & - & - & $0,000^{\star}$ & - \\
\hline & direção & - & - & Reteste > Pós & - \\
\hline \multirow{2}{*}{ Atenção Alternada } & p-valor & - & - & $0,000^{\star}$ & - \\
\hline & direção & - & - & Reteste > Pós & - \\
\hline
\end{tabular}


$\mathrm{Na}$ avaliação desta variável pelo teste $A C E-R$, subescala atenção e orientação, verificou-se diferença significante no grupo controle entre o pré e pósteste $(p=0,001)$, porém a direção da diferença indica que o grupo teve melhor desempenho no pré do que no pós-teste. No grupo experimental, diferenças significantes ocorreram entre o pré e o pós-teste $(p=0,015)$, entre o pós e reteste ( $p$ $=0,002)$ e entre o pré e o reteste na subescala Atenção e orientação. Tomados em conjunto estes resultados indicam tanto uma melhoria no desempenho, quanto a permanência desta melhoria ao longo do tempo do estudo.

No teste Trilhas A, constataram-se diferenças significantes na categoria Erros $(p=0,015)$ e na categoria Tempo $(p=0,001)$ entre o pré e o pós-teste; e na categoria Erros $(p=0,007)$ e na categoria Tempo $(p=0,001)$ entre o pré e o reteste. No teste Trilhas $B$, ocorreram diferenças significantes na categoria Erros $(p=0,000)$ e na categoria Tempo $(p=0,000)$ entre o pré e pós-teste; e na categoria Erros $(p=$ $0,000)$ e na categoria Tempo $(p=0,000)$ entre o pré e o reteste. Em ambas as comparações, o grupo experimental apresentou melhor desempenho no pós e reteste quando comparados ao pré-teste.

As comparações entre o pós e o reteste no grupo experimental no teste BPA - atenção geral, atenção concentrada, atenção dividida e atenção alternada indicaram diferenças significantes $(p=0,000)$ em todos os subitens no sentido do reteste para o pós-teste. Ou seja, o número de acertos no reteste foi maior do que o pós-teste.

\subsubsection{Escala de Autoestima}

As informações relacionadas à análise da escala de autoestima, grupo experimental, encontra-se na Tabela 36. 
Tabela 36 - Comparação entre as respostas nas diferentes fases do estudo referente à autoestima por meio do teste estatístico Wilcoxon, grupo experimental $(n=34)$.

\begin{tabular}{|c|c|c|c|c|}
\hline \multirow[t]{2}{*}{ TESTES } & & \multicolumn{3}{|c|}{ FASES } \\
\hline & & Pré x Pós & Pós $x$ Reteste & Pré $\mathrm{x}$ Reteste \\
\hline Escala de autoestima & $\begin{array}{l}\mathrm{p} \text {-valor } \\
\text { direção }\end{array}$ & $\begin{array}{c}0,131 \\
- \\
\end{array}$ & $\begin{array}{c}0,007 \text { * } \\
\text { Reteste > Pós }\end{array}$ & $\begin{array}{c}0,001 \text { * } \\
\text { Reteste > Pré }\end{array}$ \\
\hline
\end{tabular}

Não houve diferença significante na escala de autoestima na comparação entre o pré e o pós-teste mas, entre o pós e o reteste a diferença mostrou-se significante $(p=0,007)$ no sentido reteste-pós. Entre o pré e reteste, também ocorreu diferença significante $(p=0,001)$ no sentido reteste-pré.

\subsubsection{Testes complementares}

Os valores referentes às comparações entre as diferentes fases do estudo na escala ACE-R, MEEM (grupos controle e experimental) e WASI - subtestes Raciocínio Matricial e Semelhanças (no grupo experimental) são apresentados na Tabela 37. 
Tabela 37 - Comparação entre as respostas nas diferentes fases do estudo na escala ACE-R, no MEEM e no subteste Raciocínio Matricial e Semelhanças da Escala Wechsler Abreviada de Inteligência (WASI), por meio do teste estatístico Wilcoxon, grupo controle $(n=32)$ e grupo experimental $(n=34)$.

\begin{tabular}{|c|c|c|c|c|c|}
\hline \multirow[t]{2}{*}{ TESTES } & & \multirow{2}{*}{$\begin{array}{l}\text { CONTROLE } \\
\text { Pré x Pós }\end{array}$} & \multicolumn{3}{|c|}{ EXPERIMENTAL } \\
\hline & & & Pré x Pós & Pós x Reteste & Pré $x$ Reteste \\
\hline & p-valor & 0,143 & $0,001^{\star}$ & 0,090 & 0,000 * \\
\hline ACE-R & direção & - & Pós > Pré & - & Reteste > Pré \\
\hline MEEM & $\begin{array}{l}\text { p-valor } \\
\text { direção }\end{array}$ & $\begin{array}{c}0,009^{\star} \\
\text { Pré > Pós }\end{array}$ & $\begin{array}{c}0,023^{*} \\
\text { Pós > Pré }\end{array}$ & $\begin{array}{c}0,048^{*} \\
\text { Reteste > Pós }\end{array}$ & $\begin{array}{c}0,001{ }^{\star} \\
\text { Reteste > Pré }\end{array}$ \\
\hline $\begin{array}{c}\text { WASI - subteste Raciocínio } \\
\text { Matricial }\end{array}$ & $\begin{array}{l}\text { p-valor } \\
\text { direção }\end{array}$ & - & - & $\begin{array}{c}0,000 * \\
\text { Reteste }>\text { Pós }\end{array}$ & - \\
\hline WASI - subteste Semelhanças & $\begin{array}{l}\text { p-valor } \\
\text { direção }\end{array}$ & - & - & $\begin{array}{c}0,000^{*} \\
\text { Reteste > Pós }\end{array}$ & - \\
\hline
\end{tabular}

Observa-se que, apenas no grupo experimental, a diferença entre os resultados do ACE-R foi significante entre o pré e pós-teste $(p=0,001)$, no sentido pós-pré-teste; e entre o pré e reteste $(p=0,000)$, no sentido reteste-pré-teste.

$\mathrm{Na}$ análise do MEEM, observa-se diferença significante no grupo controle entre o pré e pós-teste $(p=0,009)$, no sentido pré-pós-teste, indicando que o maior número de acertos ocorreu na fase pré-teste. No grupo experimental todas as comparações se mostraram significantes, indicando melhor desempenho no pósteste e no reteste.

Na comparação entre o pós e o reteste no grupo experimental, no teste WASI - subteste raciocínio matricial e subteste semelhanças verificou-se diferenças significantes $(p=0,000)$ em ambos os subtestes no sentido reteste-pós-teste, indicando que o número de acertos no reteste foi maior do que no pós-teste. 


\subsubsection{Comparações Intergrupos}

\subsubsection{Resolução de problemas}

Os dados referentes às comparações entre os grupos controle e experimental, no pré e pós-teste, dos indicadores interpretativos do Wisconsin são apresentados na Tabela 38.

Tabela 38 - Comparação entre os grupos controle e experimental no pré e pós-teste nos indicadores interpretativos do Wisconsin por meio do teste estatístico Mann-

Whitney, grupo controle $(n=32)$ e grupo experimental $(n=34)$.

\begin{tabular}{|c|c|c|c|}
\hline \multicolumn{2}{|l|}{$\begin{array}{l}\text { TESTES } \\
\end{array}$} & \multicolumn{2}{|c|}{ FASES } \\
\hline & & PRÉ & Pós \\
\hline \multicolumn{4}{|l|}{ WISCONSIN - INDICADORES INTERPRETATIVOS } \\
\hline \multirow{2}{*}{ Número de ensaios administrados } & p-valor & 0,332 & $0,001^{\star}$ \\
\hline & direção & - & Control > Exp \\
\hline \multirow{2}{*}{ Número total de respostas corretas } & p-valor & 0,092 & $0,001^{\star}$ \\
\hline & direção & - & Exp $>$ Control \\
\hline \multirow{2}{*}{ Número total de erros } & p-valor & 0,076 & 0,000 * \\
\hline & direção & - & Control > Exp \\
\hline \multirow{2}{*}{ Respostas perseverativas } & p-valor & 0,011 * & 0,000 * \\
\hline & direção & Control $>$ Exp & Control > Exp \\
\hline \multirow{2}{*}{ Erros perseverativos } & p-valor & 0,030 * & 0,000 * \\
\hline & direção & Control > Exp & Control > Exp \\
\hline \multirow{2}{*}{ Erros não perseverativos } & p-valor & 0,093 & 0,441 \\
\hline & direção & - & - \\
\hline \multirow{2}{*}{ Respostas de nível conceitual } & p-valor & 0,256 & 0,000 * \\
\hline & direção & - & Exp $>$ Control \\
\hline \multirow{2}{*}{ Número de categorias completadas } & p-valor & 0,542 & 0,000 * \\
\hline & direção & - & Exp $>$ Control \\
\hline \multirow{2}{*}{ Ensaios para completar a primeira categoria } & p-valor & 0,692 & 0,810 \\
\hline & direção & - & - \\
\hline \multirow{2}{*}{ Fracasso em manter o contexto } & p-valor & $0,026^{*}$ & 0,501 \\
\hline & direção & Exp $>$ Control & - \\
\hline
\end{tabular}

Como se pode observar, as diferenças entre os resultados dos dois grupos (controle e experimental) foram significantes no pré para os seguintes indicadores interpretativos do WCST: respostas perseverativas $(p=0,011)$; erros perseverativos $(p=0,030)$ e fracasso em manter o contexto $(p=0,026)$. Nos demais indicadores as 
diferenças não foram significantes, indicando que os grupos não diferiam no préteste. No pós-teste, diferenças significantes ocorreram nos indicadores interpretativos: número de ensaios administrados $(p=0,001)$; número total de respostas corretas $(p=0,001)$; número total de erros $(p=0,000)$; respostas perseverativas $(p=0,000)$; erros perseverativos $(p=0,000)$; respostas de nível conceitual $(p=0,000)$; número de categorias completadas $(p=0,000)$. É importante salientar que a direção da diferença indica um melhor desempenho do grupo experimental.

\subsubsection{Memória}

Os dados referentes às comparações entre os grupos controle e experimental no pré e pós-teste dos testes para avaliação da variável memória, são apresentados na Tabela 39.

Tabela 39 - Comparação entre os grupos experimental e controle no pré e pós-teste na avaliação da variável memória, por meio do teste estatístico Mann-Whitney, grupo controle $(n=32)$ e grupo experimental $(n=34)$.

\begin{tabular}{|c|c|c|c|}
\hline \multirow[t]{2}{*}{ TESTES } & & \multicolumn{2}{|c|}{ FASES } \\
\hline & & PRÉ & Pós \\
\hline \multirow{2}{*}{ ACE-R subescala Memória } & p-valor & 0,591 & $0,003^{*}$ \\
\hline & direção & - & Exp $>$ Control \\
\hline \multirow{2}{*}{ TMLP } & p-valor & 0,160 & $0,018^{*}$ \\
\hline & direção & - & Exp $>$ Control \\
\hline Pseudopalavras & $\begin{array}{l}\text { p-valor } \\
\text { direção }\end{array}$ & $\begin{array}{c}0,266 \\
- \\
\end{array}$ & 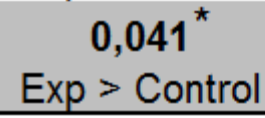 \\
\hline
\end{tabular}


Não ocorreu diferença significante entre os grupos controle e experimental no pré-teste, tanto para o teste ACE-R subescala memória quanto para o teste TMLP e para o teste Pseudopalavras, indicando que os grupos não diferiam na variável no início da intervenção.

No pós-teste, foram verificadas diferenças significantes em todos os testes: ACE-R subescala memória $(p=0,003), \operatorname{TMLP}(p=0,018)$ e Pseudopalavras $(p=$ 0,041), no sentido experimental-controle, indicando o melhor desempenho do grupo experimental nos três testes de memória.

\subsubsection{Atenção e Concentração}

A Tabela 40 apresenta os valores referentes à comparação entre as respostas dos grupos controle e experimental no pré e pós-teste do ACE-R, subescala atenção e orientação, Trilhas A e Trilhas B. 
Tabela 40 - Comparação das respostas entre os grupos controle e experimental no pré e pós-teste, no teste ACE-R, Trilhas A e B, por meio do teste estatístico MannWhitney, grupo controle $(n=32)$ e grupo experimental $(n=34)$.

\begin{tabular}{|c|c|c|c|}
\hline \multicolumn{2}{|l|}{ TESTES } & \multicolumn{2}{|c|}{ FASES } \\
\hline & & PRÉ & Pós \\
\hline \multicolumn{4}{|l|}{ ACE-R } \\
\hline Subescala Atenção e & p-valor & 0,731 & 0,000 * \\
\hline Orientação & direção & - & Exp $>$ Control \\
\hline \multicolumn{4}{|l|}{ Trilhas A } \\
\hline \multirow{2}{*}{ Erros } & p-valor & 0,523 & $0,025^{*}$ \\
\hline & direção & - & Control > Exp \\
\hline \multirow{2}{*}{ Tempo } & p-valor & $0,019^{*}$ & $0,001^{*}$ \\
\hline & direção & Control > Exp & Control > Exp \\
\hline \multicolumn{4}{|l|}{ Trilhas B } \\
\hline \multirow{2}{*}{ Erros } & p-valor & 0,400 & $0,002^{\star}$ \\
\hline & direção & - & Control > Exp \\
\hline \multirow{2}{*}{ Tempo } & p-valor & 0,744 & 0,022 * \\
\hline & direção & - & Control > Exp \\
\hline
\end{tabular}

De acordo com a tabela acima, pode-se verificar diferença significante no préteste na categoria tempo do teste Trilhas $A(p=0,019)$. Conforme a direção indica, o melhor desempenho nesta fase foi o do grupo experimental, uma vez que quanto menor o tempo melhor desempenho do grupo no teste.

No pós-teste, diferenças significantes ocorreram na subescala atenção e orientação $(p=0,000)$, indicando melhor desempenho do grupo experimental; no teste Trilhas A categoria erros $(p=0,025)$ e categoria tempo $(p=0,001)$; no teste Trilhas B categoria erros $(p=0,002)$ e categoria tempo $(p=0,022)$. Para 0 teste Trilhas A e Trilhas B, o melhor desempenho foi o do grupo experimental, visto que a 
diferença da direção demonstra que o grupo controle cometeu o maior número de erros e levou mais tempo para a realização dos dois testes.

\subsubsection{Testes complementares}

A comparação entre os grupos controle e experimental no pré e pós-teste na escala ACE-R e no MEEM é apresentada na Tabela 41.

Tabela 41 - Comparação entre os grupos controle e experimental no pré e pós-teste na escala ACE-R e no MEEM por meio do teste estatístico Mann-Whitney, grupo controle $(n=32)$ e grupo experimental $(n=34)$.

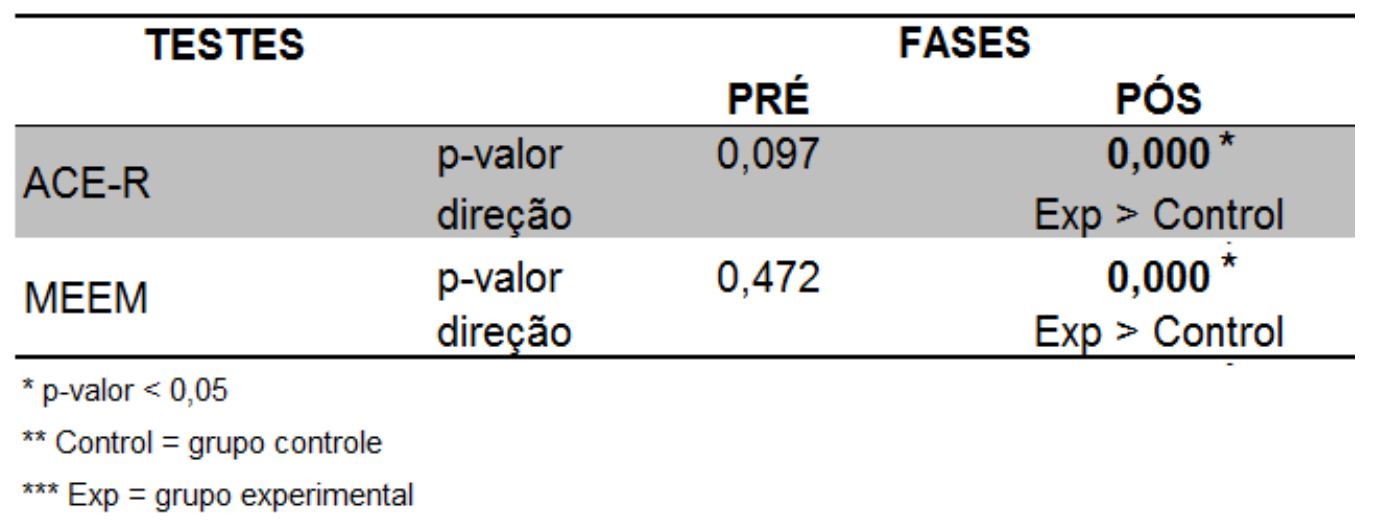

Os valores encontrados indicam diferenças significantes no pós-teste na comparação entre os dois grupos na escala ACE-R $(p=0,000)$ e no MEEM $(p=0,000)$. A direção da diferença aponta para melhor desempenho do grupo experimental nos dois testes indicando, maior número de acertos em ambos os testes.

\subsubsection{Transferência da aprendizagem}

Com o objetivo de descartar a hipótese de que o grupo experimental possa ter obtido melhores pontuações nos testes da primeira bateria no pós-teste do programa 
devido a possível aprendizagem dos mesmos no pré-teste, foi aplicada uma segunda bateria de testes denominados testes de transferência.

Cada variável do estudo foi avaliada por um ou mais testes específicos aplicados no pré, pós e reteste do programa de intervenção, a fim de verificar sua evolução. No pós-teste do programa de intervenção, além dos testes da primeira bateria, foram aplicados também outros testes equivalentes para avaliação das variáveis, aqui referidos como a segunda bateria, a fim de verificar uma possível transferência de aprendizagem.

Os testes de transferência escolhidos foram: a) para a variável resolução de problemas foi aplicado o teste WCST - indicador interpretativo de respostas de nível conceitual e o WASI - subteste cubos; b) para a variável memória foi escolhido o ACE-R - subescala memória e dígitos em ordem direta e em ordem inversa; c) para a variável atenção e concentração optou-se pelo ACE-R - subescala atenção e orientação e pelo BPA - atenção geral.

Os dados utilizados para a verificação da transferência da aprendizagem foram os do pós-teste do programa: os dados da segunda aplicação para os testes da primeira bateria e os dados da primeira aplicação para os testes da segunda bateria. Quando a bateria possuía mais de um teste da mesma variável, optou-se por utilizar aqueles que mais se assemelhavam ao método de aplicação.

O procedimento para avaliar a transferência de aprendizagem é descrito a seguir. De posse dos dados do teste da primeira bateria e dos dados da segunda bateria da variável investigada no pós-teste do programa, foi realizada a equiparação dos dados entre os dois testes, ou seja, os valores das respostas foram colocados em igualdade. Para cada teste equiparado, calculou-se o novo desvio padrão (DP) e a nova media e calculou-se o p-valor por meio do teste estatístico t-student com 
intervalo de confiança de $95 \%$ com o objetivo de verificar a significância da diferença entre as duas bases dos dados. De acordo com os resultados da análise estatística, considerou-se a ocorrência da transferência de aprendizagem nos seguintes casos: a) se não houver diferença significante, considera-se que as duas bases são iguais e houve transferência de aprendizagem; b) se houver diferença significante, a transferência é admitida no caso da direção da diferença ter sido favorável ao teste da segunda bateria.

A Tabela 42 apresenta cada variável estudada, o teste da primeira bateria utilizado para sua avaliação, o teste equivalente à avaliação desta mesma variável na segunda bateria e as médias de cada teste após a equiparação dos escores obtidos para cada sujeito da amostra.

Tabela 42 - Médias dos testes aplicados e o p-valor de cada variável de acordo com o teste estatístico $t$-student, grupo experimental $(n=34)$.

\begin{tabular}{|c|c|c|c|c|c|}
\hline VARIÁVEL & BATERIA & TESTES & Média & p-valor & direção \\
\hline \multirow{2}{*}{$\begin{array}{l}\text { Resolução de } \\
\text { problemas }\end{array}$} & $1^{a}$ & $\begin{array}{l}\text { WCST - indicador } \\
\text { interpretativo: respostas de } \\
\text { nível conceitual }\end{array}$ & 4,38 & \multirow[t]{2}{*}{0,380} & \multirow[t]{2}{*}{-} \\
\hline & $2^{a}$ & WASI - Subteste Cubos & 4,15 & & \\
\hline \multirow[b]{2}{*}{ Memória } & $1^{a}$ & ACE-R - subescala memória & 6,48 & \multirow[b]{2}{*}{0,177} & \multirow[b]{2}{*}{-} \\
\hline & $2^{a}$ & $\begin{array}{l}\text { Dígitos em ordem direta e em } \\
\text { ordem inversa }\end{array}$ & 6,75 & & \\
\hline \multirow{2}{*}{$\begin{array}{c}\text { Atenção e } \\
\text { Concentração }\end{array}$} & $1^{a}$ & $\begin{array}{l}\text { ACE-R - subescala atenção e } \\
\text { orientação }\end{array}$ & 23,50 & \multirow[t]{2}{*}{$0,000^{*}$} & \multirow[t]{2}{*}{$1^{\mathrm{a}}>2^{\mathrm{a}}$} \\
\hline & $2^{a}$ & BPA - atenção geral & 3,20 & & \\
\hline
\end{tabular}

${ }^{*} p<0,05$

Conforme se pode verificar na tabela acima, nas variáveis resolução de problemas e memória não ocorreram diferenças significantes ao nível de 5\% nessas 
variáveis. Ou seja, não é possível rejeitar a hipótese nula de que a distribuição dos dados é igual nos testes avaliados da primeira e segunda baterias, portanto são estatisticamente iguais.

$\mathrm{Na}$ atenção e concentração, houve diferença significante e a direção da diferença foi favorável à primeira bateria $(p=0,000)$. Neste caso, pode-se considerar, de acordo com os resultados da análise estatística, que não houve a transferência de aprendizagem, porém os dados apresentados não devem ser considerados isoladamente.

Durante a equiparação dos dados, verificou-se que os resultados do teste da segunda bateria (BPA) apresentavam-se dispersos. Como demonstrado no DP da análise descritiva (pós-teste DP $=53,59$ ), os resultados dos sujeitos do teste da primeira bateria (ACE-R, subescala atenção e orientação) apresentam-se mais concentrados $(\mathrm{DP}=0,73)$. Mesmo após a equiparação dos dados entre os testes ACE-R (subescala atenção e orientação) e BPA (atenção geral), ainda os resultados do ACE-R mantiveram-se concentrados. Por este motivo, o recálculo da média do ACE-R foi muito superior ao da média do BPA, o que resultou na diferença significante.

\subsubsection{Síntese dos resultados}

Em resumo, os resultados encontrados por meio da análise inferencial podem ser assim sumarizados.

Para a avaliação da variável resolução de problemas foram utilizados os testes Wisconsin - classificação de cartas versão para idosos - e o subteste Cubos da Escala Wechsler Abreviada de Inteligência. Os resultados apresentados na tabela 39, referentes aos indicadores interpretativos do Teste Wisconsin, mostram que, na 
comparação entre o pré e pós-teste no grupo controle, nenhuma diferença significante foi detectada, indicando claramente que a mera passagem do tempo e/ou a pequena familiaridade com os instrumentos psicológicos utilizados não levou a qualquer melhoria no desempenho.

Em contrapartida, no grupo experimental ocorreram diferenças significantes entre nove dos dez indicadores interpretativos na comparação entre o pré e o pósteste, sendo a direção das diferenças favorável à hipótese do trabalho, mostrando os efeitos positivos da intervenção. Em relação às comparações entre o pós-teste e o reteste, foram identificadas diferenças significantes em quatro dos dez indicadores, indicando que, ou o desempenho manteve-se inalterado, ou apresentou melhoria no pós-teste.

No subteste Cubos, aplicado somente no grupo experimental com o objetivo de verificar a transferência da aprendizagem, a diferença encontrada se mostrou significante no sentido reteste-pós. Ou seja, ocorreu transferência positiva entre estas duas fases do estudo.

A variável memória foi avaliada pelos testes ACE-R - subescala memória -, Teste Memória de Lista de Palavras e Pseudopalavras aplicados tanto no grupo controle quanto no grupo experimental. No grupo controle ocorreu apenas uma diferença significante nesses três instrumentos de avaliação, no teste Pseudopalavras e no sentido pré para o pós-teste, indicando melhor desempenho no pré do que no pós. No grupo experimental todas as comparações apresentaram diferenças significantes no sentido reteste-pré, revelando que o grupo apresentou melhorias na variável memória mesmo após três meses do término do programa, sendo o melhor desempenho evidenciado em Pseudopalavras, conforme observado na tabela 17 da seção análise descritiva. Também no teste WAIS-III - extensão de 
dígitos - aplicado apenas no grupo experimental com o objetivo de verificar a transferência de aprendizagem detectou-se diferença significante no sentido retestepós, mostrando ter ocorrido transferência. De tais resultados, tomados isoladamente ou em conjunto, pode-se inferir que o processo de memória foi positivamente influenciado pela intervenção realizada.

Nos três testes para avaliação da variável atenção e concentração (ACE-R subescala atenção e orientação -, Trilhas A e Trilhas B), o grupo experimental sempre alcançou melhor desempenho quando comparado ao grupo controle. $\mathrm{O}$ melhor resultado foi obtido no teste ACE-R - subescala atenção e orientação -, que revelou um desempenho progressivo nas três fases da aplicação do teste, sendo a direção das diferenças conforme as hipóteses do trabalho. Nos testes Trilhas A e B ocorreram diferenças significantes no pré-pós-teste tanto para a categoria tempo quanto para a categoria erros, indicando menor quantidade de erros e menor intervalo de tempo para a realização do teste no pós-teste. É importante observar que o Trilhas B é de execução mais complexa, uma vez que o sujeito deve interagir no teste com duas fontes de informação, letras e números.

Em relação ao teste BPA, utilizado para verificar a transferência de aprendizagem, no grupo experimental verificou-se diferença significante no sentido reteste-pós-teste, indicando ter ocorrido transferência de aprendizagem entre essas duas fases do trabalho.

A escala para avaliação da autoestima foi aplicada apenas no grupo experimental. De acordo com a tabela 36 na comparação pós-reteste houve diferença significante na direção do reteste apontando aumento na autoestima dos participantes após o término do programa. 
Nos testes complementares, 0 melhor desempenho foi 0 do grupo experimental quando comparado ao grupo controle. Dentre os testes realizados, o melhor resultado foi obtido no teste MEEM, que indicou um aumento progressivo no desempenho nas três fases do estudo na direção reteste-pré, evidenciando que o programa parece ter contribuído para manter e/ou melhorar as funções cognitivas dos participantes.

$\mathrm{Na}$ escala ACE-R (o somatório de todas as subescalas), os melhores resultados também foram obtidos pelo grupo experimental na direção pós-pré-teste. E em relação ao teste WASI, aplicado apenas no grupo experimental, tanto no subteste raciocínio matricial quanto no de semelhanças, diferenças significantes foram constatadas entre o pós-reteste, na direção do reteste, indicando tanto que o raciocínio abstrato como o raciocínio verbal abstrato obtiveram melhoras após três meses do final do programa de intervenção.

De acordo com esta síntese dos resultados, pode-se constatar uma melhoria geral do grupo experimental quando comparado ao de controle nas fases pós-teste e reteste, evidenciando os efeitos do programa de intervenção administrado, tanto logo após a intervenção ter sido completada (pós-teste), quanto depois de decorrido três meses do término da intervenção. Tais resultados parecem demonstrar claramente que os participantes do estudo não apenas melhoraram seu desempenho após 0 programa, mas que tais melhorias ou se mantiveram, ou ainda apresentaram progresso após seu encerramento.

Cabe agora perguntar: Como explicar esses resultados? O que eles parecem significar? O que pode ter ocorrido nas funções cognitivas avaliadas como resultado do programa de intervenção? 
A análise e discussão dos dados serão realizadas no próximo capítulo deste estudo, visando responder às questões propostas. 


\section{CAPÍTULO 5}

DISCUSSÃO

Com o objetivo de avaliar a influência do PEI nas funções cognitivas de idosos, mais especificamente na resolução de problemas, memória, atenção e concentração e autoestima, esta pesquisa comparou os resultados obtidos por meio de testes psicológicos aplicados a dois grupos de idosos: um grupo que recebeu uma intervenção cognitiva (grupo experimental) e outro grupo que não sofreu nenhuma intervenção (grupo controle).

Os testes para avaliação do programa de intervenção foram aplicados em três fases: antes da intervenção (pré-teste), ao final do término da intervenção (pós-teste) e após três meses do término da intervenção (reteste).

A análise e a discussão dos dados obtidos serão apresentadas por variável analisada tanto as de caráter quantitativo, quanto as de caráter qualitativo, referentes à escala de percepção subjetiva sobre as modificações após o programa, à perspectiva individual sobre o programa e à entrevista final, aplicadas apenas no grupo experimental.

\subsection{Controle dos efeitos da familiaridade}

Inicialmente, uma das preocupações deste estudo foi avaliar um eventual e possível efeito da familiaridade, uma vez que os mesmos instrumentos de avaliação foram utilizados no pré e pós-teste, o que poderia proporcionar melhoras no desempenho dos participantes de ambos os grupos no pós-teste. Ou seja, poder-seia pensar que a melhora no pós-teste seria devido não aos efeitos do programa de 
intervenção mas ao fato dos indivíduos terem se familiarizado com os instrumentos na fase pré-teste.

Se tal suposição fosse verdadeira, o esperado seria que os dois grupos não apresentassem diferenças significantes na fase do pós-teste. No entanto, tal como verificado, o grupo experimental demonstrou melhor desempenho em relação ao grupo controle na grande maioria dos testes aplicados, demonstrando a eficácia do programa de intervenção.

Tais resultados, vão ao encontro dos resultados de outras pesquisas que confirmam a hipótese de associação entre a participação de idosos em programas de treino cognitivo/intervenção cognitiva e melhorias no seu desempenho cognitivo (BALL et al., 2002; LASCA, 2003; VALENTIJN et al., 2005; CARVALHO, 2006; YASSUDA et al., 2006; STRAUSS et al., 2006; LEVINE et al., 2007; O'HARA et al., 2007; TOMASZCZYK \& FERNANDES \&, 2012; IRIGARAY et al., 2012; LI et al., 2015; HEINZEL et al. 2016; PAYNE et al., 2016).

Uma vez controlado uma possível influência do fator familiaridade, cabe então discutir a melhoria no desempenho do grupo experimental em cada uma das variáveis analisadas.

\subsection{Autoestima}

A autoestima diz respeito ao sentimento, ao apreço, à consideração que o indivíduo sente por si próprio, o quanto que ele gosta de si e o que ele pensa de si mesmo (DINI et al., 2004).

Na população idosa, como evidenciado por Ferreira et al. (2012) e Neri e Freire (2000), as situações de desafetos e rejeições no âmbito familiar e social, bem como as limitações físicas, psicológicas, sociais e ambientais advindas com o 
avançar da idade, somadas aos estereótipos e preconceitos culturais, contribuem para a baixa autoestima.

Em face desses aspectos citados e sempre lembrados quando se considera o envelhecimento, não seria surpresa verificar baixa autoestima entre os participantes do grupo experimental. Todavia, quando avaliados pela Escala de Avaliação da Autoestima de Rosenberg (1965) (Tabela 23) verificou-se que a média do grupo no pré-teste para esta variável foi de 32,56. Esta média representa, em dados percentuais, $81,40 \%$ do valor máximo que poderia ser obtido na escala, 40 pontos. Considerando que, quanto maior o escore obtido na escala maior é a autoestima, pode-se afirmar que o grupo adentrou ao programa com elevada autoestima.

Quando tal resultado é comparado com os dados apresentados na Tabela 29, sobre as perspectivas dos sujeitos em relação ao programa a ser desenvolvido, verificou-se que apenas $8,82 \%$ da amostra almejava a melhora na autoestima. Uma vez que a pergunta era aberta e discursiva, pode-se inferir que, embora os idosos não utilizassem o rótulo autoestima, pela categorização das respostas na tabulação é possível inferir que havia alguma compreensão sobre o conceito de autoestima.

No pós-teste, a média do grupo para esta variável foi de 33,47, uma diferença de apenas 0,71 pontos entre as medias do pré e pós-teste. Estatisticamente não houve diferença significante na comparação entre as fases pré e pós-teste $(p=$ $0,131)$.

Todavia, na comparação do pós com reteste foi constatada diferença significante $(p=0,007)$, (Tabelas 23 e 36), indicando um aumento, ainda que pequeno na autoestima de 33,47 a 34,88 .

Mesmo não apresentando diferença significante entre o pré e pós-teste, os dados coletados ao término do programa com a questão aberta sobre se as 
perspectivas ao final do programa foram alcançadas, 58,82\% dos sujeitos declararam que houve melhora na autoestima e 61,76\% afirmaram sentirem-se mais felizes e capazes. Este dado também foi evidenciado na escala de percepção sobre modificações após o programa, em que 50,00\% da amostra citou que a autoestima está muito melhor, $26,47 \%$ melhor e $17,65 \%$ bem melhor.

Mesmo que as representações sociais da velhice estejam fortemente associadas às doenças, incapacidades, dependência, depressão, improdutividade, isolamento e, em especial, a baixa autoestima (VIETTA, 2015), os idosos participantes do grupo experimental desta pesquisa não apresentaram tais características, contrariando os estereótipos a eles atribuídos. Os avanços da Medicina e o acesso às informações sobre o envelhecimento propõem aos idosos envelhecerem mais e melhor, de forma que a percepção da velhice como fase decadente e infeliz não seja mais considerada.

A elevada autoestima supõe que o idoso esteja mais motivado à realização das atividades propostas, não seja dominado pela angústia e que tenha objetivos a serem alcançados.

No entanto, como discutido por Lemos et al (2006) não podemos generalizar a postura da sociedade e nem a postura dos idosos diante do envelhecimento, mas pode-se considerar que tais idosos vivem de forma bastante diversificada e mesmo em condições psicossociais tão adversas, encontramos idosos que se sentem felizes, que se dizem contentes com sua vida.

Outro fator importante a ser considerado para a elevada autoestima apresentada pelo grupo avaliado, pode ser devido a uma tendência de maximizar a autoestima, que parece ser um problema do instrumento utilizado. Mesmo com respaldo e importância internacional, o instrumento identifica escores de autoestima 
elevados na maioria dos estudos em que é utilizado, como discutido por Meurer et. al (2011).

Considerando o aumento da autoestima entre as fases pós e reteste no grupo experimental, talvez a programa de intervenção pudesse sugerir resultados mais elevados a esta variável, se os idosos do grupo participante tivesse baixa autoestima ao adentrarem ao programa.

Para buscar uma explicação para a melhora da autoestima após três meses do término do programa, retornamos às mediações em que o programa foi aplicado, bem como a discussão sobre algumas considerações apontadas pelos autores sobre os motivos que elevam a autoestima.

A primeira consideração a ser apresentada é a estabelecida por Branden (1996) de que ao conviver com outros indivíduos com elevada autoestima, há o fortalecimento dos pilares da autoestima tais como 0 da prática da autorresponsabilidade e da autoafirmação. Coopersmith (1967) propõe que quando os pilares da autoestima são corretamente utilizados e desenvolvidos, a autoestima se fortalece.

A segunda consideração refere-se ao valor (merecimento) que o indivíduo recebe dos outros (BRADEN, 1996), tais como afeto, elogios e atenção, os quais fortalecem a autoestima relacionada ao pilar da autoaceitação. Tais valores são enfatizados durante a mediação do PEI pelos critérios de mediação, mencionados por Souza et. al (2003) e Carvalho (2008), quais sejam: a) sentimento de pertencer, que proporciona ao mediando o sentimento de inclusão, de sentir-se acolhido e aceito socialmente; b) sentimento de competência: o envolvimento do mediador no desenvolvimento da autoconfiança do mediando, motivando-o e encorajando-o a alcançar os objetivos; c) desafio: ajudar o mediando a enfrentar o medo do 
desconhecido e adquirir resistência para manter-se em situações que proporcionem desequilíbrio; d) otimismo: acreditar na possibilidade de resolver problemas; e) transcendência: promover a aquisição de princípios que sejam generalizados à outras situações.

É importante salientar que os critérios de mediação não são estanques (ver capítulo 2), todos eles estão presentes durante o desenvolvimento do processo mas, para a discussão da autoestima foram destacados apenas alguns.

Selecionou-se alguns dos relatos dos participantes que demonstraram mudanças positivas na autoestima decorrentes da intervenção.

Quando cheguei aqui eu me achava um lixo. Eu disse no primeiro dia de aula pra minha filha: Ah! filha eu nem vou saber fazer tudo aquilo de pontos (risos), que nem ia acompanhar a turma. Aí depois você foi explicando que cada pessoa fazia no seu tempo, que cada pessoa teve uma vivência, ai eu fui melhorando. E agora eu gosto mais de mim, me sinto boa para coisas, não tenho medo (grifo nosso). Vou fazer até curso de inglês. (AM3).

Eu era triste, mas bem mais triste, assim eu me preocupava muito com o problema dos outros, esquecia de mim. Agora não, eu penso em mim primeiro, depois eu vou tentar ajudar alguém. Cuido muito bem da minha família, dos meus netos, tinha menos paciência com eles, agora eu tenho. Brinco de se jogar no chão, de pintar, de escrever, de dançar. Tá muito bom. Tá ótimo. Eu tô feliz. Me sinto gente viva. (grifo nosso) (AM1).

Um dos temas focados pela pesquisadora durante as mediações e discussões nas sessões, referia-se ao conceito de ser velho, da velhice e da capacidade de executar tarefas independente da idade, de acordo com suas potencialidades e limites, o que vai ao encontro do pilar da autoaceitação. Estes 
conceitos foram discutidos porque alguns idosos, mediante a apresentação da folha do instrumento a ser desenvolvida, remetia-se a incapacidade de executá-las e dentre estas incapacidades a de ser velho era fator predominante. Ou seja, como definido por Neri (2000), social e culturalmente há uma representação de que ser velho é ser incapaz, e, mesmo que os idosos lutem contra esta ideia, muitos deles deixavam claro, nas discussões das sessões, que se sentiam incapazes. Com o decorrer das mediações, este conceito dissipou-se.

\subsection{Resolução de Problemas}

A resolução de problemas refere-se à capacidade de abstração do indivíduo, assim como à capacidade de mudar estratégias cognitivas em resposta a mudanças ambientais (BRITO et al., 2012), visando a extinção de barreiras entre o estado atual e o estado que se procura atingir (SCHNEIDER, 2006).

Para a avaliação desta variável foram utilizados o Teste WISCONSIN de Classificação de Cartas - versão para idosos (WCST) para os grupos experimental e controle e o subteste Cubos da Escala Wechsler Abreviada de Inteligência (WASI) somente para o grupo experimental, visando verificar a transferência da aprendizagem.

Os resultados apresentados na Tabela 33 quando da avaliação do WCST na análise intragrupos no pré-pós-teste indicam que o grupo experimental apresentou melhor desempenho no WCST em nove dos dez indicadores interpretativos do teste após a intervenção cognitiva, enquanto que o grupo controle não apresentou nenhuma diferença significante. A melhora do desempenho também foi observada no grupo experimental na comparação pós-reteste em quatro dos dez indicadores interpretativos, enquanto seis destes indicadores mantiveram-se sem alterações 
nesta fase. Este fato demonstra que o programa de intervenção proporcionou melhoras de desempenho nos indicadores interpretativos no pós-teste e em alguns indicadores no reteste, e manutenção de melhorias no reteste. Quando são analisados os resultados intergrupos (Tabela 38), verifica-se que o grupo experimental demonstra melhor desempenho na fase pós-teste em sete dos 10 indicadores interpretativos com a direção da diferença favorável ao grupo experimental.

No tocante ao teste de transferência, subteste Cubos da Escala Wechsler Abreviada de Inteligência (WASI), aplicado para verificar a transferência de aprendizagem, constata-se melhor desempenho do grupo experimental na fase pósreteste. Esses dados confirmam a influência positiva da intervenção sobre a variável resolução de problemas.

O Teste Wisconsin de Classificação de Cartas (WCST) é considerado uma medida das funções executivas e requer a capacidade do examinando de desenvolver e manter uma estratégia apropriada de solução de problema em meio a condições de estímulos mutáveis a fim de atingir uma meta futura (CUNHA et al. 2005; KRISTENSEN, 2007; TRENTINI et al. 2010).

No presente estudo, verificou-se um aumento significativo do desempenho dos idosos do grupo experimental, no pós-teste, em medidas de funções executivas, indicando que o treino ocasionou efeitos positivos sobres essas funções, que são mais sensíveis aos efeitos do processo de envelhecimento (LEVINE et al., 2007). Estudos mostram que déficits nas funções executivas estão associados ao declínio nas atividades funcionais e ao maior risco de mortalidade entre idosos (JOHNSON et al., 2007; LEZAK et al., 2004). LEZAK et al. (2004) ressaltam a importância da integridade das funções executivas, afirmando que o indivíduo pode permanecer 
independente e produtivo, mesmo apresentando outras formas de perdas cognitivas, se as funções executivas se encontram intactas.

De acordo com Sternberg (2003) há sete etapas no processo de solução de problemas: 1) reconhecer e identificar o problema; 2) definir e representar mentalmente o problema; 3) construir estratégias para a resolução; 4) organizar o conhecimento sobre o problema; 5) alocar recursos físicos e mentais; 6) monitorar o progresso em direção à meta; 7) avaliar a precisão da resolução do problema. Como especificado pelo autor, esta sequência não ocorre de forma rígida, porém o indivíduo para ser bem-sucedido deve apresentar flexibilidade nas mudanças de estratégias.

Esta flexibilidade na mudança de estratégias para a resolução de problemas é avaliada pelo indicador interpretativo do WCST, respostas perseverativas que apresentou decréscimo do pré para o pós-teste, mantendo-se estável no reteste.

Dos instrumentos do PEI Standard I, na percepção da pesquisadora, a tarefa de Organização de Pontos e o de llustrações, parece ter alguma relação com o indicador em apreço.

De acordo com Feuerstein e Hoffman (2000) e Souza et al. (2003), para a execução da tarefa o participante deve elaborar um plano adequado para obter sucesso e delinear os passos por meio dos quais os objetivos serão atingidos.

Durante a mediação, é necessário que o indivíduo tenha a percepção clara e precisa de qual figura será encontrada na nuvem de pontos, eliminando respostas por ensaio e erro, realizando o transporte visual da figura na nuvem de pontos antes de traçá-la. Após estas etapas, o mediando deve verificar, com exatidão, se as etapas propostas para a organização do pontos na folha do instrumento estão adequadas. 
Estas etapas envolvidas na projeção de relações virtuais para o traçado da figura na nuvem de pontos, vão ao encontro das etapas requeridas para a solução de problemas, propostas por Sternberg (2003). Caso o indivíduo verifique que as estratégias não estão adequadas para encontrar a figura na nuvem de pontos, (monitorar o progresso em direção à meta), o mediando deve ter a flexibilidade para alterar as estratégias de busca. O instrumento Organização de Pontos parece ser adequado para o desenvolvimento da variável resolução de problemas, pois, além do desenvolvimento das funções cognitivas próprias do instrumento estabelecidas pelo Prof, Reuven Feuerstein (percepção clara e precisa, orientação espacial, conservação e constância, precisão e exatidão, transporte visual, comportamento somatório, controle da impulsividade, eliminação de resposta por ensaio e erro) corrobora com as etapas propostas por Sternberg (2003) para a resolução de problemas.

Também, o instrumento llustrações, que tem como objetivo apresentar ao mediando situações problemas que levam a um desequilíbrio e devem ser percebidos e reconhecidos (FEUERSTEIN e HOFFMAN, 2000), parece contribuir para a capacidade de solucionar problemas. Segundo Souza et al. (2003), este instrumento requer que o mediando perceba a existência do problema, utilize várias fontes de informação, faça comparações e tome consciência das transformações ocorridas nos quadros da folha do instrumento. Ou seja, o instrumento propõe um problema que deve ser solucionado pelo mediando utilizando-se de hipóteses/estratégias para solução (busca de soluções para resolvê-lo). Ao final da mediação, tanto o problema como a solução são transferíveis às atividades do dia-adia do mediando, o que Feuerstein nomeia de transcendência. Neste instrumento, 
como no de Organização de Pontos, as etapas propostas por Sternberg (2003) também são bastante similares.

Os dados apresentados na Tabela 30, sobre as perspectivas que o aluno tinha em relação ao programa a ser desenvolvido, demonstram que $50,00 \%$ da amostra declarou melhoras na organização/planejamento das atividades, 73,53\% declararam melhoras em pensar e refletir antes de agir e $38,24 \%$ melhoras no pensamento rápido.

$\mathrm{Na}$ escala de percepção subjetiva sobre modificações após o programa, $23,53 \%$ da amostra selecionaram a alternativa muito melhor neste quesito, 35,29 \% bem melhor e $41,18 \%$ melhor.

Como ilustração desta percepção de melhora, dois relatos merecem destaque: ... se você querer saber, eu estou fazendo cálculos de cabeça...meu raciocínio ficou mais rápido. Eu faço as coisas de casa com mais organização, antes parava uma coisa, começava outra, não terminava as duas; agora não, começo e termino e já organizo o meu dia quando acordo. (AM1).

Eu queria fazer tudo de uma vez, muita coisa. Quando chegava seis horas da tarde eu falava: Não fiz nada. Agora eu programo e organizo tudo. (AP2).

Assim sendo, tanto em relação às percepções subjetivas da melhora na resolução de problemas, quanto aos testes psicológicos que avaliaram esta variável, o programa de intervenção parece ter sido adequado ao objetivo de melhorar esta habilidade.

\subsection{Memória}

Dentre todas as funções cognitivas, a memória é a que mais apresenta queixa entre os idosos. Quando da questão elaborada no início do programa para que o 
idoso respondesse quais eram as perspectivas visadas no programa de intervenção, $100 \%$ da amostra do grupo experimental declarou almejar melhoras na memória (Tabela 29).

Ao final do programa, novamente fez-se a pergunta sobre se as perspectivas foram alcançadas e $91,18 \%$ da amostra relatou ter percebido melhoras na memória (Tabela 30).

$\mathrm{Na}$ escala de percepção subjetiva sobre modificações após o programa, $41,18 \%$ da amostra indicou melhoras na memória, 23,53\% indicou que a memória está bem melhor e $26,47 \%$ indicou que a memória está muito melhor. Se somarmos estas percentuais, podemos constatar que $91,18 \%$ da amostra consideram ter havido, pelo menos, alguma melhora na memória após o programa de intervenção (Tabela 28).

Segundo Baddeley et al. (2011), a memória pode ser definida como a capacidade de adquirir, reter e usar informações e conhecimentos. Para Tulving (2000) ela é o meio pelo qual retemos e nos valemos de nossas experiências passadas para usar estas informações no presente. Para Squire e Kandel (2003) é o processo pelo qual aquilo que aprendemos persiste ao longo do tempo.

Para avaliar a memória nesta pesquisa, antes e após o programa de intervenção, foram utilizados quatro instrumentos: ACE-R subescala memória, Pseudopalavras, Teste de Memória de Lista de Palavras nas fases pré-pós-reteste. O Teste de Extensão de Dígitos em Ordem Direta e em Ordem Inversa da Escala de Memória de Wechsler de Inteligência para Adultos WAIS-III foi administrado na fase pós-reteste com objetivo de verificar a transferência de aprendizagem. No grupo experimental, como apontado na Tabela 34, diferenças significantes foram encontradas entre as fases pré-reteste no sentido do reteste. Estes dados parecem 
demonstrar a eficácia do programa de intervenção no tocante a esta capacidade, mesmo após três meses do término do programa (reteste).

Os testes de memória utilizados neste estudo avaliam a memória de curto prazo (memória imediata, capacidade de reter e manipular as informações) e a velocidade de processamento de informações, que também foi avaliada pelo teste Trilhas B na função atenção e concentração.

No teste de extensão de dígitos, verificou-se também diferença significante, no pós-reteste, evidenciando melhora na memória de trabalho.

Tais resultados parecem sugerir que o programa possibilitou melhor desempenho na capacidade de manipular e reter informações.

Relatos que podem evidenciar a melhora da memória, por meio das entrevistas:

Lembro dos números do telefone de primeira, antes não, eu tinha que ficar digitando, parava, olhava de novo, digitava. Agora não, eu olho o número uma vez, já digito. Lembro todos. Quando eu fiz isso eu falei: Meus Deus eu tô lembrando. (AM1).

Nossa! Carla estou muito contente, obrigada por você dar essa chance para nós. Adorei. Me ajudou muito na memória. (AL4).

Neri (2002) salienta que as perdas da memória não devem ser atribuídas apenas ao déficit no processamento de informações, mas também a podem ser atribuídas a baixa autoestima, falta de confiança nas próprias capacidades, depressão, estresse, fadiga, efeitos colaterais dos remédios, entre outros.

Relacionando os instrumentos do PEI para o trabalho de memória durante as mediações, a pesquisadora considera que os seis instrumentos do PEI trabalhados 
na intervenção tenham possibilitado ênfase na melhora da memória, uma vez que durante a mediação as informações do mediando devem ser resgatadas, manipuladas e organizadas a fim de possibilitar a resposta à folha do instrumento. Não foi identificado, nos estudos dos manuais e na literatura investigada pela pesquisadora, um instrumento específico que foque exclusivamente o trabalho de memória. Porém, pela definição dada à memória, todos os instrumentos são capazes de desenvolvê-la.

\subsection{Atenção e Concentração}

Quando da questão elaborada no início do programa para que o idoso respondesse quais eram as perspectivas almejadas com o programa de intervenção, $32,35 \%$ da amostra do grupo experimental respondeu que almejava alcançar melhoras na atenção e concentração (Tabela 29).

Ao final do programa, novamente fez-se a pergunta sobre se as perspectivas foram alcançadas ao final do programa e $44,12 \%$ da amostra relatou que houve melhoras na atenção (Tabela 30).

Juntamente com esta pergunta, foi solicitado o preenchimento da escala de percepção subjetiva sobre modificações após o programa e 44,12\% da amostra indicou melhoras na atenção e concentração, 20,59\% indicou que a atenção e concentração está bem melhor e 32,35\% indicou que a atenção e concentração está muito melhor. Se somarmos estes percentuais, podemos constatar que $97,06 \%$ da amostra consideram ter havido melhoras na atenção e concentração após o programa de intervenção (Tabela 28).

A atenção envolve algumas funções cognitivas como a memória operacional, a manutenção do estado de alerta e a capacidade de focalizar no estímulo proposto, 
ignorar estímulos distratores e modificar o foco quando necessário (MALLOY-DINIZ et al., 2008).

Para avaliarmos a atenção e concentração na pesquisa, antes e após o programa de intervenção, foram utilizados três testes para comparação entre os grupos experimental e controle (ACE-R subescala atenção e orientação, Trilhas A e Trilhas B) nas fases pré-pós-reteste e a bateria BPA na fase pós-reteste com objetivo de verificar a transferência de aprendizagem. No grupo experimental, todos os testes apresentaram diferenças significantes na direção pós-reteste, e na bateria BPA também ocorreu diferença significante no sentido reteste-pós. Estes dados parecem demonstrar a eficácia do programa de intervenção nas capacidades atenção e concentração. Importante salientar que tal melhora no desempenho manteve-se após três meses do término do programa.

Os testes utilizados para a avaliação dessas variáveis do programa foram o teste Trilhas B para a atenção dividida (STRAUSS et al., 2006; KRISTENSEN, 2007), o teste de dígitos de ordem direta e inversa para a atenção seletiva e dividida e um dos testes da bateria BPA focado na avaliação da atenção dividida. Verificouse em todos estes testes diferenças significantes no grupo experimental (Tabelas 34 e 35). Alguns autores como Kim et al. (2002), Fenimam et al. (2007) e Kinjo (2011) associam em seus trabalhos a atenção à memória, ou seja, a retenção dos dados na memória dependeria da atenção às informações. Assim, pode-se inferir que diferenças significantes nos testes de memória implicam ou resultam em melhores desempenhos em atenção e concentração.

Em relação à atenção e concentração, verificou-se que o programa possibilitou melhor desempenho na capacidade de manutenção do estado de alerta e na focalização no estímulo proposto, ignorando estímulos distratores e 
modificando o foco quando necessário, conforme a definição MALLOY-DINIZ et al. (2008) para a função.

Alguns relatos evidenciam a melhora da atenção e concentração, tais como os de dois participantes escolhidos para efeito de ilustração:

Com certeza aqueles que você citou na aula: quando a gente está fazendo uma coisa, fazer uma coisa de cada vez porque, às vezes, eu estava com a chave e tinha que guardar, aí eu achava outra coisa pra fazer, aí acabava perdendo a chave não sabia onde estava, aí eu aprendi a pensar pra fazer as coisas, para mim foi muito importante. Comecei a ler e fazer palavras cruzadas, com o tempo vai ficando com a memória melhor. Eu achei muito bom. (AM2)

A atenção melhorou sim. Às vezes você está, igual agora eu sai na rua, eu atravessava em qualquer lugar. Agora não, eu já vou mais para a faixa de pedestres, eu tenho que atravessar aqui na faixa que é mais seguro, antes eu atravessava em qualquer lugar. Quando a minha filha fala eu presto atenção e não preciso perguntar mais o que ela falou. Presto atenção em desligar o gás na hora de sair, guardar a chave no lugar certo pra não ficar procurando. (risos). Antes a minha filha falava pra comprar uma coisa. Passava o dia e quando eu ia comprar tinha que ligar pra ela pra lembrar. Agora eu já lembro. Minha filha falou que eu tô ligeira (risos). Pra pegar receita na TV; eu também presto atenção pra marcar no papel e não esqueço. (AP4).

Relacionando os instrumentos do PEI para o trabalho de atenção e concentração durante as mediações, a pesquisadora considera que os seis instrumentos do PEI trabalhados na intervenção tenham possibilitado ênfase na melhora da atenção e concentração, como enfatizado também para a variável memória, uma vez que durante a mediação os instrumentos requerem o uso da 
atenção dividida, concentrada e alternada para que o mediando possa organizar as informações a fim de possibilitar a resposta à folha do instrumento. Não foi identificado, nos estudos dos manuais e na literatura investigada pela pesquisadora, um instrumento específico que foque exclusivamente $\mathrm{o}$ trabalho de atenção e concentração.

\subsection{Raciocínio abstrato e Raciocínio verbal abstrato}

O raciocínio abstrato e o raciocínio verbal abstrato não foram focos de análise desta pesquisa. Porém, como descrito no capítulo 3 (Método), foi utilizado o subteste cubos da Escala Wechsler Abreviada de Inteligência - WASI para avaliação da variável resolução de problemas com o objetivo de verificar a transferência da aprendizagem e optou-se por aplicar os outros subtestes da escala, com exceção do subteste vocabulário.

No grupo experimental, como apontado na Tabela 37, diferenças significantes foram encontradas entre as fases pós-reteste no sentido reteste, para o subteste Raciocínio Matricial (raciocínio abstrato) e Semelhanças (raciocínio verbal abstrato). Estes dados parecem demonstrar a eficácia do programa de intervenção no tocante a estas capacidades, mesmo após três meses do término do programa (reteste).

Considerando que os instrumentos do PEI aplicados durante a intervenção possam ter contribuído para estas melhoras, torna-se importante relacionar tais resultados com os instrumentos aplicados.

Dos instrumentos do PEI Standard I, na percepção da pesquisadora, a tarefa de Percepção Analítica parece ter alguma relação com o indicador raciocínio abstrato avaliado pelo subteste Raciocínio Matricial e as tarefas Comparações e 
Classificações para o indicador raciocínio verbal abstrato avaliado pelo subteste Semelhanças.

Como salienta Souza et al. (2003), comparar requer estabelecer relações que conduzem o mediando ao pensamento abstrato. A capacidade de comparar requer mais do que reconhecer semelhanças ou diferenças, mas uma conduta organizada a fim de estabelecer relações. Para Feuerstein e Hoffman (2000), o objetivo do instrumento Comparações é o de desenvolver uma conduta comparativa; aumentar o repertório de atributos por meio dos quais objetos, eventos, pessoas, etc. podem ser comparados; introduzir parâmetros que são característicos críticos e semelhantes e formular conceitos.

A classificação baseia- se na comparação. É uma habilidade básica para o pensamento lógico pois envolve o agrupamento dos fenômenos, fatos e coisas e ideias em conjuntos e subconjuntos, com base na semelhança e diferenças entre os elementos. Requer do mediando precisão em sua percepção, rotular, comparar e discriminar, utilizar informações relevantes de diversas fontes. A habilidade de classificar está baseada nas capacidades de comparação, diferenciação e discriminação (MEIER \& GARCIA, 2009).

Desta forma, a metodologia utilizada para a realização do subteste Semelhanças da Escala Wechsler Abreviada de Inteligência vai ao encontro do trabalho desenvolvido nos instrumentos Comparações e Classificações do PEl.

O instrumento Percepção Analítica tem como objetivo desenvolver no mediando as habilidades de diferenciação (dividir uma figura em partes) e integração (reunir as partes em um todo) de modo que ele (o mediando) possa utilizar os processos de percepção para o desenvolvimento de estratégias cognitivas para resolver a folha do instrumento (FEUERSTEIN \& HOFFMAN, 2000). 
Souza et al. (2003) aponta que, neste instrumento, o mediando utilizará de experiências aprendidas nos outros instrumentos a fim de que possa reestruturar um determinado campo visual, o que parece ser aplicado quando da resolução das pranchas do subteste Raciocínio Matricial da Escala Wechsler Abreviada de Inteligência.

\subsection{Considerações e limitações do trabalho}

Em face dos seus resultados finais, acreditamos que é possível afirmar que o PEI possibilitou uma melhora geral no desempenho cognitivo de idosos do grupo que recebeu a intervenção quando comparado aos idosos que não receberam a intervenção nas áreas ou domínios da solução de problemas, memória, atenção e concentração.

Assim, a hipótese geral deste trabalho de que idosos submetidos à intervenção apresentariam um melhor desempenho nas variáveis estudadas quando comparados a idosos que não foram a ela submetidos, parece ter sido confirmada.

Todavia, faz-se necessário lembrar algumas limitações deste trabalho para melhor contextualizar seus resultados e orientar eventuais réplicas.

A primeira limitação citada diz respeito ao pequeno número de sujeitos participantes. Tal limitação ocorreu principalmente em face do critério de seleção dos sujeitos estabelecer que apenas idosos considerados saudáveis poderiam participar do estudo. Grande parte dos idosos entrevistados faziam uso de psicotrópicos e/ou demonstravam escores sugestivos de depressão, e por este motivo não puderam fazer parte da amostra. Deste modo, a possibilidade de uma ampla generalização dos dados fica sensivelmente prejudicada. 
Uma segunda limitação refere-se ao prazo estipulado para o final da intervenção, com datas definidas para início e fim, sem muita flexibilidade, o que pode ter prejudicado a elaboração das informações por parte dos alunos mais lentos e não permitiu que fossem utilizadas todas as folhas dos instrumentos.

É preciso ressaltar também que, ao assumir a dupla tarefa - de mediar e pesquisar - assumiu-se conscientemente os riscos, uma vez que críticas poderiam ser feitas em ambas as decisões. Um de tais riscos é o de que as respostas às entrevistas possam ter sido influenciadas pela presença da mediadora-pesquisadora que realizou a intervenção. Talvez os alunos se sentissem mais à vontade para emitir suas críticas e opiniões se o entrevistador fosse outro professor/pessoa. Não pareceu à pesquisadora que isto tenha ocorrido, porém tal possibilidade não pode ser inteiramente eliminada.

Finalmente, é importante assinalar que este estudo foi realizado em apenas um grupo de pessoas de classe média, predominantemente feminina (dos 66 participantes, apenas 7 eram do sexo masculino), na faixa etária acima de 60 anos, o que limita seu poder de generalização. É sugerido e esperado que sejam realizadas pesquisas semelhantes abrangendo diferentes faixas etárias, níveis sociais e classes econômicas e de gênero.

Em suma, apesar das limitações, inevitáveis em qualquer trabalho científico, a autora e seu orientador acreditam e esperam que este trabalho possa auxiliar os profissionais ligados à Educação, Psicologia, Gerontologia e Saúde Pública a aumentar a adesão dos idosos às atividades cognitivas, relacionadas ao PEI ou a outras intervenções, fundamentais para melhorar a qualidade de vida destes indivíduos e lhes proporcionar uma velhice bem-sucedida. 


\section{REFERÊNCIAS BIBLIOGRÁFICAS ${ }^{5}$}

Associação Brasileira de Empresas de Pesquisa (ABEP). CRITÉRIO DE CLASSIFICAÇÃO ECONÔMICA BRASIL Disponível em: www.abep.org/Servicos/Download.aspx?id=02. Acesso em fev. 2014.

AGUERO-TORRES, $\mathrm{H}$. et al. Dementia is the major cause of functional dependence in the elderly: 3-year follow-up data from a population-based study. American Journal Public Health, New York, v. 88, p. 1452-1456, 1998.

AGUERO-TORRES, $\mathrm{H}$. et al. The impact of somatic and cognitive disorders on the functional status of the elderly. Journal Clinical Epidemiology, USA, v. 55, n. 10, p. 1007-1012, 2002.

ALVARENGA, M.R.; CERCHIARI, E.A.N.; ESPINDOLA, A.C.L.; MARTINS, P.C.S. Oficina de memória como estratégia de intervenção na saúde mental de idosos. Estudos interdisciplinares do envelhecimento, Porto Alegre, v. 20, n. 1, p. 205-218, 2015.

ALMEIDA, O. P. Instrumentos para avaliação de pacientes com demência. Revista Psiquiatria Clínica, v . 26, n . 2, p. 152-157, 1998.

ANNUNCIATO, N. Plasticidade do Sistema Nervoso e Reabilitação. Porto Alegre, 2005.

ANTUNES, G.; MAZO G. Z.; BALBE, G.P. Relação da autoestima entre a percepção de saúde e aspectos sociodemográficos de idosos praticantes de exercício físico. Revista de Educação Física UEM, 2001 Disponível em: https://dx.doi.org/ 10.4025/reveducfis.v22i4.10825. Acesso em 11 jun. 14.

APOSTOLO, J.L.A.; CARDOSO, D.F.B.; MARTA, L.M.G.; AMARAL, T.I.O. Efeito da estimulação cognitiva em idosos. Revista de Enfermagem Referência. v. 3, n. 5, p. 193-201, 2011.

ARAUJO, L.U.A.; SILVA GAMA, A.Z.; NASCIMENTO, F.L.A.; OLIVEIRA, H.F.V.; AZEVEDO, W.M.; DE ALMEIDA, H.J.B. Avaliação da qualidade da atenção primária à saúde sob a prespectiva do idoso. Revista Ciência \& Saúde Coletiva, v. 18, n. 8, p. 3521-3532, 2014.

\footnotetext{
${ }^{5}$ De acordo com a Associação Brasileira de Normas Técnicas. NBR 6023.
} 
BADDELEY, A. D.; HITCH, G. Working memory. In: Bower GH, editor. The Psychology of Learning and Motivation. V. 8, pp. 47-89, New York: Academic Press; 1974.

BADDELEY, A.; WILSON, B. A. Prose recall and amnesia: implications for the structure of working memory. Neuropsychologia, v. 40, n. 10, p.1737-1743, 2002.

ARTDMED, 2011.

ANDERSON, M.C.; EYSENCK, M.W. Memória.Porto Alegre:

BADHAM, S.P.; MAYLOR, E.A. Age-related associative deficits and the isolation effect. Aging, Neuropsychology, and Cognition. v. 20, n. 4, p. 405-428, 2013.

BALTES, P. B. Envelhecimento Cognitivo: potencialidades e limites. Gerontologia. v. 1, n. 2, p. 23-44., 1994.

BALTES, M. M. (1991). Psychological perspectives on successful aging: the model of selective optimization with compensation. In: Successful aging: perspectives from the behavioral sciences. Cambridge: Cambridge University Press. 1991.

BALL., K.; BERCH, D.B.; HELMERS, K.F.; JOBE, B.J.; LEVECK, M.D.; MARSISKE, M.; MORRIS, J. N.; REBOK, G. W.; SMITH, D.M.; TENNSTEDT, S.L.; UNVERZAGT, F.W. ; WILLS, S. L. Effects of Cognitive Training Interventions With Older Adults. The Journal of the American Medical Association, v. 288, n. 18, p. 2271-2281, 2002.

BANHATO, E.F.C.; NASCIMENTO, E. Função executiva em idosos: um estudo utilizando subtestes da Escala WAIS-III. Psico-USF, v. 12, n. 1, p. 65-73, jan./jun. 2007.

BATISTA, J.J.A. Os efeitos da metodologia de Feuerstein no desempenho de trabalhadores do setor de serviços: um estudo de caso. Porto Alegre, 2000. $232 \mathrm{f}$. Dissertação (Mestrado) - Escola de Administração, Universidade Federal do Rio Grande do Sul, Porto Alegre, 2000.

BEAR, M. F; CONNORS, B. W.; PARADISO, M. A. Neurociências: desvendando o sistema nervoso. Porto Alegre: Artmed, 2002.

BECKERT, M. Perfil neuropsicológico de idosos com e sem depressão maior. Porto Alegre, 2015. 81f. Dissertação (Mestrado em Gerontologia Biomédica) - Instituto de Geriatria e Gerontologia, Pontifícia Universidade Católica do Rio Grande do Sul PUCRS. 
BELTRÁN. J.M. La Mediación en el proceso de aprendizaje. Madrid:Bruno, 1994.

BERMAN, K.F.; OSTREM, J.L.; RANDOLPH, C.; GOLD, J.; GOLDBERG, T.; COPPOLA, R.; CARSON, R.E.; ALTES, P. B.; HERSCOVITCH, P.; WEINBERGER, D.R.. Physiological activation of a cortical network during performance of the Wisconsin Card Sorting Test: A positron emission tomography study. Neuropsychologia. v. 33, n. 8, p. 1027-1046.

BERTOLUCCI, P. H. F.; BRUCKI, S. M. D.; CAMPACCI, S. R.; JULIANO, Y. O miniexame do estado mental em uma população geral: Impacto da escolaridade. Arquivos de Neuropsiquiatria, v. 52, p. 1-7, 1994.

; OKAMOTO, I.H.; BRUCKI, S.M.D.; SIVIERO, M. O.; TONIOLO, N. J.; RAMOS, L.R. Applicability of the CERAD neuropsychological battery to brazilian elderly. Arquivos de Neuropsiquiatria. v. 59, p. 532-536, 2001

BETTI, M.P.; KNIJNIK, J.; VENÂNCIO, L.; SANCHES NETO, L. Fundamentos filosóficos e antropológicos da Teoria do Se-movimentar e a formação de sujeitos emancipados, autônomos e críticos: o exemplo do currículo de Educação Física do Estado de São Paulo. Movimento, Porto Alegre, v. 20, n. 4, p. 1631-1653, out./dez. de 2014.

BOGDAN, R.; BIKLEN, S. Investigação qualitativa em educação. Porto: Porto, 1997.

BOTTINO, C.M.C. et al. Doença de Alzheimer, transtorno cognitivo leve e envelhecimento normal: avaliação por medidas de ressonância magnética. Revista de psiquiatria clínica, v. 25, n. 2, p-88-97, 1988.

BRANDEN, N. The psychology of self-esteem: a revolutionary approach to selfunderstanding that launched a new era in modern psychology. 32 ed. São Francisco: Jossey-Bass, 1996.

BRITO, I.L.; AREOSA, S.C.; LOPES, R.M.F.; ARGIMON, I.I.L. Avaliação das funções executivas em idosos acometidos por doenças crônico-degenerativas.. Cuadernos de Neuropsicología, v. 6, n. 1, p-88-97, 2012.

BROWN, A.L. The development of memory: knowing, knowing about knowing, and knowing how to know. Advances in child development and behavior, v.10,1975.

BRUCKI, S.M.D.; NITRINI, R.; CARAMELLI, P.; BERTOLUCCI, P.H.F.; OKAMOTO, I.H. Sugestões para o uso do Mini-Exame do Estado Mental no Brasil. Arquivos de Neurosiquiatria, v.61, p. 777-778, 2003. 
; ROCHA, M. S. G. Category fluency test: Effects of age, gender and education on total scores, clustering, in Brazilian Portuguese-speacking subjeticts. Brazilian Journal of Medical and Biological Research, v. 37, n. 12, p-1771-1777, 2004.

BRUM, P.S. Treino de memória para idosos saudáveis e com comprometimento cognitivo leve: benefícios sobre parâmetros cognitivos. 2012. 139 f. Dissertação (Mestrado) - Faculdade de Medicina da Universidade de São Paulo, São Paulo, 2012.

BUENO, J.M.; MARTINO, H.S.D.; FERNADES, M.F.S.; COSTA, L.S.; SILVA, R.R. Avaliação nutricional e prevalência de doenças crônicas não transmissíveis em idosos pertencentes a um programa assistêncial. Ciência e Saúde Coletiva. V. 13, n. 4, p. 1237-1246, 2008.

CALDAS, C. P. Cuidando do idoso que vivência uma síndrome demencial: a família como cliente da enfermagem. Texto Contexto Enfermagem, Florianópolis, v. 10, n. 2, p. 68-93, 2001.

CARVALHO, L.A. Mediação didática e aprendizagem na sala de aula. Perspectivas on line, v. 5, n. 2, 2008. Disponível em: http://www.perspectivas online.com.br. Acesso em 14 maio 2013.

CARVALHO, F.R.C. Treino de memória episódica com idosos normais. 2006. Dissertação (Mestrado) - Faculdade de Educação da UNICAMP, Campinas, 2006.

CRUZ, S. B. A teoria da modificabilidade estrutural de Feuerstein: aplicação do Programa de Enriquecimento Instrumental (PEI) em estudantes da $3 \stackrel{a}{a}$ série de escolas do ensino médio. 2007. 345 f. Tese (Doutorado) - Faculdade de Educação da Universidade de São Paulo, São Paulo, 2007.

CARVALHO, F. C. R.; NERI, A. L.; YASSUDA, M. S. Treino de Memória Episódica com Ênfase em Categorização para Idosos sem Demência e Depressão. Psicologia: Reflexão e Crítica, v. 23, n. 2, p. 317-323, 2010a.

CARVALHO, V. A.; BARBOSA, M. T.; CARAMELLI, P. Brazilian version of the Addenbrooke Cognitive Examination-revised in the diagnosis of mild Alzheimer disease. Cognitive Behavior Neurology. v. 23, n. 1, p.8-13. 2010 b.

; CARAMELLI, P. Brazilian adaptation of the Addenbrooke's Cognitive Examination-Revised (ACE-R). Dementia \& Neuropsychologia. v. p. 212216. 2007. 
CARVALHO, S. A.; BARRETO, S. M.; GUERRA, H. L.; GAMA, A. C. C. Oral language comprehension assessment among elderly: A population based study in Brazil. Preventive Medicine, v. 49, p 541-545, 2009.

CÉSAR, K.G. Estudo da prevalência de comprometimento cognitivo leve e demência na cidade de Tremembé, estado de São Paulo. 2014. 156 f. Tese (Doutorado) Faculdade de Medicina da Universidade de São Paulo, São Paulo, 2014.

COLL, C.; POZO, J.I.; SARABIA, B.; VALLS, E. Os conteúdos na reforma: ensino e aprendizegem de conceitos, procedimentos e atitudes. Porto Alegre: ARTMED, 1998.

COLLIE, A., MARUFF, P.; DARBY, D.G.; MCSTEPHEN, M. 2003. The effects of practice on the cognitive test performance of neurologically normal individuals assessed at brief test-retest intervals. Journal of the International Neuropsychological Society, v .9, n. 3, p. 419-428, 2003.

COOPERSMITH S. The Antecedents of self-esteem. São Francisco: Freeman \& Co; 1967.

CORREA, R.C.R. Uma proposta de reabilitação neuropsicológica através do programa de enriquecimento instrumental (PEI). Ciência e Cognição, v .14, n. 2, p. 47-58, 2009.

COSENZA, R.M.; GUERRA, L.B. Neurociência e Educação: como o cérebro aprende. Porto Alegre: ArtMed, 2011.

CRUZ, S. B. A teoria da modificabilidade estrutural de Feuerstein: aplicação do Programa de Enriquecimento Instrumental (PEI) em estudantes da $3 \stackrel{a}{a}$ série de escolas do ensino médio. 2007. 345 f. Tese (Doutorado) - Faculdade de Educação da Universidade de São Paulo, São Paulo, 2007.

CUNHA, J. A.; TRENTINI, C. M.; ARGIMON, I. L.; OLIVEIRA, M. S.; WERLANG, B. G.; PRIEB, R. G. Teste Wisconsin de Classificação de Cartas - adaptação e padronização brasileira. São Paulo, SP: Casa do Psicólogo, 2005.

DA ROS, S.Z. Pedagogia e mediação em Reuven Feuerstein. O processo de mudança em adultos com história de deficiência. São Paulo: Plexus Editora, 2002.

DAMASCENO, B.P. Envelhecimento cerebral - o problema dos limites entre 0 normal e o patológico. Arquivos de Neuropsiquiatria, v. 57, n 1, p. 78-83, 1999. 
DELAZER, M.; SINZ, H. ZAMARIAN, L.; BENKE, T. Decision-making with explicit and stable rules in mild Alzheimer's disease. Neuropsychologia, n. 45 v. 8, p. $1632-$ 1641, 2007.

DELPERO, C.; MIONI, G.; RUBIO, J.L.; RAMOS, V.J.; MILÁN, E.G.; STABLUM, F. Decision-making and feedback sensitivity: A comparison between older and younger adults, Journal of Cognitive Psychology, v. 27, n. 7, p. 882-897, 2015.

DI CARLO, A.; LAMASSA, M.; BALDERESCHI, M.; INZITARI, M.; SCAFATO, E.; $\mathrm{FARCHI}, \mathrm{G}$. CIND and $\mathrm{MCl}$ in the italian elderly: frequency, vascular risk factors, progression to dementia. Neurology, v. 68, n. 22. p. 1909-1916, 2007.

DINI, G.M. Tradução para a língua portuguesa, adaptação Cultural e validação do questionário de auto-estima de Rosenberg. Dissertação (Mestre em Ciências Médicas - Cirurgia Plástica) - Universidade Federal de São Paulo - Escola Paulista de Medicina. São Paulo, 2000.

; QUARESMO, M.R.; FERREIRA L.M. Adaptação cultural e validação da versão brasileira da escala de auto-estima de Rosenberg. Revista da Sociedade Brasileira de Cirurgia Plástica, 2004; v. 19, n. 1

Disponível: http://www.rbcp.org.br/imageBank/PDF/19-01-04pt.pd. Acesso em 09 jun. 2014.

DIRIK, A. et al. Identifying the relationship among mental status, functional independence and mobility level in Turkish institutionalized elderly: Gender differences. Archives of Gerontology and Geriatrics, v. 42, n. 3, p. 339-350, 2006.

DUNLOSKY, J.; HERTZOG, C. Training programs to improve learning in later adulthood: helping olders adukts educate themselves. Ih: Hacker, D.J. DUNLOSKY, J. (orgs) Metacognition in educational theory and practice, Mahwah; New Jersey. p. 249-276, 1998.

FARIA JUNIOR, A. Ensino e educação para o idoso. Rio de Janeiro, 2000. Concurso para titular da Faculdade de Educação da Universidade do Estado do Rio de Janeiro.

FENIMAN, M.R.; ORTELAN, R.R.; LAURIS, R.P.; CAMPOS, C.F.; CRU, M.S. Proposta de instrumento comportamental para avaliar a atenção auditiva sustentada. Revista Brasileira de Otorrinolaringologia, v. 73, n. 4, p. 523-527, 2007.

FERREIRA, A.J.; GOULART, D.; STOBAUS, C.D.; MOSQUERA, J.J.M. Investindo na educação para um envelhecimento com qualidade. In: _ (org). Envelhecimento \& Educação. Porto Alegre : EdiPUCRS, 2012, p. $153-\overline{157 .}$

FERREIRA, C.L; SANTOS, L.M.O.; MAIA, E.M.C. Resiliência em idosos atendidos na Rede de Atenção Básica de Saúde em município do nordeste brasileiro. Revista 
da Escola de Enfermagem. 2014. Disponível em: http://dx.doi.org/10.1590/S008062342012000200009. Acesso: em 10 jun 2014.

FERRETTI, F.; BESKOW, G.C.T.; SLAVIERO,. R.C. RIBEIRO, C.G. Análise da qualidade de vida em idosos praticantes e não praticantes de exercício físico regular. Estudos interdisciplinares do envelhecimento, Porto Alegre, v. 20, n. 3, p. 729-743, 2015.

FERNANDES, P.M.; CIPRIANO, P.P.; BEZERRA, M, V. Síndrome da fragilidade e sua relação com aspectos emocionais, cognitivos, físicos e funcionais em idosos institucionalizados. Revista Kairós Gerontologia, v . 18, n. 1, p.163-175. 2015.

FERRI, C. P. et al. Global prevalence of dementia: a Delphi consensus study. Lancet, v. 366, n. 9503, p. 2112-2117, 2005.

FERRO, A.O; LINS, A.E.S.; FILHO, T.; EUCLIDES, M. Comprometimento cognitivo e funcional em pacientes acometidos de acidente vascular encefálico: Importância da avaliação cognitiva para intervenção na Terapia Ocupacional. Cadernos de Terapia Ocupacional da Universidade Federal de São Carlos, v. 21, n. 3, p. 521-527, 2013.

FEUERSTEIN, R. Instrumental Enrichment. An Intervention Program for Cognitive Modificability. Glenview: Scott, Foresman and Company, 1980.

; HOFFMAM. M.B. Guia do Professor. Salvador: ICELP/ Fundação Luis Eduardo Magalhães, 2000.

; KLEIN, P.; TANNENBAUM, A. Mediated learning experience (MLE). Theoretical, psychosocial and learning implications. 2 ed. London: Freund Publishing House, 1994.

Teoría da Modificabilidad Cognitiva Estructural. In: .; MAYOR, S.J.; MARTÍNEZ, B.J.M.; KRECHEWSKY, M.; TZURIEL, D.; HAYWOOD. H.C. Es modificable la inteligencia? Madrid: Editorial Bruno, 1998.

FALIK, L. H.; FEUERSTEIN, R. S. The cognitive elements of neural plasticity. 2013. Disponível em: http://www.neuropsychotherapist.com/cognitiveelements-neural-plasticity. Acesso em: 01 jul. 2013.

FIGUEIREDO, V.L.; Desempenhos nas Duas Tarefas do Subteste Dígitos do WISCIII e do WAIS-III. Psicologia: Teoria e Pesquisa, v. 23, n. 3, p. 313-318, 2007.

FINUNCARE, M.L.; ALHAKAMI, A.; SLOVIC, P. HIBBARD, J.H.; PETERTS, E.; MERTZ, C.K. MacGREGOR, D.G. Aging and decision making competence: an analysis of comprehension and consistency skills in older versus younger adults 
considering health-plan options. Journal Behavioral Decision Making. v. 15, n. 2, p. 141-167, 2002.

FOLSTEIN, M.F; FOLSTEIN, S.E. MCHUGH, P.R. Minimental state: a practical method for grading the cognitive state of patients for the clinician. Jounal Psychiatric Research. v. 12, n .3, p.189-198, 1975.

FONSECA, V. Aprender a aprender: a educabilidade cognitiva. Porto Alegre: Artmed, 1998.

- Modificabilidade cognitiva: aprendizagem neuropsicológica da aprendizagem humana. São Paulo: Salesiana, 2002a.

.Pedagogia mediatizada: transferência de estratégias para novas aprendizagens. São Paulo: Salesiana, 2002b.

.Interatividade na aprendizagem: avaliação psicopedagógica dinâmica.

São Paulo: Salesiana, 2002c.

FREIRE, S.A. Envelhecimento bem-sucedido e bem-estar psicológico, 1998.

GALLUCCI, N. J.; TAMELINI, M. G.; FORLENZA, O.V. Diagnóstico diferencial das demências. Revista de Psiquiatria Clínica. v . 32, n. 3, p.119-130, 2005.

GATHERCOLE, S.; BADDELEY, A. Working memory and language processing. Hove: Lawrence Erlbaum Associates, 1994.

GODINHO, C.C. Incidência de demência e comprometimento cognitivo leve e identificação de preditores numa amostra de base populacional. 2012. 110 f. Tese (Doutorado) - Universidade Federal do Rio Grande do Sul, Porto Alegre, 2012.

GOMES, C. M. A. Feuerstein e a construção mediada do conhecimento. Porto Alegre: Artmed, 2002.

GORDON,B.A.; SHELTON, J.T; BUGG, J.M.; McDANIEL, M.A.; HEAD, D. Structual correlates of prospective memory. Neuropsychologia., v. 49, p. 3795-3800, 2011.

GORETTI, L.C.; OLIVEIRA, D L.C.; PEREIRA, L.S.M. O Desempenho de Idosos Institucionalizados com Alterações Cognitivas em Atividades de Vida Diária e Mobilidade: estudo-piloto. Revista Brasileira de Fisioterapia, v. 10, n. 1, p. 91-96, 2006.

GOULART, A. M. P. L. O professor na mediação cultural: as contribuições de Reuven Feuerstein junto a alunos com necessidades especiais. 2000. Tese 
(Doutorado) - Faculdade de Educação da Universidade de São Paulo, São Paulo, 2000.

HALL, E. Adult development and aging. Michigan, Marion Perlmutter, 1992

HEATON, R. K.; CHELUNE, G. J.; TALLEY, J. L.; KAY, G. G.; CURTISS, G. Manual do Teste Wisconsin de Classificação de Cartas. São Paulo: Casa do Psicólogo, 2005.

HEINZEL, S.; SCHULTE, S.; ONKEN, J.; LAM-QUVNH, D.; RIEMER, G.T.; HEINZ, A.; KATHMANN, N.; RAPP, M. Working memory training improvements and gains in non-trained cognitive tasks in young and older adults. Aging, Neuropsychology, and Cognition, v. 21,n. 2, p. 146-173, 2016.

HOBSON, P., LEEDS, L. Executive functioning in older people. Clinical Gerontology, v.11, p. 361-372, 2001.

IRIGARAY, T.Q.; SCHNEIDER, R. H.; GOMES, I. F. Efeitos de um treino cognitivo na qualidade de vida e no bem-estar psicológico de idosos. Psicologia: Reflexão e Crítica. v. 24. n. 4, p.810-818, 2011.

; GOMES, I. F.; SCHNEIDER, R. H. Efeitos de um treino de atenção, memória e funções executivas na cognição de idosos saudáveis. Psicologia: Reflexão e Crítica. v. 25. n. 1, p. 182-187, 2012.

ISHIZAKI, J.; MEGURO K.; AMBO H.; SHIMADA M.; YAMAGUCHI S.; HAYASAKA,C.; KOMATSU H.; SEKITA, Y.; YAMADORI, A. A normative communitybased study of Mini-Mental State in elderly adults: the effect of age and educational level. Journal of Gerontology: Psychological Sciences, v. 53, n. 6, p. 359-363, 1998.

ISHIZAKI, T. et al. Effects of cognitive function on functional decline among community-dwelling non-disabled older Japanese. Archives of Gerontology and Geriatrics, Atlanta, v. 42, n. 1, p. 4758, 2006.

IZQUIERDO, I. Memória. Porto Alegre: ArtMed, 2002.

, I.A.; MYSKIW, J.C.; BENETTI, F.; FURINI, C.R.G. Memória: tipos e mecanismos - achados recentes. REVISTA USP, n. 98, p. 9-16, 2013.

JOHNSON, M.K.; RAUE, C.L.; MITCHELL, K.J.; GREEN, E.J.; ANDERSON, A.W. FMRI evidence for an organization of prefrontal cortex by both type of process and type of information. Cerebral Cortex, v. 13, p. 265-273, 2007. 
JORM, A. F. A short form of the Informant Questionnaire on Cognitive Decline in the Elderly (IQCODE): development and cross-validation. Psychological Medicine, v. 24, n.1, p.145-153, 1994.

; KORTEN, A.E. Assessment of cognitive decline in the elderly by informant interview. The British Journal of Psychiatry. v. 152, n. 2, p. 209-213, 1988.

; SCOTT R.; CULLEN J. S.; MACKINNON, A. J. Performance of the Informant Questionnaire on Cognitive Decline in the Elderly (IQCODE) as a screening test for dementia. Psychological Medicine, v. 21. n. 3 , p.785-790, 1991.

; CHRISTENSEN, H.; KORTEN, A. E.; JACOMB, P.A.; HENDERSON, A. S. Informant ratings of cognitive decline in old age: validation against change on cognitive tests over 7 to 8 years. Psychological Medicine, v. 30, n . 4, p.981-985, 2000.

KAMP, S.M.; ZIMMER, H.D. Contributions of attention and elaboration to associative encoding in young and older adults Neuropsychologia. v. 75, p. 252-264, 2015.

KANDEL, E. R.; SCHWARTZ, J. H.; JESSELL, T. M. Fundamentos da neurociência e do comportamento. Rio de Janeiro: Guanabara Koogan; 2000.

KISSAKI, P.T.; LIMA-SILVA, T.B.; ORDONEZ, T.N.; MELO, R.C. SATHLER, T.B.; DOMINGUES, M.A.; LOPES, A.; YASSUDA, M.S.; CACHIONI, M. O impacto da participação em Universidade Aberta à Terceira Idade no desempenho cognitivo. Kairós Gerontologia, v.15, n. 7, p. 71-87, 2012.

KIM, S.Y.H.; KARLAWISH, J.H.T.; CAINE, E.D. Current state of research on decision-making competence of cognitively impaired elderly persons. American Journal of Geriatric Psychiatry, v. 10, n. 2, p. 151-165, 2002.

KRISTENSEN, C.H. Funções executivas e envelhecimento. In: PARENTE, M.A.M.P.; Cognição e envelhecimento. Porto Alegre: Artmed, 2007, p. 97- 112.

LAGE, G.M. Exercício Físico. In: MALLOY-DINIZ L.F.; FUENTES, D.; COSENZA, R.M. (org). Neuropisicologia do Envelhecimento: uma abordagem multidimensional. Porto Alegre: Artmed, 2013. p. 412-427.

LA RUE, A. Aging and neuropsychological assessment. New York: Plenum Press, 2012.

LAKS, J. et al. Prevalence of cognitive and functional impairment in communitydwelling elderly. Arquivo Neuro Psiquiatria, Rio de Janeiro, v. 63, n. 2-A, p. 207-212, 2005. 
LASCA, V. Treinamento de memória no envelhecimento normal: um estudo experimental utilizando a técnica de organização. 2003. Dissertação (Mestrado) Faculdade de Ciências Médicas, Unicamp, Campinas, 2003.

LEMOS, M. SOUZA, A.R.; MENDES, M.M.R. Perfil da população idosa cadastrada em uma Unidade de Saúde da Família. Revista Mineira de Enfermagem. v. 10, n. 3, p. 218-225, 2006.

LEVINE. B.; STUSS, D.T.; WINOCUR, G.; BINNS, M.A.; FAHY, L.; MANDIC, M.; BRIDGES, K.; ROBERTSON, I.H. Cognitive rehabilitation in the elderly: Effects on strategic behavior in relation to goal management. Journal of the International Neuropsychological Society, v. 13, n. 1, p. 143-152. 2007.

LOPES, R.M.F. AFunções executivas e memória em idosos: um estudo sobre os efeitos de um treino cognitivo e repercussões na qualidade de vida. 2014. $125 \mathrm{f}$. Tese (Doutorado) - Faculdade de Psicologia - Pontificia Universidade Católica do rio Grande do Sul, Porto Alegre, 2014.

LEZAK, M. D.; HOWIESON, D. B., e LORING, D. W. Neuropsychological assessment. $4^{\mathrm{a}}$ ed. Oxford: University Press. 2004

LI, X.; YA-HUIXIAO; QINGZHAO; LEUNG, A.W.W; CHEUNG, E.F.C.; CHAN, R.C.K.The neuroplastic effect of working memory training in healthy volunteers and patients with schizophrenia: Implications for cognitive rehabilitation Neuropsychologia. v. 75, n. 1, p. 149-162, 2015.

LIU, X.; HERMALIN, A.I.; CHUANG, Y. The effect of education on mortality among old Taiwanese and its pathways. Journal of Gerontology, v. 53b n. 2, p. S71-S82, 1998.

LOPES, R.M.F. AFunções executivas e memória em idosos: um estudo sobre os efeitos de um treino cognitivo e repercussões na qualidade de vida. 2014. $125 \mathrm{f}$. Tese (Doutorado) - Faculdade de Psicologia - Pontificia Universidade Católica do rio Grande do Sul, Porto Alegre, 2014.

LOPES, M. A.; BOTTINO, C. M. C. Prevalência de demência em diversas regiões do mundo Análise dos estudos epidemiológicos de 1994 a 2000. Arquivo Neuro Psiquiatria, Rio de Janeiro, v. 60, n. 1, p. 61-69, 2002.

MALLOY-DINIZ, L. F. ; PAULA, J. J.; LOSCHIAVO-ALVARES F. Q.; FUENTES, D.; LEITE, W. B. Exame das funções executivas. IN: L. F. MALLOY-DINIZ, L.F; FUENTES, D.; MATTOS, P.; ABREU, N. (Orgs.). Avaliação neuropsicológica. Porto Alegre: Artmed, 2008. 
MAGILA, C.; CARAMELLI, P. Funções executivas no idoso. In FORLENZA V.; CARAMELLI, P. (Orgs.), Neurosiquiatria Geriátrica. São Paulo: Atheneu, p. 517-525, 2001

MARIZ DE OLIVEIRA Significado e objetivo da educação física no ensino fundamental. In: SEMINÁRIO DE EDUCAÇÃO FÍSICA ESCOLAR: AVALIAÇÃO EM EDUCAÇÃO FíSICA ESCOLAR, 5, São Paulo, SP, 1999. Anais..São Paulo, SP: Escola de Educação Física e Esporte da Universidade de São Paulo. p. 17-18, 1999.

. Da Educação Física à Cinesiologia Humana, São Paulo, 2005.

MATSUDO. S.M; MATSUDO, V.K.R.; NETO, T.L.B.N. Atividade física e envelhecimento: aspectos epidemiológicos. Revista Brasileira de Medicina do Esporte. Niterói, v. 7, n. 1, p. 02-13, 2001.

MEIER, M.; GARCIA, S. Mediações da aprendizagem: contribuições de Feuerstein e de Vygotsky. 5 ed. Curitiba: Edição do autor, 2009).

MEUER, S.T; BENEDETTI, T.R.B; MAZO, G.Z. Aspectos da autoimagem e autoestima de idosos ativos. Motriz. 2011 Disponível em: http://cev.org.br/biblioteca/aspectos-autoimagem-autoestima-idosos-ativos/. Acesso em: 10 jun. 14.

MCKHANN et al. The diagnosis of dementia due to Alzheimer's disease: recommendations from the National Institute on Aging-Alzheimer's Association workgroups on diagnostic guidelines for Alzheimer's disease. Alzheimer's \& Dementia, v.7, n. 3, 2011, p. 263-269.

MIRANDA, O. Programa de Enriquecimento Instrumental II. CBM - Centro Brasileiro da Modificabilidade. São Paulo: Mimeo, 2010.

MOURA, M.P. A organização conceitual em adultos pouco escolarizados. In: OLIVEIRA, M.B.; OLIVEIRA, M.K. (orgs.) Investigações cognitivas, conceitos, linguagem e cultura. Porto Alegre: Artes Médicas Sul, 1999.

MURRAY, M.A.; BYRNE, R.M. Cognitive change in insight problem solving: Initial model errors and counterexamples. Journal of Cognitive Psychology, v. 25, n. 2, p. 210_219, 2013.

NASCIMENTO, E. "WAIS-III: Escala de Inteligência Wechsler para Adultos-manual técnico." São Paulo: Casa do Psicólogo, 2005. 
NERI, A. L. Qualidade de vida no adulto maduro: interpretações teóricas e evidências de pesquisa. In: (org.). Qualidade de vida e idade madura. Campinas: Papirus, 1993. p. 9 - 56.

. Psicologia do envelhecimento: temas selecionados na perspectiva de curso de vida. In: Psicologia do envelhecimento: uma área emergente. Campinas: Papirus, 1995. P. 13-40.

; FREIRE, S. A. Qual a idade da velhice? In: (org.). E por falar em boa velhice. Campinas: Papirus, 2000. p. 7-19.

. Desenvolvimento e envelhecimento: perspectivas biológicas, psicológicas e sociológicas. Campinas: Papirus, 2001.

; CARVALHO, V. A. M. L. O bem-estar do cuidador: aspectos psicossociais. In: FREITAS, E. V et al (orgs.). Tratado de geriatria e gerontologia. Rio de Janeiro: Guanabara Koogan, 2002. p. 778-90.

NETO, J. G. et al. Diagnóstico diferencial das demências. Revista de psiquiatria clínica. v. 32, n. 3, São Paulo maio/junho, 2005.

DIOGO, M. J. D.; CACHIONI, M. (orgs.). Saúde e Qualidade de Vida na Velhice. 4. ed. Campinas: Alínea, 2013.

NEGRI,M.D.X. Enriquecimento cognitivo na atuação do enfermeiro: uma vivência prática. 2004. 217 f. Dissertação (Mestrado) - Faculdade de Enfermagem Universidade Federal do Paraná, Paraná, 2004.

NITRINI, R.; CARAMELLI, P. Demências. In: NITRINI, R.; BACHESCHI, L. A. A neurologia que todo médico deve saber. São Paulo: Atheneu, 2003. p. 323-334.

NITRINI, R.; CARAMELLI, P.; MANSUR, L. L. Neuropsicologia: das bases anatômicas à reabilitação. São Paulo: Grupo de neurologia cognitiva e do comportamento de neurologia da Faculdade de Medicina da USP, 2003.

NITRINI, R.; BOTTINO, C. M. C.; ALBALA, C.; CAPUNAY, N. S. C.; KETZOIAM, C.; RODRIGUEZ, J. J. L.; MAESTRE, G. E.; RAMOS-CERQUEIRA, A. T.; CARAMELLI, $P$. Prevalence of dementia in Latin America: a collaborative study of populationbased cohorts. International Psychogeriatrics, v. 21, p. 622-630, 2009.

NYGARD, L. Instrumental activities of daily living: a stepping-stone towards Alzheimer's disease diagnosis in subjects with mild cognitive impairment? Acta Neurologica Scandinavica, Denmark, v. 107, n. Supplemento 179, p. 42-6, 2003. 
O'HARA, R.; BROOKS, J.O.; FRIEDMAN, L.; SCHRODER, C.M.; MORGAN, K.S. Long-term effects of mnemonic training in community-dwelling older adults. Journal of Psychiatric Research. v. 41, n. 7, p. 585-590, 2007.

OLCHIK, M.R. Treino de memória: um novo aprender no envelhecimento. 2008. 133 f. Tese (Doutorado) - Faculdade de Educação da Universidade Federal do Rio Grande do Sul. Rio Grande do Sul, 2008.

OLIVEIRA, A. R. R. Envelhecimento, a doença de Alzheimer e as contribuições do programa de enriquecimento instrumental (PEI). Cuadernos de neuropsicologia. v. 4, n. 1 p 31-41, 2010.

OLIVEIRA, S.C.; SANTOS, A.A.; PAVARINI, S.C.I. Relação entre sintomas depressivos e a funcionalidade familiar de idosos institucionalizados. Revista da Escola de Enfermagem da USP. v. 48, n. 1, p. 66-72, 2014.

OLIVEIRA, J.M.; MARTINS, I.R.; BRACHT, V. Relações da Educação Física com o programa saúde na escola: visão dos professores das escolas de Vitória/ES. Pensar a Prática, Goiânia, v. 18, n. 3, jul./set. 2015.

OPDEBEECK, C.; MARTYR, A.; CLARE, L. Cognitive reserve and cognitive function in healthy older people: a meta-analysis. Aging, Neuropsychology, and Cognition: A Journal on Normal and Dysfunctional Development. v. 23, n. 16. p. 40-60, 2016.

OKUMA, Silene, Sumire. O idoso e a atividade física. São Paulo: Papirus, 2002.

PAPALÉO NETO, M. O estudo da velhice no século $X X$ : histórico, definição do campo e termos básicos. In: FREITAS, E.V. et al. Tratado de Geriatria e Gerontologia. Rio de Janeiro: Ed. Guanabara. 2002. p. 2-12.

PAPALIA, D.E.; OLDS, S.W. Desenvolvimento físico e cognitivo na terceira idade. In: Desenvolvimento Humano. Porto Alegre: ArtMed. 2000. p. 493-521.

2013.

; FELDMAN, R.D. Desenvolvimento humano. Porto Alegre: ArtMed,

PAULA. J.J.; SILVA, K.K.M.; FUENTES, D. MALLOY-DINIZ, L.F. Funções executivas e envelhecimento. In: MALLOY-DINIZ, L.F.; FUENTES, D.; COSENZA, R.M (org). Neuropisicologia do Envelhecimento: uma abordagem multidimensional. Porto Alegre: Artmed, 2013. p. 226-242.

PAYNE, B.R.; GAO, X.; NOHS, S.R.; ANDERSON, C.J.; STINE-MORROW, S. The effects of print exposure on sentence processing and memory in older adults: 
evidence for efficiency and reserve. Aging, Neuropsychology, and Cognition, v. 19, n. 1-2, p. 122-149, 2016.

PFEFFER, R. I.; KUROSAKI, T. T.; HARRAH, C. H. Jr.; CHANCE, J. M.; FILOS, S., Measurement of functional activities in older adults in the community. Journal of Gerontology, v. 37, n. 3, p. 323-329, 1982.

PRINCE, M.; ACOSTA, D.; FERRI, C.P.; GUERRA, M. HUANG, Y.; LLIBRE, R. J.J. Dementia incidence and mortality in middle_income countries, and associations with indicators of cognitive reserve: a 10/66 Dementia Research Group population-based cohort study. Lancet. v. 380, n. 9836, p. 50-58, 2012.

RABBITT, P.; DIGGLE, P.; SMITH, D.; HOLLAND, F.; MC INNES, L. (2001). Identifying and separating the effects of practice and of cognitive ageing during a large longitudinal study of elderly community residents. Neuropsychologia, v .39, n. 5, p. 532-543, 2001.

REITAN, R., Validity of the Trail Making Test as an indication of organic brain damage. Perceptual and Motor Skills, v. 8, p. 271-276, 1958.

REISBERG B.; DOODY, R.; STOFFLER, A.; SCHIMITT, F.; , FERRIS, S.; MOBIUS, H. J. A 24-week open-label extension study of memantine in moderate to severe Alzheimer's disease. Archives of Neurology, v. 63, n. 1 p. 46-54, 2006.

RIBEIRO, P. C. C.; OlIVEIRA, B. H. D.; CUPERTINO, A. P. F. B.; NERI, A. L.; YASSUDA, M. S. Desempenho de Idosos na Bateria Cognitiva CERAD: Relações com Variáveis Sociodemográficas e Saúde Percebida. Psicologia: Reflexão e Crítica, v. 23, n . 1, p. 102-109, 2010.

ROSENBERG, M. Society and the adolescent self image. Princeton: Princeton University Press, 1965.

Rosenberg, M. Society and the adolescent self-image. Revised edition. Middletown, CT: Wesleyan University Press, 1989.

RUEDA, F. J. M. Bateria Psicológica para avaliação da atenção. São Paulo: Vetor Editora. 2013.

SANCHEZ, M.D.P. La modificabilidad estructural cognitiva y el Programa de Enriquecimiento Instrumental de Reuven Feuerstein. Madrid: Bruno, 1989. 
SANCHEZ, M. A. S., Questionário baseado no relato do informante para a detecção do declínio cognitivo em idosos: tradução, adaptação transcultural e estudo da confiabilidade. Dissertação (Mestrado em ciências médicas). Universidade do Estado do Rio de Janeiro, Rio de Janeiro, 2007.

SANTOS, F. H; BUENO, O. F., Validation of the Brazilian Children's Test of Pseudoword Repetition in Portuguese speakers aged 4 to 10 years. Brazilian Journal of Medical and Biological Research, v. 36, n .11, p. 1533-1547, 2003.

SANTOS DE SÁ, M.A. A. O idoso e o computador: condições facilitadoras e dificultadoras para o aprendizado. São Paulo, 1999. Dissertação (mestrado). Faculdade de Educação. Pontifícia Universidade Católica.

SANTOS, A.; SANTOS DE SÁ, M.A.Á.. De volta às aulas: ensino e aprendizagem na terceira idade. In: NERI, A. FREIRE, S.A.A. (orgs) E por falar em boa velhice. Campinas, SP: Papirus, 2000

SASSON, D. Educacion, liberdad y realizacion personal por Reuven Feuerstein: lós ninos de la ceniza. Santiago do Chile: Artes y Letras, 2001.

SATTLER, J.M. 1998 Assessment of children (3 edição ) San Diego, CA Author

SCHNEIDER, D.G. Processo de resolução de problemas e tomada de decisão no processo de envelhecimento. In: PARENTE, M.A.M.P. (org). Cognição $e$ envelhecimento. Porto Alegre: Artmed, 2007, p. 113- 128.

; PARENTE, M.A.M.P. O desempenho de adultos jovens na lowa Gambling Task (IGT): um estudo sobre a tomada de decisão. Psicologia: reflexão e crítica, n19 v 3 pg 442-450. 2006.

SHEPHARD, R.J. Envelhecimento, atividade física e saúde. São Paulo: Phorte. 2003.

SILVA, T. B. L.; YASSUDA, M. S.; GUIMARÂES, V. V.; FLORINDO, A. A. Fluência Verbal e Variáveis Sociodemográficas no Processo de Envelhecimento: Um Estudo Epidemiológico. Psicologia: Reflexão e Crítica, v. 24, n. 4, p. 739-746, 2011.

SILVA, A.O.; PEREIRA, A.P.M.; GONÇALVES, D.R.; VIEIRA, A.S.; MEDEIROS, R.F.; ALTERMANN, C.D.C.; CARPES, P.B.M. Perfil Cognitivo de Idosos Institucionalizados de Uruguaiana/RS. Revista Contexto \& Saúde, v. 10, n . 20, p. 1185-1190, 2011.

SILVA, M.E.P.O.; PEREIRA, J.L.. AVANÇOS CONCEITUAIS NA ALFABETIZAÇÃO: UM ESTUDO SOBRE A CONSTRUÇÃO DA LEITURA E DA ESCRITA A PARTIR 
DA MODIFICABILIDADE COGNITIVA. In: V EDUCON - Colóquio Internacional Educação e Contemporaneidade, 2011, São Cristovão - SE. V EDUCON - Colóquio Internacional Educação e Contemporaneidade, 2011.

SILVIA FILHO, J.H. Validade e normas do Wisconsin Card Sorting Test em adultos da região de Ribeirão Preto. 2007. 226 f. Tese (Doutorado) - Faculdade de Filosofia Ciências e Letras de Ribeirão Preto - USP. Ribeirão Preto, 2007.

SIMÕES, A. Desenvolvimento intelectual do adulto. In: LIMA, L.C. (org.) Educação de adultos. Forum I. Braga, Editora Universidade de Minho, 1994.

SIMÕES, M. Os testes de fluência verbal na avaliação neuropsicológica: Pressupostos, funções examinadas e estruturas anatómicas envolvidas. Psychologica 32, 25-48, 2003.

SMITH, G. E.; IVNIK, R. J. Normative neuropsychology. In: Petersen, R. C. Mild cognitive impairment. New York: Oxford, 2003.

STERNBERG, R.J. Recognizing, defining and representing problems. In: DAVIDSON, J.E.; STERNBERG, R.J. (org). The psychology of problem solving. USA: Cambridge University Press.

SOUZA, A.M.M.; DEPRESBITERIS, L.; MACHADO, O.T.M. A mediação como princípio educacional: bases teóricas das abordagens de Reuven Feuerstein. 2 ed. São Paulo: Editora Senac, 2003.

SOUSA. C.S.; MIRANDA, F.P.R. Envelhecimento e educação para resiliência no idoso. Educação \& Realidade, Porto Alegre, v. 40, n. 1, p. 33-51, jan./mar. 2015.

SOUZA, R.O.; IGNÁCIO, F.A.; CUNHA, F.C.R., OLIVEIRA, D.L.G.; MOLL, J. Contribuição à neuropsicologia do comportamento executivo: Torre de Londres e Teste de Wisconsin em indivíduos normais. Arquivos de Neuro-Psiquiatria, São Paulo, v. 59, n. 3A, p. 526-531, setembro, 2001.

SOUZA, I.S.M.; TEIXEIRA, K.M.D. Rastreamento cognitivo de idosos institucionalizados em instituição de longa permanência para idosos. Oikos: Revista Brasileira de Economia Doméstica, Viçosa, v. 22, n. 2, p. 3-18, 2013.

SPIGNER-LITTLES, D. ANDERSON, C. E. Constructivism: a paradigm for older learners. Education Gerontology, 25, p. 203-209, 1999.

SPIRDUSO, W.W. Dimensões físicas do envelhecimento. São Paulo: Editora Manole, 2005. 
SPREEN, O.; STRAUSS, E. A compendium of neuropsychological tests: administration, norms and commentary. New York: Oxford University Press; 1991.

SQUIRE, L.R.; KANDEL, E.R. Memória: da mente às moléculas. Porto Alegre: Artmed, 2003.

STERNBERG RJ. Psicologia cognitiva. Porto Alegre: Artes Médicas, 2000.

STRAUSS, E.; SHERMAN, E. M. S.; SPREEN, O. A compendium of neuropsychological tests: Administration, norms, and commentary (3a ed.). New York: Oxford University Press, 2006.

STREIT, I.A.; BENETTI, M.Z.; MOTA, J.A.P.S.; MAZO, G.Z. Nível de atividade física e condições de saúde em idosos centenários. DO CORPO: Ciências e Artes. v. 5, n. 1, p.1 a 10, 2015.

TRENTINI, C.M.; ARGIMON, I.I.L; OLIVEIRA, M.S; WERLANG, B.G. Teste Wisconsin de Classificação de Cartas - Versão para idosos. São Paulo: Casa do Psicólogo, 2010.

Inteligência - manual. São Paulo: Casa do Psicólogo. 2014.

; YATES, D.B.; HECK, V.S. WASI - Escala Wechsler Abreviada de

TOMASZCZYK, J.C.; FERNANDES, M.A. A positivity effect in autobiographical memory, but not phonemic fluency, in older adults. Aging, Neuropsychology, and Cognition, v . 19, n . 6, p. 699-722, 2012.

TULVING, E. What is episodic memory? Current Directions in Psychological Science. v. 2 , n. 3, p. $67-10,2000$.

VALENTE, T. G. Qualidade de vida e atividade física em idosos. 2015. 49 f. Trabalho de Conclusão de Curso - Instituto de Biociências da Universidade Estadual Paulista Júlio de Mesquita Filho - Campus de Rio Claro, 2015.

VALENTIJN, S. A.; HOOREN, S. A.; BOSMA, H.; TOUW, D. M.; JOLLES, J.; BOXTEL, M. P. The effect of two types of memory training on subjective and objective memory performance in healthy individuals aged 55 years and older: a ramdomized controlled trial. Patient Education and Counseling, v. 57, p. 106-114, 2005.

VARELA, A. Informação e autonomia: a mediação segundo Feuerstein. São Paulo: Editora SENAC, 2007. 
VERAS, R. Envelhecimento populacional contemporâneo: demandas, desafios e inovações. Revista de Saúde Pública, v. 43, n. 3, p. 548-554, 2009.

VERHAEGHEN, P. et al. Improving memory performance in the aged trough mnemonic training: a meta-analytic study. Psycholgy and Aging. V.7, n. 2, p. 242-251, 2000.

VIEIRA, E.B.; KOENIG, A.M. Avaliação cognitiva. In: FREITAS, E.V. et al. Tratado de geriatria e gerontologia. Rio de Janeiro: Guanabara Koogan, 2002.

VIELA et al. Benefícios da atividade física no envelhecimento. Revista Guará, n. 3, p. $17-25,2015$.

VIETTA, E.P. Que idade teria se não soubesse a idade que tem? Disponível em: http://www.ufrgs.br/psicoeduc/ed23/tag/infeliz/ Acesso em maio/2015.

WAGNER, G.P. Disfunções executivas no envelhecimento cognitivo: investigações com os instrumentos Tarefa do Jogo e Teste Wisconsin de classificação de cartas. 2006. 121 f. Dissertação (Mestrado) - Universidade Federal do Rio Grande do Sul. Porto Alegre, 2006.

WECHSLER, D. Wechsler Abbreviated Scale of Intelligence Manual. San Antonio: Psychological Corporation. 1999

WECHSLER, D. Manual: Escala de Inteligência de Wechsler-III. São Paulo: Casa do Psicólogo, 2005.

WECHSLER, D. Manual for the Wechsler Memory Scale-Revised, The Psychological Corporation, San Antonio, TX, 1987.

WEINERT, N.A.C. A mediação da aprendizagem em sala de recursos por meio de jogos, $2008 . \quad$ Disponível em: http://www.diaadiaeducacao.pr.gov.br/portals/pde/arquivos/2249-8.pdf. Acesso em: fev/2014.

WHO - World Health Organization. In. Demencia: una prioridad de salud pública. Disponível em: http://www.who.int/iris/handle/10665/75263. Acesso em: 23 feb. 2014.

YASSUDA, M.S. Memória e envelhecimento saudável. In: FREITAS, E.V. et al. Tratado de Geriatria e Gerontologia. Rio de Janeiro: Ed. Guanabara. 2011. p. 914-20 
.; BASTITONI, S.S.T.; FORTES, A.G. NERI, A.L. Treino de memória no idoso saudável: benefícios e mecanismos. Psicologia: Reflexão e Crítica, v. 19, n.3, p. $470-481,2006$.

. Desempenho de memória e percepção de controle no envelhecimento saudável. In: NERI, A.L.; YASSUDA, M.S.;CACHIONI, M. Velhice bem-sucedida: aspectos afetivos e cognitivos. Campinas: Papirus, 2004, p. 111-125.

YATES.D.B.; TRENTINI, C.M.; TOSI, S.D.; CORRÊA, S. K.; POGGERE, L.C.; VALLI, F. Apresentação da Escala de Inteligência Wechsler abreviada (WASI). Avaliação Psicológica. v.5, n. 2, p. 227-233, 2006.

YESAVAGE, J. A.; BRINK, T. L.; ROSE, T. L.; LUM, O.; HUANG, V.; ADEY, M.; LEIRER, O., Development and validation of a geriatric depression screening scale: a preliminary report. Journal of Psychiatric Research, v. 83, n.1, p. 37-49, 1983.

YI, Y.; FRIEDMAN, D. Age-related differences in working memory: ERPs reveal agerelated delays in selection- and inhibition-related processes. Aging, Neuropsychology, and Cognition, v. 21, n. 4, p. 483-513, 2014.

YUN, R.J.; LACHMAN, M. E. Perceptions of aging in two cultures: Korean and American views on old age. Journal of Cross-Cultural Gerontology, v. 21, p. 55-70, 2006.

ZAHNG, M.; GALE, S.D.; ERICKSON, L.D.; BROWN, B.L.; WOODY, P.; HEDGES, D.W. Cognitive function in older adults according to current socioeconomic status. Aging, Neuropsychology and Cognition, v. 22, n. 5, p. 534-543, 2015.

ZASLAVSKY, C.; GUS, I. Idoso. Doença cardíaca e comorbidade. Arquivos Brasileiros de Cardiologia, São Paulo, v.79, n.6, p. 635-39, 2002.

ZIMERMAN, G.I. Velhice aspectos biopsicossociais. Porto Alegre: ArtMed, 2007.

ZOLLIG, J.; MATTLI, F.; SUTTER, C.; AURELIO, A.; MATIN, M. Plasticity of prospective memory through a familiarization intervention in old adults. Aging, Neuropsychology, and Cognition. v. 19, n. 1-2, p. 168-194, 2012.B 


\section{APÊNDICE A}

\section{TERMO DE CONSENTIMENTO LIVRE E ESCLARECIDO}

Gostaria de convidá-lo (a) a participar do estudo Uma avaliação da influência do Programa de Enriquecimento Instrumental no desempenho cognitivo de idosos que estou realizando. Meu nome é Carla Ulasowicz e sou aluna do curso de pós-graduação em Psicologia Escolar e do Desenvolvimento Humano do Instituto de Psicologia da Universidade de São Paulo, nível doutorado. O objetivo deste estudo é verificar quais os benefícios que um programa de intervenção cognitiva poderá proporcionar no desempenho cognitivo de idosos saudáveis nos seguintes aspectos: resolução de problemas, memória, atenção e concentração e autoestima. Para tanto, você será submetido a uma bateria de testes, aplicada por uma neuropsicóloga, nos meses de Maio e Junho de 2014 (pré-teste), nos meses de Janeiro e Fevereiro de 2015 (pós-teste).

Todos os procedimentos serão explicados detalhadamente antes da realização de cada tarefa.

Os dados individuais de cada participante permanecerão em absoluto sigilo, sendo apresentados apenas as médias gerais da pesquisa, sem qualquer informação a respeito do local e de dados que possam identificar todos aqueles que dela participarem.

Sua participação é voluntária e o sr (a) poderá retirar seu consentimento a qualquer momento. 
$\mathrm{Na}$ avaliação da autora deste projeto de pesquisa e de seu orientador, não identificamos quaisquer riscos para os participantes. Todas as dúvidas serão esclarecidas conforme for solicitado.

Qualquer dúvida ou esclarecimento poderá ser dado pelo pesquisadora responsável, Carla Ulasowicz, que pode ser contatada no endereço e no telefone . Ou

pelas seguintes instituições em que a pesquisa está vinculada:

A) IPUSP - Instituto de Psicologia da Universidade de São Paulo

Avenida Professor Mello de Morais, 1721 - Cidade Universitária, São Paulo SP, 005508-030, telefone (11) 3091-4356;

B) Comitê de Ética e Pesquisa com Seres Humanos - IPUSP

Avenida Professor Mello de Morais, 1721 - BLOCO G, 2aa andar, sala 27 -

Cidade Universitária, São Paulo - SP, 005508-030, telefone (11) 3091-4182.

O Termo de Consentimento Livre e Esclarecido será assinado em duas vias, ficando uma via em poder da pesquisadora responsável e outra via no poder da $\operatorname{Sr}(a)$.

Obrigada pela sua colaboração.

Eu

$R G n^{\circ}$ nascido(a) em

com idade de anos, do sexo ( ) Feminino ( ) Masculino, residente à na cidade de declaro ter sido informado (a) e estar devidamente esclarecido (a) sobre os objetivos desse estudo, 
sobre as técnicas e procedimentos a que estarei sendo submetido e sobre os riscos e desconfortos que poderão ocorrer.

Recebi garantias de total sigilo e de obter novos esclarecimentos sempre que desejar. Assim, concordo em participar voluntariamente do estudo e sei que posso retirar meu consentimento a qualquer momento, sem nenhum prejuízo.

Data:

Assinatura do sujeito da pesquisa

ou representante legal

Eu, Carla Ulasowicz, responsável pela pesquisa Uma avaliação da influência do Programa de Enriquecimento Instrumental no desempenho cognitivo de idosos declaro que obtive espontaneamente o consentimento desse sujeito de pesquisa (ou de seu representante legal) para realizar esse estudo.

Data: 1

Assinatura do Pesquisador Responsável

Eu, José Fernando Bitencourt Lomônaco, responsável pela pesquisa Uma avaliação da influência do Programa de Enriquecimento Instrumental no desempenho cognitivo de idosos declaro que obtive espontaneamente o consentimento desse sujeito de pesquisa (ou de seu de seu representante legal) para realizar esse estudo.

Data:

Assinatura do Orientador 


\section{APÊNDICE B}

\section{TERMO DE CONSENTIMENTO LIVRE E ESCLARECIDO}

Gostaria de convidá-lo (a) a participar do estudo Uma avaliação da influência do Programa de Enriquecimento Instrumental no desempenho cognitivo de idosos que estou realizando. Meu nome é Carla Ulasowicz e sou aluna do curso de pós-graduação em Psicologia Escolar e do Desenvolvimento Humano do Instituto de Psicologia da Universidade de São Paulo, nível doutorado. O objetivo deste estudo é verificar quais os benefícios que um programa de intervenção cognitiva poderá proporcionar no desempenho cognitivo de idosos saudáveis nos seguintes aspectos: resolução de problemas, memória, atenção e concentração e autoestima. Para tanto, você será submetido a uma bateria de testes, aplicada por uma neuropsicóloga, antes do início do programa (pré-teste), ao término do mesmo (pós-teste) e após três meses do término do programa (reteste). No final do programa, a pesquisadora fará uma entrevista com você objetivando coletar dados sobre as modificações perceptíveis a respeito do seu comportamento durante e após o término da intervenção.

O programa de intervenção, é composto por sete instrumentos que objetivam fazer o aluno refletir sobre seu pensamento, bem como sobre a formulação e argumentação de suas respostas e será ministrado pela pesquisadora responsável nos meses de Julho, Agosto, Setembro, Outubro, Novembro e a primeira quinzena de Dezembro do corrente ano (2014) em uma aula semanal com a duração de 90 minutos cada, totalizando 21 aulas. 
Todos os procedimentos serão explicados detalhadamente antes da realização de cada tarefa.

Os dados individuais de cada participante permanecerão em absoluto sigilo, sendo apresentados apenas as médias gerais da pesquisa, sem qualquer informação a respeito do local e de dados que possam identificar todos aqueles que dela participarem.

Sua participação é voluntária e o sr (a) poderá retirar seu consentimento a qualquer momento.

$\mathrm{Na}$ avaliação da autora deste projeto de pesquisa e de seu orientador, não identificamos quaisquer riscos para os participantes. Todas as dúvidas serão esclarecidas conforme for solicitado.

Qualquer dúvida ou esclarecimento poderá ser dado pelo pesquisadora responsável, Carla Ulasowicz, que pode ser contatada no endereço e no telefone $\mathrm{Ou}$

pelas seguintes instituições em que a pesquisa está vinculada:
A) IPUSP - Instituto de Psicologia da Universidade de São Paulo

Avenida Professor Mello de Morais, 1721 - Cidade Universitária, São Paulo SP, 005508-030, telefone (11) 3091-4356;

B) Comitê de Ética e Pesquisa com Seres Humanos - IPUSP

Avenida Professor Mello de Morais, 1721 - BLOCO G, 2aa andar, sala 27 Cidade Universitária, São Paulo - SP, 005508-030, telefone (11) 3091-4182.

O Termo de Consentimento Livre e Esclarecido será assinado em duas vias, ficando uma via em poder da pesquisadora responsável e outra via no poder da $\operatorname{Sr}(\mathrm{a})$. 
Obrigada pela sua colaboração.

$\mathrm{Eu}$

$R G n^{\circ}$ nascido(a) em

com idade de anos, do sexo ( ) Feminino ( ) Masculino, residente à na cidade de declaro ter sido informado (a) e estar devidamente esclarecido (a) sobre os objetivos desse estudo, sobre as técnicas e procedimentos a que estarei sendo submetido e sobre os riscos e desconfortos que poderão ocorrer.

Recebi garantias de total sigilo e de obter novos esclarecimentos sempre que desejar. Assim, concordo em participar voluntariamente do estudo e sei que posso retirar meu consentimento a qualquer momento, sem nenhum prejuízo.

Data:

Assinatura do sujeito da pesquisa ou representante legal

Eu, Carla Ulasowicz, responsável pela pesquisa Uma avaliação da influência do Programa de Enriquecimento Instrumental no desempenho cognitivo de idosos declaro que obtive espontaneamente o consentimento desse sujeito de pesquisa (ou de seu representante legal) para realizar esse estudo.

Data:

Assinatura do Pesquisador Responsável

Eu, José Fernando Bitencourt Lomônaco, responsável pela pesquisa Uma avaliação da influência do Programa de Enriquecimento Instrumental no desempenho 
cognitivo de idosos declaro que obtive espontaneamente o consentimento desse sujeito de pesquisa (ou de seu de seu representante legal) para realizar esse estudo. Data: 
FICHA DE IDENTIFICACÃO $^{6}=$ Data:

\section{Dados pessoais}

Nome Completo:

R.G. $\mathrm{n}^{\circ}$

Sexo: ( ) F ( ) M

Endereço:

Telefones:

E-mail :

Idade: anos

Data de Nascimento:

Nacionalidade: Idioma materno:

Estado Civil （）Casado/vive em união （）Viúvo （）Separado （）Solteiro

\section{Participação no grupo ( ) Controle}

\section{( ) Experimental}

Se você escolheu participar do grupo experimental, assinale qual dos horários abaixo pretende frequentar o programa:

( ) Turma 1 - Quarta-feira: das 8h as 9h30

( ) Turma 2 - Quarta-feira: das 9h30min às $11 \mathrm{~h}$

( ) Turma 3 - Sexta-feira: das 8h as 9h30

( ) Turma 4 - Quarta-feira: das 13h30min as 15h

( ) Turma 5 - Quarta-feira: das 15h às 16h30min

( ) Turma 6 - Sexta-feira: das 13h30min às $15 \mathrm{~h}$

\footnotetext{
${ }^{6}$ Adaptada de : OLIVEIRA, R. Compreensão oral de sentenças em idosos cognitivamente saudáveis: caracterização e investigação de sua relação com fatores sociodemográficos e outros aspectos do funcionamento. 73 f. Dissertação (Mestrado) - - Universidade Federal do ABC, Santo André, 2014.
} 
( ) Turma 7 - Sexta-feira: das 15h às 16h30min

\section{Escolarização}

Escolaridade: ( ) 1aa a $4^{\mathrm{a}}$ série do Fundamental I

( ) 5a a 8 série do Fundamental II

( ) Ensino Médio (Colegial)

( ) Ensino Universitário Área

( ) Pós-graduação

Área

\section{Atividade profissional}

Atualmente exerce atividade profissional: ( ) Sim Qual:

( ) Não

( ) aposentado ( ) estudante ( ) outros

\section{Renda familiar}

Somando a sua renda com a renda das pessoas que moram com você, quanto é, aproximadamente, a renda familiar mensal?

( ) Nenhuma renda.

( ) Até 1 salário mínimo (até $\mathrm{R} \$ 724,00$ ).

( ) De 1 a 3 salários mínimos (de $R \$ 724,00$ até $R \$ 2.172,00$ ).

( ) De 3 a 6 salários mínimos (de $\mathrm{R} \$ 2.172,00$ até $\mathrm{R} \$ 4.344,00$ ).

( ) De 6 a 9 salários mínimos (de $\mathrm{R} \$ 4.344,00$ até $\mathrm{R} \$ 6.516,00$ ).

( ) De 9 a 12 salários mínimos (de $R \$ 6.516,00$ até $R \$ 8.688,00$ ). 
Classificação Econômica Brasil

Pontuação obtida:

Classe:

\begin{tabular}{|c|c|c|c|c|c|}
\hline \multirow[t]{2}{*}{ Posse de itens } & \multicolumn{5}{|c|}{ Qtde de ítens } \\
\hline & 0 & 1 & 2 & 3 & 4 ou + \\
\hline Televisão em cores & 0 & 1 & 2 & 3 & 4 \\
\hline Rádio & 0 & 1 & 2 & 3 & 4 \\
\hline Banheiro & 0 & 4 & 5 & 6 & 7 \\
\hline Automóvel & 0 & 4 & 7 & 9 & 9 \\
\hline Empregada mensalista & 0 & 3 & 4 & 4 & 4 \\
\hline Máquina de lavar & 0 & 2 & 2 & 2 & 2 \\
\hline $\begin{array}{l}\text { Videocassete e/ou } \\
\text { DVD }\end{array}$ & 0 & 2 & 2 & 2 & 2 \\
\hline Geladeira & 0 & 4 & 4 & 4 & 4 \\
\hline $\begin{array}{l}\text { Freezer (aparelho } \\
\text { independente ou parte } \\
\text { da geladeira duplex) }\end{array}$ & 0 & 4 & 2 & 2 & 2 \\
\hline
\end{tabular}

Nome do chefe de família:

Grau de instrução do chefe de família

\begin{tabular}{|c|c|c|}
\hline Nomenclatura antiga & Pontos & Nomenclatura atual \\
\hline Analfabeto/Primário incompleto & 0 & $\begin{array}{l}\text { Analfabeto / até 3a série } \\
\text { fundamental }\end{array}$ \\
\hline Primário completo & 1 & $4^{\mathrm{a}}$ série fundamental \\
\hline ginasial completo & 2 & Fundamental completo \\
\hline Colegial completo & 4 & Médio completo \\
\hline Superior completo & 8 & Superior completo \\
\hline
\end{tabular}


Pontuação total:( posse de itens + grau de instrução do chefe da família):

\begin{tabular}{|c|c|c|}
\hline CLASSES & CORTE & RESULTADO \\
\hline A1 & 42 a 46 pontos & \\
\hline A2 & 35 a 41 pontos & \\
\hline B1 & 29 a 34 pontos & \\
\hline B2 & 23 a 28 pontos & \\
\hline C1 & 18 a 22 pontos & \\
\hline C2 & 14 a 17 pontos & \\
\hline D & 8 a 13 pontos & \\
\hline E & 0 a 7 pontos & \\
\hline
\end{tabular}

\section{Dados sobre saúde}

Utilize óculos? ( ) Sim ( ) Não

Possui deficiência auditiva? ( ) Sim ( ) Corrigida

Possui doenças ( ) reumáticas? Qual?

$$
\begin{aligned}
& \text { ( ) neurológicas? Qual? } \\
& \text { ( ) Não }
\end{aligned}
$$

História prévia de problema neurológico (AVC, TCE, Epilepsia, Meningite, Neurossifilis, Tumor cerebral, Hidrocefalia) ( )Sim ( ) Não Há quanto tempo?

História prévia de problema psiquiátrico (Depressão, Mania, Esquizofrenia, Psicose)

$$
\text { ( ) Sim ( ) Não Há quanto tempo? }
$$

História prévia de doenças cardiovasculares (Pressão alta, Cardiopatias)

( ) Sim ( ) Não Há quanto tempo?

Fuma? ( ) Sim ( ) Não Quanto/ Há quanto tempo? 
Bebe? ( ) Sim ( ) Não Quanto/ Há quanto tempo?

Faz reposição hormonal? ( ) Sim ( ) Não Há quanto tempo?

Usa medicamentos regularmente? ( ) Não ( ) Sim

\begin{tabular}{|l|r|r|r|l|}
\hline & Nome & Posologia & Horário & Tempo de Uso \\
\hline $1-$ & de $\mathbf{m g}$ & & \\
\hline 2- & de $\mathbf{m g}$ & & \\
\hline $3-$ & de $\mathbf{m g}$ & & \\
\hline 4- & de $\mathbf{m g}$ & & \\
\hline $5-$ & de $\mathbf{m g}$ & & \\
\hline
\end{tabular}

Tem hábitos de leitura? ( ) Nunca （）Raramente （）Frequentemente

Tem hábitos de escrita? ( ) Nunca ( ) Raramente ( ) Frequentemente 


\section{APENDICE D}

\section{ENTREVISTA FINAL}

Vamos realizar esta entrevista com o objetivo de saber se programa foi capaz de proporcionar algumas modificações, as quais são ou não perceptíveis ao sr (sra). É apenas uma conversa e iremos gravá-la. Sinta-se à vontade para responder as questões e seja bem sincero(a).

1) O sr. (sra) percebeu algumas modificações no seu comportamento durante/após a aplicação do programa? Se sim, o sr (sra) poderia citá-las?

2) Irei mencionar algumas modificações que o programa pode ou não proporcionar ao participante. Lembre-se de alguma situação que elas podem ter ocorrido. Ao final de cada modificação o sr (sra) irá responder sim, caso esta modificação tenha acontecido e citará em que situação ela ocorreu, e não caso não tenha ocorrido.

- Pensamento reflexivo;

- Controle da impulsividade (ansiedade);

- Comunicação clara e precisa;

- Concentração;

- Consciência do seu potencial;

- Elevação da autoestima;

- Motivação para aprender;

- Maior autonomia;

- Melhora da memória.

3) Você considera que as informações fornecidas durante o programa foram importantes para a realização das tarefas do seu cotidiano? Dê um exemplo.

4) Você gostaria de realizar algum comentário sobre o programa? 


\section{APENDICE E}

\section{ESCALA DE PERCEPCÃO SUBJETIVA SOBRE MODIFICACÕES}

\section{APÓS O PROGRAMA}

Neste quadro há 12 modificações que o programa pode ou não ter proporcionado a você. Para tanto, assinale a opção que melhor reflete sua opinião.

\begin{tabular}{|l|l|l|l|l|l|}
\hline 1 - Atenção e Concentração & $\begin{array}{c}\text { Muito } \\
\text { melhor }\end{array}$ & $\begin{array}{c}\text { Bem } \\
\text { melhor }\end{array}$ & Melhor & $\begin{array}{c}\text { Sem } \\
\text { alteração }\end{array}$ & Pior \\
\hline $\begin{array}{l}\text { (ansiedade) nas ações do dia-a- } \\
\text { dia }\end{array}$ & & & & & \\
\hline 3 - Resolução de problemas & & & & & \\
\hline $4-$ Memória & & & & & \\
\hline $5-$ Autoestima & & & & & \\
\hline $\begin{array}{l}\text { 6- Pensar antes de agir para } \\
\text { solucionar os problemas }\end{array}$ & & & & & \\
\hline $\begin{array}{l}7-\text { Motivação para aprender } \\
\text { coisas em geral }\end{array}$ & & & & & \\
\hline $\begin{array}{l}\text { 8 - Capacidade de comunicar-se } \\
\text { com as pessoas de maneira mais } \\
\text { clara e objetiva }\end{array}$ & & & & & \\
\hline $\begin{array}{l}9 \text { - Capacidade de classificar, } \\
\text { comparar, organizar, discriminar } \\
\text { as informações para a resolução } \\
\text { de problemas }\end{array}$ & & & & & \\
\hline $\begin{array}{l}10 \text { - Capacidade de percepção e } \\
\text { análise }\end{array}$ & & & & & \\
\hline $\begin{array}{l}11 \text { - Orientar-se no espaço em } \\
\text { relação aos objetos e pessoas }\end{array}$ & & & & & \\
\hline 12 - Maior autonomia & & & & & \\
\hline
\end{tabular}


INSTRUMENTOS DO PROGRAMA DE ENRIQUECIMENTO INSTRUMENTAL

STANDARD I

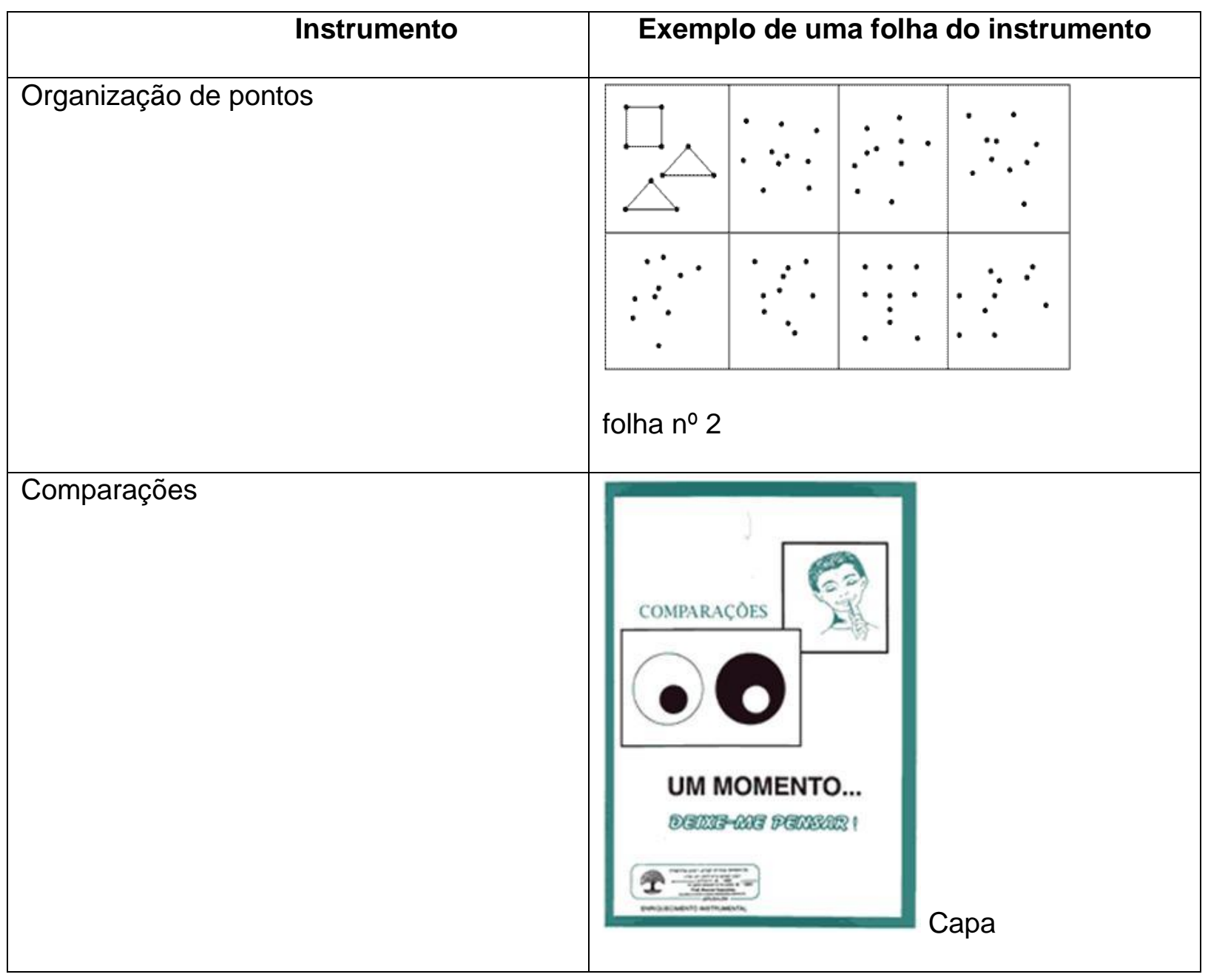




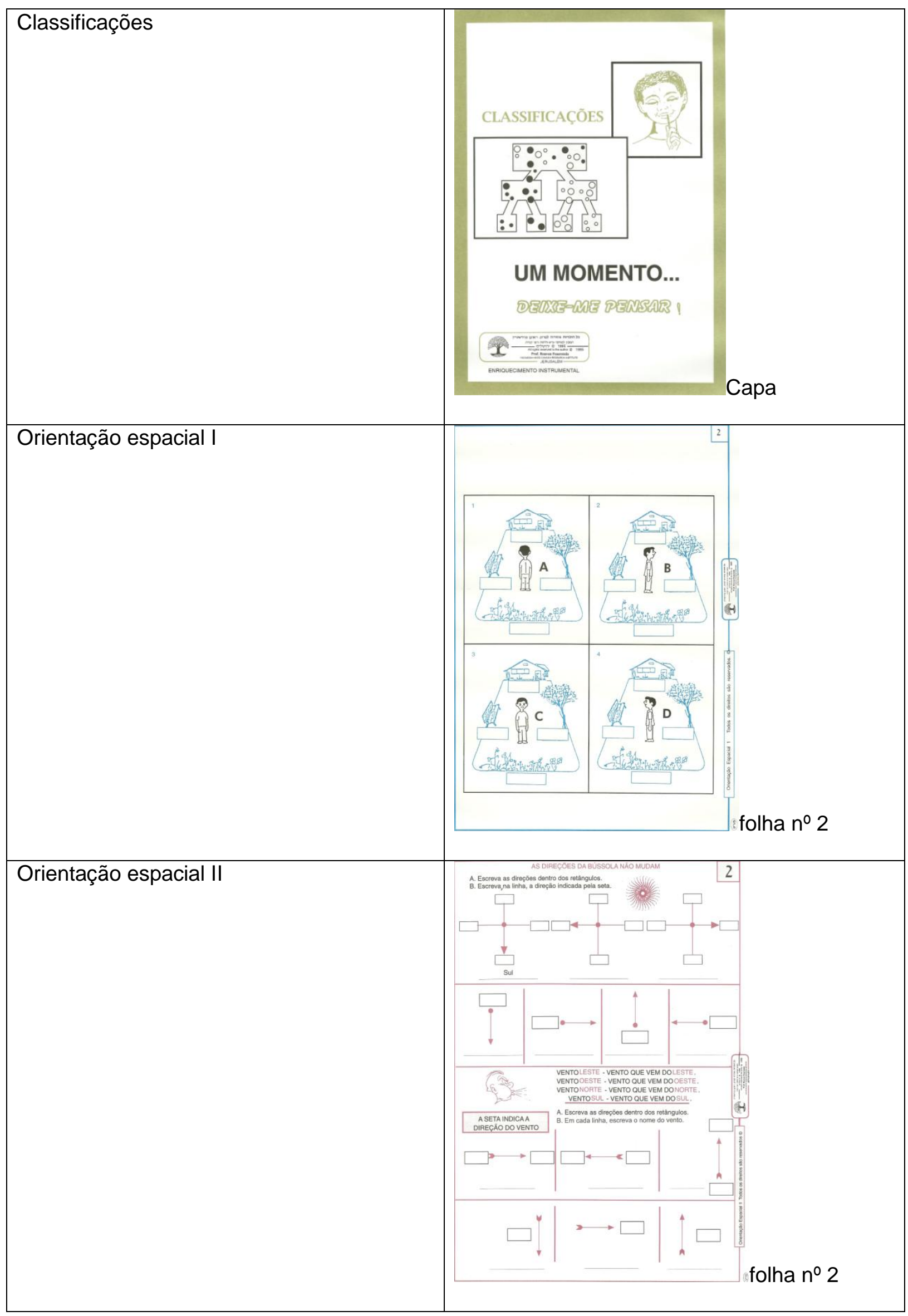




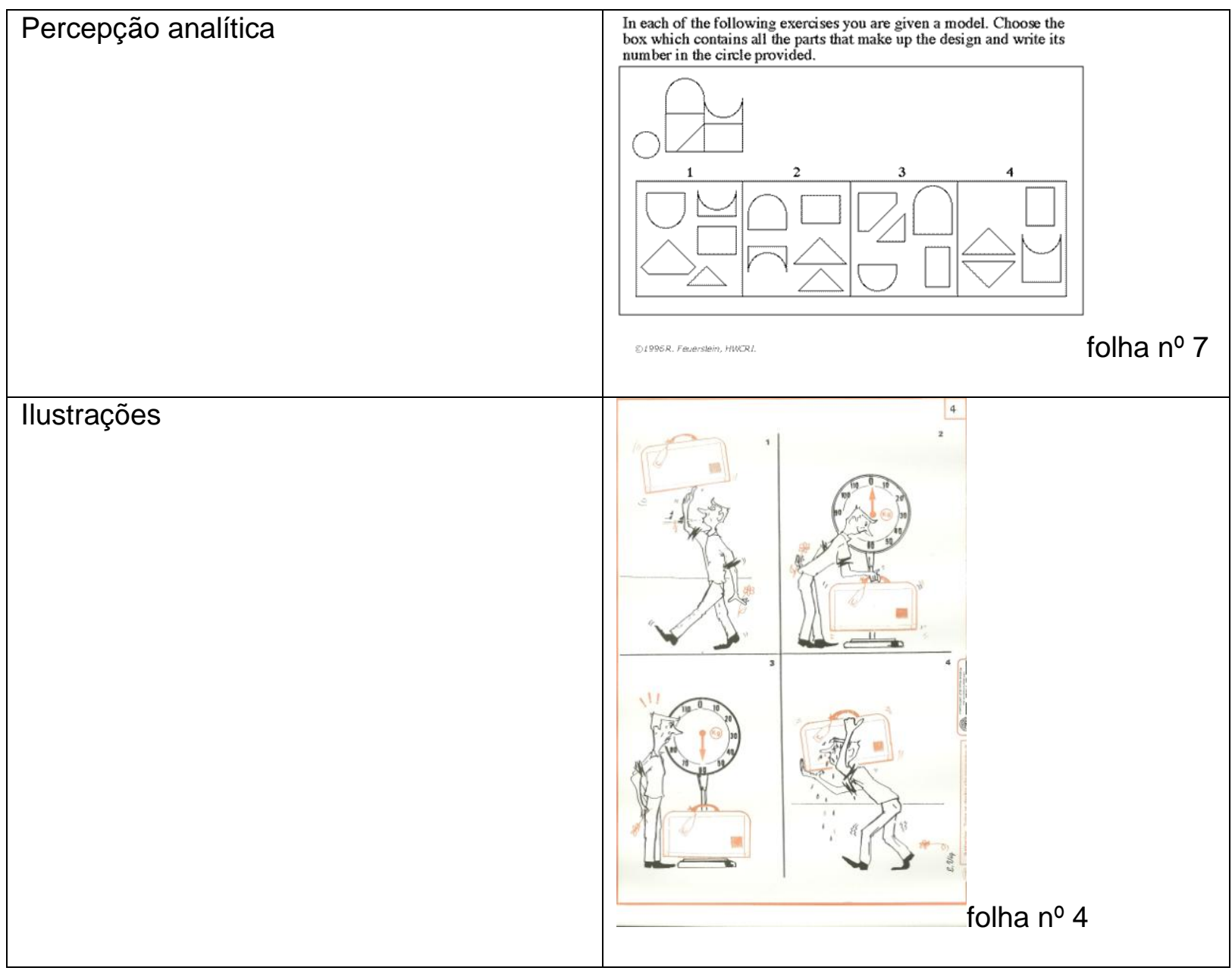

Fonte: BEYER, H.O. O Fazer psicopedagógico: a abordagem de Reuven Feuerstein a partir de Piaget e Vygotsky. Porto Alegre: Artmed, 1996. 